

Evaluation and implementation of discards policies under catch-based fisheries management regimes 


\section{Thesis committee}

\section{Promotor}

Prof. Dr A.D. Rijnsdorp

Professor of Sustainable Fisheries Management

Wageningen University \& Research

\section{Co-promotors}

Dr J.J. Poos

Assistant Professor, Aquaculture and Fisheries Group

Wageningen University \& Research

Dr I. Mosqueira

Joint Research Center- European Commission, Ispra, Italy

\section{Other members}

Dr P. Marchal, IFREMER, French Research Institute of the Sea, Boulogne-sur-Mer, France

Prof. Dr S. Bush, Wageningen University \& Research

Dr A. Richter, Wageningen University \& Research

Dr H. Polet, Flanders Research Institute for Agriculture, Fisheries and Food (ILVO), Oostende, Belgium

This research was conducted under the auspices of the Graduate School of Wageningen Institute of Animal Sciences 


\title{
Evaluation and implementation of discards policies under catch-based fisheries management regimes
}

\author{
Nekane Alzorriz Gamiz
}

Thesis

submitted in fulfilment of the requirements for the degree of doctor at Wageningen University by the authority of the Rector Magnificus

Prof. Dr A.P.J. Mol

in the presence of the

Thesis Committee appointed by the Academic Board to be defended in public

on Wednesday 4 December 2019

at 01:30 p.m. in the Aula. 
Nekane Alzorriz Gamiz

Evaluation and implementation of discards policies under catch-based fisheries management regimes, 206 pages.

PhD thesis, Wageningen University, Wageningen, NL (2019)

With references, with summary in English

ISBN 978-94-6380-620-6

ISBN: 978-94-6395-216-3

DOI: https://doi.org/10.18174/507129 
To my beloved father A mi añorado padre Aita, zure oroimenez 



\title{
Contents
}

\author{
$1 \mid \begin{aligned} & \text { ChAPTER } 1 \\ & \text { Introduction }\end{aligned}$
}

1.1 Background . . . . . . . . . . . . . . . . . . . 14

1.2 Thesis objective . . . . . . . . . . . . . . . 22

1.3 Thesis outline . . . . . . . . . . . . . . 30

1.4 References . . . . . . . . . . . . . . . 31

2 Review of discard management regimes

2.1 Abstract . . . . . . . . . . . . . . . . . . 38

2.2 Introduction . . . . . . . . . . . . . . . . . 39

2.3 Drivers for successful discard bans . . . . . . . . . . . 40

2.4 Discussion- Overall Lessons . . . . . . . . . . . . . . . 53

2.5 References . . . . . . . . . . . . . . 56

$3 \begin{aligned} & \text { CHAPTER } 3 \\ & \text { Questioning the effectiveness of technical measures im- } \\ & \text { plemented by the Basque Bottom Otter Trawl fleet: } \\ & \text { implications under the EU landing obligation }\end{aligned}$

3.1 Abstract . . . . . . . . . . . . . . . 66 66

3.2 Introduction . . . . . . . . . . . . . . 67

3.3 Material and methods . . . . . . . . . . . . . . . 69

3.4 Results . . . . . . . . . . . . . . . . . 75

3.5 Discussion . . . . . . . . . . . . . . . . . 84

3.6 Acknowledgements . . . . . . . . . . . . . . . . . . 89

3.7 References . . . . . . . . . . . . . . . . . . 90 
CHAPTER 4

Likely status and changes in the main economic and fishery indicators under the landing obligation: A case study of the Basque trawl fishery

4.1 Abstract .................... 96

4.2 Introduction . . . . . . . . . . . . . . . . . 97

4.3 Methods ...................... 99

4.4 Results..................... 108

4.5 Discussion . . . . . . . . . . . . . . . . 114

4.6 Conclusions . . . . . . . . . . . . . . . . . 118

4.7 Acknowledgements .. . . . . . . . . . . . . . . 118

4.8 References ..................... 119

$5 \mid \begin{aligned} & \text { CHAPTER } 5 \\ & \text { Modelling long-term effect of management strategies } \\ & \text { in mixed fisheries }\end{aligned}$

5.1 Abstract ..................... . . 123

5.2 Introduction . . . . . . . . . . . . . . . . 124

5.3 Methods .................... . 126

5.3.1 Scenarios .................. 135

5.4 Results ...................... 136

5.5 Discussion . . . . . . . . . . . . . . . . . . . 144

5.6 Conclusions . . . . . . . . . . . . . . . . . . 148

5.7 Acknowledgements . . . . . . . . . . . . . . . . 148

5.8 References ..................... 149

6 Synthesis 6

6.1 General discussion . . . . . . . . . . . . . . . . 155

6.2 Fishers adaptation . . . . . . . . . . . . . 157

6.2.1 Improving gear selectivity . . . . . . . . . . . 158

6.2.2 Choices on space and time . . . . . . . . . 161

6.3 Regulations in support of the implementation of the EU landing obligation ............... . . 165

6.4 Compliance issues . . . . . . . . . . . . . . 171 
6.5 Management Strategy Evaluation . . . . . . . . . . . . 174

6.6 Outlook . . . . . . . . . . . . . . . . 177

6.7 References . . . . . . . . . . . . . . . . . . 181

$$
\text { A } \mid \begin{aligned}
& \text { Chapter A } \\
& \text { Addendum }
\end{aligned}
$$

I Summary . . . . . . . . . . . . . . . . 193

II List of abbreviations . . . . . . . . . . . . . . . 195

III Dankwoord . . . . . . . . . . . . . . . . 196

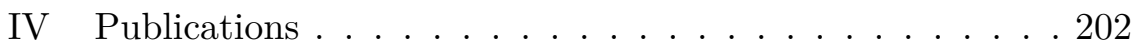

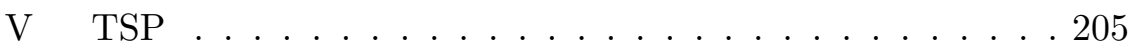

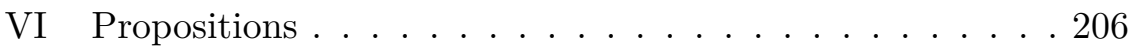





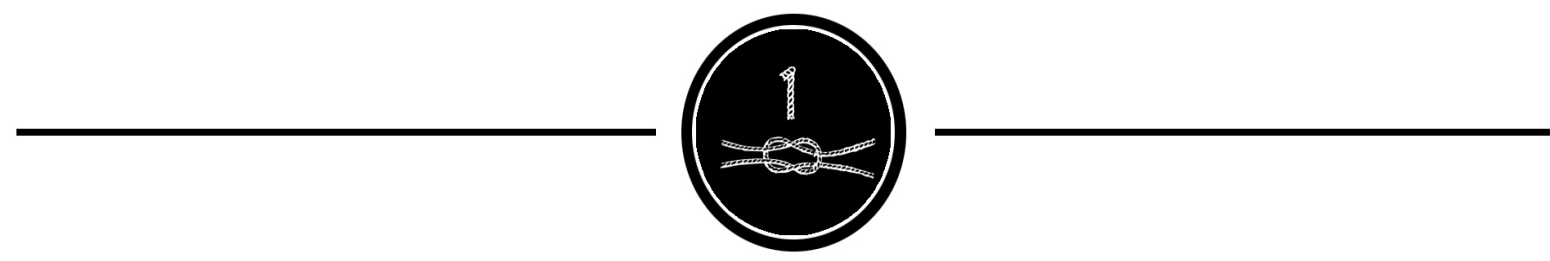

- INTRODUCTION · 


\subsection{Background}

The current European policy frameworks for the marine environment (Common Fisheries Policy (CFP), Marine Strategy Framework Directive) aim at a progressive implementation of an ecosystem approach to fisheries, coupled with the objective of providing EU citizens with a stable, secure and healthy food supply for the long term. To achieve the objectives of the CFP (EU, 2013), EU fisheries will be mostly managed by multi-annual plans and governed by both the ecosystem approach and the precautionary principle. The challenge is therefore set to make fishing environmentally, economically, and socially sustainable. The elimination of discarding unwanted catches was identified as one of the main objectives under the 2012 reform of the CFP (Box 1; EU (2011a,b,c)). Hence, an important component of the new CFP is the introduction of a landing obligation - also known as a discard ban — prohibiting the at-sea disposal of some or all commercially valuable species from 2015 (Box 2, Article 15, Regulation (EU) 1380/2013; EU (2013)).

\section{Box 1. Why is discarding a problem?}

Throughout this thesis, discards are defined as the part of the catch that is brought on deck only to be returned to the sea. In most cases discarded organisms do not survive. Discarding is a global problem (FAO, 2016). The practice is widely known as a waste of living resources (human food and economic resources, biological resources), and therefore undermines conservation policies by killing fish without making any economic returns. Discards are also a source of unaccounted mortality as long as this catch is unreported and mortality rates of releases undocumented, increasing the uncertainty of stock assessments (Cardinale and Svedäng, 2004; Diamond and Beukers-Stewart, 2009; Jensen and Vestergaard, 2002).

By discarding juvenile fish, fish of little or no economic interest or those which are over-quota, future yields are being lost. Discards of mature fish both waste resources in the short term and reduce the amount of adult fish which would otherwise have been available to support future productivity (EC, 2007). 


\section{Box 2. CFP- Landing Obligation covered in Article 15}

The CFP is the EU's instrument for the management of fisheries and aquaculture. In 2013, the Council and Parliament reached agreement on a new CFP for the long-term environmental, economic, and social sustainability of fishing and aquaculture activities. The new CFP's basic regulation (EU, 2013) entered into force on 1 January 2014. The regulation makes fundamental changes to the way that Europe's fisheries are managed, with the aim of managing fish stocks sustainably to ensure a prosperous fishing industry and a healthy marine environment. Thus, the reform includes making use of the MSY reference points as targets for exploiting commercially important fish stocks.

One of the most important points in the CFP is the introduction of a landing obligation. The landing obligation is only applicable to TAC-regulated species in the Atlantic and to species previously subject to minimum landing size regulations in the Mediterranean Sea. Thus, catches must be retained on board, recorded, and landed. The landing obligation requires all catches of regulated commercial species on-board to be counted against quota whilst undersized fish cannot be marketed for direct human consumption purposes. It is being phased in across fisheries and species, starting with pelagic fisheries and fisheries in the Baltic Sea in 2015 and is to be completed by 2019 , in accordance with a specified time frame (Fig. 1.1).

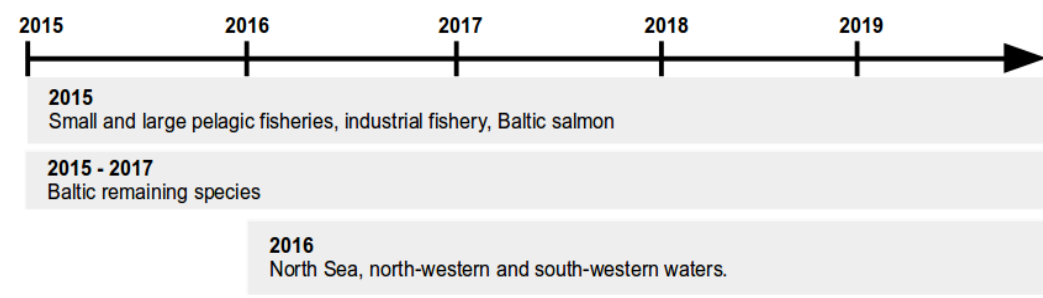

$2017-2019$

Mediterranean, Black Sea, other relevant waters (remaining species).

Figure 1.1: Time-frame for the landing obligation implementation. 
In theory, the introduction of the landing obligation should facilitate the application of an ecosystem approach to fisheries: all catches of quotaregulated species from the North-East Atlantic are being landed and the total amount can be constrained by species-specific total allowable catches (TACs). This implies that vessels must ideally have adequate quotas for all species included in the ban that they are likely to catch during the course of their operations. Failing that, the fishery would need to be restricted or closed once one or more quota for the stocks are exhausted, even if quotas were still available for other species.

While some elements of the landing obligation are set out in European Regulations, there are also some exemptions and flexibilities in how to implement them, both at Member States (MS) and national level (Box 3 ). The implementation of the landing obligation therefore requires high levels of at-sea monitoring and effective control. However, there are no specific additional requirements for its monitoring and control, except for an obligation to document the catches. This means that MS need to address a number of new problems to help ensure compliance with the landing obligation and operate in the context of other elements of the CFP such as maximum sustainable yield (MSY) and maintenance of the reproduction viability, regionalisation, and multi-annual plans.

\section{Box 3. Landing Obligation: exemptions, provisions and requirements}

By 2019, all species subject to TAC limits and minimum conservation reference sizes (MCRS, comparable, but not equivalent, to the previously known minimum landing size) in the Mediterranean will be subject to the landing obligation. The landing obligation is applied fishery by fishery. Details of the implementation are included in multi-annual plans, or in specific discard plans when no multi-annual plan is in place. The plans detail the species covered, provisions on catch documentation, MCRS, and exemptions for different areas. The plans have a maximum duration of 3 years and the provisions of the landing obligation will eventually become incorporated into multi-annual plans. 


\section{Exemptions:}

The landing obligation includes three specific exemptions in case of which catches can be returned to the sea:

- species for which fishing is prohibited (e.g. basking sharks, some ray species),

- species that have high survival rates after being discarded (taking into account gear, fishing practice and environment), and

- catches that fall under the de-minimis exemption of up to $5 \%$ of the total annual quota to be discarded under certain circumstances (and up to $7 \%$ and $6 \%$ in the first two years respectively).

The de-minimis exemption shall apply in the following cases:

- where scientific evidence indicates that increases in selectivity are very difficult to achieve; or

- to avoid disproportionate costs of handling unwanted catches, but only where the bycatch of the gear in question does not represent more than a certain percentage of the catch.

\section{Provisions and requirements:}

TACs are adjusted to account for the previously discarded part of the catch, although the details of this adjustment are not clear (EU, 2016). To mitigate the strict implications, the Regulation includes:

- Inter-species flexibility derogation: the ability to deduct catches of a species for which quota is no longer available from the quota of another species, by up to $9 \%$ of the quota of the target species (only applicable where the stock of the non-target species is within safe biological limits).

- Year to year flexibility derogation: banking and borrowing provision, whereby up to $10 \%$ of a quota can be utilised in addition to the full quota or saved to be utilised in the next year. 


\section{Box 4. Trends in discards}

The practice of discarding occurs in almost all developed fisheries worldwide (Kelleher, 2005). In the past, total estimates performed by the UN Food and Agricultural Organisation (FAO) have provided a yearly mean global estimate of 27 million tonnes of discards (a discard ratio of approximately 35\%) (Alverson et al., 1994). A decade later, an update estimated global average yearly discards as 7.3 million tonnes (a ratio of approximately 8\%). These two assessments, while not directly comparable owing to their different methodologies, suggest a significant decline in global discards in the ten years between the studies.

A recent study by (Pauly and Zeller, 2016) reflects declines in industrial catches and, to a smaller extent, declining discards despite industrial fishing having expanded from industrialised countries to the waters of developing countries (Fig. 1.2).

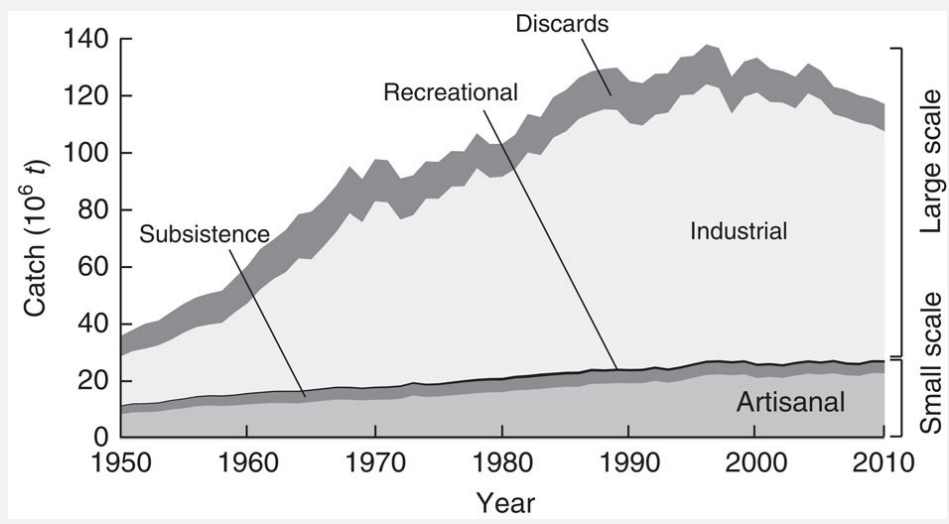

Figure 1.2: Reconstructed catches for all countries in the world, plus High Seas, by large-scale (industrial) and small-scale sectors (artisanal, subsistence, recreational), with discards (overwhelmingly from industrial fisheries) presented separately. Source: Pauly and Zeller (2016).

Globally, high levels of discards in many fisheries have been considered an issue for many years (Fig. 1.2).In the European Union, discards represent a major source of undocumented (or poorly documented) mortality, contributing to the overfishing of European fish stocks (EU, 2011b). 
Discarding involves a conscious decision made by fishers to reject part of the catch (Box 4). These large quantities of releases have attracted worldwide attention in the recent past (Alverson et al., 1994; Andrew and Pepperell, 1992; Kennelly, 1995; Saila, 1983) and continue to be one of the most important issues (EU, 2013).

The discarding of target species can occur for several reasons. One reason is related to fishing regulations, such as if fish are below the minimum landing size or if the fisher holds insufficient quota for the species (Catchpole et al., 2005) (Box 5). When the quota for a species has been exceeded, the decision is often taken, especially in mixed fisheries, to continue fishing for other species even when this implies discarding individuals of the species for which the quota has been exceeded (Bellido et al., 2011). There are also economic reasons, such as differences in the market prices of different species and/or size classes, and so-called "high grading", whereby less valuable species and size classes are discarded to use the limited storage space for the more valuable catch (Punt et al., 2006). Other reasons for discarding include damage or degradation of the catch, and catching non-commercial species.

Discard surveys in recent years have revealed that discards may correspond in some cases to a substantial part of the catch and, for some stocks may even exceed the reported landings (ICES, 2013). Discarding levels in EU fisheries vary between locations, gears, species and fishing grounds (Sigurǒardóttir et al., 2015; Uhlmann et al., 2013). In general, there is a relationship between the selectivity of the fishing gears and the percentage of catch discarded. The use of gears with a large mesh size induces less discarding (10-15\% by weight) than the use of gears with a small mesh size (50\% or more in some cases) (Villasante et al., 2015).

Demersal trawling is the most problematic form of fishing with respect to discards (Hall and Mainprize, 2005). It accounts for approximately $22 \%$ of the world's total landings but $50 \%$ of the total estimated discards (Kelleher, 2005) (Box 6). Consequently, the main focus throughout the thesis is on discards within demersal trawl fisheries. 


\section{Box 5. Global causes of fisheries discards}

Discarding is influenced by various economic, sociological, technical, legislative, environmental and biological factors (Vestergaard, 1996).

Fishing gears generally are not perfectly selective and thus generate catches containing unmarketable fish such as undesired species or non-commercial, rare, or protected species. Furthermore, they can also generate catches containing under-sized target species, non-target species, over-quota catches, and lower valued fish of quota species. These catches are subsequently discarded (Catchpole et al., 2005; Gillis et al., 1995).

Minimum landing size regulations also lead to some discards when the selectivity of the gear is such that some fish below the minimum landing sizes are caught. This is particularly the case in mixed fisheries as there is not one gear design which corresponds to the minimum landing size of all the species caught together (Feekings et al., 2012; Madsen, 2007; McClanahan, 2010; Santurtún et al., 2014).

Other reasons for discarding relate to both market considerations and regulatory requirements. Market-driven discarding (high grading) can take place when low market price, or catch of non commercial species because of low demand that do not compensate sorting and handling costs. Species with no demand, as well as individuals of certain sizes and/or in poor quality condition (e.g., damaged or not fresh) may result in fish being discarded. A management system which relies on landing quotas as the main regulator of fishing activity will lead to discards particularly when various species are caught together in mixed fisheries. For example, quota restrictions for a stock below safe biological limits with advice to reduce fishing mortality - but retaining opportunities for other species - e.g. cod (Gadus Morhua) in early 2000s; or lack of quota opportunity for species historically allocated to others- e.g. hake (Merluccius merluccius). 


\section{Box 6. Bottom trawl discards}

The FAO defines trawling as the use of "cone-shaped netting bags that are towed through the water to catch different target species in their path" (FAO, 2016). Bottom trawling is based on the contact of the net with the sea floor with the aim of catching benthic or bottom-dwelling species. Trawls can be towed with one or two boats (pair trawling) and a range of different kind of rigs can be used (e.g. twin and triple trawls). The gear and method used depends on the fishing target. Trawls are used throughout most of the world's oceans (FAO, 2016), despite the fact that they are poorly selective and retain large quantities of non-target species (Broadhurst, 2000).

Within Europe, 60-70\% of discarded resources are roundfish and flatfish species. These discards originate mostly in the demersal trawl (otter trawl and beam trawl) fisheries targeting roundfish, flatfish and Norway lobster (Nephrops norvegicus) (Catchpole et al., 2005). North-East Atlantic pair trawlers discard $40-60 \%$ of their catch, while single bottom trawlers discard $20-40 \%$ of their catch throughout the North-East Atlantic (STECF, 2006). In the Mediterranean, discard ratios from bottom trawlers show large differences between areas and operations, varying from $20 \%$ to $65 \%$ (Bellido Millán et al., 2014; Tsagarakis et al., 2014). For pelagic fisheries, discard ratios are generally known to be low, although the discard data available for these fisheries is very limited.

The main objective of any catch quota management system with landing obligations is to create economic incentives for the industry to reduce the capture of both unwanted species and smaller individuals through improvements in selectivity (Kindt-Larsen et al. (2011); Marine Management Organisation, 2012). It could also improve accuracy in recording catches and prevent wastage of food (Clucas, 1996). However, this objective is difficult to achieve for mixed fisheries, where there is a potential mismatch between the current allocated TACs and the catch distribution (Kraak et al., 2013). A section of the catch in these mixed fisheries will always consist of species or commercial categories that cannot be sold on the human consumption market due to weak or absent demand 
or because they consist of fish under the minimum landing size.

A total discard ban may compromise the profitability of some discardintensive fisheries (at least in the short term) because retaining, manipulating and landing size categories or species that were previously discarded will reduce income-per-unit-effort (Condie et al., 2014). Potentially, there would still be some economic incentive to discard if the catch included significant proportions of unwanted organisms. Furthermore, the immediate loss of landings incurred through discard reduction measures will remain an obstacle to their implementation (Catchpole et al., 2005).

In contrast, poor enforcement in European fisheries has often been identified as a factor that contributes to a situation where the potential economic benefits for fishers of non-compliance often outweigh the risks of detection (Catchpole et al., 2005) and the cost of sanctions (Batsleer et al., 2013). Non-compliance is likely to remain a significant problem because, for those likely to incur increased costs due to discard limitations, there may be little incentive to comply with regulations as long as enforcement remains weak. In general, the success of fisheries management regimes, such as a discard ban, can be said to be strongly dependent on compliance from the industry, which itself depends on a delicate balance between enforcement costs and benefits, and between the establishment of mechanisms to promote active voluntary compliance and the unavoidable control measures necessary to discourage and punish non-compliance.

Fisheries advice should be extended to offer predictions of stock trajectories not only under a range of possible management measures, but also for a number of realistic outcomes in terms of compliance and enforcement of regulations (Fulton et al., 2011). Following these predictions, and prior to implementation, a discards management regime should be evaluated (to the extent possible) by simulation, to ensure its robustness to prevailing uncertainties including those related to implementation (Butterworth, 2007; Punt and Donovan, 2007).

\subsection{Thesis objective}

The aim of this $\mathrm{PhD}$ is to explore the effects of fisheries management plans regarding discard reductions on the population dynamics of fish 
stocks and the economics of mixed fisheries. To this end, this thesis addresses three key aspects of the implementation of a landing obligation.

\section{Box 7. Worldwide discard management regimes experiences}

Discard restrictions and discard management regimes have been implemented to different extents in a number of fisheries around the world (e.g., Chile, Norway, Faroe Islands, Iceland, New Zealand, Namibia, Canada, and the US).

Experiences from fisheries around the world show that choosing the right measures is not a simple process. Different regulations are required for different fisheries, dependent upon the distribution of activities, the gear in use, the scale of enforcement that is available, and the species that are targeted and incidentally caught (Hutton et al., 2010). These measures will mean little unless fishing mortality is constrained to a sustainable level, whether through quotas or effort controls. These challenges will be faced by fisheries managers throughout Europe if the proposed changes to the CFP are implemented.

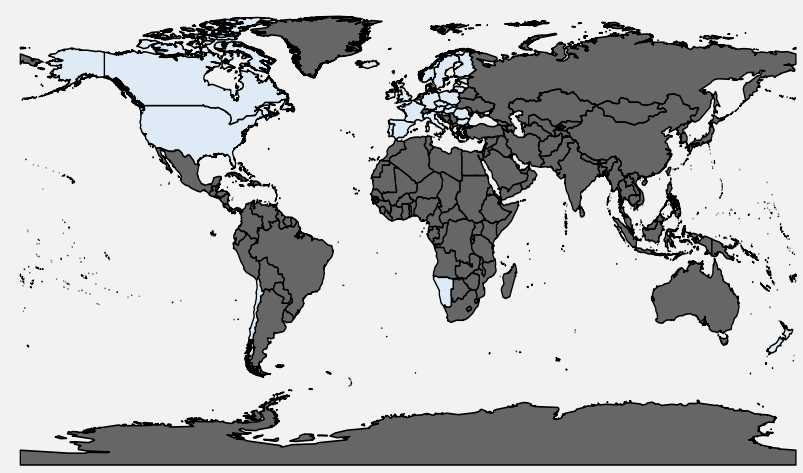

Figure 1.3: Main countries where discard bans are currently implemented.

The first chapter focuses on how discard problems have led to a variety of management strategies worldwide that try to reduce the impacts of large bycatches (Box 7). A key focus of this chapter, therefore, is to review current experience at the global level, identifying the most im- 
portant factors affecting the implementation of these policies. Generally, global experience has highlighted that a policy of mandatory landings can result in a reduction in discards, but relies upon economic incentives to encourage fishers to land more of their catch or to simultaneously implement complementary measures that will encourage compliance with discarding rules (Catchpole and Ribeiro Santos, 2015; Condie et al., 2013; Hedley et al., 2015).

Changing the selectivity patterns of fishers is seen as one of the fundamental outcomes of the reformed CFP. Improving the selectivity of fishing gears remains one of the most applied tools to avoid discards or minimise bycatch (Broadhurst, 2000). However, there are numerous ways in which fishers may alter the selectivity of a trawl. Fishers can adapt and change their behaviour in relation to imposed constraints, which can lead to unforeseen consequences of fisheries management (Branch et al., 2006; Hilborn, 1985). An exhaustive review of all potential gear modifications is not possible, since it would need to be conducted at the level of specific fisheries. Therefore, the second part of the thesis focuses on Basque trawl fisheries (Box 8) and how they might alter the selectivity of their fishing operations. This investigation considers both the current technical measures in use and fisher behaviour.

The introduction of the landing obligation shifts the emphasis from prescribing which fishing gears are permissible to a results-based system where the onus is on the fishers to develop gears that will avoid unwanted catches. Such a shift to a results-based system presents both a challenge and an opportunity to develop alternative gears that are more selective to avoid unwanted catches of undersized species. Therefore, in this second part, attention is specially focused on testing gear-specific regulations to address whether the current Basque trawler gear configuration effectively achieves the intended objective of releasing unwanted catches. Furthermore, since no new technical measures are foreseen to specifically accompany the implementation of the EU landing obligation, attention is also given to how fishers may adapt their fishing behaviour to mitigate the full impact of the landing obligation. 


\section{Box 8. The Basque trawl fisheries}

The Spanish trawl fleet operating in the Bay of Biscay, and particularly that of the Basque country, comprises vessels using either bottom otter trawl (OTB) or high vertical opening pair bottom trawl (PTB; Iriondo et al. (2008)). These vessels fish in one of three fishing areas: ICES sub-areas 6, 7 and 8 (divisions $8 \mathrm{a}, 8 \mathrm{~b}$, and $8 \mathrm{~d}$ ). The Basque trawl fleet is managed through total allowable landings (TALs) and total allowable effort (TAE), as well as other technical and physical measures (Iriondo et al., 2013). The fleet operates as a mixed fishery, characterised by a complex and variable catch composition. Vessels exploit a high variety of species and present important seasonal differences in terms of target species and bycatch. The fishing characteristics of this fleet changes with the gear used.

In the Basque fleet, discarding of target and bycatch species can be substantial. For example, in 2012, discards represented approximately $60 \%$ and $15 \%$ by weight of the total estimated catch of OTB and PTB, respectively $(12,991 \mathrm{t}$ and $6,622 \mathrm{t}$, respectively; (Rochet et al., 2014)). Approximately $80 \%$ of the discards were made to adhere to fishing regulations. Vessels in this fishery discard catch when there is a lack of quota for certain species (e.g., mackerel (Scomber scombrus), when captured individuals are smaller than the minimum landing size (e.g., hake), or in the absence of a market (e.g., horse mackerel (Trachurus trachurus) and blue whiting (Micromesistius poutassou)); (Rochet et al., 2014)). The introduction of the landing obligation is thus expected to negatively affect the fishery because it reduces the short-term economic flexibility provided by discarding as a means of accommodating several quota species for which single-species quotas are set.

In recognition of the potential difficulties that fishing businesses may face when making the transition to the new management system that have been noted in Box 3, there are a number of exemptions (prohibited and high survival species, de minimis exemption) and tools designed to support its successful implementation (inter-species flexibility deroga- 
tion, year to year flexibility derogation and quota increases). However, the influence of measures on the individual fisher and fishing communities are often overlooked, underestimating the range of factors likely affecting fisher behaviour. To this end, borrowing methodology from the more general question of state-dependent foraging decisions in ecological systems (Clark and Mangel, 2000; Houston and McNamara, 1999), simulation tools for such fisher responses are used to gain insight in the spatial distribution of fishing fleets and to understand the decisions of individual fishers when implementing a new management system (Box $9)$.

\section{Box 9. Dynamic state variable model}

Many fisheries are managed under TACs and a substantial part by individual quotas. This approach has not been successful in mixed fisheries where fishers continue to fish while discarding marketable or undersized fish. Using a spatially explicit dynamic-state variable model (Clark and Mangel, 2000; Houston and McNamara, 1999), the optimal fishing strategy of fishers that are both constrained by annual individual quotas and facing uncertainty in catch rates can be studied.

New tools for studying state-dependent behaviour of individual fishing vessels, translated into behaviour of the fleet and implemented using stochastic dynamic programming, have been developed and applied in a broad range of fisheries-related problems (Batsleer et al., 2015; Dowling et al., 2011; Gillis et al., 1995; Poos et al., 2010). These models generally predict the effect in the short term (within a fishing trip or a quota year) by optimising a utility function and determining which choices yield the best chance of increasing utility, while monitoring the state of each individual. The effect of a choice on the utility depends on the economic environment, such as the home port of the vessel and the distance to fishing grounds, and the biological environment, such as the spatial distribution of the resources. The effects of behaviours such as discarding have been modelled using such dynamic variable state models Batsleer et al. (2013, 2015); Gillis et al. (1995). 
The strength of this model approach is that it allows short-term choices to be accommodated against long-term constraints, such as fishers facing annual catch quotas and discarding limitations but making decisions about the fishing ground, to deciding whether to target or discard part of the catch, to deciding whether to go fishing or not. Within this model it is possible to simulate how fishing fleets will adapt to different discard management scenarios given the spatial and temporal differential in catch rates, sizes compositions, prices, costs of fishing effort, quota constraints, discard limitations, and fines.

The model used in this thesis extends the model structure in Batsleer et al. (2015) to accommodate the range of quota flexibility and exemptions proposed (EU, 2013). The model incorporates annual fines for exceeding landings or catch quota as in Batsleer et al. (2015, 2016), and extends earlier approaches by including errors in decision-making (following Dowling et al. (2011)) rather than assuming that individuals always make optimal choices. Extending the dynamic state variable model contributes to developing a generic model to explore the consequences of implementing the landing obligation management measures on short-term decisions. The model includes more complex dynamics that govern decisionmaking (and errors in decision-making) such as gear choice and the spatial and temporal distribution of effort (and the socio-economic consequences thereof) for a wider range of management systems of demersal fisheries.

Fishers will be prompted to avoid catching low-value fish because these will be deducted from their quota allocation. They will also avoid those species with the most restricted quotas because catching these could result in an effort reduction for the fishing season. So, based on these principles, fishers will be motivated to reduced undesirable catches of undersized species for which they have limited quota and to catch other valuable species. To achieve this, it is anticipated that fishers will change the location, timing, and fishing gears used in order to control the underlying selectivity patterns of harvests. Therefore, by combining the different exemptions introduced by the new management system, the 
costs and benefits associated with the different behaviours adopted by fishers are quantified.

If the landing obligation changes selectivity patterns as anticipated, then longer term changes would also be expected to occur in both fish populations and the economy of the fishery. Such analyses are the domain of bio-economic management strategy evaluations (MSE), where the feedback between fleet and stock dynamics are modelled explicitly (Andersen et al., 2010; Prellezo et al., 2016; Punt et al., 2016). Therefore, the third part of the thesis focuses on such models, in which the effects of the changing selectivity of the fishing fleets on the reference points for sustainable exploitation can be evaluated (Box 10).

To enable longer term prediction of the effects of changes in fisheries management, and thus complete the MSE (Bunnefeld et al., 2011; Sainsbury, 2000; Smith, 1994), one needs to couple the fleet dynamic models that forecast the fleet response to management (Box 9) with biological dynamic models that forecast the fish population responses to the changing fleet response. In other words, it is necessary to measure changes in population abundance in order to measure the effect of the potential consequences associated with the fishers' optimal choices and to locate the underlying assumption of the current state-dependent behaviour of individual fishing vessels.

A key focus of this chapter, therefore, is to understand the fleet dynamics in a spatially and temporally heterogeneous, mixed, quota-regulated fishery while it changes from unmanaged (unconstrained catch quota) to management by MSY. Therefore, this chapter encompasses the individual decision-making process of the fisher and the socio-economic drivers of management effectiveness, evaluating whether this approach leads to a better balance between quotas and catches under the new management system. Doing so involves creating simulation models that best represent current knowledge and uncertainty on the dynamics of fish stocks under fishing pressure, the effect of variations in stock status and availability on fishers, and their responses to changes to both management regimes and stock. Costs and benefits, both economic and in terms of risks to both stock and livelihoods, can be computed and compared across scenarios and management regimes. 


\section{Box 10. Management Strategy Evaluation (MSE) framework}

Management strategy evaluation (Bunnefeld et al., 2011; Sainsbury, 2000; Smith, 1994) seeks to study the implications of management strategies using simulation (Punt et al., 2016). Such simulation should include all the important processes of a fishery (an inherently socio-ecological system) with coupled dynamics of the fishing fleets, the exploited stocks, and their governance (Punt et al., 2016; Rademeyer et al., 2007). In such a modelling framework, advice and management systems can be quantitatively evaluated (Dichmont et al., 2013; Kell et al., 2007). Such analyses are the domain of bio-economic management strategy evaluations where the feedback between fleet and stock dynamics are modelled explicitly (Andersen et al., 2010; Prellezo et al., 2016; Punt et al., 2016). In such models, the effects of the changing selectivity of the fishing fleets on the reference points for sustainable exploitation can be evaluated.

The framework consists of an operating model (OM) and a management procedure (MP) (see Fig. 5.1 on page 127). In the fishery, there are three essential elements: (i) a collection of size structured fish stocks, whose dynamics are governed by annual reproduction, growth, migration, and mortality; (ii) a management body that evaluates the fishing pressure and aims to set annual quotas in accordance with fishing mortalities dictated by Fmsy reference points; and (iii) a fleet of individual fishers who aim to make the best use of their annual quota. Within this mixed fishery, individual vessels make adaptive choices about fishing location and discarding that depend on the distribution of the resources, and the quota that hold, the (real or perceived) local abundance and catchability of the fished stocks, and various resource costs, principally that of fuel. The constraints include the obvious management-imposed constraints such as levels of TAC, and economical constraints such as the contribution of the annual fines for exceeding catch quotas. 


\subsection{Thesis outline}

Chapter 2 addresses a global review of different conceptual papers that explain and identify different management regimes and regulatory factors and the key drivers of the effective implementation of policies limiting or eliminating discards at sea.

Chapter 3 deals with testing gear-specific regulations to address if the current Basque trawler gear configuration effectively achieves the intended objective of releasing unwanted catches. The introduction of the landing obligation shifts the emphasis from prescribing the fishing gears that are permissible, to a results-based system where the onus is on the fishers to develop gears that will avoid unwanted catches.

Chapter 4 investigates the effects of various implementations of discard managements on the spatial distribution of the Basque trawl fleet. Constraints set on discards play an important role in structuring the spatio-temporal distribution of fishing effort and also in varying the catch rates.

Chapter $\mathbf{5}$ shows the implications of the changing fleet dynamics on the exploitation of a simulated mixed fishery, in terms of changing selectivity-at-length resulting from the changes in spatial distribution of the fishery when trying to reach the Fmsy.

Chapter 6 provides a general discussion of the results obtained. This puts the findings in a broader perspective, discusses some of assumptions made, as well as potential avenues for future research that could provide answers to the questions that remain. 


\subsection{References}

Alverson, D. L., Freeberg, M. H., Pope, J. G., and Murawski, S. A. 1994. A global assessment of fisheries bycatch and discards. FAO Fisheries Technical Paper 339, Rome. Retrieved from: page 233. URL http://www.fao.org/ docrep/003/t4890e/t4890e00.htm.

Andersen, B. S., Vermard, Y., Ulrich, C., Hutton, T., and Poos, J. J. 2010. Challenges in integrating short-term behaviour in a mixed-fishery Management Strategies Evaluation frame: A case study of the North Sea flatfish fishery. Fisheries Research, 102(1-2):26-40.

Andrew, N. L. and Pepperell, J. G. 1992. The by-catch of shrimp trawl fisheries. Oceanography and Marine Biology: Annual Review, 30:527-565.

Batsleer, J., Poos, J. J., Marchal, P., Vermard, Y., and Rijnsdorp, A. D. 2013. Mixed fisheries management: Protecting the weakest link. Marine Ecology Progress Series, 479:177-190.

Batsleer, J., Hamon, K. G., van Overzee, H. M. J., Rijnsdorp, A. D., and Poos, J. J. 2015. High-grading and overquota discarding in mixed fisheries. Reviews in Fish Biology and Fisheries, 25: 715-736.

Batsleer, J., Rijnsdorp, A. D., Hamon, K. G., van Overzee, H. M. J., and Poos, J. J. 2016. Mixed fisheries management: Is the ban on discarding likely to promote more selective and fuel efficient fishing in the Dutch flatfish fishery? Fisheries Research, 174:118-128.

Bellido, J. M., Santos, M. B., Pennino, M. G., Valeiras, X., and Pierce, G. J. 2011. Fishery discards and bycatch: Solutions for an ecosystem approach to fisheries management? Hydrobiologia, 670(1):317-333.
Bellido Millán, J. M., Carbonell Quetglas, A., Garcia Rodriguez, M., Garcia Jimenez, T., and González Aguilar, M. 2014. The Obligation to Land All Catches - Consequences for the Mediterranean. European Parliament Study IP/B/PECH/IC/2013-168.

Branch, T. A., Hilborn, R., Haynie, A. C., Fay, G., Flynn, L., Griffiths, J., Marshall, K. N., Randall, J. K., Scheuerell, J. M., Ward, E. J., and Young, M. 2006. Fleet dynamics and fishermen behavior: lessons for fisheries managers. Canadian Journal of Fisheries and Aquatic Sciences, 63(7):16471668 .

Broadhurst, M. K. 2000. Modifications to reduce bycatch in prawn trawls: A review and framework for development. Reviews in Fish Biology and Fisheries, 10(1):27-60.

Bunnefeld, N., Hoshino, E., and MilnerGulland, E. 2011. Management strategy evaluation: A powerful tool for conservation? Trends in Ecology and Evolution, 26(9):441-447.

Butterworth, D. S. 2007. Why a management procedure approach? Some positive and negatives. ICES Journal of Marine Science, 64(1995):613-617.

Cardinale, M. and Svedäng, H. 2004. Mismanagement of fisheries: Policy or science? Fisheries Research, 93:244247.

Catchpole, T. and Ribeiro Santos, A. 2015. The landing obligation and its implications on the control of fisheries. European Parliament Study $I P / B / P E C H / I C / 2014-20$.

Catchpole, T. L., Frid, C. L. J., and Gray, T. S. 2005. Discards in North Sea fisheries: causes, consequences and solutions. Marine Policy, 29(5):421-430. 
Clark, C. W. and Mangel, M. Dynamic state variable models in ecology: methods and applications. Oxford University Press, New York, 2000.

Clucas, I. J. Reduction of fish wastage - An introduction. In Report on the Technical Consultation on Reduction of Wastage in Fisheries. Technical report, FAO Fisheries Report 547 supplement, FAO, Rome, Tokyo, Japan, 28 October - 1 November 1996, 1996.

Condie, H. M., Grant, A., and Catchpole, T. L. 2013. Does banning discards in an otter trawler fishery create incentives for more selective fishing? Fisheries Research, 148(2013):137-146.

Condie, H. M., Catchpole, T. L., and Grant, A. 2014. The short-term impacts of implementing catch quotas and a discard ban on English North Sea otter trawlers. ICES Journal of Marine Science, 71(5):1266-1276.

Diamond, B. and Beukers-Stewart, B. D. 2009. Fisheries Discards - Waste of a Resource or a Necessary Evil?: Report to the EU on the reform of the Common Fisheries Policy. Marine Ecosystem Management Report. University of York. Retrieved from: URL http: //eprints.whiterose.ac.uk/105474/.

Dichmont, C. M., Ellis, N., Bustamante, R. H., Deng, R., Tickell, S., Pascual, R., Lozano-Montes, H., and Griffiths, S. 2013. Evaluating marine spatial closures with conflicting fisheries and conservation objectives. Journal of Applied Ecology, 50:1060-1070.

Dowling, N. A., Wilcox, C., Mangel, M., and Pascoe, S. 2011. Assessing opportunity and relocation costs of marine protected areas using a behavioural model of longline fleet dynamics. Fish and Fisheries, 13(2):139-157.

EC. 2007. European Commission. Eliminating discards in EU fisheries: Questions and Answers. Retrieved from. URL http://europa. eu/rapid/press-release_MEMO-07120_en.htm?locale=en.

EU. Reform of the Common Fisheries Policy. Communication from the Commission to the European Parliament, the Council, the European Economic and Social Committee and the Committee of the regions. Brussels: Commission of the European Communities, 2011a.

EU. Proposal for a Regulation of the European Parliament and of the Council on the Common Fisheries Policy. Brussels: Commission of the European Communities, 2011b.

EU. High level meeting on banning discards, Brussels 1 March 2011. Nonpaper. Brussels: Commission of the $\mathrm{Eu}-$ ropean Communities, 2011c.

EU. Regulation (EU) No 1380/2013 of the European Parliament and of the Council of 11 December 2013 on the Common Fisheries Policy, 2013.

EU. Regulation (EU) 2016/72 of the European Parliament and of the Council of 22 January 2016 fixing for 2016 the fishing opportunities for certain fish stocks and groups of fish stocks, applicable in Union waters and, for Union fishing vessels, in certain non-Union waters, and amending Regulation (EU) 2015/104, 2016.

FAO. 2016. The State of World Fisheries and Aquaculture 2016. Contributing to food security and nutrition for all. Rome. Retrieved from: page 200. URL http://www.fao.org/3/a-i5555e.pdf.

Feekings, J., Bartolino, V., Madsen, N., and Catchpole, T. 2012. Fishery discards: factors affecting their variability within a demersal trawl fishery. PLoS ONE, 7(4):e36409.

Fulton, E. A., Link, J. S., Kaplan, I. C., Savina-Rolland, M., Johnson, P., 
Ainsworth, C., Horne, P., Gorton, R., Gamble, R. J., Smith, A. D. M., and Smith, D. C. 2011. Lessons in modelling and management of marine ecosystems: the Atlantis experience. Fish and Fisheries, 12(2):171-188.

Gillis, D. M., Pikitch, E. K., and Petermanc, R. M. 1995. Dynamic discarding decisions: foraging theory for highgrading in a trawl fishery. Behavioral Ecology, 6(2):146-154.

Hall, S. J. and Mainprize, B. M. 2005. Managing by-catch and discards: how much progress are we making and how can we do better? Fish and Fisheries, 6:134-155.

Hedley, C., Catchpole, T., and Santos, A. 2015. The Landing Obligation and its Implications on the Control of Fisheries. European Union, page 122. URL https://publications. europa.eu/en/publication-detail//publication/9ec98ef8-7644-454aad61-d1cd33125ca5/language-en.

Hilborn, R. 1985. Fleet Dynamics and Individual Variation: Why Some People Catch More Fish than Others. Canadian Journal of Fisheries and Aquatic Sciences, 42(1):2-13.

Houston, A. and McNamara, J. Models of Adaptive Behaviour. Cambridge University Press, Cambridge, 1999.

Hutton, T., Thebaud, O., Fulton, B., Pascoe, S., Innes, J., Kulmala, S., and Tudman, M. 2010. Use of Economic Incentives to Manage Fisheries Bycatch: An Application to Key Sectors in Australia's Southern and Eastern Scalefish and Shark Fisheries. Cleveland, Australia, page 174. URL http://www.afma.gov.au/wpcontent/uploads/2010/06/Use-ofeconomic-incentives-to-managefisheries-bycatch-August-2010.pdf.

ICES. 2013. Report of the Working Group on the Assessment of South- ern Shelf Stocks of Hake, Monk and Megrim (WGHMM) ICES Headquarters , Copenhagen International Council for the Exploration of the Sea. ICES, CM/AC(10-16 May):727. URL http://www.ices.dk/sites/ pub/Publication\%20Reports/Expert\% 20Group\%20Report/acom/2013/WGHMM/ WGHMM $\% 202013$.pdf.

Iriondo, A., Prellezo, R., Santurtún, M., Garcia, D., and Quincoces, I. 2008. Basque trawl metier definition for 20032007 period. Revista de Investigacion Marina, 3:263-264.

Iriondo, A., Aranda, M., and Santurtún, M. 2013. El reparto de cuotas individuales de pesca por buque de la flota de altura espanola en aguas del Nordeste Atlántico. Revista de Investigación Marina, AZTI-Tecnalia, 20(2):23-28.

Jensen, F. and Vestergaard, N. 2002. Moral hazard problems in fisheries regulation: the case of illegal landings and discard. Resource and Energy Economics, 24(4):281-299.

Kell, L. T., Mosqueira, I., Grosjean, P., Fromentin, J. M., Garcia, D., Hillary, R., Jardim, E., Mardle, S., Pastoors, M. A., Poos, J. J., Scott, F., and Scott, R. D. 2007. FLR: an open-source framework for the evaluation and development of management strategies. ICES Journal of Marine Science, 64:640-646.

Kelleher, K. Discards in the world's marine fisheries An update. Technical report, FAO Fish Tech Pap T470, Rome, 2005.

Kennelly, S. J. 1995. The issue of bycatch in Australian demersal trawl fisheries. Rev. Fish Biol. Fish., 5:213-214.

Kindt-Larsen, L., Kirkegaard, E., and Dalskov, J. 2011. Fully documented fishery: a tool to support a catch quota management system. ICES Journal of Marine Science, 68(8):1606-1610. 
Kraak, S. B. M., Bailey, N., Cardinale, M., Darby, C., De Oliveira, J., Eero, M., Graham, N., Holmes, S., Jakobsen, T., Kempf, A., Kirkegaard, E., Powell, J., Scott, R. D., Simmonds, E. J., Ulrich, C., Vanhee, W., and Vinther, M. 2013. Lessons for fisheries management from the EU cod recovery plan. Marine Policy, 37:200-213.

Madsen, N. 2007. Selectivity of fishing gears used in the Baltic Sea cod fishery. Reviews in Fish Biology and Fisheries, 17:517-544.

McClanahan, T. R. 2010. Effects of fisheries closures and gear restrictions on fishing income in a Kenyan coral reef. Conservation Society, 24(6):1519-28.

Pauly, D. and Zeller, D. 2016. Catch reconstructions reveal that global marine fisheries catches are higher than reported and declining. Nature Communications, 7(10244).

Poos, J. J., Bogaards, J. A., Quirijns, F. J., Gillis, D. M., and Rijnsdorp, A. D. 2010. Individual quotas, fishing effort allocation, and over-quota discarding in mixed fisheries. ICES Journal of Marine Science, 67(2):323-333.

Prellezo, R., I., G., and García, D. 2016. The bad, the good and the very good of the landing obligation implementation in the Bay of Biscay: A case study of Basque trawlers. Fisheries Research, 181:172-185.

Punt, A. E., Smith, D. C., Tuck, G. N., and Methot, R. D. 2006. Including discard data in fisheries stock assessments: Two case studies from southeastern Australia. Fisheries Research, 79(3):239-250.

Punt, A. E., Butterworth, D. S., de Moor, C. L., De Oliveira, J. A. A., and Haddon, M. 2016. Management strategy evaluation: Best practices. Fish and Fisheries, 17:303-334.
Punt, E. and Donovan, G. P. 2007. Developing management procedures that are robust to uncertainty: lessons from the International Whaling Commission. ICES Journal of Marine Science, 64: 603-612.

Rademeyer, R., Plagányi, E., and Butterworth, D. 2007. Tips and tricks in designing management procedures. ICES Journal of Marine Science, 64(4):618625 .

Rochet, M. J., Arregi, L., Tereza, F., Pereira, J., Perez, N., Ruiz Gondra, J., and Valeiras, J. 2014. Demersal discard atlas for the South Western Waters. Report, page 121. URL http://www.repositorio.ieo.es/eieo/handle/10508/9074.

Saila, S. B. 1983. Importance and assessment of discards in commercial fisheries. FAO Fishery Circular, 765, page 62 .

Sainsbury, K. 2000. Design of operational management strategies for achieving fishery ecosystem objectives. ICES Journal of Marine Science, 57(3):731741.

Santurtún, M., Prellezo, R., Arregi, L., Iriondo, A., Aranda, M., Korta, M., Onaindia, I., Garcia, D., Merino, G., Ruiz, J., and Andonegi, E. 2014. Characteristics of multispecific fisheries in the European Union. STUDY IPBPECHIC2013 088. URL https://www.researchgate. net/publication/266082516.

Sigurǒardóttir, S., Stefánsdóttir, E. K., Condie, H., Margeirsson, S., Catchpole, T. L., Bellido, J. M., Eliasen, S. Q., Goñi, R., Madsen, N., Palialexis, A., Uhlmann, S. S., Vassilopoulou, V., Feekings, J., and Rochet, M. J. 2015. How can discards in European fisheries be mitigated? Strengths, weaknesses, opportunities and threats of potential mitigation methods. Marine Policy, 51: 366-374. 
Smith, S. J. 1994. Analysis of Data from Bottom Trawl Surveys. NAFO Sci. Coun. Studies, 28:25-53.

STECF. 2006. Scientific, Technical and Economic Committee for Fisheries. Discards from community vessels report. Retrieved from:, page 56. URL http://ec.europa.eu/fisheries/ cfp/fishing_rules/discards/ official_documents/stecf_2006_ discards_report.pdf.

Tsagarakis, K., Palialexis, A., and Vassilopoulou, V. 2014. Mediterranean fishery discards: review of the existing knowledge. ICES Journal of Marine Science, 71:1219-1234.

Uhlmann, S. S., van Helmond, A. T. M., Kemp Stefánsdóttir, E., Sigurǒardóttir, S., Haralabous, J., Bellido, J. M., Carbonell, A., Catchpole, T., Damalas, D.,
Fauconnet, L., Feekings, J., Garcia, T., Madsen, N., Mallold, S., Margeirsson, S., Palialexis, A., Readdy, L., Valeiras, J., Vassilopoulou, V., and Rochet, M. J. 2013. Discarded fish in European waters: general patterns and contrasts. ICES Journal of Marine Science, 71(5): 1235-1245.

Vestergaard, N. 1996. Discard Behavior, Highgrading and Regulation : The Case of the Greenland Shrimp Fishery. $M a-$ rine Resource Economics, 11:247-266.

Villasante, S., Pazos Guimeráns, C., Rodrigues, J., Antelo, M., Rodríguez, R., DaRocha, J., Coll, M., Pita, C., Pierce, G., Hastie, L., and Sumaila, R. 2015. Small-Scale Fisheries and the Zero-Discard Rate. European Parliament Study, IP/B/PECH/IC/2014084. 



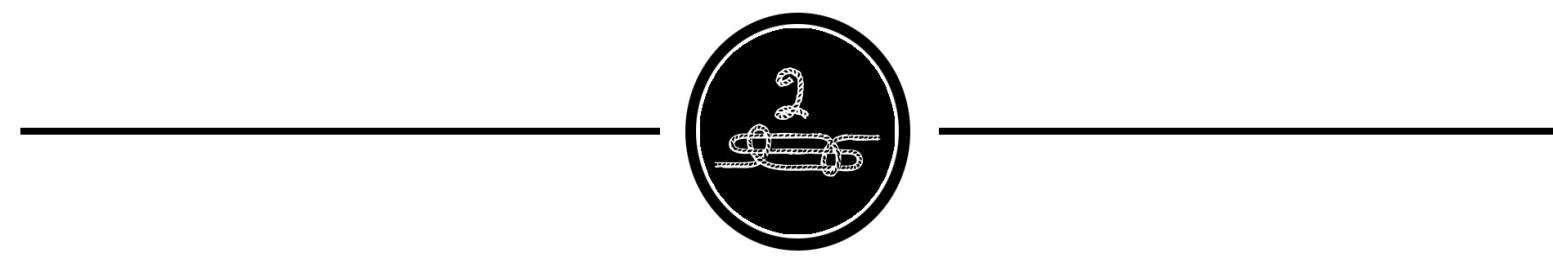

- REVIEW OF DISCARDS MANAGEMENT REGIMES. 


\subsection{Abstract}

Discarding is a common practice in fisheries. Although discards have been recognised to be substantial around the world, estimated to be as much as $33 \%$ of global marine catch in commercial fisheries, there are no recent reliable estimates. In EU fisheries, discards vary from more than $60 \%$ of the catch (in weight) on average in beam trawls to very low in others, such as pelagic trawl or seine fisheries. Discarding is an undesirable practice because of the waste of resources. It is also contributes to the overexploitation of fish stocks around the world as discards are not correctly or fully monitored. Discarding restrictions and discard management regimes have been implemented to different extents in a number of fisheries around the world. This study compares the details and performance of fisheries management regimes in the EU with those of Chile, Norway, the Faroe Islands, Iceland, New Zealand, Namibia, Canada and the US, which all implemented discard restrictions before the discard ban imposed in the reformed European Common Fisheries Policy.

\section{Keywords:}

landing obligation, discard management regimes, maximum sustainable yield, Common Fisheries Policy 


\subsection{Introduction}

Discarding, where a portion of a vessel's catch is returned to the sea dead or alive (FAO, 2010), is a widespread problem in EU fisheries (STECF, 2006). The practice is a wasteful use of resources and an impediment to the management and recovery of fish stocks, and thus many traditional fisheries management measures, such as the EU quota system, have effectively encouraged discarding. The inferences made about the drivers for discarding are numerous, including a mix of market, the length of the fish being captured by fishing gear of limited selectivity, and the existence of different regulations (MRAG, 2007). Despite the global importance of discarding and growing attention to overfishing, some assessed fish stocks worldwide continue to decline and still require rebuilding (Worm et al., 2009). Unsustainable fishing emerges as the main cause of this decline, with $31 \%$ of stocks considered overfished (WWF, 2016). The widespread recognition of the economic and ecological risks caused by progressive depletion of global fisheries (Britten et al., 2017), scientists and policy makers have shifted their focus to the rebuilding of depleted stocks (Worm et al., 2009). In Europe, rebuilding initiatives have received major support, with the major fisheries reform. The establishment of the landing obligation, also known as the discard ban, is a major provision of the latest reform of the EU's Common Fisheries Policy (CFP) and aims to gradually eliminate discards of commercially exploited stocks (Article 15 of EU Reg. 1380/2013; (EU, 2013)).

The gradual introduction of the EU's landing obligation, in combination with exemptions, provisions and specific requirements, aims to allow the fishing industry to adapt their fishing practices to comply with the changes introduced (EU, 2013). However, the costs and benefits derived from different mechanisms and levels of enforcement, for both direct users of the resource and society as a whole, are likely to be affected by the implementation of any additional management measures. In biological terms, a discard ban will be beneficial if total removals are reduced (Condie et al., 2014) or if at the same amount of removals, these are obtained from fishing pattern closer to the optimal exploitation pattern (Frangoudes and Guillen, 2015). Such a reduction of removals can take place without reducing landings, by avoiding undersized fish. Experience shows that in the absence of incentives to fish more selectively and avoid the capture of formerly discarded catch, a discard ban will 
not result in more sustainable fisheries (Bellido et al., 2011). Hence, in these cases where selectivity improvements cannot avoid the catch of undersized fish and consequently reduce fishing mortality, it is necessary to establish economic incentives to have a positive effect.

The implementation, monitoring and control of the landing obligation generates some new challenges. Given the strong economic incentives for discarding it must be expected that when a discard ban is imposed, if there are no economic incentives to land the capture of formerly discarded fish, discarding may still take place. Principally, under circumstances where enforcement is weak or the legal consequences do not match the immediate economic benefits from discarding. Typically fisheries control and enforcement is quite costly (Arnason, 2014); in particular, the focus of monitoring and control shifts from landings to activities at sea, leading to potentially higher costs of enforcement (Catchpole and Ribeiro Santos, 2015). Consequently a high level of surveillance to ensure the full implementation of an EU discard ban could be very costly considering the size of the EU fleet (Condie et al., 2014).

Discard restrictions and discard bans have been implemented in a number of fisheries around the world, including Norway, the Faroe Islands, Iceland, New Zealand, Namibia, Canada and the US. Both Chile and Europe are currently in the implementation phase. The aim of this paper is to build a common framework based on the regulations and measures employed to avoid and reduce discards in the countries that have implemented discard bans and restrictions.

There is a need for better understanding of the importance of different regulatory factors in the effective implementation of a policy limiting or eliminating discards at sea in complex mixed fisheries that are managed under catch limits. The following keys are used to structure this review: (i) historical background and eliminating discards management strategies, (ii) management measures enforced, and (iii) management effects and later evaluations.

\subsection{Drivers for successful discard bans}

This section aims to assess the effect of discard bans around the world and their surrounding management systems, identifying whether any benefits of the policy have been observed in original scientific publica- 
tions. The review includes papers that contained observations of implementing discard management systems, review papers, and papers pertaining to the enforcement of management measures, such as monitoring through on-board observations, quota flexibilities, discarding exceptions and real-time area closures (Annex I). These publications contribute to a common data-frame from which it is possible to extract observations and lessons that can be used by fisheries managers when implementing the new discard management policy under the reformed CFP (Annex II).

\section{Historical background and discard management strategies}

Each of the countries included in this review use management regimes that are based on ITQ (individual transferable quota) systems. The exceptions are New Zealand, Europe and the Faroe Islands, which combine both ITQs and extra management regimes ((Marchal et al., 2016; Motos and Wilson, 2006; Sanchirico et al., 2006); Table 2.1). New Zealand also has annual catch entitlements, which are generated by multiplying the proportional ITQ by the annually available TAC, and can be bought and sold independently (MRAG, 2007). Europe and the Faroe Islands also operate under an effort management system. Furthermore, the EU does not have authority to allocate quotas to individual fishers, and only some member states have formally or informally adopted individual quotas or ITQs for some of their fisheries (Marchal et al., 2016). The Faroe Islands introduced the ITQ system with the establishment of a discards ban (FHRG, 1994)).

In the selected case studies, discarding less valuable fish has been occurring in order to maximise the benefits for fishers. Most now accept discarding as an inevitable part of multi-species ITQ management because the ability to discard effectively eliminates the possibility that the catch of one species may be limited by the TAC of another. The Faroe Islands abandoned the system of ITQs only two years after its implementation (Hopkins et al., 2013; Jákupsstovu et al., 2007), in response to wide-reaching criticism of both the TAC-based ITQ system from the fishing industry, and extensive discarding as well as under- and misreporting of substantial parts of the catch (Gezelius, 2008; Johnsen and Eliassen, 2011).

Despite using common management regimes, attitudes towards discard 
restrictions also differ across the case studies. Based on the reviewed literature, the selected countries were aggregated by different ranges of discarding restrictions managements (Table 2.1- Annex I), and the complexity of their fisheries was categorised based on the number of target species caught (Annex II). The value of this category could be low (less than 5 target species), medium (between 5 and 10 target species) or high (more than 10 species).

A total ban on discards applies in Norway, the Faroe Islands, Iceland and Chile (Borges et al., 2016; Catchpole and Ribeiro Santos, 2015). Their discarding bans were applied to limited number of stocks and were gradually extended until they covered almost all commercial stocks. Chile introduced a total discard ban in 1991, however it was not strictly enforced. Since 2012, a research and monitoring program has been developed to establish a baseline for evaluation of the implementation and success of the discard ban and to help design technical and management measures that will simplify its implementation (Ministerio de Economia, Fomento y Turismo, 2013).

Namibia, New Zealand, Iceland and Europe have banned the discarding of quota-managed species, with exceptions in the latter three cases for species with high survival rates, non-commercial species, and undersized fish (Arnason, 2014; EU, 2013; Villasante et al., 2015) respectively. In order to allow fishers to adapt to the change, the EU landing obligation will be introduced gradually between 2015 and 2019 for all commercial fisheries, namely species under catch limits, TACs or under minimum sizes.

Canada and the US have no formal bans on discards (Arnason, 2014). However, in certain fisheries there are some retention requirements (i.e., discard bans) for some species, such as the Canadian Nova Scotia groundfish fishery, Canadian British Columbia groundfish fishery, and the US Alaskan groundfish fishery (Table 2.1).

Attitudes towards discarding (before the discard restrictions) also differed across the different reviewed cases (Fig. 2.1). Levels of discards before the ban ranged from $2 \%$ to $60 \%$ of the catch weight among the different countries (Fig. 2.1). In some cases, there were no reliable time series estimates of the levels of discards before ban implementations. 
Table 2.1: Summary of the management systems, complexity of fisheries and type of discards bans applied in each country (Key: NOR (Norway), FRO (Faroe Islands), CHL (Chile), ISL (Iceland), NZL (New Zealand), NAM (Namibia), EU (European Union), $C A N_{N S G}$ (Canadian Nova Scotia groundfish fishery), $C A N_{B C G}$ (Canadian British Columbia groundfish fishery), $U S A_{A L G}$ (USA Alaskan groundfish fishery), ITQ (individual transferable quota), TAE (total allowable effort), IQ (individual quota) and ACE (annual catch entitlement).

\begin{tabular}{|c|c|c|c|}
\hline Country & $\begin{array}{c}\text { Management } \\
\text { system }\end{array}$ & $\begin{array}{l}\text { Complexity of } \\
\text { the fishery }\end{array}$ & $\begin{array}{c}\text { Type of } \\
\text { discard ban }\end{array}$ \\
\hline $\begin{array}{l}\text { NOR } \\
\text { FRO } \\
\text { CHL }^{*} \\
\text { ISL }\end{array}$ & $\begin{array}{c}\text { ITQs } \\
\text { TAE- ITQs } \\
\text { ITQs } \\
\text { ITQs }\end{array}$ & $\begin{array}{c}\text { Low } \\
\text { Low } \\
\text { Medium } \\
\text { Medium }\end{array}$ & $\begin{array}{l}\text { Full } \\
\text { ban }\end{array}$ \\
\hline $\begin{array}{l}\text { NZL } \\
\text { NAM } \\
\text { EU * }\end{array}$ & $\begin{array}{c}\text { ITQs-ACE } \\
\text { ITQs } \\
\text { ITQs-IQ-TAE }\end{array}$ & $\begin{array}{l}\text { Medium } \\
\text { Medium } \\
\text { High }\end{array}$ & $\begin{array}{c}\text { Ban } \\
\text { on quota } \\
\text { species }\end{array}$ \\
\hline $\begin{array}{l}C A N_{N S G} \\
C A N_{B C G} \\
U S A_{A L G}\end{array}$ & $\begin{array}{l}\text { ITQs } \\
\text { ITQs } \\
\text { ITQs }\end{array}$ & $\begin{array}{l}\text { Medium } \\
\text { High } \\
\text { Low }\end{array}$ & $\begin{array}{c}\text { Ban } \\
\text { on some } \\
\text { species }\end{array}$ \\
\hline
\end{tabular}

Fisheries with lower complexity within their catch distribution seemed to have lower discard ratios according to these discards estimates (under $15 \%$ of catch weight, Table 2.1 and Fig. 2.1). Medium complexity fisheries such as Iceland, New Zealand, Namibia and the Canada Nova Scotia groundfish fishery suggest higher discard ratios (less than $40 \%$ of catch weight, Table 2.1 and Fig. 2.1). European fisheries and the Canadian British Columbia groundfish fishery cover the most complex multi-species fisheries, with discard ratios of up to $60 \%$ of the catch weight (Table 2.1 and Fig. 2.1). However, since no two fisheries are alike, it is difficult to assess to what extent the complexity of the fisheries or the level of discards before the ban contributed to the management outcomes of these diverging discard policies of the different regions under review. 


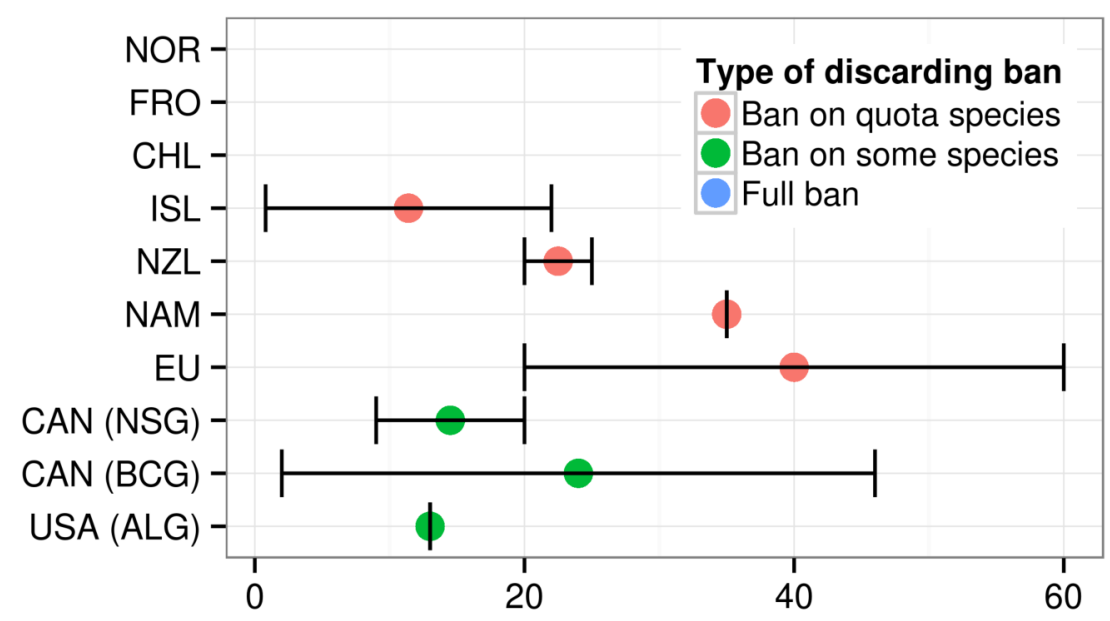

Figure 2.1: Discard ratio before the implementation of each ban. No data found for Norway, Faroe Islands and Chile.

\section{Management measures enforced}

Changes in the incentives facing fishers through management measures and flexibilities may have a positive impact on both the level of bycatch and discards. The implementation, monitoring, and control of the landing obligation generates some new challenges. A key focus of this section, therefore, is to review current experiences from around the world with respect to the multiple measures that support implementation and encourage voluntary compliance with discarding rules.

Under the CFP regulation, all catches have to be kept on board, landed and counted against the quotas. In order to facilitate the implementation of this policy, the EU regulation introduces some limited exceptions in certain cases, such as where unwanted fish have a high chance of survival if returned to sea, where increases in selectivity are impossible to achieve, or where fishers would incur disproportionate costs when handling unwanted catches (EU, 2013). The details of the implementation and requests for exceptions to be included in multi-annual plans, or in specific discards plans when no multi-annual plans are in place, are considered on a case by case basis (STECF, 2015, 2016). 


\section{Monitoring}

For the successful implementation of a discard ban, the focus of monitoring and control shifts from landings to activities at sea, leading to potentially increased costs of enforcement as this might require full observer coverage or self-reporting system monitoring (Catchpole and Ribeiro Santos, 2015). Each of the case studies enforce their discard bans by using onboard observers, but they do so to a very different extent (Fig. 2.2 and Annex II). Norway, the Faroe Islands and Iceland have very low onboard observer coverage with values lower than $5 \%$ (Buisman, undated; Gullestad et al., 2015). While New Zealand and the Canada Nova Scotia groundfish fishery have a higher coverage of up to the 20\%. Namibia and the US have a very high observer coverage in their fisheries of approximately 80\% (Arnason, 2014). The Canadian British Columbia groundfish fishery is unique with its full coverage of onboard observers (Government of Canada, 2007).

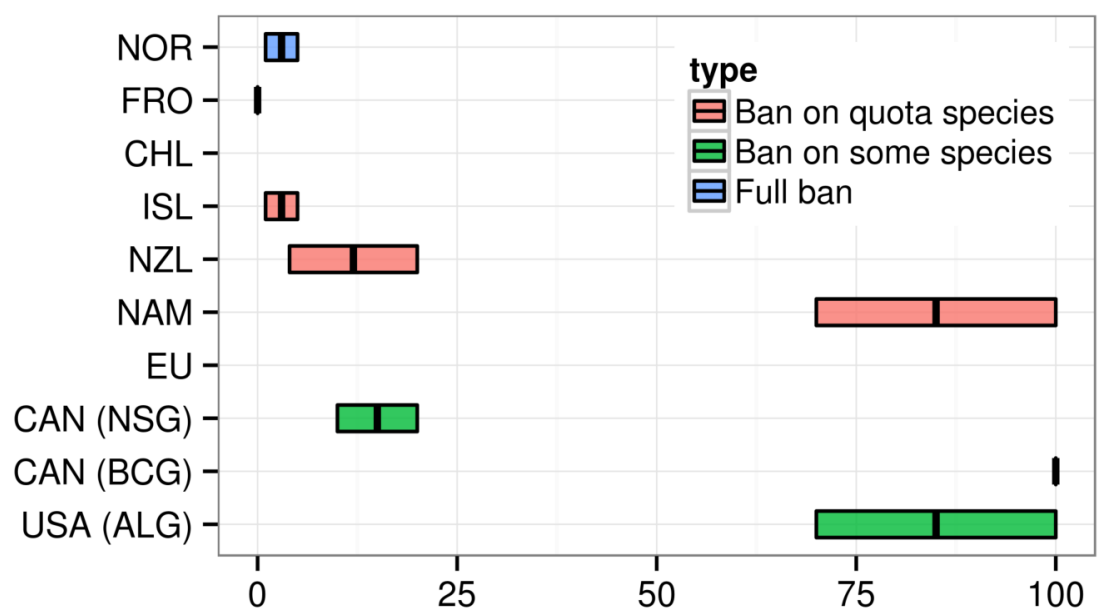

Figure 2.2: Observer onboard coverage.

Chile is unique in that it relies on the use of closed circuit televisions (CCTV) to directly monitor discarding practices (Fig. 2.3). The other case studies rely on indirect evidence of discarding practices through a combination of monitoring landings onshore and/or applying risk analysis based on catch statistics (Arnason, 2014). In other words, they 
compare observed catch compositions against unobserved reported catch compositions as a mechanism to detect likely discarding. In the Faroe Islands, where no direct discard observations are carried out, the whole monitoring effort relies on monitoring landings in port (Hopkins et al., 2013).
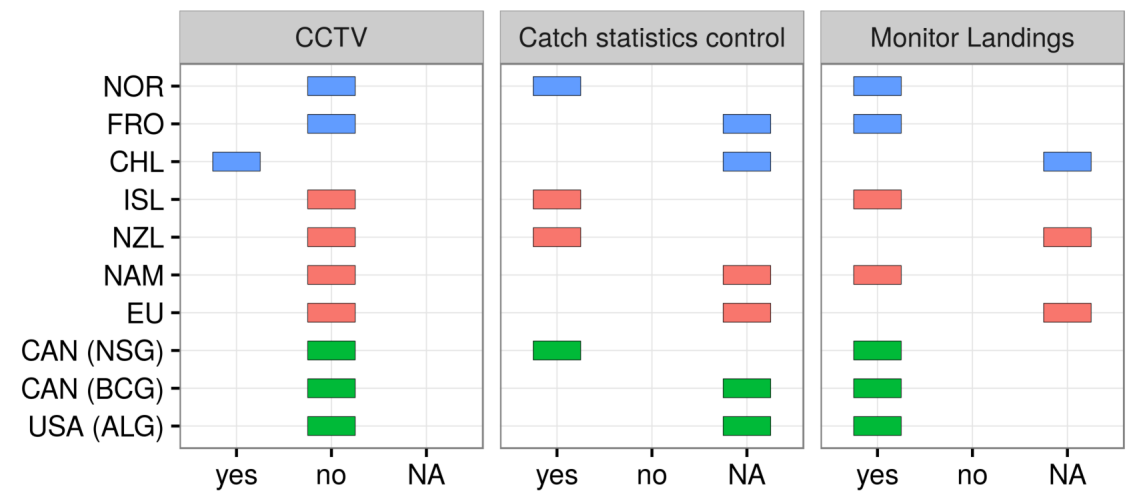

Figure 2.3: Monitoring means for the discard bans: onboard observers coverage, CCTV system, catch statistics control and landings monitoring.

Experiences show that a range of other monitoring methods are implemented in those countries where onboard observers are rarely or not at all present. In the case of the EU, there are no specific additional requirements for monitoring and control, except for the obligation to document the catches, details of which are again to be specified in multi-annual plans (EU, 2013).

\section{Quota flexibility mechanisms}

All case countries have implemented considerable quota flexibility mechanisms in their management systems, albeit to different extents (Fig. 2.4). The flexibilities assessed in this chapter consist of:

- Feasibility to land and commercialise a limited amount of undersized fish without counting against the species quota. The main goal is to incentivise fishers to retain the undersized catch that was previously discarded.

- Feasibility to land and commercialise a limited amount of non- 
target fish without buying specific quota for it. The aim of this measure is the same as the former.

- Possibility to aggregate species quota on one single quota to avoid an early interruption of fishing due to the constraints of the quota of one species.

- Possibility to move quotas between species within some established limitations (e.g., inter-species swapping).

- Possibility of banking and borrowing quota between consecutive years.

Iceland, New Zealand and the Canadian British Columbia fishery have introduced a higher range of flexibilities into their management systems (Fig.4). Globally, the possibility to catch and commercialise undersized fish and non-target fish without using any quota is limited. Iceland has implemented both measures, combining these flexibilities with real-time area closures (RTCs). Fishers are allowed to land some undersized fish and bycatch species before an area is closed (see section 2.3 on real-time area closures) (Arnason, 2014).

Norway, New Zealand and the Canadian Nova Scotia groundfish fishery have joint stock quota to avoid the closure of mixed fisheries when the most restricting quota is filled. The landing of over-quota, non-target or bycatch species is allowed, incentivising compliance (Hutton et al., 2010). All countries except the EU have implemented the limited possibility to catch and commercialise non-target fish without using any quota (Arnason, 2014). On the other hand, the EU, along with Iceland and the Canadian British Columbia fishery, have the possibility to move some of their quota in certain species to other species, at a prespecified conversion ratio or conditions (Arnason, 2014; Condie et al., 2014; Government of Canada, 2007).

In the Faroese case, the total allowable effort system replaced the ITQ system. It consists of limited fishing days regulating the amount of time to fish in approved areas. The existing ban on discards was continued, with the exception of undersized fish regulations and protected species, fishers are allowed to land and sell whatever they can catch within their effort quotas (Hopkins et al., 2013).

In the case of the EU, the basic provision of the quota flexibility tool is 
to allow transfers of quota between donor (target) and recipient (nontarget) species. The tool allows for catches in excess of quotas or catches of species for which a participating unit in the fishery has no quota. The provision limits the transfer to $9 \%$ of the quota of the target species and there is a condition which stipulates that the recipient non-target species must be within safe biological limits (EU, 2013). However, speculative use of this exchange quota or the absence of monitoring may cause serious stock impacts when quota from a high volume/low value species is moved to a low volume/high value stock.
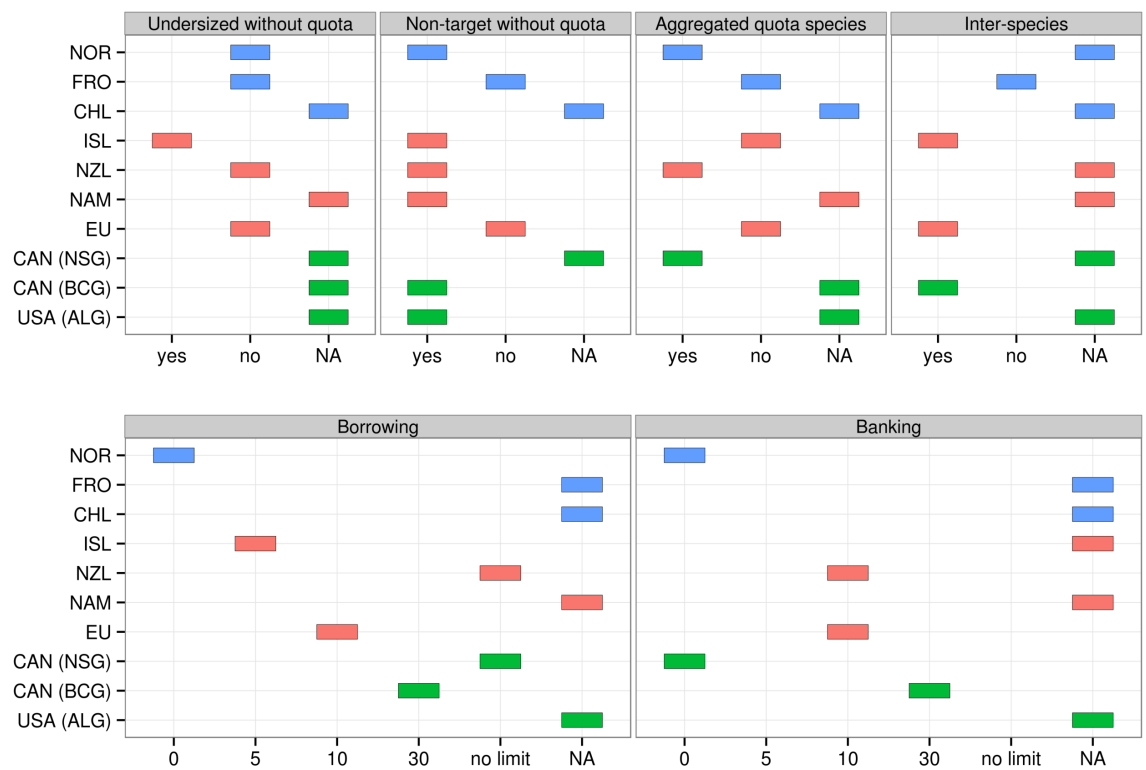

Figure 2.4: Quota flexibilities implemented by different discards limitations: Landing and commercialisation of undersized fish outside quota, landing and commercialisation of non-target fish without quota, aggregate quota for some species, and species equivalence to substitute quota from one specie to others, carry quota back from the previous year and carry quota forward for the following year.

Regarding restrictions on borrowing and banking quota, New Zealand and Canada are the only countries that have not established any limit in quota flexibility across years (Arnason, 2014). In both cases, the borrowed quota is discounted from the following year (Condie et al., 2014). In addition, New Zealand has introduced the mechanism of deemed 
value, which works as a graduated penalty for overage, establishing an over-catch trigger point at which deemed value is increased in order to avoid abuse of the flexibility (Lock and Leslie, 2007; Mace et al., 2014; Marchal et al., 2016). These countries also allow up to $10 \%$ of uncaught quota to carry over to the next year (Arnason, 2014)). The Canadian British Columbia fishery allows an extra over-quota allowance for hake and halibut of $15 \%$ and $37.5 \%$, respectively, on top of the existing $30 \%$ borrow and bank quota (Condie et al., 2014). Namibia's annual quotas also have somewhat limited tradability (Arnason, 2014).

Norway is the only case where there is no possibility of banking and borrowing (Johnsen and Eliassen, 2011). However, the system offers the possibility to land small overruns of quota or larger catches if they are caught unintentionally. This overrun catch is confiscated by the sales organisation (Gezelius, 2008). Both the Faroe Islands and Chile cases have no data available. This is due to the effort management system in the Faroe Islands and the lack of implementation data for Chile.

\section{Discarding allowance}

Every case study has introduced some flexibilities within discard regulations, allowing fishers to discard under some situations (Fig. 2.5 and Annex II). In all cases, discarding is allowed for species for which scientific evidence demonstrates high survival rates. Furthermore, where the discard ban is not applied totally, species with no quota or those not prohibited by the ban can be discarded.

The Canadian British Columbia fishery allows the discarding of quota species if they have been recorded and counted against the quota. In Namibia, fishers just may discard if the observer present allows it (Government of Canada, 2007). In Chile, the ban will not come into effect until a research program has been completed (commencement in 2014; (Borges et al., 2016)). This research program aims to quantify the extent of discards and incidental catches in the fishery and to identify the causes of discards. The results will be used to create a reduction plan (a set of measures to mitigate discards and incidental catches), to develop of new markets for discarded species, and to provide incentives for the development of innovative gear solutions. Under this program, discards are allowed and non-sanctions are implemented to avoid bias in the data (Borges et al., 2016). 


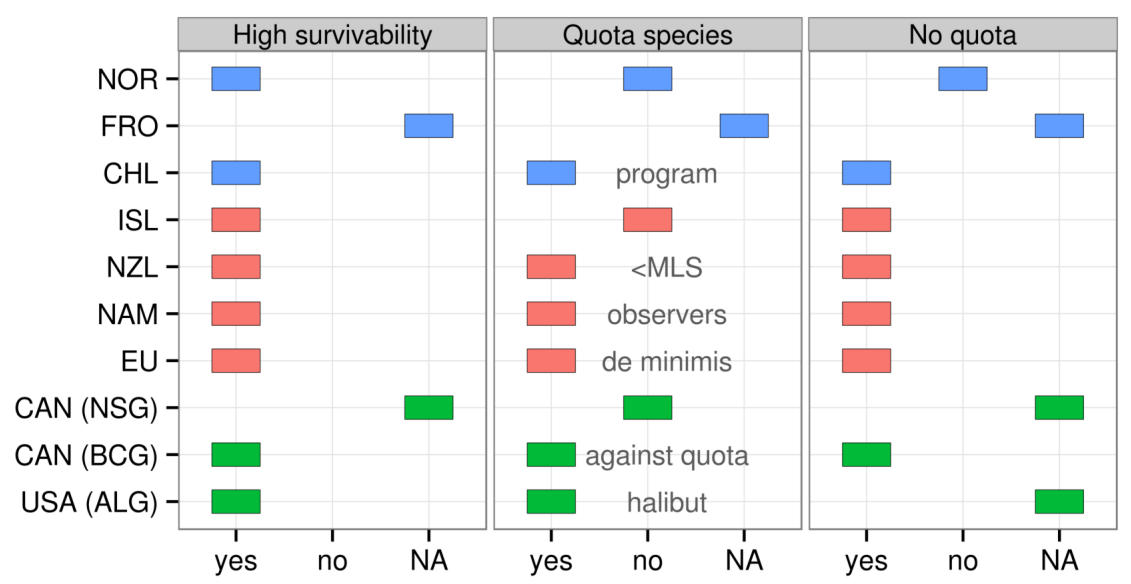

Figure 2.5: Allowances for discarding under different conditions: species with high survivability, species with quota after measuring and recording, species with no quota.

In the case of Europe, the CFP have inserted a specific provision relating to discard allowances under certain conditions. The basic elements of the de-minimis provision include the establishment of limits on the percentage of catches that can be discarded under certain conditions (EU, 2013). These discards need to be recorded but do not count against quotas and are intended to offer a limited facility to assist in the continuity of fishing operations. The percentages of total catches concerned are relatively small and will be phased in over a transitional period, measuring $7 \%$ for first two years, $6 \%$ for next two years, and $5 \%$ thereafter (EU, 2013).

\section{Real-time area closures}

Real-time area closures have been implemented to some extent in a number of countries (Fig. 2.6). The details of implementation vary from place to place and depending on the nature of the feature being protected (Bailey et al., 2010). RTC schemes are designed to achieve specific objectives in spatial areas where the level of bycatches and discards, the number of undersized fish, or the fishing mortality of targeted species exceeds permitted limits by temporarily closing certain areas. 
Figure 2.6 shows some of the RTC schemes adopted for the selected cases. Norway, the Faroe Islands, Iceland, New Zealand, Canada, and the US have implemented these area restrictions (Bailey et al., 2010; Condie et al., 2014; Hopkins et al., 2013). In almost all cases, the temporary RTCs have been included to protect juveniles, spawning fish, and protected species, thus helping to reduce bycatch discards (for specific reasons for area closures, see Fig. 2.6). However, it is difficult to evaluate how successful these measures have been in achieving conservation benefits (Marchal et al., 2016). To date, the EU does not have a centrally managed system of RTCs to lead closures when a high retention of undersized fish is taken by a specific fishery. Rather, individual member states have recently instigated national programs as part of efforts to reduce the fishing mortality of cod (Bailey et al., 2010).

Figure 2.6: Real-time area closures according to various criteria for the different countries selected. 


\section{Management effects and later evaluations}

The enforcement and monitoring of rules on discarding is relevant for all cases in this review. Discarding is no longer seen as a major problem in any of the countries where a discard ban has been applied. It appears that discards have been reduced over time due to the measures taken. The rate of discards after the ban ranged from $0.1 \%$ to $13 \%$ of the catch weight among the different countries (Annex II). However, much uncertainty remains surrounding the effectiveness of the bans, as there does not appear to be any assessment of whether or not the discard bans have improved the situation for the countries that have implemented them (Arnason, 2014). This is likely because an illegal activity such as discarding fish at sea is notoriously difficult to detect.

The Canadian Nova Scotia ground-fish fishery required comprehensive dockside and at-sea monitoring to ensure accuracy in reporting, while the Canadian British Columbia fishery was required to cover the costs of at-sea observers (Arnason, 2014). Iceland's penalties have been difficult to implement because the burden of proof has been excessively tilted toward the prosecution (Arnason, 2014; Catchpole and Ribeiro Santos, 2015). However, it would appear that the implementation and enforcement of Iceland's no-discards policy has been quite effective, with indications that discards of catch in Iceland's mixed fisheries are among the lowest in existence (Arnason, 2014). In Norway, the number of infringements reported and later prosecuted is small (Arnason, 2014; Gullestad et al., 2015).

In the Faroese case, self-reporting incentives related to bycatches have appeared to work well (Hopkins et al., 2013) and the discarding of bycatch has been negligible since the introduction of the TAE quota system (Gezelius, 2008; Johnsen and Eliassen, 2011; Løkkegaard et al., 2007). However, the Faroese Ministry of Fisheries has noted that there is no scientific estimate of the effect of the closed areas on overall fishing mortality (Hopkins et al., 2013). In another case, New Zealand's ministry is unable to provide enough observers to meet the assessment requirements of the planned program. There are, however, indications that discards of hoki have decreased substantially compared to earlier periods (Anderson and Smith, 2005; MRAG, 2007). In Namibia, enforcement costs, especially for the observer program, are very high. However, the contribution of the observer program and the high penalties to the reduction 
in discards relative to other enforcement activities is not clear. Thus, questions remain about the net benefits of the discard ban and its enforcement (Arnason, 2014).

The size of the discarding impact in the different countries depends on the enforcement of the discard restrictions and on the discard regulations themselves. In general, the success of fisheries management regimes, such as a discard ban, can be said to be strongly dependent on compliance from the industry. The industry, in turn, depends on a delicate balance between the costs and benefits of enforcement, and between the establishment of mechanisms to promote active voluntary compliance and the unavoidable control measures necessary to discourage and punish non-compliance.

\subsection{Discussion- Overall Lessons}

Flexible quota constraints, the ability to land unwanted catch without it being counted against quota, RTCs, enforcement, and discarding restrictions are some of the ways to reduce discards under the discard management regimes reviewed here. Discarding is no longer seen as a major problem in any of the countries included in the review.

As shown in Iceland and North America, monitoring through self-reporting or the implementation of an observer program leads to a greater likelihood of compliance. In these countries, a discard ban can result in a reduction in discards and provide more reliable catch data. However, implementing an observer program similar to that of Canadian British Columbia in EU fisheries may be impractical (Condie et al., 2014). Total observer coverage is expensive, and is unlikely to be cost-effective in the case of EU fisheries (Graham et al., 2007).

Assessment of the effects of the introduction of the different discard bans is sparse, and data risks should not be overlooked (Hentati-Sundberg et al., 2014). In Northeast Atlantic (the EU), the lack of discard time series data has long hampered the assessment accuracy of several fish stocks, and thereby the advice to decision-makers on sustainable catch levels (Viana et al., 2013). Current estimates of fisheries discards, obtained through intensive observer programmes, might not be available in the future as collecting scientific data about an activity that has become illegal is likely to be difficult. It is likely not safe to assume that future 
estimates of total catch will be less biased than current ones (Bousquet et al., 2010; Cotter et al., 2004; Walters and Maguire, 1996). It remains to be seen whether the EU landing obligation will have marked effects on the precision of stock assessments and, more generally, the performances of the fisheries management system (Marchal et al., 2016).

Additional management measures, such as the ones introduced in the CFP, are likely to be needed under any discard ban to incentivise more selective fishing. Experiences from fisheries around the world have shown that choosing the right measures is not a simple process. Implementing gear restrictions or area closures may help to reduce discards by encouraging a reduction in the capture of unwanted catch and moving to areas where the catch composition is likely to be more appropriate (Bailey et al., 2010; MRAG, 2007). In addition, increased flexibilities in management systems that allow the transfer, purchase (annual catch entitlements), or banking/borrowing of quota to match the catch composition of vessels will reduce the incentive to discard non-mandated catch (Hutton et al., 2010; MRAG, 2007; Sanchirico et al., 2006). However, flexibility mechanisms may increase the value generated by the multispecies complex, but they may also increase the risk of overexploitation without proper assignment and monitoring (Condie et al., 2014). On the other hand, a very strict and rigid formulation will increase the incentives for non-compliance, driven by the increase in operational costs. Therefore, achieving the right balance between flexibility, over-exploitation risk, and administrative simplicity is critical for the profitability and sustainability of multispecies fisheries.

Anecdotal evidence from Norway and Iceland suggests that discard bans and accompanying measures can generate social or economic incentives for more selective fishing. However, the reviewed literature (Annex I) concluded that very little data are available from the case studies to suggest that a discard ban alone directly results in the avoidance of unwanted catch. Moreover, encouraging compliance with a discard ban through landing incentives may reduce the benefit of avoiding unwanted catch (Clucas, 1997; MRAG, 2007).

Poor enforcement has often been identified as a factor in European fisheries, leading to a situation where the potential economic benefits for fishers of non-compliance often outweigh the risks of detection (Catchpole et al., 2005) and the cost of sanctions (Batsleer et al., 2013). Within 
the CFP, it is unclear how the change in regime will develop and also how some of the control and regulatory approaches will be (Catchpole and Ribeiro Santos, 2015). Under a discard ban, there is no certainty that the quota lease market or international swap arrangements will operate in the same manner. The costs of this additional flexibility, however, may be a loss of precision in TAC management, potential effects on the performance of the lease market, and a greater administrative burden. Mechanisms should be explored to ensure that the trade in quota can continue. Moreover, different regulations will be required for different fisheries. It is important to emphasise that each fishery is unique, involving numerous biological, technological, and socio-economic variables. Management measures will mean little unless fishing mortality is constrained to a sustainable level, whether through quotas or effort controls. Therefore, fisheries advice should be extended to offer predictions of stock trajectories not only under a range of possible management measures, but also a number of realistic outcomes in terms of compliance and enforcement of regulations (Fulton et al., 2011). Following this, more extensive regional co-management should be developed and evaluated by simulations to the extent possible. This will help ensure the robustness of regulations to prevailing uncertainties, including those related to discard plans implementation. 


\subsection{References}

Anderson, O. and Smith, M. 2005. Fis discards and non-target fish catch in the New Zealand hoki trawl fishery 19992000 and 2002-03. New Zealand Fisheries Assessment Report, 3.

Arnason, R. 2014. Best practice in the use of rights-based management to reduce discards in mixed fisheries. Directorate-general for international policies, policy department B: structural and cohesion policies. Fisheries. European Parliament.

Bailey, N., Campbell, N., Holmes, S., Needle, C., and Wright, P. 2010. Real time closures of fisheries. Directorategeneral for international policies, policy department B: structural and cohesion policies. Fisheries. European Parliament.

Bellido, J. M., Santos, M. B., Pennino, M. G., Valeiras, X., and Pierce, G. J. 2011. Fishery discards and bycatch: Solutions for an ecosystem approach to fisheries management? Hydrobiologia, 670(1):317-333.

Borges, L., Cocas, L., and Nolde, K. N. 2016. Discard ban and balanced harvest: a contradiction? ICES Journal of Marine Science, 73:1632-1639.

Bousquet, N., Cadigan, N., Duchesne, T., and Rivest, L. 2010. Detecting and correcting underreported catches in fish stock assessment: trial of a new method. Canadian Journal of Fisheries and Aquatic Sciences, 64:1247-1261.

Britten, G., Dowd, M., Kanary, L., and Worm, B. 2017. Extended fisheries recovery timelines in a changing environment. Nature Communications, 8:15325.

Buisman. undated. Best practice in the use of rights-based management to reduce discards in mixed fisheries. Directorate-general for international policies, policy department B: structural and cohesion policies. Fisheries. European Parliament.

Catchpole, T. and Ribeiro Santos, A. 2015. The landing obligation and its implications on the control of fisheries. European Parliament Study IP/B/PECH/IC/2014-20.

Catchpole, T. L., Frid, C. L. J., and Gray, T. S. 2005. Discards in North Sea fisheries: causes, consequences and solutions. Marine Policy, 29(5):421-430.

Clucas, I. 1997. A study of the options for utilization of bycatch and discards from marine capture fisherie. FAO Fisheries Circular. No. 928. Rome, page 59. Condie, H. M., Grant, A., and Catchpole, T. L. 2013. Does banning discards in an otter trawler fishery create incentives for more selective fishing? Fisheries Research, 148(2013):137-146.

Condie, H. M., Grant, A., and Catchpole, T. L. 2014. Incentivising selective fishing under a policy to ban discards; lessons from European and global fisheries. Marine Policy, 45:287-292.

Cotter, J., Armstrong, M., Woods, T., Dann, J., White, P., and Keable, J. 2004. Final Report Programme 8: Gear selectivity in the Irish Sea. Part I: Eastern Irish Sea place fishery. Retrieved from, pages 1-19. URL http://citeseerx.ist.psu.edu/ viewdoc/download?doi=10.1.1.177. $4147 \& r e p=r e p 1 \&$ type $=p d f$.

EU. Regulation (EU) No 1380/2013 of the European Parliament and of the Council of 11 December 2013 on the Common Fisheries Policy, 2013.

FAO. Report of the Technical Consultation to Develop International Guidelines on Bycatch Management and Reduction of Discards. Technical Report 957, FAO Fisheries and Aquaculture Report, Rome, 2010. 
FHRG. 1994. Løgtingslóg um vinnuligan fiskiskap. Parliament Law nr 28 of 10 March 1994 and subsequent amendments: Commercial Fisheries Act]. Løgtinget, Torshavn. URL http://www . megf.fo/serv01.htm.

Frangoudes, K. and Guillen, J. 2015. DiscardLess. Strategies for the gradual elimination of discards in European fisheries. Deliverable No.22. Appropriate economic and social criteria to evaluate the Discard Mitigation Strategies and the defined management scenarios. Retrieved from. URL http://www.discardless.eu/media/ results/DiscardLess_Deliverable__D2-2_17Sept2015.pdf.

Fulton, E. A., Link, J. S., Kaplan, I. C., Savina-Rolland, M., Johnson, P., Ainsworth, C., Horne, P., Gorton, R., Gamble, R. J., Smith, A. D. M., and Smith, D. C. 2011. Lessons in modelling and management of marine ecosystems: the Atlantis experience. Fish and Fisheries, 12(2):171-188.

Gezelius, S. S. 2008. Management responses to the problem of incidental catch in fishing: A comparative analysis of the EU, Norway, and the Faeroe Islands. Marine Policy, 32:360-368.

Government of Canada. 2007. National Plan of Action for the Conservation and Management of Sharks. Retrieved from. URL http://waves-vagues.dfompo.gc.ca/Library/40584306.pdf.

Graham, N., Ferro, R. S. T., Karp, W. A., and Macmullen, P. 2007. Fishing practice, gear design, and the ecosystem approach - three case studies demonstrating the effect of management strategy on gear selectivity and discards. ICES Journal of Marine Science, 64: 744-750.

Gullestad, P., Blom, G., Bakke, G., and Bogstad, B. 2015. The "Discard Ban
Package": Experiences in efforts to improve the exploitation patterns in Norwegian fisheries. Marine Policy, 54:1-9. Hentati-Sundberg, J., Hjelm, J., and Osterblom, H. 2014. Does fisheries management incentivize non-compliance? Estimated misreporting in the Swedish Baltic Sea pelagic fishery based on commercial fishing effort. ICES Journal of Marine Science, 71:1846-1853.

Hopkins, C. C. E., Hegland, T. J., and Wilson, D. C. K. 2013. 'Maximising yield of fisheries while balancing ecosystem, economic and social concerns.' Review of the Faroe Islands fisheries governance system: Objective setting and implementation. EU FP' Project No: 289257.

Hutton, T., Thebaud, O., Fulton, B., Pascoe, S., Innes, J., Kulmala, S., and Tudman, M. 2010. Use of Economic Incentives to Manage Fisheries Bycatch: An Application to Key Sectors in Australia's Southern and Eastern Scalefish and Shark Fisheries. Cleveland, Australia, page 174. URL http://www.afma.gov.au/wpcontent/uploads/2010/06/Use-ofeconomic-incentives-to-managefisheries-bycatch-August-2010.pdf. Jákupsstovu, S. H. i., Cruz, L. R., Maguire, J.-J., and Reinert, J. 2007. Effort regulation of the demersal fisheries at the Faroe Islands: a 10-year appraisal. ICES Journal of Marine Science, 64:730-737.

Johnsen, J. and Eliassen, S. 2011. Solving complex fisheries management problems: what the EU can learn from the Nordic experiences of reduction of discards. Marine Policy, 35:130-139.

Khalilian, S., Froese, R., Proelss, A., and Requate, T. 2010. Designed for failure: A critique of the Common Fisheries Policy of the European Union. Marine Policy, 34:1178-1182. 
Lock, K. and Leslie, S. 2007. New Zealand's Quota Management System: a History of the First 20 Years. Motu Economic and Public Policy Research, pages 1-8. URL https://fs.fish. govt.nz/NR/rdonlyres/1DEC83868681-4414-9FEE-7B27487C14BF/0/ qms_intro_pages.pdf.

Løkkegaard, J., Levring Andersen, J., Boje, J., Frost, H., and Hovgård, H. 2007. Report on the Faroese Fisheries Regulation - The Faroe Model. Institute of Food and Resource Economics, University of Copenhagen, page 153. URL http://findit.dtu.dk/en/ catalog/2389481002.

Mace, P., Sullivan, K., and Cryer, M. 2014. The evolution of New Zealand's fisheries science and management systems under ITQs. ICES Journal of Marine Science, 71:204-215.

Marchal, P., Andersen, J. L., Aranda, M., Fitzpatrick, M., Goti, L., Guyader, O., Haraldsson, G., Hatcher, A., Hegland, T. J., Le Floc'h, P., Macher, C., Malvarosa, L., Maravelias, C. D., Mardle, S., Murillas, A., Nielsen, J. R., Sabatella, R., Smith, A. D. M., Stokes, K., Thoegersen, T., and Ulrich, C. 2016. A comparative review of fisheries management experiences in the European Union and in other countries worldwide: Iceland, Australia, and New Zealand. Fish and Fisheries, 17:803-824.

Ministerio de Economia, Fomento y Turismo. 2013. Ley N8 20657 de 31 de enero de 2013 del Ministerio de Economia, Fomento y Turismo; Subsecretaria de Pesca y Acuicultura. Modifica en el ambito de la sustentabilidad de recursos hidrobiologicos, acceso a la actividad pesquera industrial y artesanal y regulaciones para la investigaciony fiscalizacion, la ley general de pesca y acuicultura contenida en la ley n.818.892 y sus modifica- ciones. Diario Oficial de la Republica de Chile. URL http://www.leychile. $\mathrm{cl} /$ Navegar?idNorma $=1048776$.

Motos, L. and Wilson, D. 2006. The role of science within modern management processes with the development of model-based evaluation tools. "The knowledge base for fisheries management". The Netherlands: Elsevier.

MRAG. 2007. Impact assessment of discard policy for specific fisheries. European Commission Studies and Pilot Projects for Carrying out the Common Fisheries Policy. No. FISH/2006/17 - Lot 1, Brussels, page 289. URL http://ec.europa.eu/ fisheries/documentation/studies/ impact_assessment_discard_policy_ 2007_en.pdf.

Sanchirico, J. N., Holland, D., Quigley, K., and Fina, M. 2006. Catch-quota balancing in multispecies individual fishing quotas. Marine Policy, 30(6):767-785.

STECF. 2006. Scientific, Technical and Economic Committee for Fisheries. Discards from community vessels report. Retrieved from:, page 56. URL http://ec.europa.eu/fisheries/ cfp/fishing_rules/discards/ official_documents/stecf_2006_ discards_report.pdf.

STECF. 2015. Scientific, Technical Economic Committee for Fisheries. Landing Obligation-Part 5 (demersal species for NWW, SWW and North Sea) (STECF15-10). Publications Office of the European Union, Luxembourg, 27407.

STECF. 2016. Scientific, Technical Economic Committee for Fisheries. Evaluation of the landing obligation joint recommendations (STECF-16-10). Publications Office of the European Union, Luxembourg, 27758.

Viana, M., McNally, L., Graham, N., Reid, D., and Jackson, A. 2013. Ignoring discards biases the assessment of 
fisheries' ecological fingerprint. Biology Letters, 9:20130812.

Villasante, S., Pazos Guimeráns, C., Rodrigues, J., Antelo, M., Rodríguez, R., DaRocha, J., Coll, M., Pita, C., Pierce, G., Hastie, L., and Sumaila, R. 2015. Small-Scale Fisheries and the Zero-Discard Rate. European Parliament Study, IP/B/PECH/IC/2014084.

Walters, C. and Maguire, J.-J. 1996. Lessons for stock assessment from the northern cod collapse. Reviews in Fish Biology and Fisheries, 6:125-137.
Worm, B., Hilborn, R., Baum, J., Branch, T., Collie, J., Costello, C., Fogarty, M., Fulton, E., Hutchings, J., Jennings, S., Jensen, O., Lotze, H., Mace, P., McClanahan, T., Minto, C., Palumbi, S., Parma, A., Ricard, D., Rosenberg, A., A, Watson, R., and Zeller, D. 2009. Rebuilding global fisheries. Science, 325:578-585.

WWF. 2016. World Wide Fund for Nature. Living planet report 2016: risk and resilience in a new era. Retrieved from. URL http: //awsassets.panda.org/downloads/ lpr_living_planet_report_2016.pdf. 
Table 2.2: Summary of worldwide discard ban frameworks. Quantitative data sourced from: Arnason (2014); Bailey et al. (2010); Bellido et al. (2011); Condie et al. (2013); Gezelius (2008); Johnsen and Eliassen (2011); Khalilian et al. (2010); MRAG (2007); Sanchirico et al. (2006).

\begin{tabular}{|c|c|c|c|c|c|}
\hline Type of ban & Country & Date frame & $\begin{array}{l}\text { Complexity } \\
\text { fishery }\end{array}$ & $\begin{array}{c}\text { Discard ratio } \\
\text { before the ban } \\
(\%)\end{array}$ & $\begin{array}{c}\text { Management } \\
\text { regimes }\end{array}$ \\
\hline \multirow{3}{*}{ Full ban } & NOR & 1983 & low & not reported & ITQS \\
\hline & FRO & 1994 & low & $\mathrm{NA}$ & $\begin{array}{c}90 \% \text { effort } 10 \% \\
\text { Quotas }\end{array}$ \\
\hline & ISL & 1989 & medium & $0.8-22$ & ITQs \\
\hline \multirow{2}{*}{ Ban on quota species } & NZL & 1986 & medium & $20-25$ & ITQs-ACE \\
\hline & NAM & 2000 & medium & 35 & ITQs \\
\hline \multirow{3}{*}{ Ban on some species } & $\mathrm{CAN}_{\mathrm{NSG}}$ & 1995 & medium & $9-20$ & ITQs \\
\hline & $\mathrm{CAN}_{\mathrm{BCG}}$ & 1995 & high & $2-46$ & ITQs \\
\hline & $\mathrm{USA}_{\mathrm{ALG}}$ & 1998 & low & 13 & ITQs \\
\hline \multirow{2}{*}{ Ban to be implemented } & $\mathrm{CHL}^{1}$ & 2017 & NA & NA & ITQs \\
\hline & $\mathrm{EU}$ & 2015 & high & $20-60$ & ITQs Effort \\
\hline
\end{tabular}

${ }^{1}$ In 1991 with the Fisheries Law discards were prohibited for all commercial species. However, the law was never implemented and discards continue normally. 
Table 2.3: Summary of worldwide implemented measures, focused just on the discard bans implementations. Quantitative data sourced from: Arnason (2014); Bailey et al. (2010); Bellido et al. (2011); Condie et al. (2013); Gezelius (2008); Johnsen and Eliassen (2011); Khalilian et al. (2010); MRAG (2007); Sanchirico et al. (2006).

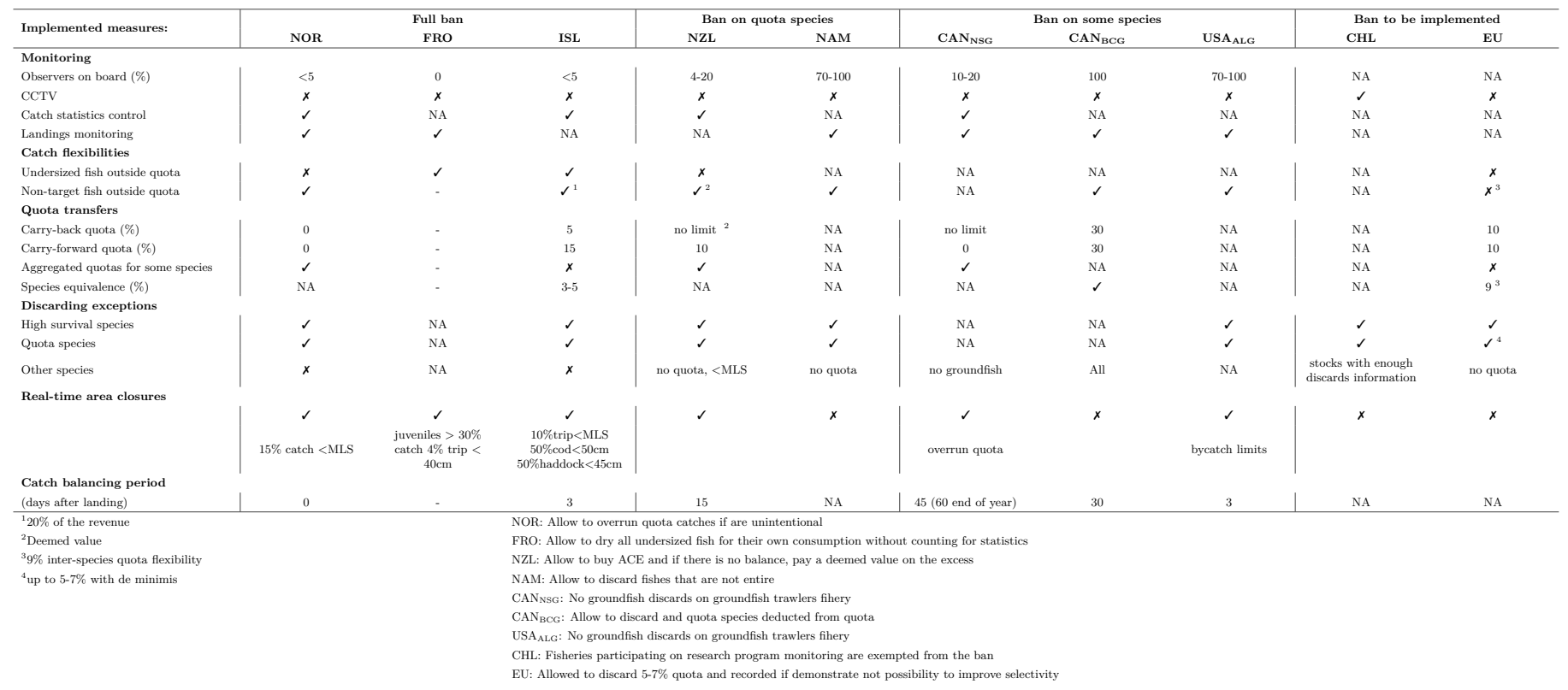


Table 2.4: Effects and later evaluations:Summary of worldwide discard ban frameworks. Quantitative data sourced from: Arnason (2014); Bailey et al. (2010); Bellido et al. (2011); Condie et al. (2013); Gezelius (2008); Johnsen and Eliassen (2011); Khalilian et al. (2010); MRAG (2007); Sanchirico et al. (2006).

\begin{tabular}{|c|c|c|c|c|}
\hline & Country & $\begin{array}{c}\text { Discard ratio after } \\
\text { ban }(\%)\end{array}$ & Compliance & Enforcement \\
\hline \multirow{3}{*}{ Full ban } & NOR & $2-10$ & medium & low \\
\hline & FRO & NA & $\begin{array}{l}\text { medium, discarding } \\
\text { does occur }\end{array}$ & $\begin{array}{l}\text { medium not always } \\
\text { enforced }\end{array}$ \\
\hline & ISL & $1-3$ & medium & high quite effective \\
\hline \multirow{2}{*}{ Ban on quota species } & NZL & $<10$ & low & low \\
\hline & NAM & $<10$ & low & $\begin{array}{l}\text { low, observer } \\
\text { programme being } \\
\text { subverted }\end{array}$ \\
\hline \multirow{3}{*}{ Ban on some species } & $\mathrm{CAN}_{\mathrm{NSG}}$ & & low & NA \\
\hline & $\mathrm{CAN}_{\mathrm{BCG}}$ & $0.1-13$ & high & NA \\
\hline & $\mathrm{USA}_{\mathrm{ALG}}$ & $0.5-6$ & $\begin{array}{l}\text { high, although some } \\
\text { discards are observed } \\
\text { when the fishery is } \\
\text { closed }\end{array}$ & NA \\
\hline \multirow{2}{*}{ Ban to be implemented } & CHL & $?$ & $?$ & $?$ \\
\hline & $\mathrm{EU}$ & $?$ & $?$ & $?$ \\
\hline
\end{tabular}




- QUESTIONING THE EFFECTIVENESS OF TECHNICAL MEASURES IMPLEMENTED BY THE BASQUE BOTTOM OTTER TRAWL FLEET:

IMPLICATIONS UNDER THE EU LANDING OBLIGATION•

N. ALZORRIZ, L.ARREGI, B. HERRMANN M.SISTIAGA, J.CASEY AND J.J.POOS

FISHERIES RESEARCH 175(2016) 116-126 


\subsection{Abstract}

The selective properties of a bottom trawl fitted with a $70 \mathrm{~mm}$ diamond mesh codend and a $100 \mathrm{~mm}$ top square mesh panel (SMP) for hake (Merluccius merluccius), pouting (Trisopterus luscus and Trisopterus minutus) and red mullet (Mullus surmulletus) were investigated over the period 2011-2013. The experiments were carried out over three separate cruises aboard two commercial Basque bottom otter trawlers in the Bay of Biscay area. "Fall-through" experiments were also undertaken to estimate the potential size selection of $100 \mathrm{~mm}$ square mesh for the same species. Results from the "Fall-through" experiments and the at-sea selectivity cruises demonstrated that a $100 \mathrm{~mm}$ SMP has the potential to enable undersized and immature individuals to escape through the meshes. However, the selectivity cruises demonstrated that in practice, the SMP was largely ineffective at releasing undersized individuals as only a small fraction of the fish entering the trawl attempted to escape through the SMP during their drift towards the codend. The fraction attempting to escape was quantified by the "SMP contact probability" and was less than $4 \%$ for hake and red mullet and less than $15 \%$ for pouting. Furthermore, for each species, the release potential for the diamond mesh codend was found to be significantly lower than the length-at-maturity and the legal minimum conservation reference size. On average, the proportions of the total catch of undersized individuals of each species retained by the gear, were $52 \%, 17 \%$ and $45 \%$ for hake, pouting and red mullet respectively. Based on our findings, we conclude that the gear currently deployed by the Basque bottom otter trawl fleet operating in the Bay of Biscay is largely ineffective at releasing undersized hake, pouting and red mullet. The introduction of the obligation to land all catches, under the 2013 reform of the EU Common Fisheries policy will create new challenges for the Basque bottom otter trawl fleet and thereby an incentive to improve selectivity to avoid unwanted catches of undersized individuals.

\section{Keywords:}

Bottom trawl, Landing obligation, Square mesh panel (SMP), Selectivity, Contact probability, Discards, Bay of Biscay. 


\subsection{Introduction}

Over the past 30 years, numerous technical regulations and associated amendments have been introduced in almost all developed fisheries worldwide in an attempt to improve fishing gear selectivity, reduce discards and enhance the status of fish stocks (Feekings et al., 2012; Madsen, 2007; McClanahan, 2010; Santurtún et al., 2014). Despite such measures, discarding in some European fisheries remains high (Uhlmann et al., 2013). The capture and discarding of small immature fish reduces the potential biomass of the exploitable stock and affects subsequent recruitment (Graham et al., 2003). While discarding is a widely recognized problem in many fisheries, it is particularly acute in multi-species trawl fisheries (Daan, 1997). The Basque bottom otter trawl fishery in the Bay of Biscay (ICES Divisions, VIII a, b, d) is one such fishery. Currently, the fleet comprises 7 vessels, ranging from $37-42 \mathrm{~m}$ overall length. The fleet deploys trawls that have a low headline, typically below 2 meters vertical opening, wingspreads between $22 \mathrm{~m}$ and $26 \mathrm{~m}$, and footropes between $80 \mathrm{~m}-100 \mathrm{~m}$ in length. Trawling is carried out at a towing speed of 4 knots at depths ranging from $30 \mathrm{~m}$ to $200 \mathrm{~m}$. Trip duration varies from 5 to 7 days. The main target species are megrim (Lepidorhombus whiffiagonis), anglerfish (Lophius spp.), hake (Merluccius merluccius) although squids (Loligo spp.), red mullet (Mullus surmulletus), pouting (Trisopterus minutus and T. luscus), sole (Solea solea), horse mackerel (Trachurus trachurus) and mackerel (Scomber scombrus) also comprise target species depending on the fishing ground, season and quota availability (Iriondo et al., 2008, 2010). Discarding of both target and bycatch species in the fishery can be substantial. In 2013, on average, estimated discards represented about $52-65 \%$ by weight of the total estimated catch (8532 t) of the fleet (Rochet et al., 2014). Discarding occurs for a variety of reasons including capture of individuals below minimum legal landing size, lack of quota, the absence of a market, damaged or degraded individuals in the catch, and high-grading.

In 2002, a recovery plan was introduced for the northern stock of European hake, in an attempt to allow the stock to recover from its then depleted state (EC, 2002). The recovery plan prescribed inter alia, an increase in the minimum codend mesh size for trawls from $70 \mathrm{~mm}$ to 100 $\mathrm{mm}$ in the Bay of Biscay (EC, 2002). However, since 2006 the provisions of Annex III, Appendix 3 of EC (2006) were introduced to provide an 
optional alternative to the mandatory use of bottom otter trawls with a $100 \mathrm{~mm}$ codend mesh size. Such provisions permit the deployment of otter trawls with a minimum codend mesh size of $70 \mathrm{~mm}$ provided that a $100 \mathrm{~mm}$ square mesh panel (SMP) is inserted into the middle of the top panel of the rear tapered section of the trawl just in front of the untapered section constituted by the extension piece and the codend; a configuration intended to improve the selectivity for undersized hake.

Square mesh panels are known to have great potential for improving selectivity in trawls; e.g. Broadhurst et al. (2002); Fonteyne and Polet (2002); Madsen et al. (2002); Tschernij et al. (2002), by increasing the probability to release both undersized individuals and non-target species entering the trawl (Catchpole and Revill, 2008). However, their effectiveness varies for different species and several studies have shown that they are largely ineffective at releasing certain demersal species (Briggs, 1992; Frandsen et al., 2009; Rosen et al., 2012). The efficiency of such selective devices depends not only on the gear characteristics such as the dimensions of the panel itself, the size of the meshes and the position of the panel in the trawl (Herrmann et al., 2015), but also on the reactions of the fish in the trawl during the fishing operation. Such factors determine whether fish are able to come into contact with the panel and escape through the meshes (Glass and Wardle, 1995; Herrmann et al., 2015; Zuur et al., 2001).

Despite the adoption of the $70 \mathrm{~mm}+\mathrm{SMP}$ provisions by the majority of the vessels that comprise the Basque trawl fleet, to date, the effectiveness of the $100 \mathrm{~mm}$ SMP has not been investigated and quantified. Furthermore, the average discards of hake over the period 2011-2013 are estimated to be approximately $50 \%$ of the total catch in weight of hake, $97 \%$ or which comprised individuals less than the minimum conservation reference size (MCRS) (Rochet et al., 2014).

Today, most policy frameworks for the marine environment aim to progressively implement an ecosystem approach (Garcia and Cochrane (2005); Hering et al. (2010); Article 2(3) of EU (2013)). In an ecosystem approach to fisheries management, one of the basic tenets is that harvesting should be conducted with minimal impact on juvenile fish and that discards should be reduced (Bellido et al. (2011); Graham et al. (2007); Article 2(5a) of EU (2013)). Under the provisions of Article 15 of the 
2013 reform of the CFP (the landing obligation; EU (2013)), by 2019, discards of most species will no longer be permitted and fishers from EU Member States will be required to land all catches of quota species from the northeast Atlantic and all species subject to a MCRS from the Mediterranean and Black Seas. The rationale for the landing obligation is that it should create economic incentives for the industry to develop measures to improve selectivity to reduce or avoid the capture of juvenile fish, unwanted catches of bycatch species and any potential over-quota catches.

Hence, the question remains whether the provisions of Annex III, Appendix 3 of EC (2006) are sufficient to meet the objective of releasing undersized hake, whether they allow the Basque fleet to avoid undersized catches of hake and mitigate the potential impacts of the obligation to land all catches. The aim of the present study is therefore to evaluate the selective properties of bottom otter trawl gear deployed by the majority of the Basque fleet and especially the effectiveness of the $100 \mathrm{~mm}$ SMP at releasing immature and undersized fish.

\subsection{Material and methods}

\section{Sea trials and data collection}

Selectivity cruises were performed at sea on board two Basque commercial trawlers "Gure Gaskuña" (39 m overall length (LOA), $590 \mathrm{hp}$ ) and "J. Kalamendi" (40 m LOA, $1190 \mathrm{hp}$ ). Three cruises were performed between November 2011 and July 2013 (Table 3.1). The cruises were conducted in the Bay of Biscay on fishing grounds with depths that varied between $26 \mathrm{~m}$ and $267 \mathrm{~m}$ (Fig. 3.1).

All three cruises were conducted using trawls with codends of $70 \mathrm{~mm}$ diamond netting attached to an extension of $90 \mathrm{~mm}$ diamond mesh constructed using $2.5 \mathrm{~mm}$ single polyamide (PA) -twine. The wings and the top panel were PA with a nominal mesh size of $100 \mathrm{~mm}, 2.5 \mathrm{~mm}$ singletwine. In each cruise, the SMP was made from $100 \mathrm{~mm}$ (nominal, knot to knot) meshes extended into the middle of the upper section of the extension, positioned 12 meshes in front of the codend. The SMP was one-fourth of the full width of the extension section, where the mean internal vertical opening of the gear was around $1.5 \mathrm{~m}$ (240 meshes round). The specifications for the gears used on each cruise varied with respect 
Table 3.1: General information about the three cruises. Mean depth, mean towing duration and speed, and ranges (in parentheses).

\begin{tabular}{lccc}
\hline & Cruise 1 & Cruise 2 & Cruise 3 \\
\hline Date & November-December 2011 & July 2012 & June-July 2013 \\
& $100 \mathrm{~mm}$ top SMP & $100 \mathrm{~mm}$ top SMP & $100 \mathrm{~mm}$ top SMP \\
Gear setup & $13 \mathrm{~m}$ from the codline & $7 \mathrm{~m}$ from the codline & $7 \mathrm{~m}$ from the codline \\
& & & \\
Depth (m) & $61.3(31-144)$ & $103.3(28-182)$ & $125.2(26-267)$ \\
Towing time (min) & $170(40-215)$ & 15 & 15 \\
Towing speed (knots) & $3.9(3.9-4.0)$ & $3.6(2.6-4.1)$ & $3.6(2.9-4.0)$ \\
No. of hauls & 15 & 27 & 26 \\
& & & \\
\hline
\end{tabular}

Figure 3.1:

The Bay of Biscay, showing $100 \mathrm{~m}, 200 \mathrm{~m}$ and 1000 $m$ depth isobaths and fishing position for all hauls during the three cruises between November 2011 and July 2013. Key: X (total selectivity estimation; SMP + $\mathrm{C})$ and $\Delta$ (selection properties of the SMP alone; SMP $+\mathrm{CL})$.

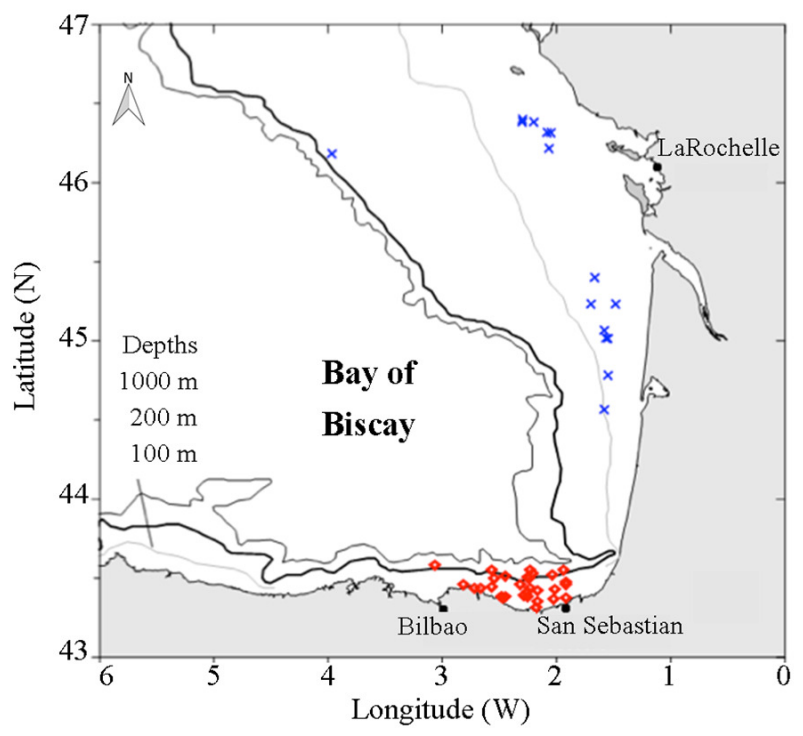

to length of headline and footrope, codend length and panel position in relation to the codline and are summarised in Table 3.2.

During the first cruise carried out aboard FV "Gure Gaskuña" between November and December 2011, a single otter trawl with a stretched circumference of $61.4 \mathrm{~m}$ was operated under commercial conditions on its usual fishing grounds. The codend (CO) was $12 \mathrm{~m}$ long, in consequence the SMP was positioned $13 \mathrm{~m}$ from the codline. Size selectivity data were collected using a three compartment setup, based on the design described by Sistiaga et al. (2010). The codend cover (CC) was installed on the aft of the trawl and mounted with two rigid rings to minimize 
Table 3.2: Specifications of the gears used during the three cruises. $\left(^{*}\right)$ Measured with an OMEGA gauge (Fonteyne et al., 2007) according to the guidelines described in regulation (EC No. 517/2008).

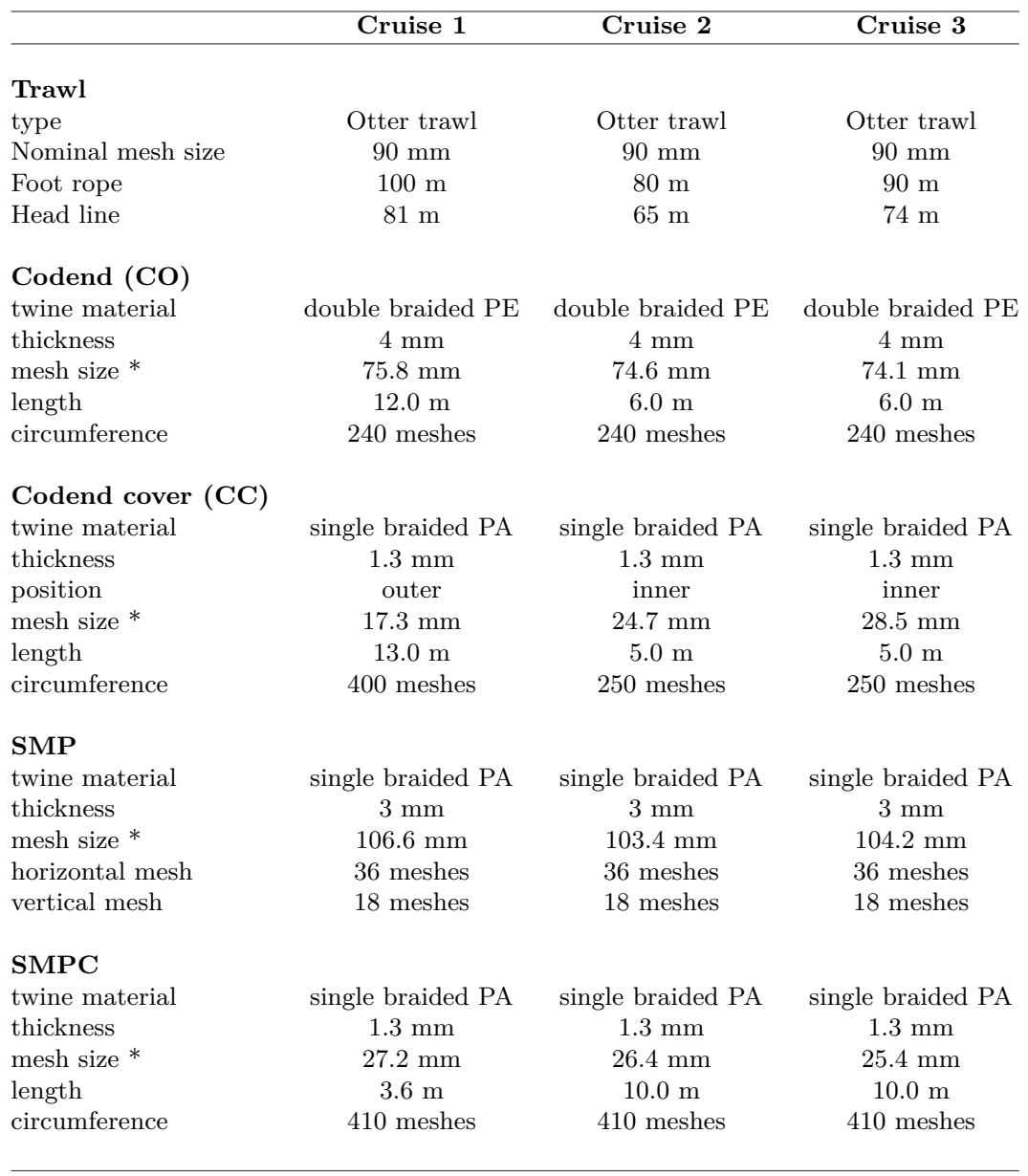

any potential masking effect (Wileman et al., 1996). The square mesh panel cover (SMPC) installed over the SMP was the same design as that used by Larsen and Isaksen (1993) and then fitted with three rings and floats (Fig. 3.2a).

For the second and third cruises (July 2012 and June-July 2013, respectively), modified versions of the single otter trawl normally deployed by FV "J. Kalamendi" were used. These cruises were carried out during 

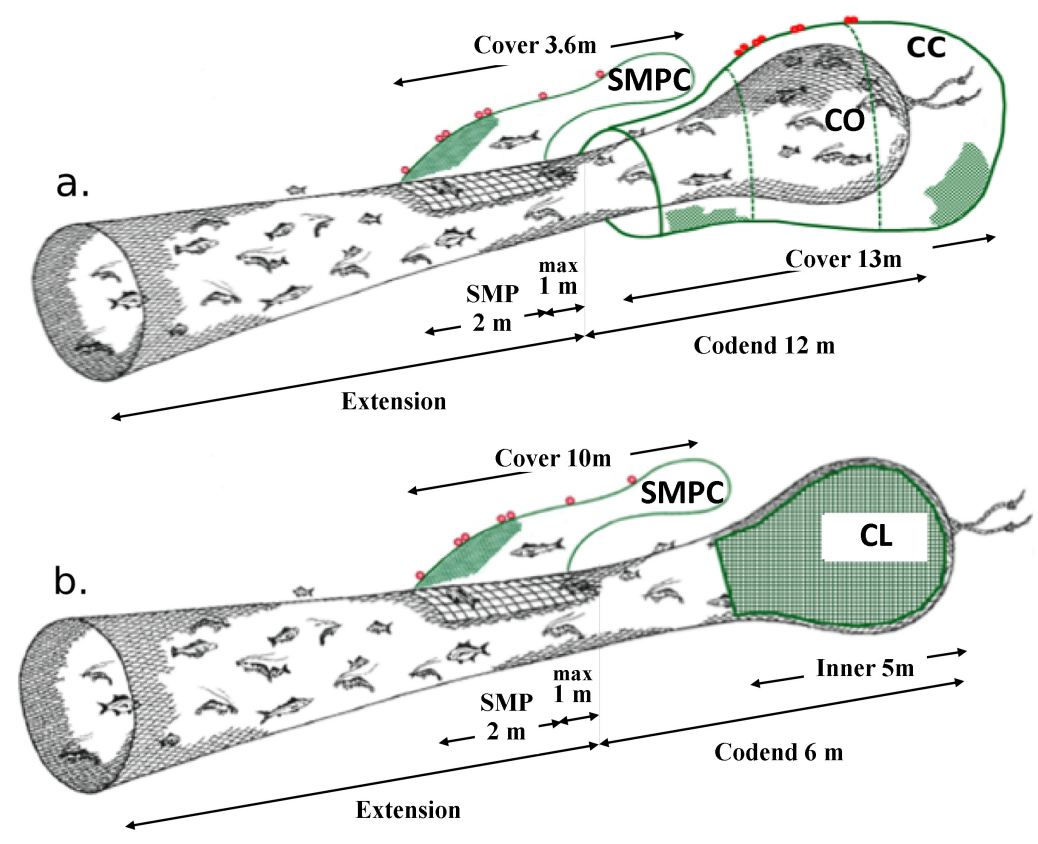

Figure 3.2: Gear setup for selectivity cruises. Setup a) Total selectivity setup (SMP $+\mathrm{CO}$ ) with the SMPC and the CC used onboard the F/V Gure Gaskuña in 2011. Setup b) SMP properties setup (SMP + CL) with the SMPC used onboard the F/V J. Kalamendi for the 2012-2013 surveys. Key: SMPC (square mesh panel cover), CO (codend), CC (codend cover) and CL (codend liner).

research surveys designed to estimate fish abundance and the gears used were those prescribed for the abundance surveys and incorporated small mesh codend liners (see below). In both cruises the codend was $6 \mathrm{~m}$ long with the SMP positioned $7 \mathrm{~m}$ from the codline. To investigate the selection properties of the SMP, a two-compartment setup was used; a codend incorporating a small mesh liner (CL, lining the full width of the codend and almost the $85 \%$ of the length) and a SMPC over the SMP (Fig. 3.2b).

After each haul, the catch was sorted by species. Only hauls with at least 10 individuals of the same species in the same haul were included in the analysis. Size selection data was collected for hake, pouting and red mullet. These species were available in sufficient numbers in the catch 
to enable the evaluation of gear performance. Moreover, individuals of these species are potential discard species due to quota restrictions, market demand and minimum size regulations (i.e. hake with MCRS of $27 \mathrm{~cm}$, pouting and red mullet with MCRSs corresponding to minimum landing weights of $50 \mathrm{~g}$ and $40 \mathrm{~g}$ respectively; EC (1996)). All individuals of each species or a representative sub-sample from each net compartment (CO, CC and SMPC or CL and SMPC, see Figure 3.2) were measured to the nearest centimetre below. Sub-sample numbers were raised to total catch number by the ratio sample weight to total weight caught.

Furthermore, a fall-through experiment (Herrmann et al., 2009), using a similar SMP as the one fitted to the gear in all experiments, was carried out on board to assess the potential size selectivity of the $100 \mathrm{~mm}$ square mesh. Around 150 fish of each of the selected species were tested. Total length for each fish was measured and its ability to physically pass headfirst through the $100 \mathrm{~mm}$ square mesh under by the force of gravity only was determined. The individuals were non-randomly selected from the catch in order to cover the widest possible size range.

In addition, underwater observations were recorded to observe fish behaviour in the trawl during the fishing operation and to analyse the escape mechanisms of those individuals that escaped from the gear, either through the SMP or elsewhere. Recordings were made using a Konsberg Simrad OE 1324 camera connected to a self-contained recorder unit with a DVR and two GoPro cameras. All cameras were placed inside the net, ahead of the SMP facing the codend.

\section{Data analyses}

We assessed the basic size selective potential for the $100 \mathrm{~mm}$ square mesh by fitting a logit size selection model with parameters $L 50$ (length at which a fish has $50 \%$ chance of being retained) and $S R$ (selection range, L25-L75) (Wileman et al., 1996) to the fall through data species by species. The purpose of this exercise was to assist the evaluation of the size selectivity of the square mesh panel in the sea trials. Fall through results can help solving potential confounding problems in data analysis from sea trials regarding contact probability with the panel and contact selectivity in terms of $L 50_{S M P}$. Specifically, we used the requirement (constraint) that estimated $L 50_{S M P}$ should be at least $50 \%$ 
of the assessed fall through $L 50$.

To analyse the size selection data from the cruise using the three compartment setup (Fig. 3.2a), species by species, we used the dual selection model first described by Zuur et al. (2001) and later applied by O'Neill et al. (2006). This model quantifies both the size selection in the SMP and in preceding codend. For the SMP the size selection is described by three parameters: $C_{S M P}, L 50_{S M P}$ and $S R_{S M P} . C_{S M P}$ quantifies the assumed length independent probability for a fish to make contact with the SMP during its drift towards the codend. A $C_{S M P}$ value of 1.0 would mean that every fish came into contact with the SMP and attempted to escape through it, while a value of 0.3 for example would mean that only $30 \%$ of the fish did contact the SMP and attempted to escape through it. $L 50_{S M P}$ and $S R_{S M P}$ are the $L 50$ and $S R$ values for the fraction of fish that make contact with the SMP based on a logit size selection model. The size selection in the codend was described by a traditional logit model with the parameters $L 50_{C O}$ and $S R_{C O}$. Thus, it was assumed that every fish entering the codend would make contact with its meshes and have a size dependent probability of being released. By using the definition of $L 50$ and $S R$, we could estimate the overall selectivity parameters of the combined system consisting of the SMP and the codend ( $L 50_{\text {dual }}$ and $\left.S R_{\text {dual }}\right)$. This combined selectivity is then defined as the dual selection and it can be estimated based on the values of the five parameters $\left(C_{S M P}, L 50_{S M P}, S R_{S M P}, L 50_{C O}\right.$ and $\left.S R_{C O}\right)$. This estimation procedure is thoroughly described in Sistiaga (2010) for a dual selection system with an escapement grid followed by a size selective codend. The model has an identical model structure as for the SMP + codend system applied here. The hauls belonging to the cruise with the three-compartment setup were used to define a group of hauls. For each species separately, we fitted the dual selection model to the pooled data for the group of hauls using the maximum likelihood method based on the procedure described in Sistiaga (2010). This estimation method includes a double bootstrap procedure to account for uncertainty in estimation both due to within- and between haul-variation in the selection processes in the gear. Further the method accounts for additional uncertainty due to sub-sampling of data, based on the procedure described in Eigaard et al. (2012). We applied 1000 bootstrap repetitions for the analysis. 
To analyse the size selection data from the sea trials using the twocompartment setup (Fig. 3.2b) species by species, we used the same procedure as described above for the three-compartment setup with the exception that the analysis only involved the estimation of the size selection in the SMP. By quantifying the $C_{S M P}, L 50_{S M P}, S R_{S M P}$ parameters lead to a size selection model which is similar to the one applied for a "grid only size selection" described by Herrmann et al. (2013).

The selectivity data were analysed using the analysis tool SELNET (SELection in trawl NETting; Herrmann et al. (2012)). Evaluating the ability of the model to describe the data sufficiently well was based on inspecting the fit statistics, i.e., the p-value and the model deviance versus the degrees of freedom (DOF), following the procedures described by Wileman et al. (1996). The p-value expresses the likelihood to obtain at least as big a discrepancy between the fitted model and the observed experimental data by coincidence. In case of a poor fit statistics (p-value being $<0.05$; deviance being $>>D O F$ ), the residuals were inspected to determine whether the poor result was due to structural problems when describing the experimental data using the model or if it was due to over-dispersion in the data (Wileman et al., 1996).

In addition to the evaluation based on the selection parameters, we also calculated the length-averaged retention probability of undersized individuals in the gear based on the three-compartment trials and the length averaged escapement through the SMP of undersized individuals based on all sea trials. This estimation which was also conducted in the analysis tool SELNET follows the estimation method described in (Özbilgin et al., 2015; Sala et al., 2015; Wienbeck et al., 2014). To estimate the length-averaged retention and escapement of the undersized individuals, the minimum landing weight for pouting and red mullet was converted to length using the species-specific length-weight relationship given in Dorel (1986). The MCRSs for pouting (50 g) and red mullet (40 g) equate to lengths of approximately $16 \mathrm{~cm}$ and $15 \mathrm{~cm}$ respectively.

\subsection{Results}

\section{Fall-through experiment}

The results of the fall through experiments are summarised in Table 3.3 and the length distributions of the fish and the fitted curves and 
95\% confidence intervals for the potential size selection properties of the $100 \mathrm{~mm}$ square mesh are shown in Figure 3.3. The p-value and model deviance compared to number of DOF indicate that the model describes the data adequately (Table 3.3). Using the values from the fitted selection curve, the lengths at which the potential probability for each species to escape through the $100 \mathrm{~mm}$ square mesh is $95 \%\left(L_{\text {fall }}\right)$ are estimated at $50.41 \mathrm{~cm}, 23.79 \mathrm{~cm}$ and $31.36 \mathrm{~cm}$ for hake, pouting and red mullet respectively. In the case of $L 50_{\text {fall }}$, the values are estimated at $51.01 \mathrm{~cm}, 26.10 \mathrm{~cm}$ and $31.49 \mathrm{~cm}$ respectively. Since both the $L_{\text {fall }}$ and the $L 50_{\text {fall }}$ estimates are above the MCRS and the length-at-maturity $\left(L_{\text {mat }}\right)$ for all species the SMP has the potential to release undersized and immature individuals.

Table 3.3: Results of fall-through experiments: Fitted selectivity parameters, 95\% CI (in brackets) and fit statistics for each species.

\begin{tabular}{lccc}
\hline & Hake & Pouting & Red mullet \\
\hline & & & \\
$L 50_{\text {fall }}(\mathrm{cm})$ & $51.05(50.50-52.03)$ & $26.10(25.58-26.50)$ & $31.49(31.02-31.52)$ \\
$S R_{\text {fall }}(\mathrm{cm})$ & $0.10(0.10-0.10)$ & $1.72(0.10-2.43)$ & $0.10(0.10-0.10)$ \\
$L_{\text {fall }}(\mathrm{cm})$ & $50.41(49.39-52.61)$ & $23.79(22.73-26.37)$ & $31.36(30.39-31.39)$ \\
& & & $<0.01$ \\
deviance & $<0.01$ & 1.08 & 6 \\
DOF & 6 & 6 & $>0.99$ \\
p-value & $>0.99$ & 0.98 & \\
& & & \\
\hline
\end{tabular}

\section{Selectivity experiments}

A total of 68 hauls were carried out during the three cruises (Table 1). Hauls in which fewer than 10 individuals of each species of hake, pouting and red mullet were present were excluded from the selectivity analysis. The results in terms of valid hauls, numbers and size ranges of fish retained by the codend and covers are summarised separately by cruise and species in Table 3.4. For those hauls where sub-sampling took place the raised catch was used for the analysis. Over all three cruises, the length ranges of each species caught were 6-62 cm, 7-36 cm and 9-41 cm, for hake, pouting and red mullet respectively. From the total catch of each species, the proportions of fish below the average $L_{\text {mat }}$ were $73.7 \%$, $12.6 \%$ and $56 \%$ for hake, pouting and red mullet respectively. Similarly, the proportion of fish below MCRS were $60 \%, 1.7 \%$ and $27.5 \%$ for hake, 


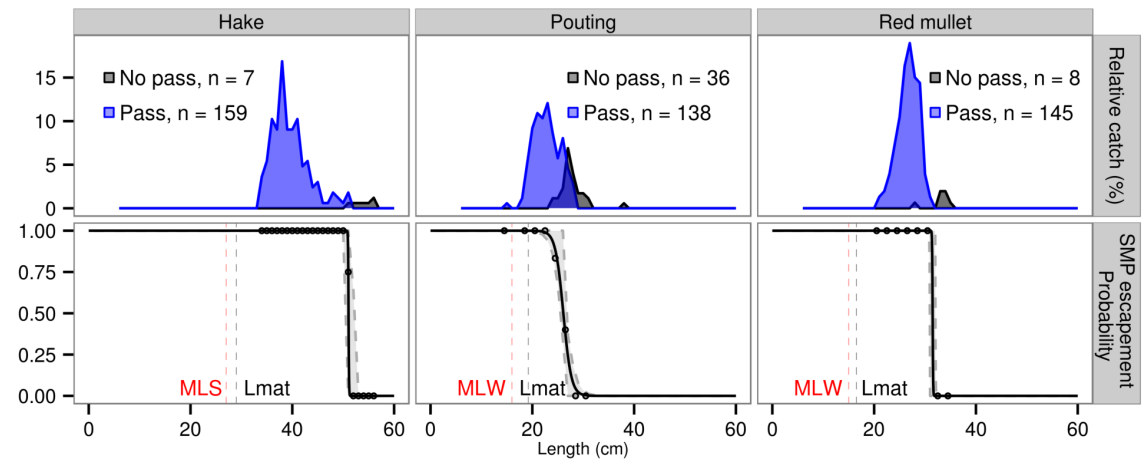

Figure 3.3: Relative catch size-frequency distributions for the fall-through experiment and the fitted escapement curves (black) indicating potential SMP escapement probability with the $95 \%$ confidence intervals (grey area). Lengthat-maturity $\left(L_{\text {mat }}\right)$ for pouting, hake and red mullet is $19.2 \mathrm{~cm}, 29 \mathrm{~cm}$ and $16.5 \mathrm{~cm}$ on average respectively (Alonso-Fernández et al., 2008; El Habouz et al., 2011; Mahé et al., 2005). For hake the minimum conservation reference size (MCRS) is $27 \mathrm{~cm}$ and for pouting and red mullet the minimum landing weights of $50 \mathrm{~g}$ and $40 \mathrm{~g}$ equate to $16 \mathrm{~cm}$ and $15 \mathrm{~cm}$ respectively.

pouting and red mullet respectively. The catch of most individuals of all species studied were retained in the codend.

\section{Dual selection estimation (CO + SMP); Cruise 1}

A total of 15 hauls were carried out during the first cruise designed to investigate the selective properties of the trawl gear configuration currently used by the Basque otter trawl fleet in the Bay of Biscay (Fig. 3.2a). For hake, pouting and red mullet, 8, 10 and 11 of the 15 hauls respectively were considered valid. The relative proportions by length retained by the $\mathrm{CO}, \mathrm{CC}$, and SMPC for hake, pouting and red mullet are shown in Figure 3.4 together with the fitted selection curves and 95\% confidence intervals obtained for the SMP escapement, codend escapement and dual retention (combined retention of the codend and the SMP). The results are summarized in Table 3.5. The p-value and model deviance compared to number of DOF indicate that generally the model describes the data adequately. In contrast to the results for hake and pouting, the p-value for modelling the selectivity data for red mullet was below 0.05 and the model deviance was far above the DOF. Such a result 
Table 3.4: Summary statistics by species for all valid hauls used for the selectivity analysis. No. retained by net compartment and No. < MCRS (sub-sample number in parentheses) and length range of all individuals caught.

\begin{tabular}{lccc}
\hline & $\begin{array}{c}\text { Hake } \\
\text { MCRS (27 cm) }\end{array}$ & $\begin{array}{c}\text { Pouting } \\
\text { MCRS (16 cm) }\end{array}$ & $\begin{array}{c}\text { Red mullet } \\
\text { MCRS (15 cm) }\end{array}$ \\
\hline Cruise 1 & & & \\
No. of valid hauls & 8 & 10 & 11 \\
Length range (cm) & $12-62$ & $7-36$ & $9-33$ \\
Total No. in CO & $766(766)$ & $2079(1118)$ & $4498(1157)$ \\
No. in CO <MCRS & $356(356)$ & $7(5)$ & $932(287)$ \\
Total No. in CC & $354(354)$ & $324(324)$ & $2931(1292)$ \\
No. in CC <MCRS & $324(324)$ & $30(30)$ & $1112(550)$ \\
Total No. in SMPC & $8(8)$ & $13(13)$ & $67(67)$ \\
No. in SMPC <MCRS & $5(5)$ & $5(5)$ & $18(18)$ \\
& & & \\
Cruise 2 & 22 & 4 & 7 \\
No. of valid hauls & $9-60$ & $12-33$ & $14-39$ \\
Length range (cm) & $6267(3513)$ & $522(522)$ & $311(311)$ \\
Total No. in CL & $5449(2955)$ & $294(294)$ & $1(1)$ \\
No. in CL <MCRS & $281(281)$ & $0(0)$ & $2(2)$ \\
Total No. in SMPC & $233(233)$ & $0(0)$ & $0(0)$ \\
No. in SMPC <MCRS & & & \\
Cruise 3 & 22 & 5 & 6 \\
No. of valid hauls & $6-60$ & $18-35$ & $14-41$ \\
Length range (cm) & $5321(3783)$ & $211(211)$ & $235(235)$ \\
Total No. in CL & $4566(3187)$ & $0(0)$ & $3(3)$ \\
No. in CL <MCRS & $251(251)$ & $0(0)$ & $1(1)$ \\
Total No. in SMPC & $232(232)$ & $0(0)$ & $0(0)$ \\
No. in SMPC $<$ MCRS & & & \\
& & & \\
\hline
\end{tabular}

could indicate problems with using the dual selection model to describe the experimental selectivity data for red mullet. However, inspection of the deviations between the observed and modelled size selectivity does not reveal any clear pattern (Fig. 3.4). Therefore, we consider that the low p-value for red mullet is likely to be due to over-dispersion in the experimental data, and are therefore confident in applying the dual selection model to describe the selectivity curve for red mullet. The $L 50_{S M P}$ values are estimated at $37.56 \mathrm{~cm}, 13.05 \mathrm{~cm}$ and $20.52 \mathrm{~cm}$ for hake, pouting and red mullet respectively. For all the species studied, the average $L 50_{S M P}$ is estimated to be below Lfall, but above the MCRS for the hake and red mullet. The estimates of $C_{S M P}$ are 0.01 for hake and red mullet, and 0.15 for pouting, meaning that only a low proportion ( $1 \%$ and $15 \%$, respectively) of these species came into contact with 
the SMP during their drift towards the codend.

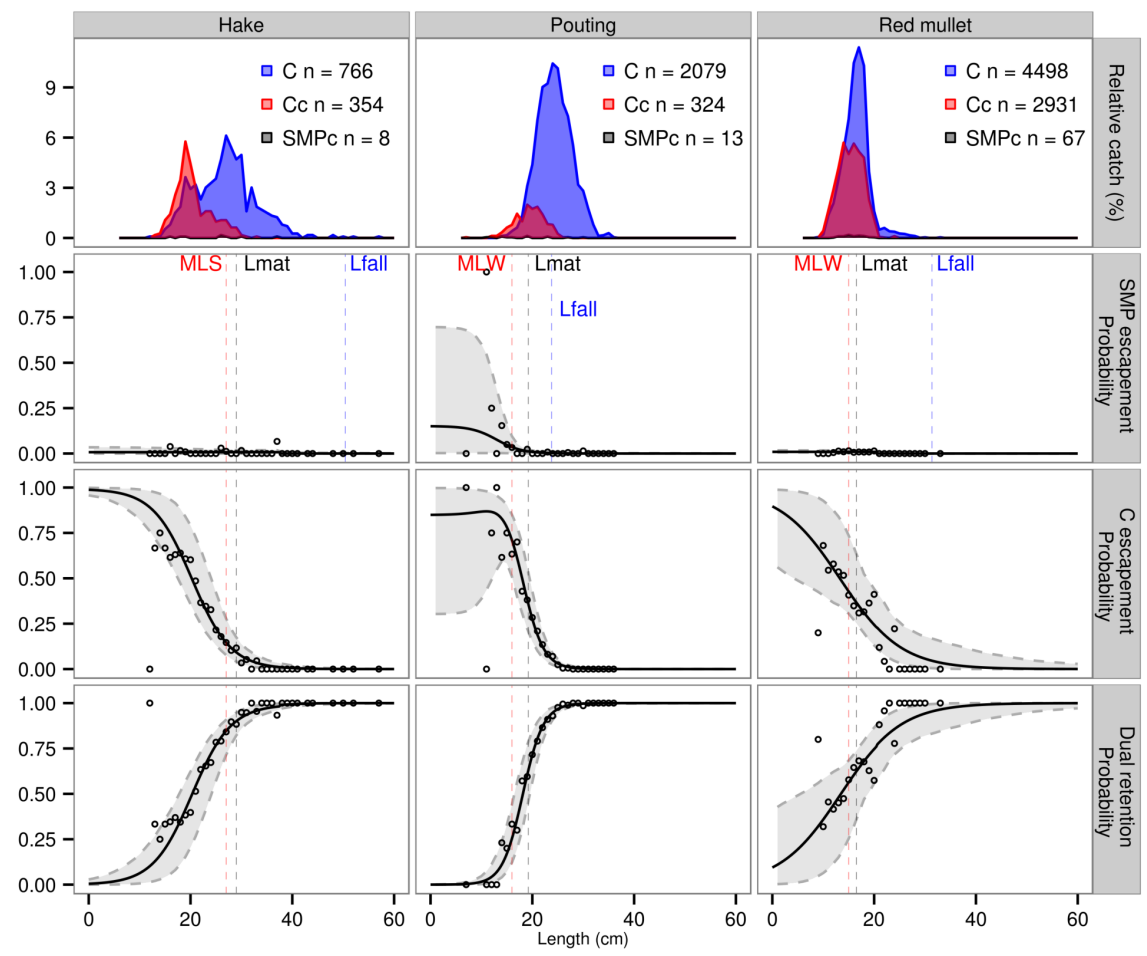

Figure 3.4: Relative catch size-frequency distributions of fish retained in the codend (CO), codend cover (CC) and SMP cover (SMPC) and the mean escapement curves (black) for the SMP escapement, codend escapement and dual retention curves (combined effect of the codend and the SMP) and $95 \%$ confidence intervals (grey area) during the first cruise.

The $L 50_{C O}$ values are estimated at $20.29 \mathrm{~cm}, 18.08 \mathrm{~cm}$ and $13.36 \mathrm{~cm}$ for hake, pouting and red mullet respectively. For the combination of the SMP and the codend, the L50dual is estimated to be $20.34 \mathrm{~cm}, 18.15$ $\mathrm{cm}$ and $13.47 \mathrm{~cm}$ for hake, pouting and red mullet respectively. The differences between the estimates for $L 50_{C O}$ and $L 50_{\text {dual }}$, and $S R_{C O}$ and $S R_{\text {dual }}$ are small and not significant, which reflects that the SMP is not making an important contribution to the combined selectivity (see Table 3.5 and Figure 3.4). Most of the individuals of the species studied that escaped from the gear did so through the codend.

Regarding catches of under-sized $(<27 \mathrm{~cm})$ hake, the estimated propor- 
Table 3.5: Selectivity results from cruise 1 (3-compartment experiment): Fitted selectivity parameters, average retention/ escapement probability for undersized individuals, 95\% CI (in brackets) and fit statistics for each species and gear compartment.

\begin{tabular}{|c|c|c|c|}
\hline & Hake & Pouting & Red mullet \\
\hline \multicolumn{4}{|l|}{$L 50(\mathrm{~cm})$} \\
\hline SMP & $37.56(25.50-37.62)$ & $13.05(13.05-27.52)$ & $20.52(16.01-20.56)$ \\
\hline $\mathrm{CO}$ & $20.29(17.64-24.08)$ & $18.08(16.31-19.47)$ & $13.36(4.89-18.68)$ \\
\hline Dual & $20.34(17.81-24.13)$ & $18.15(16.45-19.50)$ & $13.47(5.56-18.77)$ \\
\hline \multicolumn{4}{|l|}{$S R(\mathrm{~cm})$} \\
\hline SMP & $0.10(0.10-100.0)$ & $5.51(0.10-21.34)$ & $0.10(0.10-5.91)$ \\
\hline $\mathrm{CO}$ & $8.40(5.59-11.73)$ & $4.45(3.73-5.29)$ & $13.04(6.31-32.80)$ \\
\hline Dual & $8.47(5.66-11.73)$ & $4.41(3.73-5.18)$ & $13.19(6.28-33.33)$ \\
\hline$C_{S M P}$ & $0.01(0.00-0.03)$ & $0.15(0.01-0.70)$ & $0.01(0.01-0.02)$ \\
\hline SMP escapement <MCRS (\%) & $0.73(0.00-2.70)$ & $11.90(0.00-34.78)$ & $0.87(0.39-1.57)$ \\
\hline CO escapement $<$ MCRS $(\%)$ & $47.30(27.47-75.84)$ & $71.43(35.08-90.24)$ & $53.93(35.41-82.07)$ \\
\hline Dual retention <MCRS (\%) & $51.97(23.77-70.82)$ & $16.67(0.00-41.34)$ & $45.20(16.83-63.51)$ \\
\hline deviance & 0.01 & 48.03 & 74.35 \\
\hline DOF & 63 & 49 & 41 \\
\hline p- value & 0.99 & 0.51 & 0.01 \\
\hline
\end{tabular}

tion retained in the codend was $51.97 \%$, while the proportions that escaped through the codend and SMP were $47.30 \%$ and $0.73 \%$ respectively. For pouting, $16.67 \%$ of under-sized individuals were retained by the codend and $71.43 \%$ and $11.90 \%$ escaped through the codend and the SMP and for red mullet, $45.20 \%$ of the under-sized individuals were retained by the codend and $53.93 \%$ and $0.87 \%$ escaped through the codend and the SMP (Table 3.5 and Figure 3.4).

The above results demonstrate that the majority of undersized individuals of all species that escaped the gear did so through the codend. However, approximately half of the catch of undersized hake and red mullet and about $17 \%$ of undersized pouting was retained by the gear. It is clear that the SMP does not improve the selectivity for undersized hake and red mullet much because less than $1 \%$ of all undersized individuals escaped through the SMP. For pouting, only a marginal improvement in selectivity was attributable to the SMP (12\% of undersized escapees). 


\section{Selection properties of the SMP alone; Cruises 2 and 3}

A total of 27 and 26 hauls were carried out during the second and third cruises respectively (years 2012 and 2013), designed to investigate the selective properties of the $100 \mathrm{~mm}$ SMP. The numbers of valid hauls for hake, pouting and red mullet during the second cruise were 22, 4 and 7, while during the third cruise were 22, 5 and 6 respectively (tab:hauls). The specification of the gear used in both cruises is illustrated in Figure $3.2 \mathrm{~b}$. The relative size-frequency distribution of individuals retained by the SMPC and the CL for the different species based on the total number of fish caught from all valid hauls is shown in Figure 3.5. As observed in the three-compartment experiment described above, escapement of hake, pouting and red mullet through the SMP was low in both cruises 2 and 3. The total catches of hake, pouting and red mullet were 11950, 733 and 549 individuals respectively, but only 452 hake, 3 red mullet and not a single pouting passed through SMP into the SMPC.

Figure 3.5 shows the fitted selection curves for the SMP by species for the second and third set of trials (years 2012 and 2013). Table 3.6 summaries the results for modelling the size selection for the SMP. Similar to the results from the dual selection modelling for red mullet, inspection of the p-values and the model deviance compared with the DOF for hake could indicate problems with the modelling. However, although the pvalue for hake was below 0.05 and the model deviance was far above the DOF we could also attribute this to over-dispersion in the experimental data (Fig. 3.5). Using the same rationale as for red mullet we consider that it is appropriate to use the applied selection model to describe the selectivity curve for hake. For pouting the $250_{S M P}$ could not be estimated since no fish escaped through the SMP (Table 3.6). For hake and red mullet, while the average estimates for $L 50_{S M P}$ differed between the second and third cruises, the differences were not significant since the confidence intervals overlap (Fig. 3.5 and Table 3.6). As for cruise 1, $L 50_{S M P}$ for hake and red mullet in cruises 2 and 3 are estimated to be below Lfall, but significantly above the MCRS and $L_{m a t}$, which means that the SMP has the potential to allow undersized fish to escape. However, the estimated contact probabilities $\left(C_{S M P}\right)$ were very low (zero in the case of pouting and about $5 \%$ and $1 \%$ for hake and red mullet respectively; Table 3.6). The estimates of $C_{S M P}$ and the associated 

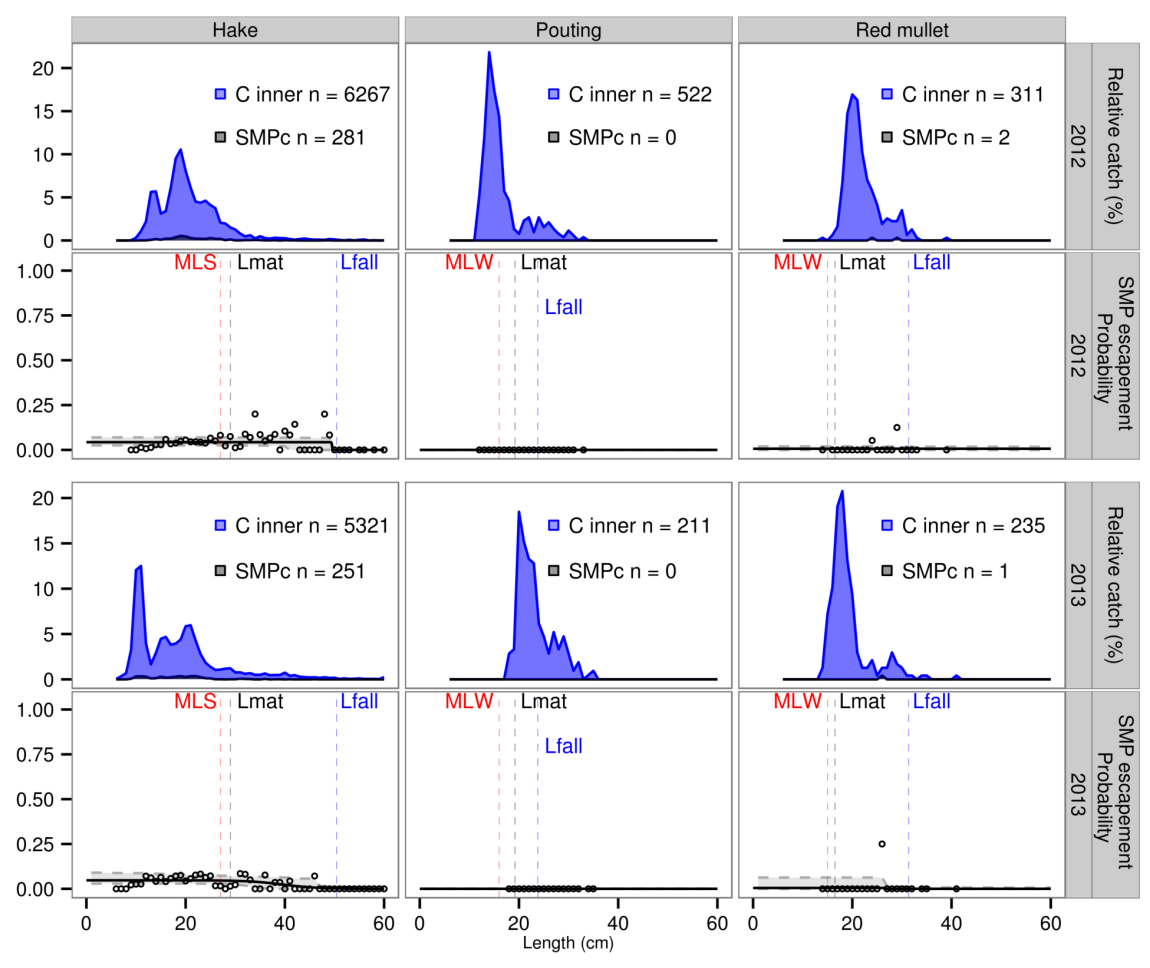

Figure 3.5: Relative catch size-frequency distribution for hake, pouting and red mullet for the codend liner (CL) and square mesh panel cover (SMPC) during cruises 2 and 3 (2012 and 2013). Fitted escapement curves (solid black line) and $95 \%$ confidence intervals (grey area) are also shown.

95\% confidence intervals for all the species studied were similar for both years, and in in line with those obtained from the three-compartment experiment (Table 3.6).

It is clear that the SMP does not improve the selectivity for undersized hake because less than $5 \%$ of hake undersized individuals $(4.10 \%$ and $4.83 \%$ for the second and third trial respectively) escaped through the SMP. For pouting and red mullet, the SMP was wholly ineffective at releasing undersized fish as not a single under-sized individual escaped through the SMP (Table 3.6 and Figure 3.5). 
Table 3.6: Selectivity results from cruises 2 and 3 (2-compartment experiments): Fitted selectivity parameters, average escapement probability for undersized individuals, 95\% CI (in brackets) and fit statistics for each species.

\begin{tabular}{|c|c|c|c|}
\hline & Hake & Pouting & Red mullet \\
\hline \multicolumn{4}{|c|}{$L 50_{S M P}(\mathrm{~cm})$} \\
\hline cruise 2 & $49.51(40.47-49.98)$ & * & $29.56(15.75-31.49)$ \\
\hline cruise 3 & $39.64(26.47-46.56)$ & $*$ & $26.59(15.75-31.49)$ \\
\hline \multicolumn{4}{|c|}{$\boldsymbol{S R}_{S M P}(\mathbf{c m})$} \\
\hline cruise 2 & $0.10(0.10-6.36)$ & * & $0.10(0.10-11.7)$ \\
\hline cruise 3 & $7.80(0.10-20.05)$ & $*$ & $0.10(0.10-100.0)$ \\
\hline \multicolumn{4}{|l|}{$\boldsymbol{C}_{S M P}$} \\
\hline cruise 2 & $0.04(0.03-0.07)$ & 0.00 & $0.01(0.00-0.02)$ \\
\hline cruise 3 & $0.05(0.03-0.09)$ & 0.00 & $0.01(0.00-0.06)$ \\
\hline \multicolumn{4}{|c|}{ SMP escapement <MCRS (\%) } \\
\hline cruise 2 & $4.10(2.29-6.83)$ & $0.00(0.00)$ & $0.00(0.00)$ \\
\hline cruise 3 & $4.84(2.95-8.27)$ & $0.00(0.00)$ & $0.00(0.00)$ \\
\hline \multicolumn{4}{|c|}{ deviance } \\
\hline cruise 2 & 65.14 & $<0.01$ & 10.08 \\
\hline cruise 3 & 76.89 & $<0.01$ & 8.23 \\
\hline \multicolumn{4}{|l|}{ DOF } \\
\hline cruise 2 & 46 & 18 & 17 \\
\hline cruise 3 & 52 & 14 & 19 \\
\hline \multicolumn{4}{|l|}{ p-value } \\
\hline cruise 2 & 0.03 & $>0.99$ & 0.90 \\
\hline cruise 3 & 0.01 & $>0.99$ & 0.98 \\
\hline
\end{tabular}

* No estimation since no fish escaped through the SMP.

\section{Underwater observations}

Underwater observations confirmed that the SMP meshes remained wide open during fishing (Fig. 3.6). However, none of the species studied seemed to react to the SMP open meshes. In the vicinity of the SMP hake individuals were observed to be passively drifting towards the codend with no apparent active escapement behaviour in relation to the SMP. Video observations showed that ground contact of the footrope constantly dislodged sand particles and sludge that created turbidity inside the trawl. Consequently, there was reduced visibility (Fig. 3.6), which together with the apparent affinity of pouting and red mullet to remain close to the lower panel of the trawl may explain why the SMP 
was not effective at releasing these species. Some pelagic species such as anchovy (Engraulis encrasicolus), horse mackerel and blue whiting (Micromesistius poutassou) were observed escaping through the SMP or swimming underneath the SMP for long periods until they became exhausted.

\section{Figure 3.6:}

Snapshot from an underwater video showing the presence of turbidity in the lower section of the net in the vicinity of the SMP.

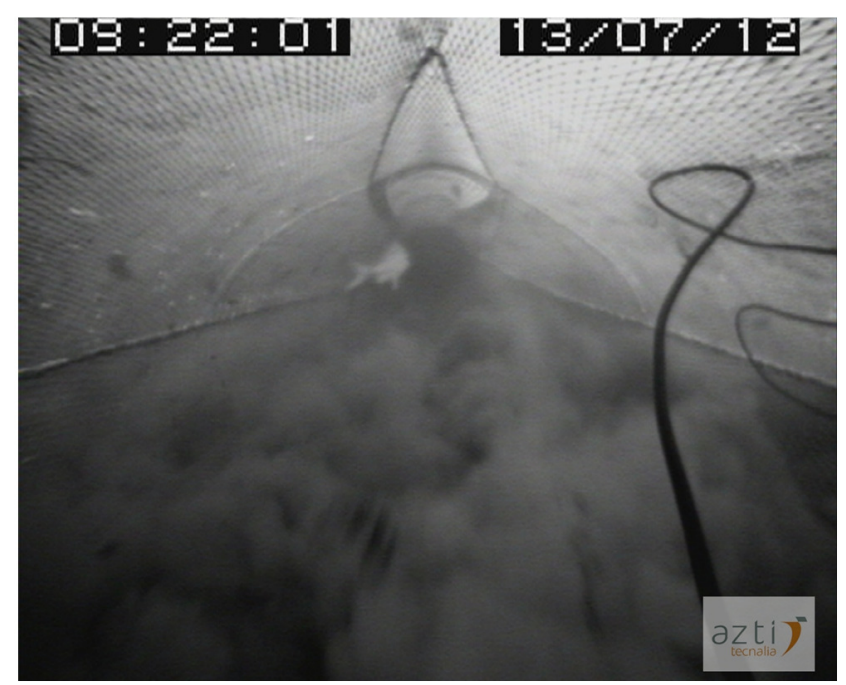

\subsection{Discussion}

The experimental cruises undertaken in the present study aimed to investigate the selective properties of the fishing gears used by Basque otter trawlers operating in the Bay of Biscay (ICES Divisions VIII a, $\mathrm{b}$ and $\mathrm{d}$ ). The gears used are bottom otter trawls with a codend mesh size of $70 \mathrm{~mm}$, incorporating a $100 \mathrm{~mm}$ SMP in the extension ahead of the codend as prescribed in Council Regulation (EC) 51/2006. These provisions were introduced as an optional alternative to the mandatory use of bottom otter trawls with a $100 \mathrm{~mm}$ codend mesh size prescribed in (EC, 2002) and were intended primarily to improve selectivity for juvenile hake. The cruises provide an opportunity to investigate the selective properties of the SMP for hake, but also for pouting and red mullet, which are also caught in the Basque otter trawl fishery.

Results from the fall-through experiments revealed that the size-selective properties of the $100 \mathrm{~mm}$ SMP would potentially enable immature and undersized fish of all the species studied to escape through the SMP 
meshes (Table 3.3). The selection curves obtained from the at sea selectivity cruises also demonstrate that the value for $250_{S M P}$ is higher than the MCRS for hake and red mullet (Tables 3.5 and 3.6). Therefore, undersized individuals of the species studied could potentially escape through the SMP. However, they show only a low probability to encounter the SMP (contact probabilities are only 1- $4 \%$ for hake, between $0-15 \%$ for pouting, and $1 \%$ for red mullet) and hence the effectiveness of the SMP in releasing undersized individuals is very low. This is supported by the results of underwater observations made during the cruises which demonstrated that hake, pouting and red mullet did not display any active escapement behaviour in the region of the SMP and fish were simply observed to drift past the SMP towards the codend during the fishing operation. The ineffectiveness of the SMP is confirmed by comparing the differences in the estimates for $L 50_{C O}$ and $L 50_{d u a l}$, and $S R_{C O}$ and $S R_{\text {dual }}$, which were small and not significant (Table 3.5).

While the combination of $70 \mathrm{~mm}$ codend mesh size and $100 \mathrm{~mm}$ SMP aims at improving the selectivity for juvenile hake, Nikolic et al. (2015) also concluded that release of juvenile hake with SMP is inefficient in the French Nephrops trawl fishery. The dual retention results for hake in the present study (Table 3.5) show that approximately $52 \%$ of the catch in number of undersized hake $(<\mathrm{MCRS}=27 \mathrm{~cm})$ was retained by the codend of the trawl used by the Basque fleet. Furthermore, the majority of the undersized individuals that escaped did so through the $70 \mathrm{~mm}$ codend meshes (47.3\%) and less than 1\% (0.73\%) escaped via the $100 \mathrm{~mm}$ SMP. Compared to a $70 \mathrm{~mm}$ diamond mesh codend $\left(L 50_{C O}\right.$ $20.29 \mathrm{~cm}$ ), our findings reveal no improvement in size selection for hake ( $L 50_{\text {dual }} 20.34 \mathrm{~cm}$ ) by inserting a $100 \mathrm{~mm}$ SMP in the extension of the trawl. The value of $L 50_{C O}$ estimated for the $70 \mathrm{~mm}$ diamond codend is slightly higher than that estimated by Campos et al. (2003) for a $65 \mathrm{~mm}$ diamond codend $\left(L 50_{C O} 17.0 \mathrm{~cm}\right)$, suggesting that an increase in codend mesh size can improve the selection pattern for hake, i.e. proportionally fewer smaller individuals are retained by the codend. Another effective means to improve the selection pattern for hake is the insertion of sorting grids in the extension section of trawls, as demonstrated by Fonseca et al. (2005).

The dual selection results for pouting show that approximately $17 \%$ of the catch in number of undersized pouting $(<\mathrm{MCRS}=16 \mathrm{~cm})$ was re- 
tained by the codend of the trawl used by the Basque fleet, and approximately $83 \%$ escaped (Table 3.5), although the majority of the undersized individuals that escaped $(71.43 \%)$, did so through the $70 \mathrm{~mm}$ codend meshes. The values of $L 50_{C O}(18.08 \mathrm{~cm})$ and $S R_{C O}(4.45 \mathrm{~cm})$ were in the range of those estimated by Mendes et al. (2004) for a $65 \mathrm{~mm}$ square mesh codend (but for Trisopterus luscus only). The observed similarity in the results from both studies can be explained by the steepness of the estimated selection curve for pouting (Fig. 3.4). In contrast however, even though in our first cruise, the release potential of the SMP for undersized pouting was $12 \%$, similar to the $10 \%$ escapement observed by Fonseca et al. (2005) using a trawl fitted with a grid with $30 \mathrm{~mm}$ bar spacing and a SMP located above the grid, the contact probabilities for pouting differed markedly in the other two cruises (Tables 3.5 and 3.6). Hence we are unable to conclude that the SMP is equally effective at releasing pouting as the grid-SMP combination used by Fonseca et al. (2005).

For red mullet, the dual selection results show that approximately $45 \%$ of the catch in number of undersized individuals $(<\operatorname{MCRS}=15 \mathrm{~cm})$ were retained by the codend, and less than $1 \%$ of the juvenile red mullet escaped through the $100 \mathrm{~mm}$ SMP. In contrast, Metin et al. (2005) found that compared to a $40 \mathrm{~mm}$ diamond mesh codend, selectivity experiments using a $40 \mathrm{~mm}$ diamond mesh codend incorporating a 40 mm SMP positioned in the forward part of the top panel of the codend significantly increased the release of juvenile red mullet. Our study estimated a similar value of $L 50_{\text {dual }}$ to Metin et al. (2005) $(13.47 \mathrm{~cm}$ vs. $12.55 \mathrm{~cm})$ but a much bigger value of $S R_{\text {dual }}(13.19 \mathrm{~cm}$ vs. $2.27 \mathrm{~cm})$. The observed differences may be explained by differences in both the panel location and the length range sampled. However, and as found for hake, our estimates for $L 50_{C O}$, both for pouting and red mullet, are similar to our estimates for L50dual. Therefore, the combined selectivity of the gear is mainly attributable to the escapement of individuals through the codend.

The low escapement of these demersal species through the SMP can be attributed to the fact that they did not display any active escape behaviour in the region of the SMP, as confirmed by our underwater observations. These observations are also in line with the findings of Briggs (1992); Frandsen et al. (2009); Rosen et al. (2012) for cod. Furthermore, 
Fonseca et al. (2005) demonstrated that compared to pelagic species, the escape behaviour of demersal species was much less active in the area of the SMP. However, previous studies have shown that other factors, such as the location if the SMP can also affect escapement through the SMP of species that exhibit less active escape behaviour. For example, in selectivity trials undertaken by Graham and Kynoch (2001), no significant differences in the L50 s for haddock (Melanogrammus aeglefinus), whiting (Merlangius merlangus) and cod (Gadus morhua) were found between trials using trawls fitted with a $100 \mathrm{~mm}$ diamond mesh codend, and trawls with a $3 \mathrm{~m}$ long, $80 \mathrm{~mm}$ SMP inserted in the extension section ahead of a $100 \mathrm{~mm}$ diamond mesh codend. However, when the $80 \mathrm{~mm}$ SMP was inserted in the codend, it significantly improved the selectivity of the gear. Furthermore, other studies also on haddock, whiting and cod have proved that when SMPs are positioned in the codend, closer to the catch accumulation zone, both the selectivity for small fish and the survival of escapees is improved (Bullough et al., 2007; Graham et al., 2003, 2004; Grimaldo et al., 2007; Herrmann et al., 2015; Madsen and Stæhr, 2005).

Glass and Wardle (1995) found that the selectivity and survival of the escapees of demersal fish can be dramatically affected by using visual stimuli to raise their vertical position in the trawl. In their study, the proportion of haddock and whiting escaping through the SMP increased from 20 to $60 \%$ with addition of a black tunnel in the extension section of the trawl behind the SMP. Fish appeared reluctant to enter the tunnel and preferred to escape through the open meshes that the SMP offered. However, underwater observations made during trawling in the present study, demonstrated that even though the SMP may have offered enhanced light penetration compared to the adjacent, almost closed diamond meshes; hake, pouting and red mullet rarely exhibited active escape behaviour inside the gear and tended to remain closer to the bottom panel of the trawl. Furthermore, bottom otter trawling by the Basque fleet is carried out at a relatively high speed of about 4 knots, which creates conditions of reduced visibility due to the presence of high densities of particulate matter in suspension. Such conditions may have influenced the ability of the fish to locate the SMP, thereby inhibiting their ability to escape the open meshes.

Currently the Basque bottom otter trawl fleet in the Bay of Biscay is 
complying with existing regulations by adopting the $70 \mathrm{~mm}$ diamond codend with the $100 \mathrm{~mm}$ SMP rather than opting for the alternative permissible configuration of $100 \mathrm{~mm}$ diamond mesh codend. Whatever the reasons for choosing the $70 \mathrm{~mm}$ codend plus SMP configuration, our results demonstrate that incorporation of the SMP, positioned in the extension section of the trawl, does not result in any significant improvement in the selectivity for small hake over and above that achieved by the $70 \mathrm{~mm}$ codend. Consequently, we conclude that this gear configuration does not effectively achieve the intended objective of releasing undersized hake and ideally its ability to do so should have been assessed before the measures were implemented. Hence we agree with Suuronen and Sarda (2007) that before implementation, gear-specific regulations should be carefully thought through and thoroughly tested in all the fisheries to which they are to apply.

We have demonstrated that under normal fishing operations, the selective properties of the trawls deployed by the Basque bottom otter trawl fleet in the Bay of Biscay, retains approximately half of undersized hake and red mullet that enter the trawl and approximately $17 \%$ of undersized pouting. To comply with current minimum size regulations, catches of undersized individuals must be discarded and the vast majority will be returned to the sea dead. However, with the implementation of the landing obligation (Article 15 of the CFP; EU (2013)), discarding of undersized quota species (hake in this case study) will no longer be permitted. Such catches will have to be retained on board and landed, will be counted against quota and shall be restricted to purposes other than direct human consumption. Whether they are discarded or landed, they are unwanted catches that reduce future potential yield and spawning stock biomass. A potential solution to avoid unwanted catches is to improve the selective properties of the fishing gear so that undersized individuals can escape. The conservation benefits of escapement of juvenile individuals depends on the survival rate. In absence of information on the survival rates of hake, pouting or red mullet following escapement from trawls the conservation benefits cannot be predicted with any certainty. If the long-term survival rate is $100 \%$, juveniles escaping from fishing gears have the potential to make a significant contribution to the future spawning potential of the stock. However, if the survival rate is close to $0 \%$, then the future conservation benefits will be minor. In either of these cases, there is a double incentive for skippers to avoid 
catching undersized individuals, both from the potential conservation benefits that might accrue to the stock and to avoid having to land undersized individuals under the landing obligation.

The introduction of the landing obligation shifts the emphasis from prescribing the fishing gears that are permissible, to a results-based system where the onus is on the fishers to develop gears that will avoid unwanted catches. Such a shift to a results-based system, presents both a challenge and an opportunity to the Basque trawl fleet to develop alternative more-selective gears in the Bay of Biscay fishery to avoid unwanted catches of undersized hake and other species. Reverting to using a $100 \mathrm{~mm}$ diamond mesh codend in the Basque bottom otter trawl fishery may provide a partial solution to mitigate the potential impact of the landing obligation. However, such a measure may also lead to losses in marketable catch and reductions in revenue that make the fishery unviable in the short-term and perhaps in the long-term. Should adoption of a $100 \mathrm{~mm}$ codend prove to be economically unviable or fail to reduce unwanted catches, fishers will be incentivised to develop alternative gears or adapt their fishing behaviour to mitigate the full impact of the landing obligation.

\subsection{Acknowledgements}

We are grateful to two anonymous reviewers who during the review process helped to improve the paper considerable. This work was funded through BAKASEL project by the Basque Government (Department of Environment, Regional Planning, Agriculture and Fisheries of the Basque Country). We thank the shipowners, skippers and the crew of the Gure Gaskuña and J Kalamendi for their help. We express our gratitude to Iñaki Quincoces for the facilitation of sea cruises during the ITSASTEKA 2012/2013 campaigns and to Julen Robles and $M^{\text {a }}$ Cruz Burgoa for the worked performed at port. The content of this paper does not reflect the official opinion of the European Commission. Responsibility for the information and views expressed in this paper relies entirely with the authors. 


\subsection{References}

Alonso-Fernández, A., DomínguezPetit, R., Bao, M., Rivas, C., and Saborido-Rey, F. 2008. Spawning pattern and reproductive strategy of female pouting Trisopterus luscus (Gadidae) on the Galician shelf of north-western Spain. Aquatic Living Resources, 21(4): 383-393.

Bellido, J. M., Santos, M. B., Pennino, M. G., Valeiras, X., and Pierce, G. J. 2011. Fishery discards and bycatch: Solutions for an ecosystem approach to fisheries management? Hydrobiologia, 670(1):317-333.

Briggs, R. P. 1992. An assessment of nets with a square mesh panel as a whiting conservation tool in the Irish Sea Nephrops fishery. Fisheries Research, 13 (2):133-152.

Broadhurst, M. K., Kangas, M. I., Damiano, C., Bickford, S. A., and Kennelly, S. J. 2002. Using composite square-mesh panels and the Nordmøregrid to reduce bycatch in the Shark Bay prawn-trawl fishery, Western Australia. Fisheries Research, 58(3):349-365.

Bullough, L. W., Napier, I. R., Laurenson, C. H., Riley, D., Fryer, R. J., Ferro, R. S. T., and Kynoch, R. J. 2007. A year-long trial of a square mesh panel in a commercial demersal trawl. Fisheries Research, 83(1):105-112.

Campos, A., Fonseca, P., and Erzini, K. 2003. Size selectivity of diamond and square mesh cod ends for four by-catch species in the crustacean fishery off the Portuguese south coast. Fisheries Research, 60(1):79-97.

Catchpole, T. L. and Revill, A. 2008. Gear technology in Nephrops trawl fisheries. Reviews in Fish Biology and Fisheries, 18(1):17-31.
Daan, N. 1997. TAC management in North Sea flatfish fisheries. Journal of Sea Research, 37(3-4):321-341.

Dorel, D. Poissons de l'Atlantique nordest: Relations taille-poids. Technical report, Institut Francais de Recherche pour l'Exploitation de la Mer, Nantes, France, 1986.

EC. 1996. Council Regulation (EC) No. 2406/96 of 26 November 1996 laying down common marketing standards for certain fishery products. Official Journal of the European Communities, L344/1.

EC. 2002. Commission regulation (EC) No 494/2002 of 19 March 2002 establishing additional technical measures for the recovery of the stock of hake in ICES sub-areas III, IV, V, VI and VII and ICES sub-areas VIII a, b, d and e. Official Journal of the European Communities, L77/8.

EC. 2006. Council Regulation (EC) No. 51/2006 of 22 December 2005 fixing for 2006 the fishing opportunities and associated conditions for certain fish stocks and groups of fish stocks, applicable in Community waters and, for Community vessels, in waters where catch. Official Journal of the European Communities, $\mathrm{L}(18): 148-149$.

Eigaard, O. R., Herrmann, B., and Nielsen, J. R. 2012. Influence of grid orientation and time of day on grid sorting in a small-meshed trawl fishery for Norway pout (Trisopterus esmarkii). Aquatic Living Resources, 25(1):15-26.

El Habouz, H., Recasens, L., Kifani, S., Moukrim, A., Bouhaimi, A., and El Ayoubi, S. 2011. Maturity and batch fecundity of the European hake (Merluccius merluccius, Linnaeus, 1758) in the eastern central Atlantic. Scientia Marina, 75(3):447-454. 
EU. Regulation (EU) No 1380/2013 of the European Parliament and of the Council of 11 December 2013 on the Common Fisheries Policy, 2013.

Feekings, J., Bartolino, V., Madsen, N., and Catchpole, T. 2012. Fishery discards: factors affecting their variability within a demersal trawl fishery. PLoS ONE, 7(4):e36409.

Fonseca, P., Campos, A., Mendes, B., and Larsen, R. B. 2005. Potential use of a Nordmøre grid for by-catch reduction in a Portuguese bottom-trawl multispecies fishery. Fisheries Research, 73 (1-2):49-66.

Fonteyne, R. and Polet, H. 2002. Reducing the benthos by-catch in flatfish beam trawling by means of technical modifications. Fisheries Research, 55(1-3):219230 .

Fonteyne, R., Buglioni, G., Leonori, I., O'Neill, F. G., and Fryer, R. J. 2007. Laboratory and field trials of OMEGA, a new objective mesh gauge. Fisheries Research, 85(1-2):197-201.

Frandsen, R. P., Holst, R., and Madsen, N. 2009. Evaluation of three levels of selective devices relevant to management of the Danish Kattegat-Skagerrak Nephrops fishery. Fisheries Research, 97 (3):243-252.

Garcia, S. M. and Cochrane, K. L. 2005. Ecosystem approach to fisheries: a review of implementation guidelines. ICES Journal of Marine Science, 62: 311-318.

Glass, C. W. and Wardle, C. S. 1995. Studies on the use of visual stimuli to control fish escape from codends. II. The effect of a black tunnel on the reaction behaviour of fish in otter trawl codends. Fisheries Research, 23(1-2):165-174.

Graham, N. and Kynoch, R. J. 2001. Square mesh panels in demersal trawls: some data on haddock selectivity in relation to mesh size and position. Fisheries Research, 49:107-218.

Graham, N., Kynoch, R. J., and Fryer, R. J. 2003. Square mesh panels in demersal trawls: further data relating haddock and whiting selectivity to panel position. Fisheries Research, 62(3):361375 .

Graham, N., O'Neill, F. G., Fryer, R. J., Galbraith, R. D., and Myklebust, A. 2004. Selectivity of a $120 \mathrm{~mm}$ diamond cod-end and the effect of inserting a rigid grid or a square mesh panel. Fisheries Research, 67(2):151-161.

Graham, N., Ferro, R. S. T., Karp, W. A., and Macmullen, P. 2007. Fishing practice, gear design, and the ecosystem approach - three case studies demonstrating the effect of management strategy on gear selectivity and discards. ICES Journal of Marine Science, 64: 744-750.

Grimaldo, E., Larsen, R. B., and Holst, R. 2007. Exit Windows as an alternative selective system for the Barents Sea Demersal Fishery for cod and haddock. Fisheries Research, 85(3):309-319.

Hering, D., Borja, A., Carstensen, J., Carvalho, L., Elliott, M., Feld, C. K., Heiskanen, A. S., Johnson, R. K., Moe, J., Pont, D., Solheim, A. L., and van de Bund, W. 2010. The European Water Framework Directive at the age of 10: A critical review of the achievements with recommendations for the future. Science of The Total Environment, 408 (19):4007-4019.

Herrmann, B., Krag, L. A., and Frandsen, R. P. 2009. Prediction of selectivity from morphological conditions: methodology and a case study on cod (Gadus morhua). Fisheries Research, 97:59-71.

Herrmann, B., Sistiaga, M., Nielsen, K. N., and Larsen, R. B. 2012. Un- 
derstanding the size selectivity of redfish (Sebastes spp.) in North Atlantic trawl codends. Journal of Northwest Atlantic Fishery Science, 44:1-13.

Herrmann, B., Sistiaga, M., Larsen, R. B., and Nielsen, K. N. 2013. Size selectivity of redfish (Sebastes spp.) in the Northeast Atlantic using grid-based selection systems for trawls. Aquatic Living Resources, 26:109-120.

Herrmann, B., Wienbeck, H., Karlsen, J. D., Stepputtis, D., Dahm, E., and Moderhak, W. 2015. Understanding the release efficiency of Atlantic cod (Gadus morhua) from trawls with a square mesh panel: effects of panel area, panel position, and stimulation of escape response. ICES Journal of Marine Science, 72(2): 686-696.

Iriondo, A., Prellezo, R., Santurtún, M., Garcia, D., and Quincoces, I. 2008. Basque trawl metier definition for 20032007 period. Revista de Investigacion Marina, 3:263-264.

Iriondo, A., Prellezo, R., Santurtún, M., García, D., Quincoces, I., and Mugerza, E. 2010. A multivariate approach for metier definition: A case study of Basque Country trawlers. Revista de Investigacion Marina, 17(6):140-148.

Larsen, R. B. and Isaksen, B. 1993. Size selectivity od rigid grids in bottom trawls for Atlantic cos (Gadus morhua) and haddock (Melanogrammus aeglefinus). ICES Mar. Sci. Symp., 196:178182.

Madsen, N. 2007. Selectivity of fishing gears used in the Baltic Sea cod fishery. Reviews in Fish Biology and Fisheries, 17:517-544.

Madsen, N. and Stæhr, K. J. 2005. Selectivity experiments to estimate the effect of escape windows in the Skagerak roundfish fishery. Fisheries Research, 71 (2):241-245.
Madsen, N., Holst, R., and Foldager, L. 2002. Escape windows to improve the size selectivity in the Baltic cod trawl fishery. Fisheries Research, 57(3):223235.

Mahé, K., Destombes, A., Coppin, F., Koubbi, P., Vaz, S., Le Roy, D., and Carpentier, A. 2005. Le rouget barbet de roche Mullus surmuletus (L. 1758) en Manche orientale et mer du Nord. Final report, page 186 .

McClanahan, T. R. 2010. Effects of fisheries closures and gear restrictions on fishing income in a Kenyan coral reef. Conservation Society, 24(6):1519-28.

Metin, C., Özbilgin, H., Tosunoglu, Z., Gökçe, G., Aydin, C., Metin, G., Ulas, A., Kaykaç, H., Lök, A., Düzbastilar, F. O., and Tokaç, A. 2005. Effect of Square Mesh Escape Window on Codend Selectivity for Three Fish Species in the Aegean Sea. Turkish Journal of Veterinary and Animal, 29:461-468.

Nikolic, N., Diméet, J., Fifas, S., Salaün, M., Ravard, D., Fauconnet, L., and Rochet, M. J. 2015. Efficacy of selective devices in reducing discards in the Nephrops trawl fishery in the Bay of Biscay. ICES Journal of Marine Science, 72 (6):1869-1881.

O'Neill, F. G., Kynoch, R. J., and Fryer, R. J. 2006. Square mesh panels in North Sea demersal trawls: Separate estimates of panel and cod-end selectivity. Fisheries Research, 78:333-341.

Özbilgin, H., Eryaşar, A. R., Gökçe, G., Özbilgin, Y. D., Bozaoğlu, A. S., Kalecik, E., and Herrmann, B. 2015. Size selectivity of hand and machine woven codends and short term commercial loss in the Northeastern Mediterranean. Fisheries Research, 164:73-85.

Rochet, M. J., Arregi, L., Tereza, F., Pereira, J., Perez, N., Ruiz Gondra, J., and Valeiras, J. 2014. Demersal 
discard atlas for the South Western Waters. Report, page 121. URL http://www.repositorio.ieo.es/eieo/handle/10508/9074.

Rosen, S., Engas, A., Ferno, A., and Jorgensen, T. 2012. Implications for Commercial Trawling. ICES Journal of Marine Science, 69(2):303-312.

Sala, A., Lucchetti, A., Perdichizzi, A., Herrmann, B., and Rinelli, P. 2015. Is square-mesh better selective than larger mesh? A perspective on the management for Mediterranean trawl fisheries. Fisheries Research, 161:182-190.

Santurtún, M., Prellezo, R., Arregi, L., Iriondo, A., Aranda, M., Korta, M., Onaindia, I., Garcia, D., Merino, G., Ruiz, J., and Andonegi, E. 2014. Characteristics of multispecific fisheries in the European Union. STUDY IPBPECHIC2013 088. URL https://www.researchgate. net/publication/266082516.

Sistiaga, M. Selectivity studies in the Barents Sea bottom trawl gadoid fishery: Gear and methods. PhD thesis, UNIVERSITY OF TROMSØ, 2010.

Suuronen, P. and Sarda, F. 2007. The role of technical measures in European fisheries management and how to make them work better. ICES Journal of Marine Science, 664:756-771.

Tschernij, V., Suuronen, P., Ministerrad, N., and Nordisk, R. 2002. Im- proving trawl selectivity in the Baltic. Utokning av tralselektion $i$ Ostersjon. TemaNord, 512:56.

Uhlmann, S. S., van Helmond, A. T. M., Kemp Stefánsdóttir, E., Sigurǒardóttir, S., Haralabous, J., Bellido, J. M., Carbonell, A., Catchpole, T., Damalas, D., Fauconnet, L., Feekings, J., Garcia, T., Madsen, N., Mallold, S., Margeirsson, S., Palialexis, A., Readdy, L., Valeiras, J., Vassilopoulou, V., and Rochet, M. J. 2013. Discarded fish in European waters: general patterns and contrasts. ICES Journal of Marine Science, 71(5): 1235-1245.

Wienbeck, H., Herrmann, B., Feekings, J. P., Stepputtis, D., and Moderhak, W. 2014. A comparative analysis of legislated and modified Baltic Sea trawl codends for simultaneously improving the size selection of cod (Gadus morhua) and plaice (Pleuronectes platessa). Fisheries Research, 150(2187):28-37.

Wileman, D. A., Ferro, R. S. T., Fonteyne, R., Millar, R. B., and (Ed.). 1996. Manual of methods of measuring the selectivity of towed fishing gears. ICES Cooperative Research Report, 215.

Zuur, G., Fryer, R. J., Ferro, R. S. T., and Tokai, T. 2001. Modelling the size selectivities of a trawl codend and an associated square mesh panel. ICES Journal of Marine Science, 58(3):657-671. 



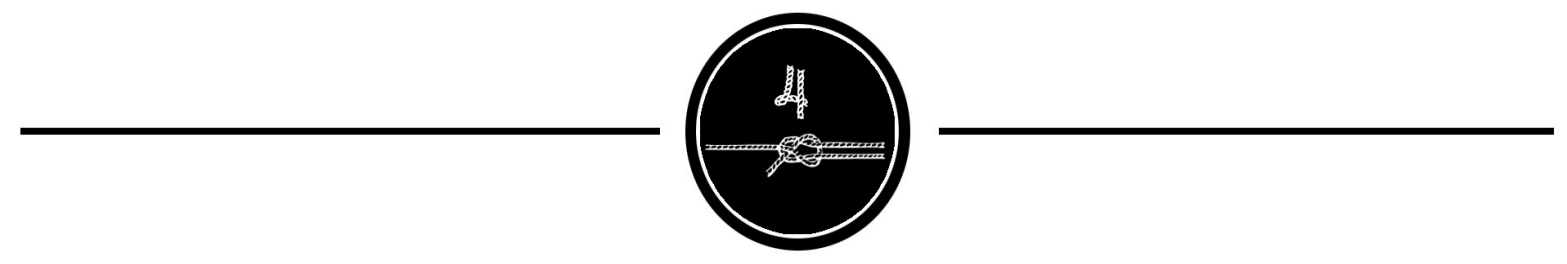

- LIKELY STATUS AND CHANGES UNDER DIFFERENT DISCARD SCENARIOS:

THE BASQUE TRAWL FISHERY CASE STUDY.

N. ALZORRIZ, E. JARDIM AND J.J.POOS

FISHERIES RESEARCH 205 (2018) 86-95 


\subsection{Abstract}

We modelled fleet dynamics and the economic impact of three implementations of the EU landing obligation for fisheries, and contrasted the results with those obtained under a scenario of no landing obligation. Simulations were performed using a dynamic state variable model of effort allocation for the Basque trawl fleet, assuming that the landing obligation had been implemented in 2012. The three implementations of the landing obligation involved different policy arrangements: (i) quota increases; (ii) international swapping of quotas; and (iii) inter-species quota flexibility. All three scenarios resulted in changes to fishing patterns caused by choke species and improved selectivity of harvest, but also resulted in a negative short-term impact on the economic performance of the fleet. We report average reductions in net revenue of up to $60 \%$ when compared with results obtained under a no landing obligation scenario. Our model results suggested that these negative short-term impacts could be alleviated by incorporation of inter-species quota flexibility in the implementation of the landing obligation. Our results indicate that there will be a strong incentive to use this policy arrangement to alleviate the choke effect problem where species with limiting quotas constrain the fishery.

Keywords:

Discards,

Landing obligation,

Fleeet dynamics,

Effort allocation,

Bay of Biscay,

Basque trawl mixed fishery. 


\subsection{Introduction}

All current European policy frameworks for the marine environment are aimed at the progressive implementation of an ecosystem approach to fisheries, to ensure a stable, secure, and healthy food supply for EU citizens. An important component of the new EU fisheries policy is the introduction of a landing obligation (also known as a discard ban) prohibiting the at-sea disposal of commercially valuable species (Article 15 in EU, 2013; Borges, 2015). Since 2015 all catches of quota-regulated species must be recorded and limited by species-specific total allowable catches (TACs). Furthermore, fishing vessels must have adequate quotas for all species they are likely to catch during the course of their operations. Once a quota for any stock is exhausted, the fisheries are either restricted or closed, even if quotas are still available for other species.

The purpose of the landing obligation is twofold: to create economic incentives for the industry to reduce the capture of unwanted species and undersized individuals through improvements in selectivity (KindtLarsen et al., 2011; Mangi and Catchpole, 2014) and to improve accuracy in recording catches (FAO, 1996). However, in mixed fisheries, there is a potential mismatch between allocated TACs for different species and their catch distribution (Kraak et al., 2013; Poos et al., 2010). While the ecological and economic effects of the landing obligation are unknown for many mixed fisheries, it is likely that fishing fleets will respond adaptively to the new policy, and will attempt to sustain viable fisheries under the new policy constraints (Alzorriz et al., 2016; Batsleer et al., 2016). This will likely occur via the development and adoption of selective devices (Alzorriz et al., 2016; Catchpole and Gray, 2010; Kindt-Larsen et al., 2011) or adjustments in fishing behaviour (Batsleer et al., 2016; Condie et al., 2014; Prellezo et al., 2016b; Simons et al., 2015).

A total discard ban may compromise the profitability of some discardintensive fisheries (at least in the short term) because retaining, manipulating and landing size categories or species that were previously discarded will reduce income-per-unit-effort (Condie et al., 2014). However, Article 15 of the Common fisheries Policy (CFP) states that the following flexibilities and exemptions to the landing obligation will be accommodated: de-minimis exemption of up to $5 \%$ of the total annual quota to be discarded under certain circumstances (and up to $7 \%$ and 
$6 \%$ in the first two years respectively), quota swaps between EU member states, banking and borrowing (year-to-year transfer) of quotas, and inter-species quota flexibility allowing up to $9 \%$ of the quota for one species to be used for landing another species (EU, 2013).

The Spanish trawl fleet operating in the Bay of Biscay, and particularly that of the Basque country, comprises vessels using either bottom otter trawl (OTB) or high vertical opening pair bottom trawl (PTB; Iriondo et al. (2008)). The trawlers using OTB fishing gear are able to exploit a mix of species, with the main target species being anglerfish (Lophius budegassa and Lophius piscatorius), megrim (Lepidorhombus whiffiagonis), and hake (Merluccius merluccius). Depending on the season and quota availability, this fleet also targets red mullet (Mullus surmuletus), squids (Loligo spp.), pouting (Trisopterus spp.), sole (Solea solea), horse mackerel (Trachurus trachurus) and mackerel (Scomber scombrus; (Iriondo et al., 2008)). The fleet using PTB mainly targets hake (80$85 \%$ of total catch). In these fleets, discarding of target and bycatch species can be substantial. For example, in 2012, discards represented about $60 \%$ and $15 \%$ by weight of the total estimated catch of OTB and PTB, respectively $(12,991 \mathrm{t}$ and 6,622 t, respectively; Rochet et al., 2014). Around $80 \%$ of the discards are discarded to adhere to fishing regulations. Vessels in this fishery discard catch when there is a lack of quota for certain species (mackerel), when captured individuals are smaller than the minimum landing size (hake), or in the absence of a market (horse mackerel and blue whiting whiting (Micromesistius poutassou) (Rochet et al., 2014). These activities typify multi-species fisheries: species with restrictive quotas are discarded to maximize the quota use for species with ample quotas (Batsleer et al., 2015). The introduction of the landing obligation is thus expected to negatively affect the fishery as it will reduce the short-term economic flexibility provided by discarding as a means of accommodating several quota species for which single-species quotas are set.

Here we use a dynamic state variable model (Clark and Mangel, 2000) and data on the fishing activities of Basque trawlers in the Bay of Biscay from 2003 to 2012, to project the likely effects of a landing obligation in this multispecies, quota-regulated, fishery. Using ecological and economic indicators, we compare the response of the fleets under a scenario that permits discards (the existing policy, Scenario I) to three landing 
obligation scenarios, involving a complete discard ban with quota increases (Scenario II), international quota swaps (Scenario III), or use of inter-species quota flexibility (Scenario IV).

\subsection{Methods}

\section{The Basque trawl fishery}

Data for Basque trawlers for the period 2003 to 2012 were collected under the EC Data Collection Framework (EC, 2008). Trawlers averaged $37 \mathrm{~m}$ in length, with an average engine power of $465 \mathrm{~kW}$. As described above, trawlers used two gear types (OTB and PTB) and fished in one of three fishing areas (Figure 4.1; ICES sub-areas 6, 7 and 8 [divisions 8a, $8 \mathrm{~b}$, and $8 \mathrm{~d}$, which we refer to as sub-area 8 for simplicity]). Vessels with OTB fishing gear fished in all sub-areas, while those with PTB fishing gear fished in sub-area 8 only. We compiled data for four stocks (northern hake, megrim, northeast Atlantic mackerel, western horse mackerel) that are likely to be affected by a landing obligation policy because they are managed under TAC constraints, and in some cases show evidence of high discard rates. We compiled data on catches of other fish species (e.g. anglerfish, red mullet, squids, pouting, sole, conger (Conger conger), blue whiting, haddock, skates and nephrops) as a single group (which we refer to as "others"). Catches of the four stocks amounted to $95 \%$ of the total landings of these fleets and $98 \%$ of gross revenue. Catches of the "others" group contributed to the gross revenue of the fleet, but did not constrain their fishing opportunities. These data were used to estimate seasonal size-structured landings, discards, and fishing effort. Catches were size structured using the regulatory Minimum Conservation Reference Size (MCRS; EC, 1998), apart from the "others" group that was simply categorized as either discards or landings. MCRS for hake, megrim, mackerel and horse mackerel were $27 \mathrm{~cm}, 20$ $\mathrm{cm}, 20 \mathrm{~cm}$ and $15 \mathrm{~cm}$ respectively.

From 2003 to 2012, 8,669 trips were undertaken by the fleet (Table 4.1). Trips generally lasted $6-7$ days. Average catch was 19,000 tonnes per year. Average weight of discards was approximately 6,800 tonnes, $13 \%$ of which was discarded because individuals were below MCRS guidelines (Table 4.1). Catches of different species and size classes varied with season, fishing gear and fishing area. The fishing effort per vessel and per season varied with the type of fishing gear used and the fishing area 
Figure 4.1:

Study area in the Bay of Biscay showing the fishing areas where the Basque trawler fleet operates.

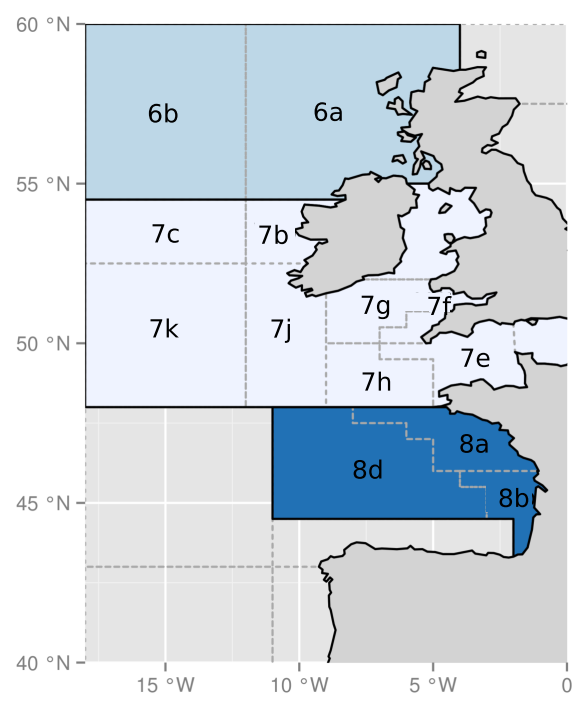

(Table 4.2).

Table 4.1: Summary statistics describing fishing activities for the Basque trawl vessels from 2003 to 2012. Shown are annual average values and their standard deviations (in brackets), aggregated by fishing area (sub-area 8: divisions $8 \mathrm{a}, 8 \mathrm{~b}$, and $8 \mathrm{~d}$ ) and type of fishing gear used (OTB: bottom otter trawl, PTB: high vertical opening pair bottom trawl). "n" gives the number of trips).

\begin{tabular}{lccccc}
\hline variables & $\begin{array}{c}\text { OTB } \\
\text { VI } \\
(\mathbf{n = 7 2 4})\end{array}$ & $\begin{array}{c}\text { OTB } \\
\text { VII } \\
(\mathbf{n}=\mathbf{5 7 8})\end{array}$ & $\begin{array}{c}\text { OTB } \\
\text { VIIIabd } \\
(\mathbf{n = 4 5 7 4})\end{array}$ & $\begin{array}{c}\text { PTB } \\
\text { VIIIabd } \\
(\mathbf{n = 2 7 9 3})\end{array}$ & $\begin{array}{c}\text { Total } \\
(\mathbf{n}=\mathbf{8 6 6 9})\end{array}$ \\
\hline $\begin{array}{l}\text { Trip characteristics } \\
\text { number of trips }\end{array}$ & $69(5)$ & $58(19)$ & $434(28)$ & $557(48)$ & $1110(88)$ \\
number of vessel & $3(1)$ & $5(5)$ & $13(3)$ & $13(6)$ & $15(4)$ \\
number of fishing days (days) & $443(46)$ & $405(131)$ & $2164(126)$ & $2499(349)$ & $5511(605)$ \\
& & & & & \\
Catch composition & & & & & \\
total catch (t) & $874(52)$ & $1225(332)$ & $10192(565)$ & $7140(340)$ & $19290(663)$ \\
landings (t) & $806(50)$ & $754(192)$ & $4567(264)$ & $6406(385)$ & $12492(423)$ \\
discards(t) & $85(18)$ & $624(165)$ & $5628(555)$ & $734(96)$ & $6798(520)$ \\
$<$ MCRS* $(\%)$ & $1(1)$ & $3(1)$ & $14(2)$ & $13(2)$ & $13(2)$ \\
& & & & & \\
\hline
\end{tabular}

* Minimum Conservation Reference Size

Information about the cost structure of Basque trawlers was obtained from accounting data (Prellezo et al., 2016a). The variable costs represented around $86 \%$ of the total costs, and included fuel costs $(\sim 40 \%)$, crew share $(\sim 35 \%)$, gear mantainance $(\sim 4 \%)$, and landing costs $(\sim$ 
Table 4.2:

Fishing effort in the four study areas and four seasons.

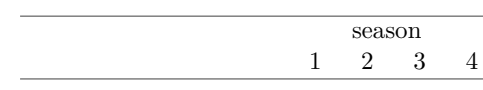

Fishing effort (days)

VI OTB

VII OTB

VIIIabd OTB

VIIIabd PTB

$\begin{array}{llll}59 & 65 & 26 & 39 \\ 38 & 47 & 28 & 28 \\ 64 & 54 & 22 & 58 \\ 62 & 61 & 40 & 62\end{array}$

$5 \%$, including cost associated with handling, transport, boxes and ice. Fuel costs depended on gear used, trip effort and fuel price. Fuel costs were estimated to be approximately 1,240 Łday $^{-1}$ (Prellezo et al., 2016a). Gear maintenance costs were assumed proportional to fishing effort, landing costs proportional to the total weight landed, and crew share variable costs proportional to the landings income. The price of the marketable catch of each species was calculated from the 2012 sales slip data. In the model, prices were assumed to be constant over time and independent of supply (Table 4.3).

Table 4.3:

Economic parameter values used in the state-dependent dynamic model.

\begin{tabular}{|c|c|c|c|c|}
\hline Variable costs & & & & \\
\hline $\begin{array}{l}\text { fuel costs }\left(€ \text { day }^{-1}\right) \\
\text { gear maintenance }\left(€ \text { day }^{-1}\right) \\
\text { crew share } \\
\text { landing costs }\left(€ \mathrm{t}^{-1}\right)\end{array}$ & & $\begin{array}{r}1,2 \\
2 \varnothing \\
35 \\
12\end{array}$ & & \\
\hline \multirow[t]{2}{*}{ Market value $\left(€ \mathrm{~kg}^{-1}\right)$} & \multicolumn{4}{|c|}{ season } \\
\hline & 1 & 2 & 3 & 4 \\
\hline hake & 2.5 & 2.9 & 1.9 & 2.4 \\
\hline megrim & 5.3 & 4.6 & 4.9 & 5.0 \\
\hline mackerel & 0.7 & 1.9 & 0.7 & 0.7 \\
\hline horse mackerel & 0.7 & 1.0 & 1.3 & 1.7 \\
\hline "others" & 3.0 & 2.3 & 2.8 & 3.3 \\
\hline
\end{tabular}

\section{Catch quota calculations}

The Basque trawl fleet was managed through total allowable landings (TALs) and total allowable effort (TAE), as well as other technical and physical measures (Iriondo et al., 2013). During the study period, fishing effort was not constraining by the TAE due to historical reductions in the fleet size (Iriondo et al., 2008; Prellezo et al., 2016a). The EU allocates landing quota TALs across Member States are based on the principle of relative stability (Table 4.4 for 2012) (EU, 2013). Quotas, 
or parts of, could be swapped between Member States, to accommodate annual fishing opportunities distinct from those provided by the relative stability principle. Spanish quotas (B in Table 4.4)) were divided over vessels based on fixed individual shares (BOE, 2012). Summing the individual shares of the Basque vessels resulted in the Basque fleet TALs (C in Table 4.4). The TALs did not consider discards since there were no penalties for discarding over-quota fish. Within Spain, quotas could also be swapped among vessels. The average and variance of the Spanish quota swaps during the period 2009 to 2012 were estimated from Fishery Data Exchange System (FIDES; D in Table 4.4). The inter-annual variation of Spanish quota swapping during this period was lower than the average for hake, but higher than the average for other species. Spanish international quota swaps thus play an important role in defining fishing opportunities for the Basque trawl fleets ( $\mathrm{G}$ in Table 4.4).

Table 4.4: Quota estimation for the four selected stocks (in 1000s of tonnes, '000 t). The capital letter in the calculation column refer to the letters in the indicator column. Quotas for the "others" group is not estimated because it consists of multiple fish stocks which do not necessarily have Total Allowable Catch (TAC) limitations.

\begin{tabular}{|c|c|c|c|c|c|c|}
\hline 2012 & indicator & calculation & hake & megrim & mackerel & $\begin{array}{c}\text { horse } \\
\text { mackerel }\end{array}$ \\
\hline \multicolumn{7}{|c|}{ Stauts quo quota ('000 t) } \\
\hline Europe TAL* & A & & 51.5 & 19.1 & 259.1 & 158.0 \\
\hline Spanish TAL & B & & 62.3 & 21.7 & 265.1 & 163.2 \\
\hline Basque TAL & $\mathrm{C}$ & & 4.6 & 1.1 & $5.0 \times 10-3$ & 4.9 \\
\hline \multicolumn{7}{|c|}{ International quota swaps (\%) } \\
\hline Spanish quota swaps & $\mathrm{D}$ & & $30 \pm 1$ & $4 \pm 8$ & $8 \pm 11$ & $-79 \pm 10$ \\
\hline \multicolumn{7}{|c|}{ ICES Stock assessment data ('000 t $)^{*}$} \\
\hline Total landings & $\mathrm{E}$ & & 85.6 & 12.7 & 186.8 & 169.9 \\
\hline Total catches & $\mathrm{F}$ & & 100.5 & 15.7 & 197.3 & 173.1 \\
\hline Total discards & G & & 14.9 & 3.0 & 10.5 & 3.2 \\
\hline \multicolumn{7}{|c|}{ Quota scenarios for Basque trawlers ('000 t) } \\
\hline TAL after int swaps & $\mathrm{H}$ & $\left(\mathrm{C}^{*}(1+\mathrm{D} / 100)\right)$ & 5.9 & 0.9 & $7.0 \times 10-3$ & 1.6 \\
\hline TAC without swaps & I & $\left(\mathrm{C}+\left(0.75^{*}(\mathrm{C} / \mathrm{A})^{*} \mathrm{G}\right)\right.$ & 5.6 & 1.2 & $5.0 \times 10-3$ & 5.1 \\
\hline TAC after int swaps & $\mathrm{J}$ & $\left(\mathrm{H}+\left(0.75^{*}(\mathrm{H} / \mathrm{A})^{*} \mathrm{G}\right)\right.$ & 7.3 & 1.2 & $6.0 \times 10-3$ & 1.7 \\
\hline TAC after int-sp swaps & $\mathrm{K}$ & $\left(\mathrm{I} \pm 0.1^{*} \mathrm{I}\right)$ & 5.6 & 1.1 & $\begin{array}{c}0.5 \\
\text { (incl. } 10 \% \text { hom) }\end{array}$ & 4.6 \\
\hline \multicolumn{7}{|c|}{ Basque trawlers catches 2012 ('000 t) } \\
\hline landings & $\mathrm{L}$ & & 5.9 & 0.1 & $7.3 \times 10-2$ & 0.2 \\
\hline catches & M & & 6.2 & 0.1 & 1.9 & 2.3 \\
\hline
\end{tabular}

Under the reform of the CFP, total allowable catch quotas (TACs) replace the existing TALs. Depending on the landing obligation implementation calendar, TACs will increase to account for the catch of previously discarded fish. The quota increases for the four selected stocks 
were limited to $75 \%$ of the estimated discards by stock, to account for uncertainty in discard estimates, following Condie et al. (2014). Consequently, the Basque fleet TACs were set by increasing landing quotas by $75 \%$ of the stock-specific discards from 2009 to 2012. These discards were estimated from ICES (ICES (2013a,b); see stock-specific average landings and catches, $\mathrm{E}$ and $\mathrm{F}$ in Table 4.4).

\section{The dynamic-state variable model}

A dynamic state variable model (Clark and Mangel, 2000; Houston and McNamara, 1999) was used to model fishing choices, extending the model structure in Batsleer et al. (2015). To accommodate the range of quota flexibility and exemptions proposed (EU, 2013), the model incorporated annual fines for exceeding landings or catch quota as in Batsleer et al. (2015, 2016). Each individual vessel in the model had a set of choices. The choices included whether or not to go fishing in one of the three areas, which fishing gear to use, and whether to discard one or more species and size-class combinations. In order to calculate statedependent choices during the year, we started by defining the annual fines for exceeding landings or catch quotas at the end of the year:

$$
\Phi\left(C_{i}, Q_{i}, F_{i}\right)=-\sum_{i}\left(\max \left(0,\left(C_{i}-Q_{i}\right)\right) * F_{i}\right), \quad . \quad . \quad .
$$

where $C_{i}$ was the cumulative annual landings or catches for species $i$ for an individual vessel. These cumulative landings defined the state of the individual. $Q_{i}$ was the annual individual quota for landings or catches for the quota species. Individual quotas were not transferable. To reduce computation time, we set quotas only for two species. $F_{i}$ was the fine per unit weight for exceeding individual landings or catch quotas was set to $1 \times 10^{6} €_{\text {day }}^{-1}$. These high fines combined with an assumed $100 \%$ detection of exceeding quotas resulted in model results in which fishers comply with quota regulations.

The maximum expected utility between current time $t$ and the end of the year was $V\left(C_{i}, Q_{i}, F_{i}, t\right)$, and the model started by setting $V\left(C_{i}, Q_{i}, F_{i}, t\right)=$ $\Phi\left(C_{i}, Q_{i}, F_{i}\right)$. For preceding times, the expected utility depended on individual choices, and at each time step individuals chose to visit fishing area $a$ (including area 0: "staying in port"), with gear $g$, and to keep or discard any combination of the size classes caught of the quota species. 
Discarding was defined by a matrix, $d$, whose size was defined by the number of species under quota constraints and the number of size classes. Each element could take the value 0 (discard) or 1 (keep on board and land). The expected utility for each state and each time step $t$ was calculated backward using stochastic dynamic programming (Clark and Mangel, 2000):

$$
V\left(C_{i}, Q_{i}, F_{i}, t\right)=\max _{a, g, d}\left(R(a, g, d, t)-G(a, g)-C(a, g)+E_{a, g, d}\left[V\left(C_{i}^{\prime}, Q_{i}, F_{i}, t+1\right]\right)\right),
$$

where $R(a, g, d, t)$ was the expected immediate contribution of the gross revenue from the sales of fish in a season resulting from choices $a, g$, and $d$. Gross revenues resulted from multiplying catches by size class of hake, megrim, mackerel, horse mackerel, and "others" by their prices. $G(a, g)$ represented the incurred fuel costs per season for fishing area $a$ with gear $g$, while $C(a, g)$ represented the variable operating costs (crew share, gear maintenance and landing costs), which in turn depended on the change in cumulative landings and fish prices. The term $E_{a, g, d}\left[V\left(C_{i}^{\prime}, Q_{i}, F_{i}, t+1\right]\right.$ denoted the expected future utility taken over all possible states resulting from choices $a, g$, and $d$. The transition of these states was based on normal distributions of catch rates, using means and variances for the species, as explained in the model conditioning section, following Poos et al. (2010).

Rather than assume that each individual always made the optimal choice, we assigned a probability to each choice proportional to its expected utility, following Dowling et al. (2012). The expected utility for any choice was

$$
U\left(C_{i}, Q_{i}, F_{i}, t\right)=R(a, g, d, t)-G(a, g)-C(a, g)+E_{a, g, d}\left[V\left(C_{i}^{\prime}, Q_{i}, F_{i}, t+1\right]\right),
$$

If $U^{*}$ was the expected utility at the optimal choice for a given $t$, we set

$$
\Delta_{a, g, d}\left(C_{i}, Q_{i}, F_{i}, t\right)=U^{*}\left(C_{i}, Q_{i}, F_{i}, t\right)-U\left(C_{i}, Q_{i}, F_{i}, t\right), \quad .
$$

and then defined the probability of a choice for a given area and discarding as

$$
P_{a, g, d}\left(C_{i}, Q_{i}, F_{i}, t\right)=\frac{e^{-\Delta_{a, g, d}\left(C_{i}, Q_{i}, F_{i}, t\right) / \sigma}}{\sum_{a} \sum_{g} \sum_{d} e^{-\Delta_{a, g, d}\left(C_{i}, Q_{i}, F_{i}, t\right) / \sigma}}, \ldots .
$$

where $\sigma$ was a tuning parameter that measured how important it was to be near the optimal choice. A large $\sigma$ resulted in uniform probabilities 
of choices, with vessels being distributed uniformly across the different fishing areas. In contrast, a small $\sigma$ forces vessels to concentrate in the optimal location (but note that $\sigma$ should be $>0$ ). For computations, we used $\sigma=1.1 \times 10^{5}$. This value was chosen based on outcomes of initial runs, so that the distribution of the fishing area choices reflected the observed distribution.

The dynamic state variable model was solved by iterating backwards in time, while finding the probability distribution choice in terms of location and discarding behaviour for all possible states, and combining the net revenue obtained from the sale of fish and the costs of a fishing trip and the effect of the annual fines when exceeding annual quota. Further details for this procedure can be found in Batsleer et al. (2016) and Dowling et al. (2012). Once the backward calculations were finished, we performed a Monte Carlo simulation where the probabilities of choices were sampled randomly using Eq. 4.5. This was done for 1,500 individual vessels. When necessary, for example, in the case of estimating the modelled seasonal effort in 2012, 15 out of the full set of 1,500 vessels were randomly selected to characterise the fleet in that year.

\section{Model conditioning and validation}

Averages and variances of catch rates per vessel in 2012 were used to validate the model. Those values were estimated for the two gear types and three areas based on time series of landings and discards. Two size classes were distinguished for the four stocks: individuals smaller than MCRS guidelines and those equal to or larger than MCRS guidelines. The fishing effort per vessel and season depended on the gear used and fishing area, and was estimated from the 2012 effort data for each fleet. Validation of the effort distribution using dynamic effort allocation was obtained by comparing the predicted effort allocation with the observed allocation in 2012. The model fit to the data was evaluated using the Pearson product-moment correlation coefficient between the observed and predicted effort allocation by gear and area across all seasons.

For the comparison among implementation scenarios, quarterly averages and variances of catch rates per vessel from the entire 10-year study period were entered into the model (estimated for the two fleets as described above; Fig. 4.2). We chose this larger time-span for the comparison of scenarios because the 2012 data used for model validation 
were not fully representative of Basque fishing opportunities (due to the absence of fishing activities in sub-area 7). Fishing effort per vessel and season depended on the gear used and fishing area, and was estimated from the fleets' effort time series (Table 4.2).

The price for undersized fish was set to $0 € \mathrm{~kg}^{-1}$ when discarding was allowed. Under the landing obligation, this fraction of the catch must be landed and will be used for non-human consumption (e.g. fish-meal production). As such, the value of fish smaller than MCRS guidelines was set to $0.2 € \mathrm{~kg}^{-1}$ when discarding is prohibited, which was similar to values used by Batsleer et al. (2016), but substantially lower than the current prices for marketable fish in this fishery (Prellezo et al., 2016b).

\section{Discard scenarios and potential limiting species approach}

Four scenarios based on the quota estimates in Table 4.4 were examined in the model. A ratio indicator between quotas and landings or catches indicated potentially limiting species in each of these scenarios (Table 4.5). Ratios $>1$ indicated that the quota was not sufficient to account for the landings or catches, potentially constraining the fishery. For each scenario the two most constraining species were selected to limit fishing opportunities.

Table 4.5: Ratios of the landings and catch to the final quota allocation for each of the landing obligation implementations (scenarios I to IV). Quotas and catches from 2012 are used as the reference. Capital letters in indicators column refer to indicators in Table 4. Ratios above 1 are in bold and indicate that the final catch quota would not have been sufficient to account for the Basque trawlers catches.

\begin{tabular}{llccccc}
\hline Scenarios & Ratio based on & indicators & hake & megrim & mackerel & $\begin{array}{c}\text { horse } \\
\text { mackerel }\end{array}$ \\
\hline I & $\frac{\text { Basque landings }}{\text { TAL after int swaps }}$ & $(\mathrm{L} / \mathrm{H})$ & $\mathbf{1 . 0 0}$ & 0.14 & $\mathbf{1 0 . 4 3}$ & 0.14 \\
II & $\frac{\text { Basque catches }}{\text { TAC }}$ & $(\mathrm{M} / \mathrm{I})$ & $\mathbf{1 . 1 2}$ & 0.11 & $\mathbf{3 6 4 . 1 3}$ & 0.45 \\
III & $\frac{\text { Basque catches }}{\text { TAC after int swaps }}$ & $(\mathrm{M} / \mathrm{J})$ & 0.86 & 0.11 & $\mathbf{2 9 8 . 4 7}$ & $\mathbf{1 . 3 5}$ \\
IV & $\frac{\text { Basque catches }}{\text { TAC after int-sp swaps }}$ & $(\mathrm{M} / \mathrm{K})$ & $\mathbf{1 . 1 2}$ & 0.12 & $\mathbf{3 . 6 4}$ & 0.49 \\
\hline
\end{tabular}




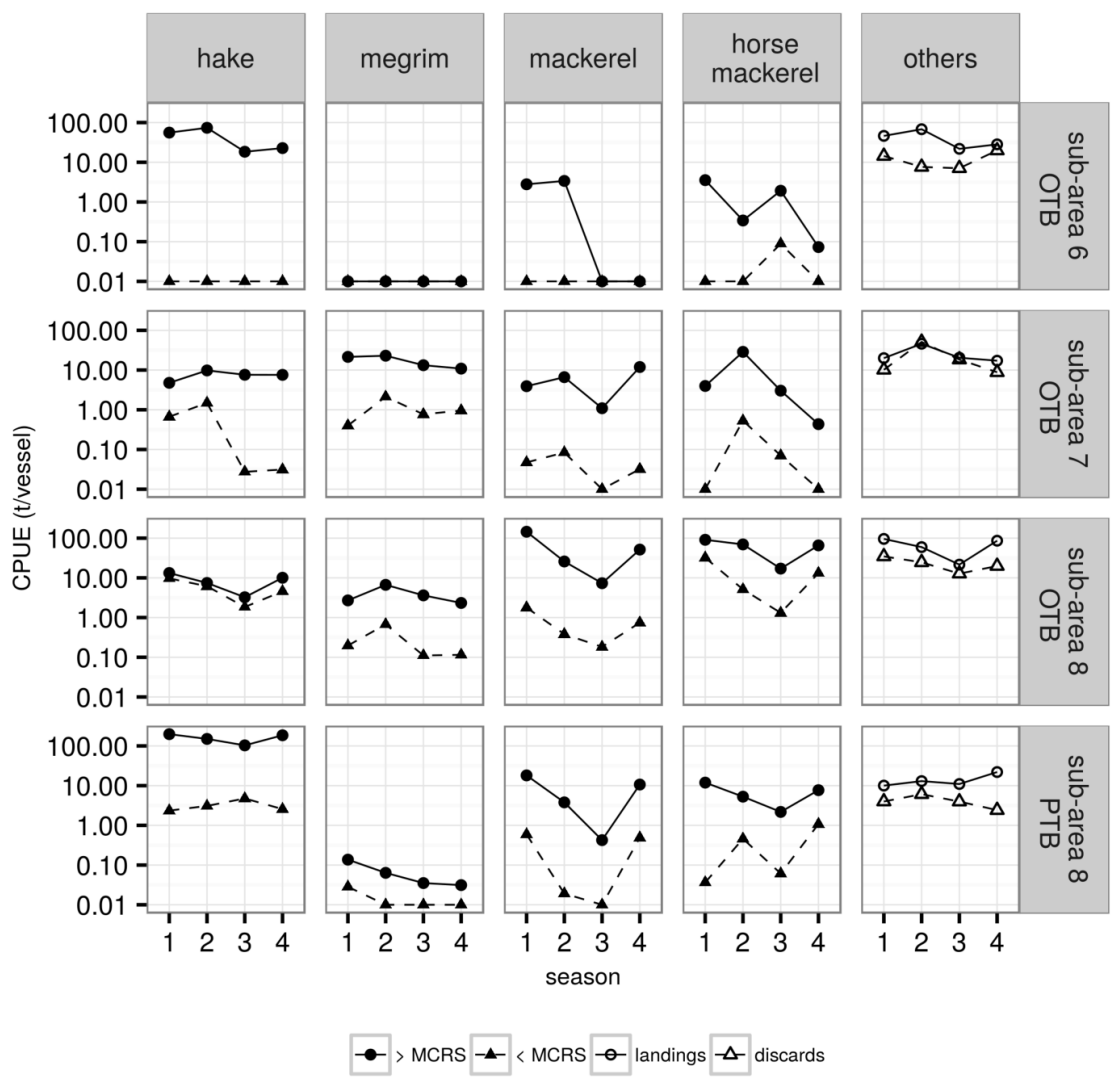

Figure 4.2: Seasonal variation in the catch per unit of effort (CPUE t/vessel) of the two size categories of hake, megrim, mackerel, horse mackerel and other species ("others") for the Bay of Biscay fishing areas. Size categories are equal to or greater than the Minimum Conservation Reference Size guidelines (>MCRS; solid lines) and smaller than MCRS guidelines (<MCRS; dashed lines). Landings (solid lines) and discards (dashed lines) are shown for the "others" group. Black lines reflect the mean CPUE inserted in the model.

The baseline scenario (scenario I) mimicked the current management situation, in which there are no penalties for discarding over-quota fish and landings were counted against final TALs after international swaps ( $\mathrm{H}$ in Table 4.4). In this scenario hake and mackerel were the limiting species (Table 4.5). Scenarios II to IV explored the effects of the 
landing obligation policy using quota flexibilities that could be applied to mitigate its short term economic effects (either international quota swaps or inter-species quota swaps). Because discarding was not allowed in scenarios II to IV, all elements in the discarding matrix $\mathrm{d}$ of the dynamic state variable model were set to 1 . In scenario II, the landing obligation was examined in the absence of international swaps. Therefore, no swaps were considered, and the fleets TAC quotas were set as the initial TAL quota, increased by $75 \%$ of the estimated stock discards I in Table 4.4). In scenario II, as with scenario I, hake and mackerel were the limiting species (Table 4.5).

In scenario III, the landing obligation was examined maintaining past known international quota swaps ( $\mathrm{J}$ in Table 4.4). Mackerel and horse mackerel were the limiting species in this scenario (Table 4.5). In scenario IV the landing obligation was examined by introducing interspecies quota flexibility, where $9 \%$ of one species catch quota could be allocated to other species as long as the receiver stocks were within safe biological limits (with the exception of megrim all stocks selected were in safe biological limits in 2012). Therefore, comparing stock-specific Basque catches against TAC without international swaps, $9 \%$ of horse mackerel catch quota was selected to increase mackerel quota ( $\mathrm{K}$ in Table 4.4). Under this scenario, hake and mackerel were the limiting species (Table 4.5).

\subsection{Results}

\section{Spatial and temporal patterns in catch rate}

Distinct seasonal and spatial patterns were observed in size-dependent catch rates for hake, megrim, mackerel, horse mackerel and the "others" category (Fig. 4.2). Moreover, the catch rates differed for the two different types of fishing gear: trawlers using PTB targeted mainly hake, while OTB catch rates were more mixed.

Catch rates of marketable hake $(>=M C R S)$ were high in sub-area 8 for vessels using PTB gear and in sub-area 6 for vessels using OTB gear. Catch rates of undersized hake $(<M C R S)$ were generally lower than catch rates for marketable hake. However, in sub-area 8 catch rates for undersized and marketable hake were of the same order of magnitude for vessels using OTB gear (Fig. 4.2). Catch rates of marketable megrim 
were highest in sub-area 7 , and showed a seasonal peak in the first and second quarters of the year. Catch rates of megrim $<M C R S$ were consistently lower than catch rates of megrim $>=M C R S$. In contrast, catch rates of marketable mackerel were highest in sub-area 8 for vessels using OTB gear and showed a clear seasonal pattern with high values in the first and final quarters of the year (Fig. 4.2). Catch rates for marketable mackerel in the same area of vessels using PTB, were lower than for vessels using OTB, but followed a similar seasonal pattern. Catch rates for undersized individuals were negligible throughout the year for all areas. Finally, catch rates of marketable horse mackerel were highest in sub-area 8 for vessels using OTB gear. The seasonal pattern of catch rates in sub-area 8 was similar for the two types of fishing gear and differed from the seasonal pattern of catch rates in the other areas. Catch rates of undersized horse mackerel were generally lower than catch rates for marketable catch and followed a similar seasonal pattern to that of the marketable catch.

Catch rates of the "others" group were higher for vessels using OTB gear, which is expected given the mixed nature of the fishery, in which multiple species are harvested. The seasonal variation in catch rates of "others" species varied between fishing areas (Fig. 4.2). This was likely caused by the fact that these catch rates were composed of a large number of species, each with their own seasonal dynamics. Landing rates were highest in the first and final quarters of the year in subarea 8, whereas in sub-areas 6 and 7 they were highest in the second quarter. The discards were generally of the same order of magnitude as the landings.

\section{Model validation}

To validate the model, the observed effort spent in each area and season in 2012 were compared to model predictions conditioned on 2012 catch data. There were no penalties for discarding over-quota fish in the validation run, and fishers did not avoid areas with undersized catches because these could be discarded without affecting net revenues. Fig. 4.3 shows that when discarding was allowed the model was able to reproduce the distribution of fishing effort in 2012. The total effort in days at sea for the model validation run also resembled the observed fleet effort for 2012 (2,800 days and 3,337 days respectively). There was a positive 
linear correlation between the model validation run and the observed distribution of fishing effort over seasons, areas and types of fishing gear $(\mathrm{r}=0.72, \mathrm{df}=10, \mathrm{p}<0.01)$. However, the model overestimated effort allocation in sub-area 6 by vessels using OTB gear, and underestimated effort by vessels using PTB gear (Fig. 4.3).

Figure 4.3:

Seasonal fishing effort (\%) and fishing areas observed and modelled for 2012 as a function of quota limitations for the Basque trawlers under a management system where discarding was allowed.

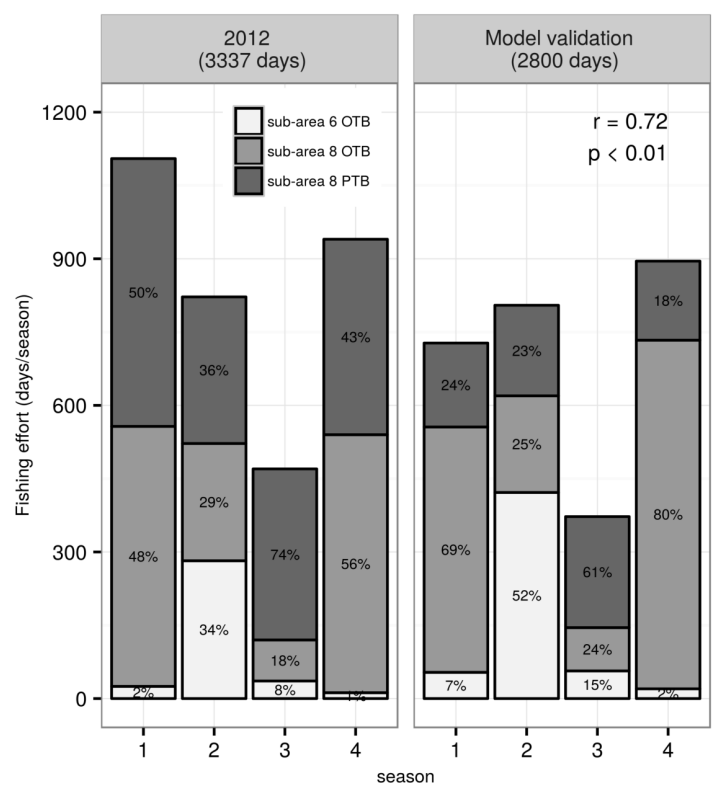

\section{Simulated gear and location choice}

There were no penalties for discarding over-quota fish in Scenario I, and fishers were not forced to avoid areas with undersized catches because these could be discarded without affecting net revenues. Vessels using both OTB and PTB fishing gear concentrated the majority of their fishing effort in sub-area 8. The proportion of effort by vessels using PTB gear in this area was especially high in the first season when hake catch rates and prices were also high. Vessels using OTB gear also expended substantial effort in sub-areas 6 and 7 , particularly in season 2, when there was a switch to sub-area 6 , because of high catch rates of hake and "others" in that area (Fig. 4.4). In season 3, fishing effort overall was reduced and dominated by vessels using PTB gear and fishing in subarea 8. This changed to vessels using OTB gear in the last season. 
Scenario II simulated a discard ban where there were no international swaps, and hake and mackerel were the limiting quota species (Table 4.5). This scenario had a clear impact on the fishing effort and resulted in the complete cessation of fishing during the first season (Fig. 4.4). Later in the year, effort was concentrated in sub-area 6 (with OTB gear) and 8 (with PTB gear). Mackerel quota limitation caused lower fishing effort by trawlers using PTB gear and for those using OTB gear to shift effort from sub-area 7 and 8 to sub-area 6 (Fig. 4.4). These choices reduced undesirable catches of undersized hake and mackerel, while allowing the opportunity to catch other valuable species. However, average revenues by vessels were around $40 \%$ of those under scenario I (where discarding was allowed). The relative contribution of using PTB fishing gear to the net revenue was reduced to a greater extent than was the use of OTB gear (Table 4.6).

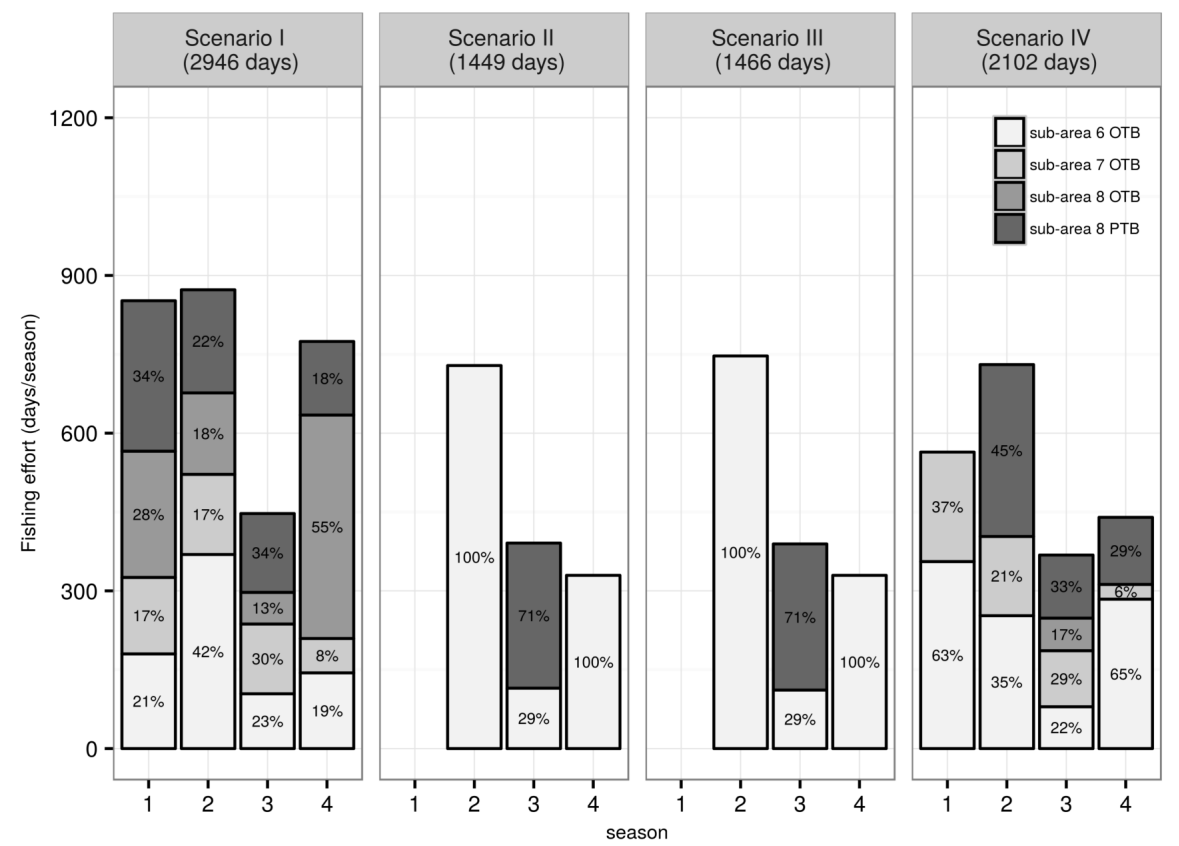

Figure 4.4: Seasonal fishing effort (\%) and fishing areas selected as a function of quota limitations for the Basque trawlers under the three discard ban scenarios.

In Scenario III, the inclusion of international quota swaps did not substantially mitigate the reduction in fishing opportunities observed in 
scenario II. Mackerel and horse mackerel were the limiting quota species in this scenario (Table 4.5). Although low quotas for horse mackerel potentially triggered reductions in fishing effort, it was effectively the mackerel quota that closed the fishery (as in scenario II, Fig. 4.4). Thus, effort was allocated in the same manner as scenario II, and model results suggested that trading quotas resulted in short-term losses that were comparable to a situation where quotas were not swapped under the landing obligation (Fig. 4.4 and Table 4.6).

Scenario IV revealed that reductions in fishing opportunities resulting from the landing obligation could be alleviated by inter-species quota flexibility. An increase in mackerel quota resulted in vessels using OTB gear fishing in sub-areas 6 and 7, where mackerel catches were sufficient (Figs 4.2 and 4.4). The limiting mackerel quota incentivized trawlers to choose to use PTB gear later in the year, particularly in season 3, and for those vessels using OTB gear to fish in sub-area 8 (Fig. 4.2). When compared with the scenario in which discarding was allowed (scenario I), scenario IV resulted in a $33 \%$ reduction in average revenues per vessel (Fig. 4.4; Table 4.6). This reduction in net revenue was not proportionally distributed between the two types of fishing gear: the average reduction in net revenue for use of PTB gear was $8 \%$, while for use of OTB gear it was $37 \%$ (Table 4.6).

\section{Landings and discards size composition}

When discarding was allowed (scenario I), landings for all species consisted of marketable fish. Discards consisted of undersized fish and, when quotas were constrained, marketable fish (Fig. 4.5 and 4.6). Landings per unit effort were higher for trawlers using OTB gear, except for hake (which is the main target species of vessels using PTB gear; Fig. 4.5). Discards mainly comprised individuals smaller than MCRS guidelines, except for hake and mackerel, where many individuals $>=$ MCRS guidelines were discarded (Fig. 4.6). For mackerel, discards of individuals $\geq$ MCRS guidelines exceeded the landings of that size class.

Under the discard ban scenarios (scenarios II, III, IV), fishers avoided areas and seasons in which there was a significant fraction of undesirable catches (undersized specimens, $<\mathrm{MCRS}$ guidelines), as a result of the fines they would face for discarding those individuals (Fig. 4.2 and 4.4). Therefore, in these scenarios fishing effort was reallocated to areas and 
Table 4.6: Average annual revenues under the four landing obligation implementations (Scenario I, where discarding is allowed and scenarios II, III, and IV, where discarding is limited). Shown are the average gross revenues, costs, and net revenues by vessel type (with 5th and 95th percentiles shown in brackets). Values are relative to the average of scenario I for the 1500 Basque vessel simulations.

\begin{tabular}{lcccc}
\hline & Scenario I & Scenario II & Scenario III & Scenario IV \\
\hline $\begin{array}{l}\text { Gross revenue by vessel (th€) } \\
\text { mean gross revenue }\end{array}$ & $100(64-132)$ & $46(10-72)$ & $44(10-71)$ & $68(34-96)$ \\
$\begin{array}{l}\text { OTB gross revenue } \\
\text { PTB gross revenue }\end{array}$ & $100(43-162)$ & $60(17-9)$ & $59(17-91)$ & $67(19-123)$ \\
& $100(34-187)$ & $45(31-57)$ & $44(31-56)$ & $89(37-135)$ \\
Costs by vessel (th€)) & & & \\
mean fuel costs & $100(84-115)$ & $51(13-74)$ & $50(13-74)$ & $69(34-96)$ \\
$\begin{array}{l}\text { OTB fuel costs } \\
\text { OTB fuel costs }\end{array}$ & $100(49-145)$ & $63(28-95)$ & $62(28-95)$ & $72(20-124)$ \\
& $100(56-173)$ & $56(56-56)$ & $56(56-56)$ & $72(56-141)$ \\
Net revenue by vessel $($ th€)) & & & & \\
mean net revenue & $100(41-154)$ & $41(5-71)$ & $40(5-70)$ & $67(27-105)$ \\
OTB net revenue & $100(26-183)$ & $59(10-96)$ & $57(9-95)$ & $63(15-123)$ \\
OTB net revenue & $100(8-191)$ & $38(18-58)$ & $38(18-57)$ & $92(27-147)$ \\
& & & & \\
\hline
\end{tabular}

gears where the discarded fraction was almost non-existent (Fig. 4.4 and 4.6). For trawlers constrained by a discard ban without the option of quota swaps or with quota swaps included based on the historical rate of international swaps, hake and "others" were the dominant species in the landings (Fig. 4.5). When mackerel quota increased due to interspecies quota flexibility in scenario IV (Table t:TAC), the quantity of marketable sized landings of all species increased (Fig. 4.5). Because all catches had to be landed, discards were absent for all species apart from the "others" group, where discarding of specimens smaller than MCRS guidelines occurred (Fig. 4.6). In general, the large confidence bands around the average modelled landings and discards in scenarios I and IV (Fig. 4.5 and 4.6) indicated differences in catch compositions since these scenarios implied greater choice of fishing areas than did scenarios II and III (Fig. 4.4). 


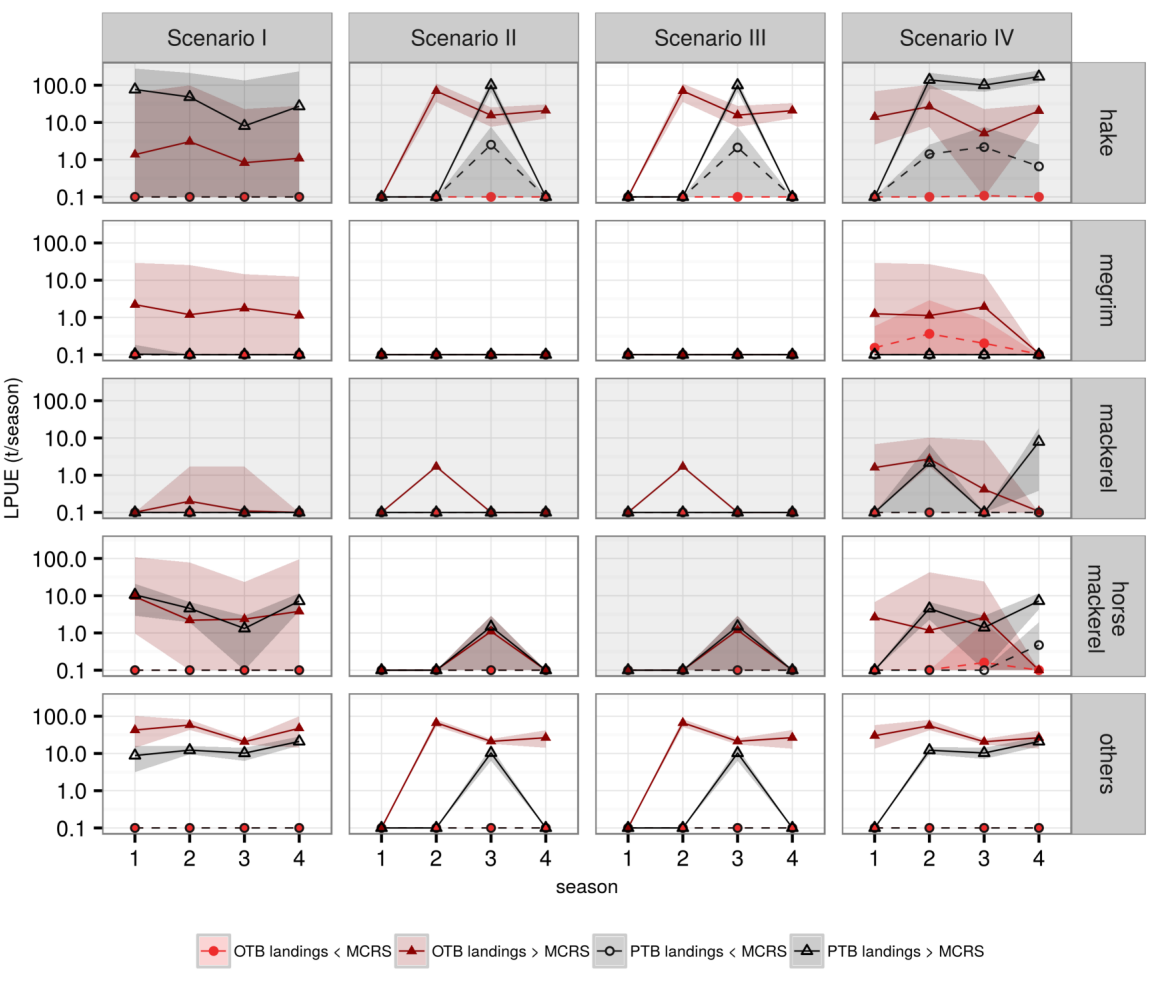

Figure 4.5: Modelled landings (t/season) of OTB and PTB trawlers across the year under the scenario that allows discarding (scenario I) and discard ban scenarios: no quota swaps allowed (scenario II), international historical swaps allowed (scenario III) and inter-species quota flexibility applied (scenario IV) with $95 \%$ confidence interval shaded. Landings smaller than Minimum Conservation Reference Size guidelines MCRS (circles, red: OTB and black: PTB), landings greater than the MCRS (triangles, red: OTB and black: PTB).

\subsection{Discussion}

Using a state-dependent decision-making model for the Basque trawl fleet we examined the potential consequences of three implementations of a landing obligation under different policy arrangements (quota increases, international quota swaps, and inter-species flexibility). Our model included temporal and spatial segregation of different size classes of the main target species, as well as differences in the selectivity of two 


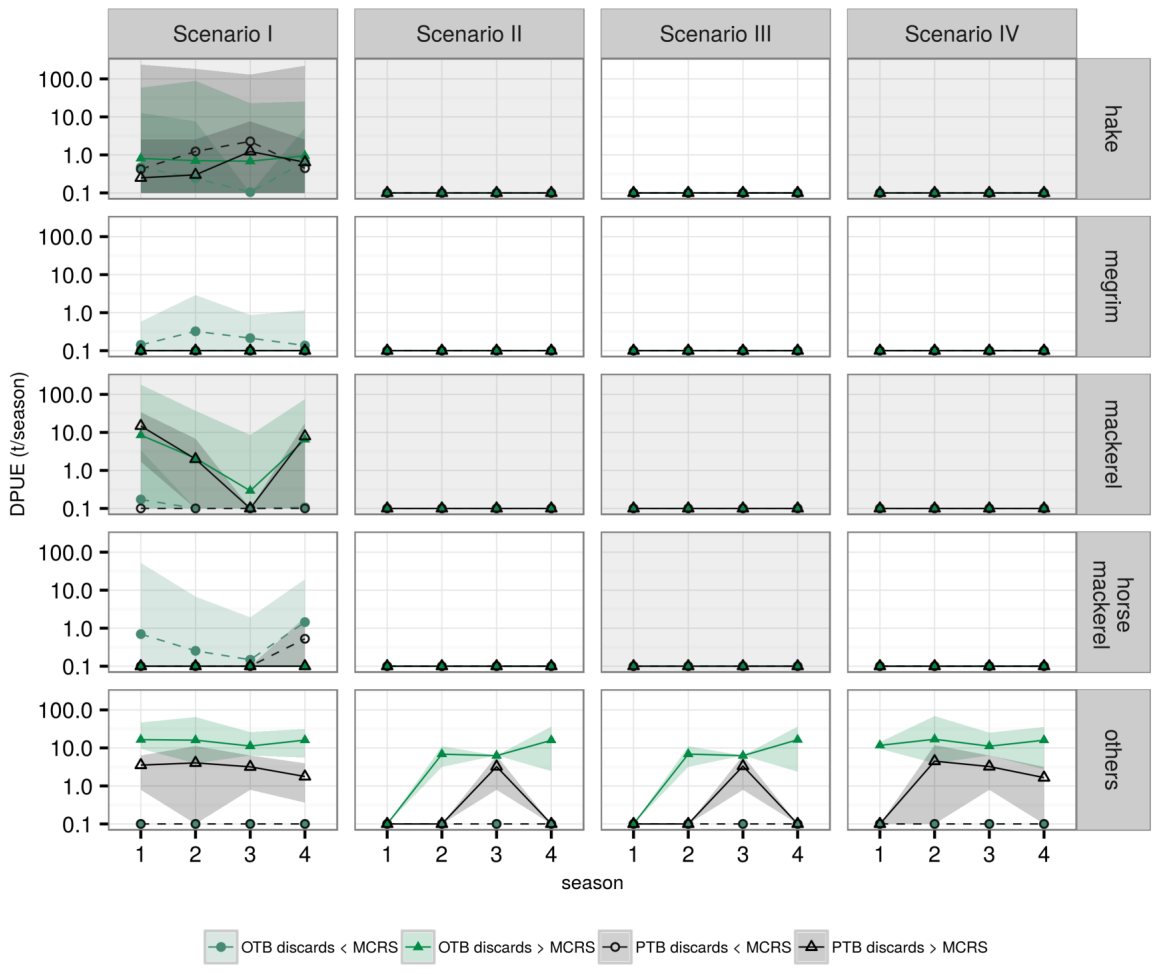

Figure 4.6: Modelled discards (t/season) of an OTB and PTB trawlers across the year under the scenario that allows discarding (scenario I) and discard ban scenarios: no quota swaps allowed (scenario II), international historic swaps allowed (scenario III) and inter-species quota flexibility applied (scenario IV) with $95 \%$ confidence interval shaded. Discards smaller than the MCRS (circles, green: OTB and black: PTB), discards larger than the MCRS (triangles, green: OTB and black: PTB).

types of trawl fishing gear, and seasonally-varying prices and variable costs. The analysis extended earlier approaches (e.g. Batsleer et al. (2016); Gillis et al. (1995)) by including errors in decision-making (following Dowling et al. (2012)) rather than assuming that individuals always make optimal decisions. The use of errors in decision-making is a technically simple way to encapsulate more complex dynamics that govern decision-making (Dowling et al., 2012). Meanwhile, our analysis made several assumptions: that there was perfect knowledge of the 
stochastic nature of catch rates, full compliance of fishers with the discarding policy, lack of transferability of individual quotas, and lack of interference competition among fishers (Batsleer et al., 2016). Also, we used seasonal time steps in the model to keep computation time low, while the time scale at which fishing trips occur may be much smaller (Iriondo et al., 2008). Finally, we did not include the existence of the de-minimis exception that allows $7 \%$ of the quota to be discarded under certain circumstances (CFP Article 15). We may thus have underestimated the flexibility of the fishery to respond to quota limitations imposed under the landing obligation. Despite these assumptions, a preliminary model validation allowed us to simulate the dynamics of the Basque trawl fleet and examine fishing effort allocations in space.

When discarding was allowed, fishers did not avoid areas where catching undersized specimens was likely because there was no incentive to do so. Under all three implementations (scenarios) of the landing obligation, however, our model showed that the Basque trawling fleet was likely to move to areas with lower catch rates of quota species to avoid exceeding quota limitations. We showed that in the short term the landing obligation would likely result in a loss in profitability for the fleet. This loss in profitability was driven by the "choke" effect for species such as mackerel (scenario II and III), which was triggered by reductions in effort as a result of rapid quota exhaustion and by greater costs associated with fishing further from home ports (scenario IV).

Our results suggest that the Basque fleet is limited by hake, horse mackerel and mackerel quota. In scenarios II and III, the choke effect of mackerel is so strong that the effect of other species limits (hake under scenario II, horse mackerel under scenario III) is negligible. Consequently, under both these scenarios our model predicts that the fleet will avoid using OTB gear and will reduce fishing effort in sub-area 7 and 8 because of their high mackerel catch rates (Fig. 4.3). Thus, fishers will likely visit sub-area 6 and 8 (using PTB gear). Revenues under these two scenarios are predicted to result in a loss of profitability (60\% less than the status quo; Table 4.6). These findings indicate that trading quotas (at rates undertaken in the past) does not alleviate the choking effect of the landing obligation. Therefore, new ways of swapping quotas would be needed under the landing obligation to alleviate the choke effect of any of the quota limiting species. Fleets with high discards rates 
of certain species will be likely to have larger incentives to increase their quotas for those species than fleets with low discard rates.

In scenario IV, the addition of inter-species quota-swapping flexibility to the landing obligation (e.g. $9 \%$ of the horse mackerel catch quota could go to increase mackerel quota) substantially decreased the mackerel choke effect and increased both fishing opportunities and net revenues, when compared to scenarios II and III. Under this scenario, revenue was $30 \%$ lower than when discarding was allowed (scenario I).

Our results suggest that reductions in fishing opportunities under a landing obligation that are caused by choke species could be alleviated by the use of inter-species quota flexibility, and that there will be strong incentives to use this flexibility. Management bodies should ensure that the use of different flexibilities will constrain catches to comply with the MSY objective in Article 2(2) of the CFP Basic Regulation. Use of inter-species quota flexibility could cause serious impacts to stock abundance when quota from a high volume/low value species is transferred to a low volume/high value stock. Achieving a balance between quota flexibility, over-exploitation risk, and administrative simplicity is critical for the profitability and sustainability of multi-species fisheries.

The success of any new regulation also depends on achieving a balance between the costs and benefits of measures that promote voluntary compliance and those that punish non-compliance. With poor enforcement the economic benefits of non-compliance outweigh the risks of detection (Batsleer et al., 2013; Catchpole et al., 2005). In our model, detection rates were assumed to be $100 \%$ and fines were set sufficiently high so that no discarding occurred, reflecting full compliance with regulations. However, if detection rates are low and the short-term benefits of non-compliance are high (as our results suggest) then non-compliance is likely to be a substantial problem in the absence of measures promoting voluntary compliance.

The landing obligation was implemented to incentivise individual businesses to improve selectivity and avoid unwanted catches. The landing obligation shifts the emphasis from prescribing the fishing gears that are permissible, to a results-based system where the onus is on the fishers to use fishing gear that will avoid unwanted catches. Therefore, fishers should be incentivised to develop alternative gear or adapt their 
fishing behaviour to mitigate the full impact of the landing obligation (Alzorriz et al., 2016). Discard ban policies may not necessarily reduce harvest rates but will change the underlying selectivity patterns of harvests (Borges et al., 2016). Our results reflect the short-term effects of a discard ban on selectivity patterns and net revenues implemented under three scenarios. If the landing obligation changes selectivity patterns as we predict, then we would also expect longer term changes in both fish populations and the economy of the fishery. Such analyses are the domain of bio-economic management strategy evaluations where the feedback between fleet and stock dynamics are modelled explicitly (Andersen et al., 2010; Prellezo et al., 2016a; Punt et al., 2016). In such models, effects of the changing selectivity of the fishing fleets on the reference points for sustainable exploitation can be evaluated.

\subsection{Conclusions}

We have shown that the landing obligation proposed by the EU CFP, under the assumption of full compliance, is likely to change the distribution of fishing effort of the Basque trawler fleet. Currently, with discarding allowed, marketable mackerel is caught and discarded. Our model predicts that when discarding is prevented under a landing obligation, the mackerel quota will constrain the Basque trawler fleet, resulting in a change to fishing effort allocation and a substantial reduction to short-term net profits. Our model also showed that inter-species quota flexibility could alleviate the choke effect of mackerel (by transfers to horse mackerel quota) and lessen the negative short-term reduction in net profits produced by the landing obligation. These results suggest that there will be a large incentive for the Basque fleet to use this quota flexibility: a finding that is likely transferable to other fleets and fisheries.

\subsection{Acknowledgements}

We are grateful to researchers from AZTI for providing logbook data. We also thank two anonymous reviewers and the editor of Fisheries Research, André Punt, for valuable comments and suggestions that greatly improved the manuscript. The content of this paper does not reflect the official opinion of the European Commission. Responsibility for the information and views expressed in this paper relies entirely with the authors. 


\subsection{References}

Alzorriz, N., Arregi, L., Herrmann, B., Sistiaga, M., Casey, J., and Poos, J. J. 2016. Questioning the effectiveness of technical measures implemented by the Basque bottom otter trawl fleet: Implications under the EU landing obligation. Fisheries Research, 175:116-126.

Andersen, B. S., Vermard, Y., Ulrich, C., Hutton, T., and Poos, J. J. 2010. Challenges in integrating short-term behaviour in a mixed-fishery Management Strategies Evaluation frame: A case study of the North Sea flatfish fishery. Fisheries Research, 102(1-2):26-40.

Batsleer, J., Poos, J. J., Marchal, P., Vermard, Y., and Rijnsdorp, A. D. 2013. Mixed fisheries management: Protecting the weakest link. Marine Ecology Progress Series, 479:177-190.

Batsleer, J., Hamon, K. G., van Overzee, H. M. J., Rijnsdorp, A. D., and Poos, J. J. 2015. High-grading and overquota discarding in mixed fisheries. $R e$ views in Fish Biology and Fisheries, 25: 715-736.

Batsleer, J., Rijnsdorp, A. D., Hamon, K. G., van Overzee, H. M. J., and Poos, J. J. 2016. Mixed fisheries management: Is the ban on discarding likely to promote more selective and fuel efficient fishing in the Dutch flatfish fishery? Fisheries Research, 174:118-128.

Borges, L. 2015. The evolution of a discard policy in Europe. Fish and Fisheries, 16:534-540.

Borges, L., Cocas, L., and Nolde, K. N. 2016. Discard ban and balanced harvest: a contradiction? ICES Journal of Marine Science, 73:1632-1639.

Catchpole, T. L. and Gray, T. S. 2010. Reducing discards of fish at sea: a review of European pilot projects. Journal of Environmental Management, 91 (3):717-723.
Catchpole, T. L., Frid, C. L. J., and Gray, T. S. 2005. Discards in North Sea fisheries: causes, consequences and solutions. Marine Policy, 29(5):421-430.

Clark, C. W. and Mangel, M. Dynamic state variable models in ecology: methods and applications. Oxford University Press, New York, 2000.

Condie, H. M., Catchpole, T. L., and Grant, A. 2014. The short-term impacts of implementing catch quotas and a discard ban on English North Sea otter trawlers. ICES Journal of Marine Science, 71(5):1266-1276.

Dowling, N. A., Wilcox, C., Mangel, M., and Pascoe, S. 2012. Assessing opportunity and relocation costs of marine protected areas using a behavioural model of longline fleet dynamics. Fish and Fisheries, 13(2):139-157.

EC. 2008. Commission Regulation (EC) No 665/2008 of 14 July 2008 laying down detailed rules for the application of Council Regulation (EC) No 199/2008 concerning the establishment of a Community framework for the collection, management and use of data in the fisher. Official Journal of the European Communities, L186.

EU. Regulation (EU) No 1380/2013 of the European Parliament and of the Council of 11 December 2013 on the Common Fisheries Policy, 2013.

FAO. 1996. Technical consultation on reduction of wastage in fisheries, FAO Fisheries Report 547 supplement. FAO, Rome, 547:338. URL http://www.fao.org/docrep/009/ w3696e/w3696e00.htm.

Gillis, D. M., Pikitch, E. K., and Petermanc, R. M. 1995. Dynamic discarding decisions: foraging theory for highgrading in a trawl fishery. Behavioral Ecology, 6(2):146-154. 
Houston, A. and McNamara, J. Models of Adaptive Behaviour. Cambridge University Press, Cambridge, 1999.

ICES. 2013a. Report of the Working Group on the Assessment of Southern Shelf Stocks of Hake, Monk and Megrim (WGHMM) ICES Headquarters , Copenhagen International Council for the Exploration of the Sea. ICES, CM/AC(10-16 May):727. URL http://www.ices.dk/sites/ pub/Publication\%20Reports/Expert\% 20Group\%20Report/acom/2013/WGHMM/ WGHMM $\% 202013$.pdf.

ICES. 2013b. Report of the Working Group on Widely Distributed Stocks (WGWIDE). ICES CM, ACOM: 15(27 August- 2September):950. URL http://ices.dk/ sites/pub/Publication\%20Reports/ Expert\%20Group\%20Report/acom/ 2013/WGWIDE/01\%20WGWIDE $\% 20$ $\% 20$ Report $\% 20$ of $\% 2$ Working $\% 20$ Group $\%$ 20 on $\% 20$ Widely $\% 20$ Distributed $\%$ 20Stocks.pdf.

Iriondo, A., Prellezo, R., Santurtún, M., Garcia, D., and Quincoces, I. 2008. Basque trawl metier definition for 20032007 period. Revista de Investigacion Marina, 3:263-264.

Iriondo, A., Aranda, M., and Santurtún, M. 2013. El reparto de cuotas individuales de pesca por buque de la flota de altura espanola en aguas del Nordeste Atlántico. Revista de Investigación Marina, AZTI-Tecnalia, 20(2):23-28.

Kindt-Larsen, L., Kirkegaard, E., and Dalskov, J. 2011. Fully documented fishery: a tool to support a catch quota management system. ICES Journal of Marine Science, 68(8):1606-1610.

Kraak, S. B. M., Bailey, N., Cardinale, M., Darby, C., De Oliveira, J., Eero, M., Graham, N., Holmes, S., Jakobsen, T., Kempf, A., Kirkegaard, E., Powell, J.,
Scott, R. D., Simmonds, E. J., Ulrich, C., Vanhee, W., and Vinther, M. 2013. Lessons for fisheries management from the EU cod recovery plan. Marine Policy, 37:200-213.

Mangi, S. C. and Catchpole, T. L. 2014. Using discards not destined for human consumption. Environmental Conservation, 41:290-301.

Poos, J. J., Bogaards, J. A., Quirijns, F. J., Gillis, D. M., and Rijnsdorp, A. D. 2010. Individual quotas, fishing effort allocation, and over-quota discarding in mixed fisheries. ICES Journal of Marine Science, 67(2):323-333.

Prellezo, R., I., G., and García, D. 2016a. The bad, the good and the very good of the landing obligation implementation in the Bay of Biscay: A case study of Basque trawlers. Fisheries Research, 181:172-185.

Prellezo, R., Santurtún, M., Andonegi, E., Louzao, M., García, D., and Iriondo, A. 2016b. The discard ban and its impact on the Maximum Sustainable Yield objective- The Atlantic Ocean: The Bay of Biscay case. Research for the PECH Committee, European Union, 17:9-81. URL http://www. europarl . europa.eu/ RegData/etudes/STUD/2016/573440/ IPOL_STU (2016) 573440_EN.pdf.

Punt, A. E., Butterworth, D. S., de Moor, C. L., De Oliveira, J. A. A., and Haddon, M. 2016. Management strategy evaluation: Best practices. Fish and Fisheries, 17:303-334.

Rochet, M. J., Arregi, L., Tereza, F., Pereira, J., Perez, N., Ruiz Gondra, J., and Valeiras, J. 2014. Demersal discard atlas for the South Western Waters. Report, page 121. URL http://www.repositorio.ieo.es/eieo/handle/10508/9074.

Simons, S. L., Doring, R., and Temming, A. 2015. Modellin fisher's re- 
spond to discard prevention strategies: the case of the North Sea saithe fishery.
ICES Journal of Marine Science, 72(5): 1530-1544. 



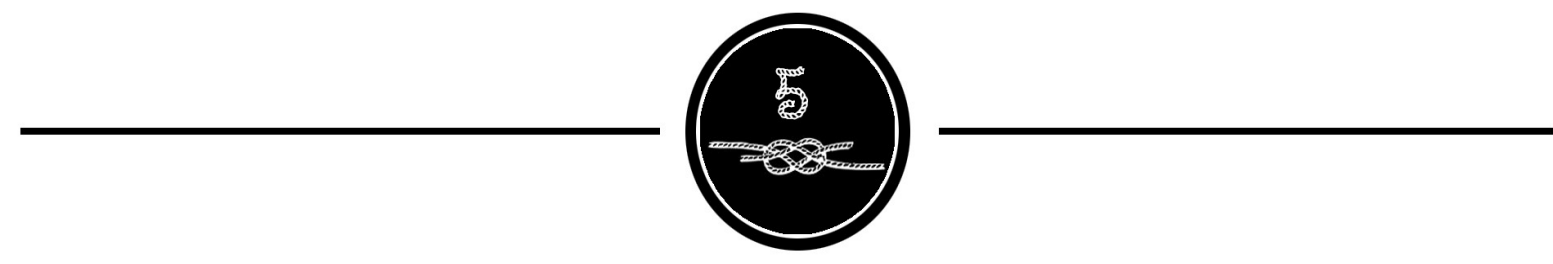

- MODELLING LONG-TERM EFFECT OF MANAGEMENT STRATEGIES IN MIXED FISHERIES • 


\subsection{Abstract}

The EU common fisheries policy (CFP), designed for the long-term environmental, economic, and social sustainability of fishing and aquaculture activities, includes making use of the maximum sustainable yield (MSY) reference points as targets for exploiting commercially important fish stocks. To incentivise individual business to improve selectivity and avoid unwanted catches, it also introduced a landing obligation. Achieving these complex objectives may not necessarily reduce harvest rates, but will change the underlying selectivity patterns of harvests. The impact of exploiting at MSY and no discarding allowance on the optimal effort allocation between fleets is analysed. We contrast two management plans to achieve MSY from two stocks and compare their effectiveness based on a management strategy evaluation that uses a dynamic state variable model including errors in decision-making in its operating model. The results show that when accounting for quota on one species and for quotas on both species, MSY landings in the short-term are $30 \%$ to $50 \%$ lower than when compared to an unmanaged situation simulations. Some years after the implementation, MSY landings are similar or $25 \%$ to $50 \%$ higher than the pre-manage situation. Optimal effort at MSY generates effort reductions of $37 \%$ to $62 \%$ over the mid-term, thus there would be some vessels that could benefit up to 1.4 times larger profits than before the CFP implementation. The results show that for both species, any of the two management plans would be beneficial to both the stock and part of the fleets over the mid-term compared with the projections over the short-term.

\section{Keywords:}

management strategy evaluation, dynamics state variable model, errors in decision-making, landing obligation, maximum sustainable yield, common fisheries policy. 


\subsection{Introduction}

Management strategy evaluation (MSE; (Bunnefeld et al., 2011; Sainsbury, 2000; Smith, 1994)) seeks to study the implications of management strategies using simulations (Punt et al., 2016). Such simulations should include all important processes of a fishery. Any fishery is inherently a socio-ecological system, with coupled dynamics of fishing fleets, exploited stocks, and their governance (Punt et al., 2016; Rademeyer et al., 2007). Given the complexity of a socio-ecological system the uncertainty about the dynamics and feedbacks are considerable. As a result, the probability of success of implementing a management measure to achieve a certain goal may thus be small compared to system stochasticity, or worse, be counteracted by unintended consequences of the management strategy. The robustness of management strategies to the uncertainty in the processes that govern fisheries systems thus need to be accounted for (Andersen et al., 2010; Kell et al., 2007; Prellezo et al., 2016a; Punt et al., 2016).

The adaptive response of fishers to their environment is one of the key uncertainties requiring attention in MSE (Fulton et al., 2007). Simulation tools for such a response are available, borrowing methodology from state-dependent foraging decisions in ecological systems (Clark and Mangel, 2000; Houston and McNamara, 1999). State-dependent behaviour of individual fishing vessels, aggregated into fleet dynamics, have been developed using stochastic dynamic programming (Alzorriz et al., 2018; Batsleer et al., 2015; Dowling et al., 2011; Gillis et al., 1995; Poos et al., 2010). These models generally predict short term (within a fishing trip, or a quota year) effects of changes in management or the environment by determining which choices yields the best chance of increasing utility, while keeping track of the state of each individual. The effect of a choice on utility depends on the state of the individual, the economic environment, such as fuel prices, and the biological environment, such as the spatial distribution of resources.

Using dynamic variable state models, effects of e.g. relocation costs of marine protected areas have been modelled (Dowling et al., 2011). Dynamic state variables have also been used to describe discarding behaviour (Alzorriz et al., 2018; Batsleer et al., 2013, 2015; Gillis et al., 1995). Some of these studies have tried to shed light on the potential outcomes of the European fisheries management reform of 2013. That 
reform added the gradual introduction of a landings obligation (LO) to the management system of Total Allowable Catches set according to the maximum sustainable yield (MSY) (EU, 2013). Using spatial and temporal distributions of catch rates within a single year, dynamic state variable models forecasted high costs in mixed fisheries in the short term as a result of the LO (Alzorriz et al., 2018; Batsleer et al., 2013, 2015). These costs result from removing the choice to discard part of the catch and in doing so adapt landings to quota (Alzorriz et al., 2018). This will result in fishing effort reallocation and early closures of fisheries once quota have been reached.

Meanwhile, the LO potentially improves selectivity of fisheries by providing incentives to move away from areas with high levels of unwanted catch and the use of more selective gears (Alzorriz et al., 2016, 2018). The improved selectivity should lead to higher long term catches. These long term benefits to fisheries that could result from improved selectivity under the $\mathrm{LO}$ are ignored in previous studies on the adaptive response of fisheries (Alzorriz et al., 2018; Batsleer et al., 2013, 2015). Ignoring the potential for improved selectivity leaves out a key element in the perceived benefit of the LO. In mixed fisheries, however, optimizing single species selectivity and achieving MSY while landing all commercial catches is challenging because of trade-offs in the catches of different species and size-classes (Batsleer et al., 2013; Ulrich et al., 2017). Forecasting whether any management will be effective requires understanding the response of fishers constrained by these trade-offs and the effects of the response on the development of fish populations (Venables et al., 2009). If the fleet dynamic model results in a short term movement of vessels to allocate effort both spatially and temporally, we also expect longer term changes to occur in fish populations and the economy of the fishery (Alzorriz et al., 2018).

We present an MSE framework that couples forecasts from a statedependent behaviour model to a biological dynamic model that forecasts population effects resulting from the collective fishers behaviour. The model includes the (real or perceived) local biomass of two populations, governed by growth, mortality, and migration. These populations are size-structured, and are modelled in a spatially heterogeneous environment. The populations are harvested by a single fleet that has annual fishing rights for both populations, consisting of individuals who make 
monthly choices on fishing locations. These choices depend on the perceived spatial distributions of biomasses, but also on various costs, principally that of fuel. The constraints on the fleet includes managementimposed constraints such as fish quotas. In the framework, these quotas are decided by a management body that observes the total biomass of the two stocks and with the goal of constraining fishing mortality so that maximum sustainable yields are achieved.

The MSE framework is used to understand the fleet dynamics in a spatially and temporally heterogeneous mixed quota-regulated fishery when reducing from unmanaged (unconstrained catch quota) to MSY managed combined with the LO where discards are not allowed, and to compare it in order to assess on the biological and economic consequences. Although there will be an incentive to continue discarding if LO and catch quotas are not fully enforced; we assumed full compliance to understand if the likely adaptive change in fishing patterns will lead to a better balance between quotas and catches.

\subsection{Methods}

The management strategy evaluation framework was used to forecast the dynamics of a hypothetical mixed fishery on two species. In the fishery, there are three essential elements: (i) a collection of size structured fish stocks, whose dynamics are governed by annual reproduction, growth, migration, and mortality; (ii) a management body that evaluates the fishing pressure and aims to set annual quotas in accordance with fishing mortalities dictated by $H_{\max }$ reference points (harvest at maximum sustainable yield); and (iii) a fleet of individual fishers who aim to make the best use of their annual quota. Within this mixed fishery, individual vessels make adaptive choices about fishing location and discarding that depend on the distribution of the resources, and their quota share. Each of these elements is discussed in more detail below. The essential elements of the framework are summarized in Figure 5.1 and 5.2.

The framework consists of an operating model (OM) and a management procedure (MP). The OM captures the key processes in the dynamics of the fish populations, the fisheries, and the management body, and can be thought of as a minimum realistic model (Punt and Butterworth, 1995). The OM thus includes individual harvester decision-making (including error) and the consequent biomass of fish stocks, including the essential 
elements for calculating the individual harvester economic performance (Fig. 5.2). The management body used the MP to make its decision on how to respond to the state of the resource. This MP thus includes the data collection from the fishery, how these are interpreted, and the harvest control rule (HCR) that dictates the limits that are set to the fishery.

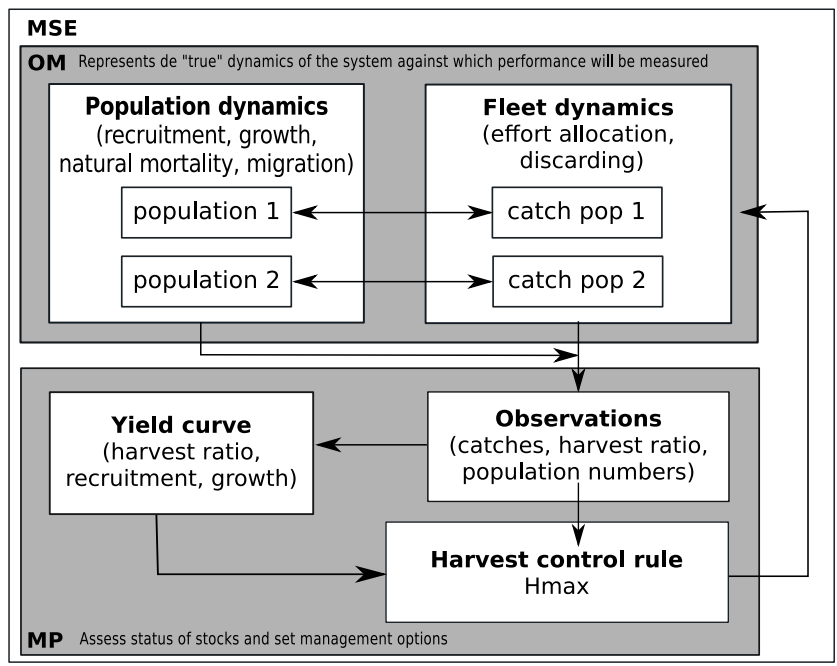

Figure 5.1: Conceptual overview of the MSE approach, including the OM and the MP components of the framework.

\section{Population dynamics}

To allow the fishery to make spatial and temporal choices, the model needed to be seasonally and spatially explicit. The dynamics of the fish stocks were modelled using an age-structured model that was spatially explicit, with seasonal time steps. In each seasonal time step, fish grow, migrate, and die. The number of fish of stock $i$ of age $a$ at year $y$, in season $s$, and area $p$ was written as $N_{i}(a, y, s, p)$. The ages in the model range between age 0 and age $A$, the maximum age in the model. Once the fish reach their maximum age, the following year, they are not taken into account in the calculations (no plus group), they die. The seasons range between season 1 and season $S$, the last season within each year. Individuals were born at age 0 , at the start of each year $y$, in season 1 . The number of recruits $R_{i}(p)$ in the model was a function of the area 


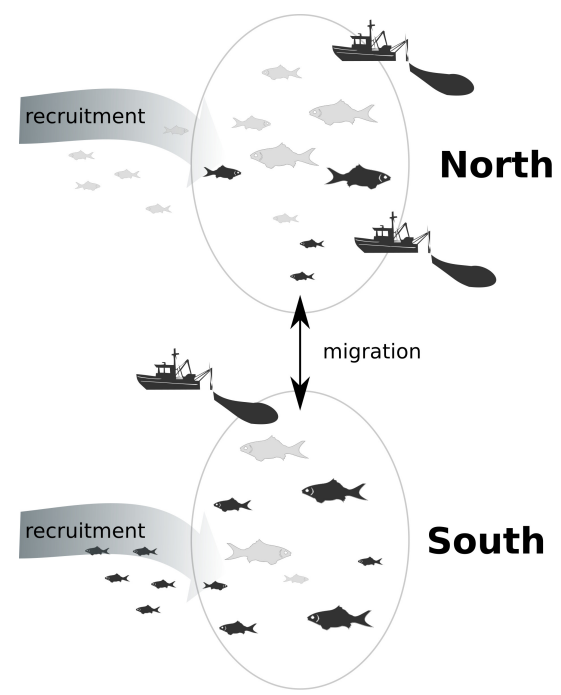

Figure 5.2: The OM component, including the key processes in the dynamics of the fish populations.

$p$ and independent of the size of the adult population. The population numbers at age 0 are thus

$$
N_{i}(0, y, 1, p)=R_{i}(p) \text {. . . . . . . . . . . . . . . . }
$$

Mortality in the model resulted from fishery catches and natural causes such as predation, diseases, and senescence. The decrease in population numbers was thus the result of the catches $\left(C_{i}(a, y, s, p)\right)$ and a natural mortality constant $M_{i}$ that described natural mortality as a fixed fraction of the population. These mortalities reduced the population numbers among a cohort of fish. Because the model was seasonally structured, the population numbers for seasons 2 to $S$ were dependent on the previous season,

$$
N_{i}(a, y, s+1, p)=N_{i}(a, y, s, p)-C_{i}(a, y, s, p)-M_{i} N_{i}(a, y, s, p) .(5 .
$$

Likewise, the population numbers in season 1 depended on the numbers in season $S$ of the previous year,

$$
N_{i}(a+1, y, 1, p)=N_{i}(a, y, S, p)-C_{i}(a, y, S, p)-M_{i} N_{i}(a, y, s, p) .
$$

Migration for each species was defined by an array $D_{i}(a, s, e m, i m)$ that defined immigration and emigration on a given stock relative to the stock 
sizes. The size of that array was defined by the number of age classes, seasons and number of areas. emigrants leave area $\mathrm{em}$ and move to area $\mathrm{im}$. The emigrated part of the population is then subtracted from each of the areas, so that that population numbers per year and season remain unaffected by migration.

Individual body growth was modelled by a von Bertalanffy growth equation to convert numbers to lengths, and an allometric equation to convert length to weight. The weights for individuals in the stock and in the catches are thus calculated as

$$
w_{i}(a, s)=\alpha *\left(L_{\infty_{i}} *\left(1-\exp ^{(-K *(a+(s / S)))}\right)\right)^{\beta} . . .
$$

The realized catches are the sum of all individual catches resulting from the dynamic state variable model. The model inputs consist of the expected individual catch rates, which are random variables. These random variables were normally distributed, with means $\hat{c}_{i}(a, y, s, p)$ being a function of population size, catchability $q_{i}$ in any year, season, and area,

$$
\hat{c}_{i}(a, y, s, p)=N_{i}(a, y, s, p) * q_{i} * w_{i}(a, s) \ldots . . . . .
$$

The standard deviations $\Sigma_{i}(a, y, s, p)$ of the catch distributions were constant fraction their means, using a ratio $\eta$.

\section{Fleet dynamics}

A dynamic state variable model was used to simulate a fleet of individual fishing vessels (Alzorriz et al., 2018; Batsleer et al., 2015; Clark and Mangel, 2000; Dowling et al., 2011; Houston and McNamara, 1999; Poos et al., 2010). The model structure was equal to (Alzorriz et al., 2018). Each individual vessels had a set of choices, which include the choice to go fishing in a season, location choice within that season. No discarding was allowed in the model. The model had annual fines for exceeding landings quota as in (Alzorriz et al., 2018). In order to calculate state dependent choices during the year, we started by defining the annual fines for exceeding landings quotas at the end of the year:

$$
\Phi\left(C_{i}, Q_{i}, F_{i}\right)=-\sum_{i}\left(\max \left(0,\left(C_{i}-Q_{i}\right)\right) * F_{i}\right), \quad . \quad . \quad .
$$

where $C_{i}$ was the cumulative annual catches for species $i$ for an individual 
vessel. These cumulative catches defined the state of the individual. $Q_{i}$ was the annual individual quota for catches for the different species. Individual quotas were not transferable. $F_{i}$ was the fine per unit weight for exceeding individual catches quota.

The maximum expected utility between current season $s$ and the end of the year was $V\left(C_{i}, Q_{i}, F_{i}, s\right)$, and the model started by setting $V\left(C_{i}, Q_{i}, F_{i}, S\right)=\Phi\left(C_{i}, Q_{i}, F_{i}\right)$. For preceding seasons, the expected utility depended on individual choices, and each time step individuals chose to visit fishing area $p$, or to stay in port. While fishing, any combination of the age classes caught of the quota species had to be landed. The expected utility for each state and each time step $s$ was calculated backward using stochastic dynamic programming (Clark and Mangel, 2000):

$$
V\left(C_{i}, Q_{i}, F_{i}, s\right)=\max _{p}\left(R(p, s)-G(p)-C(p)+E_{p}\left[V\left(C_{i}^{\prime}, Q_{i}, F_{i}, s+1\right)\right]\right),
$$

where $R(p, s)$ was the expected immediate contribution of the gross revenue from the sales of fish in a season resulting from choices $p$ (gross revenues resulted from multiplying catches different age classes of species 1, species 2 and prices). Prices of fish were assumed to be dependent over fish age (subsection size dependent pricing). $G(p)$ represented the incurred fuel costs per season from the choice of fishing area $p$, while $C(p)$ represented the variable operating costs (crew share, gear maintenance and landing costs, Table 5.1), which in turn depended on the change in cumulative catches and fish prices. The term $E_{p}\left[V\left(C_{i}^{\prime}, Q_{i}, F_{i}, s+1\right]\right.$ denoted the expected future utility taken over all possible states resulting from choices $p$. The transitions of these states were based on normal distributions of catch rates, using the means and variances for the species, as explained in the model conditioning section, following (Poos et al., 2010).

Rather than assuming that each individual always made the optimal choice, we assigned a probability to each choice proportional to its expected utility, following (Dowling et al., 2011). The expected utility for any choice was

$$
U\left(C_{i}, Q_{i}, F_{i}, s\right)=R(p, s)-G(p)-C(p)+E_{p}\left[V\left(C_{i}^{\prime}, Q_{i}, F_{i}, s+1\right)\right] .
$$

If $U^{*}$ was the expected utility at the optimal choice for a given $t$, we 
set

$$
\Delta_{p}\left(C_{i}, Q_{i}, F_{i}, s\right)=U^{*}\left(C_{i}, Q_{i}, F_{i}, s\right)-U\left(C_{i}, Q_{i}, F_{i}, s\right), \quad .
$$

and then defined the probability of a choice for a given area and discarding as

$$
P_{p}\left(C_{i}, Q_{i}, F_{i}, s\right)=\frac{e^{-\Delta_{p}\left(C_{i}, Q_{i}, F_{i}, s\right) / \sigma}}{\sum_{p} e^{-\Delta_{p}\left(C_{i}, Q_{i}, F_{i}, s\right) / \sigma}}, \quad . \quad . \quad . \quad . \quad .
$$

where $\sigma$ was a tuning parameter that measured how important it was to be near the optimal choice. A large $\sigma$ resulted in uniform probabilities of choices, with vessels being distributed uniformly across the different fishing areas. In contrast, a small $\sigma$ forces vessels to concentrate in the optimal location (but note that $\sigma$ should be $>0$ ). For computations, we used $\sigma=65000$ (Table 5.1).

The dynamic state variable model was solved for each year by iterating backwards in time, while finding the probability distribution choice in terms of location for all possible states, combining the net revenue obtained from the sale of fish and costs of a fishing trip and the effect of the annual fines when exceeding annual quota. Further details for this procedure can be found in (Alzorriz et al., 2018; Batsleer et al., 2016) and (Dowling et al., 2011).

Once the backward calculations were finished, the forward part is a Monte Carlo simulation where the probabilities of choices were sampled randomly using the probabilities in 5.10. For each year, these forward Monte Carlo simulations determine the fishing effort in each season and area $E(y, s, p)$, and the catches $C_{i}(a, y, s, p)$ for each age in each season and area. The effort allocation component of the operating model provides the link between the management decisions and the biological component of the operating model.

\section{Size dependent pricing}

Prices of fish were assumed to be fixed over time but influenced by the body weight of the individuals in the catch, as is commonly observed (Zimmermann and Heino, 2013; Zimmermann et al., 2011). Following (Zimmermann et al., 2011), the relationship between fish price and body 
Table 5.1: Model parameters.

\begin{tabular}{|c|c|c|}
\hline \multicolumn{3}{|l|}{ Population dynamics } \\
\hline number of recruits & $R_{i}(p)$ & 500 \\
\hline maximum age & $A$ & 6 \\
\hline number of areas & $p$ & 2 \\
\hline number of months & $S$ & 12 \\
\hline natural mortality & $M_{i}$ & $1 \times 10^{-4}$ \\
\hline Asymptotic length & $L_{\infty_{i}}$ & 50 \\
\hline Growth rate & $K_{i}$ & 0.6 \\
\hline Length-weight conversion factor & $\alpha_{i}$ & $2 \times 10^{-4}$ \\
\hline Length-weight isomorphy factor & $\beta_{i}$ & \\
\hline Migration & $D_{i}$ & $2.5 \times 10^{-2}$ \\
\hline \multicolumn{3}{|l|}{ Fleet dynamics } \\
\hline Number of vessels & & 8000 \\
\hline Fuel costs (Euro fishing month $^{-1}$ ) & & 2000 \\
\hline Gear maintenance (Euro fishing season ${ }^{-1}$ ) & & \\
\hline Crew share & & $0 \%$ \\
\hline Landing costs (Euro $\mathrm{t}^{-1}$ ) & & \\
\hline Optimal choice error & $\sigma$ & 65000 \\
\hline \multicolumn{3}{|l|}{ Fishery } \\
\hline Intial quota $\left(\mathrm{kg}\right.$ vessel $\left.^{-1}\right)$ & & 200 \\
\hline catchability & $q_{i}$ & $2.5 \times 10^{-5}$ \\
\hline effort $(p, s)$ & & \\
\hline Price of species at mean weight (Euro $\mathrm{kg}^{-1}$ ) & $\bar{p}_{i}$ & 30 \\
\hline Slope of species price & $\gamma_{i}$ & 15 \\
\hline Fine for overshooting quota (Euro $\mathrm{kg}^{-1}$ ) & $F_{i}$ & 3000 \\
\hline Ratio of standard deviations to catch means & $\eta$ & 0.08 \\
\hline
\end{tabular}

weight was modelled as:

where $p_{i}(a, s)$ is the price of species $i$ at age $a$ and season $s$. The price was a linear function of the weight of individuals of species $i$ at age $a$ and season $s . \bar{p}_{i}$ is the price of the species at the mean weight over the age range. The mean weight over the age range is $\bar{w}_{i} . \gamma_{i}$ gave the price increase when individual mass was increased by $\bar{w}_{i}$.

\section{Case study parametrization}

To mimic spatially heterogeneous fish populations in a mixed fishery where fishers make sequential choices on fishing areas, the model was 
divided into a 'north' and 'south' area, and twelve fishing seasons per year (Table 5.1 and Fig. 5.3). There were two fish species in the model, both of which are caught by the fishery. The annual number of recruits was equal for the two species, and arbitrarily set to 500 per year (Table 5.1). The species differed with respect to their nursery grounds: all individuals of species 1 were born in the northern area, while all individuals of species 2 were born in the southern area (Fig. 5.3). The maximum age that any individual can reach was 6 years old. During their life, individuals grew in length towards the asymptotic length, which was 50 $\mathrm{cm}$ for both species (Table 5.1). Conversion from length to weight was also equal for the two species (Fig. 5.4). Migration was parameterized so that a gradual diffusion occurred between the two areas, equal to 2.5 percent of the difference in abundance (Table 5.1). For the unfished situation this led to a clear segregation of the younger ages over the two areas, while the older ages were equally distributed over the two areas (Fig. 5.3). Mortality from natural causes such as predation, diseases, and senescence was assumed to be negligible, and $M_{i}$ set to 0.0001 . Although such absence of natural mortality is impossible in reality, one could argue that the model produced simpler results while only involving a different scaling.
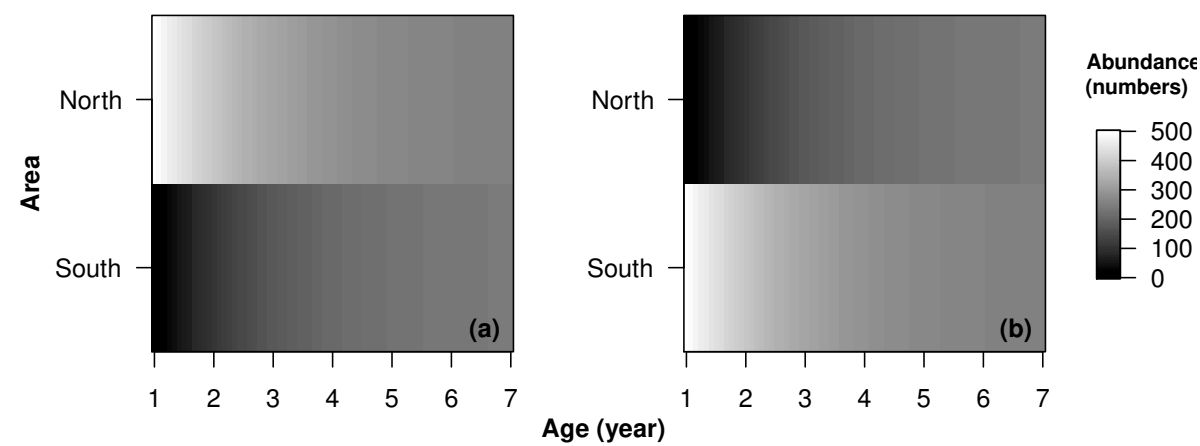

Figure 5.3: Biomass distribution in numbers over the areas as a function of age when stocks are in virgin stock status for species 1 (a) and species 2 (b). For species 1 nursery ground occurs in the northern area, while species 2 in the southern area (high biomass in white). Over the two areas, initial biomass distribution shows a clear segregation of the younger ages (high and low fish biomass, in white and black respectively), while the older ages show similar distributions (grey colours). 
Catchability linked the population biomasses to the catches in the fishery, and was thus one of the crucial parameters determining the interaction between the two. In the case study, catchability $q_{i}$ was assumed independent of age $a$, and equal for the two species (Table 5.1).

The mean prices for the two species were set to 30 euro per $\mathrm{kg}$, ranging between 17.3 euro per $\mathrm{kg}$ for the youngest age and 36.5 euro per $\mathrm{kg}$ for the oldest age (Table 5.1 and Fig. 5.4). The fines for overshooting the quota was set to 3,000 euro per $\mathrm{kg}$ (Table 5.1). These high fines combined with an assumed 100\% detection of exceeding quotas resulted in model results in which fishers comply with quota regulations.

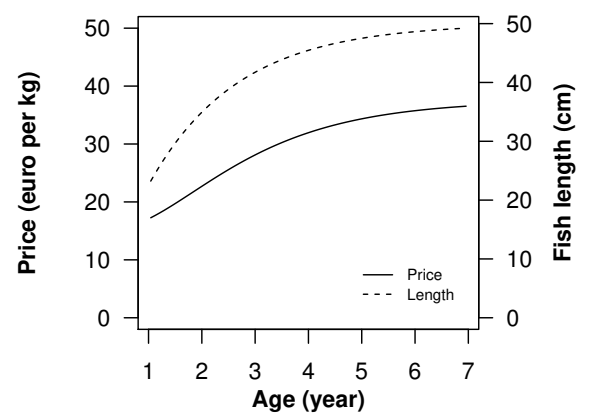

Figure 5.4: Lengths and prices of the two species.

\section{Management procedure}

The management model encompassed the harvest control rules. The HCRs referenced to biological reference points $\left(H_{\max }\right)$ to produce management actions in the form of a harvest or effort level: changes in selectivity or spatial and temporal reallocations or restrictions of fishing effort. The input to the fisheries model consisted of the expected catch rates and the individual quota that were set for each individual in the fleet. These individual quotas were set in a management procedure, which mimicked the decisions of a management body. This management body made observations on the state of the resources, and the exploitation characteristics of the fishery. In the model, the management body was assumed to collect annual observations of the biomass of the stocks, including the distribution of the biomass over the different ages. These observations stem from fisheries independent observations, 
such as surveys with known catchabilities. In addition, the management body made annual observations of the catches, including their age distribution.

The observed biomass and catches allowed for estimation of the annual harvest rates $\left(H_{i}\right)$, and the estimation of a yield per recruit curve, that was dependent on fish growth and mortality. The yield curve was dome shaped, with a maximum that is called $H_{i, \max }$. Fishing at a harvest rate that is equal to $H_{i, \max }$ should lead to maximum sustainable yields. The yield per recruit curve omitted the potential effect of the feedback between adult biomass and recruitment, which anyway was absent in the population dynamics, that assumed a constant recruitment. The HCR used by the management body resulted in annual quotas such that the harvest rate in a year corresponded to $H_{i, \max }$. These quotas were then divided equally over the individual vessels in the simulations.

$$
Q_{i, y+1}=\frac{\sum\left(\left[\frac{H_{i, \max }(a, y, s)}{H_{i}(a, s)} \times H_{i}(a, s) \times \operatorname{sum}\left(N_{i}(a, y, s, p)\right)\right] \times w_{i}(a, s)\right)}{\text { number of vessels }} .
$$

\subsubsection{Scenarios}

The model was set up in three consecutive time windows. The first window of 10 years was enough to get to stable populations. During this first period, new young individuals entered the population in the absence of fishing. This resulted in a virgin stock status. The consecutive 15 years, the fleet of 8000 vessels started fishing in the absence of any fisheries regulations. During this time window, the fishery was unmanaged, with unlimited quota for both species (pre-manage period). During the last 15 years of projections, the management procedure was introduced, the fishery was constrained by setting MSY targets while discarding was not allowed (post-manage period).

Two management scenarios were examined in the model. The two scenarios differ in the number of stocks under quota. In the "single-species catch quota" scenario quota on species 1 was controlled by the HCR. In the "both-species catch quota" quotas on both species were controlled by HCRs. The comparison among these scenarios allowed the evaluation of costs and benefits, both economic and in terms of risks to both stock and livelihoods, that resulted from the response of individual effort allocation to meet the objectives of the landing obligation regarding the 
objectives of the CFP, specially the MSY. To be able to analyse the results of this complex actions of implementing the MSY and the LO, we simulated the effects of implementing the $\mathrm{LO}$ without any exceptions or flexibility. When necessary, for example, in the case of estimating the modelled monthly mean of harvest rates, 5 years windows were selected to characterise the fleet in that pre- and post-manage period for both species (grey and green areas in Fig. 5.5, respectively).

\subsection{Results}

Stochastic simulations were carried out for the management scenarios contemplated where one or both species were managed at MSY and discarding was not allowed (LO).

Figure 5.5 shows the expected catch of the two target species and the impact of the management scenarios on simulated catch. When the fishery was unmanaged, both stocks were overexploited with a harvest rate of 4 ton per species, a value that exceeded the catch that can be harvested sustainably $\left(H_{\max }\right)$. In both scenarios, the introduction of MP caused an immediate reduction in catches of target species in the shortterm. However, after this reduction in the initial years, the stock biomass increased in the mid-term (after a transition of $<5$ years), and therefore mid-term TACs and catches were higher than before the implementation of the MP (Fig. 5.5, c and d). The most notable differences in catch between the different scenarios lied in the absence of a regulatory quota for species 2 . In the case where the fishery was limited only by HCR for species 1; higher catches for species 1 were observed in the mid-term, while the catch of species 2 remained at the reduced level similar to the unmanaged situation. As there was no quota restriction on species 2, catches of species 1 were adjusted to the estimated TAC in the HCR (Fig. 5.5 , a and b). When the fishery that was governed by quotas for both species, differences between catches and quotas were more noticeable due to the choke effect. As the mature stages of both species overlap in their spatial distribution and the young stages differed in their spatial distribution (Fig. 5.3), some fishing opportunities would always be lost under the LO. The choke effect reduced the effort and made the fleet incapable of fishing up their quota share.

Modelling results indicated that the age composition of the harvest during the post-manage period was different than during the pre-manage 


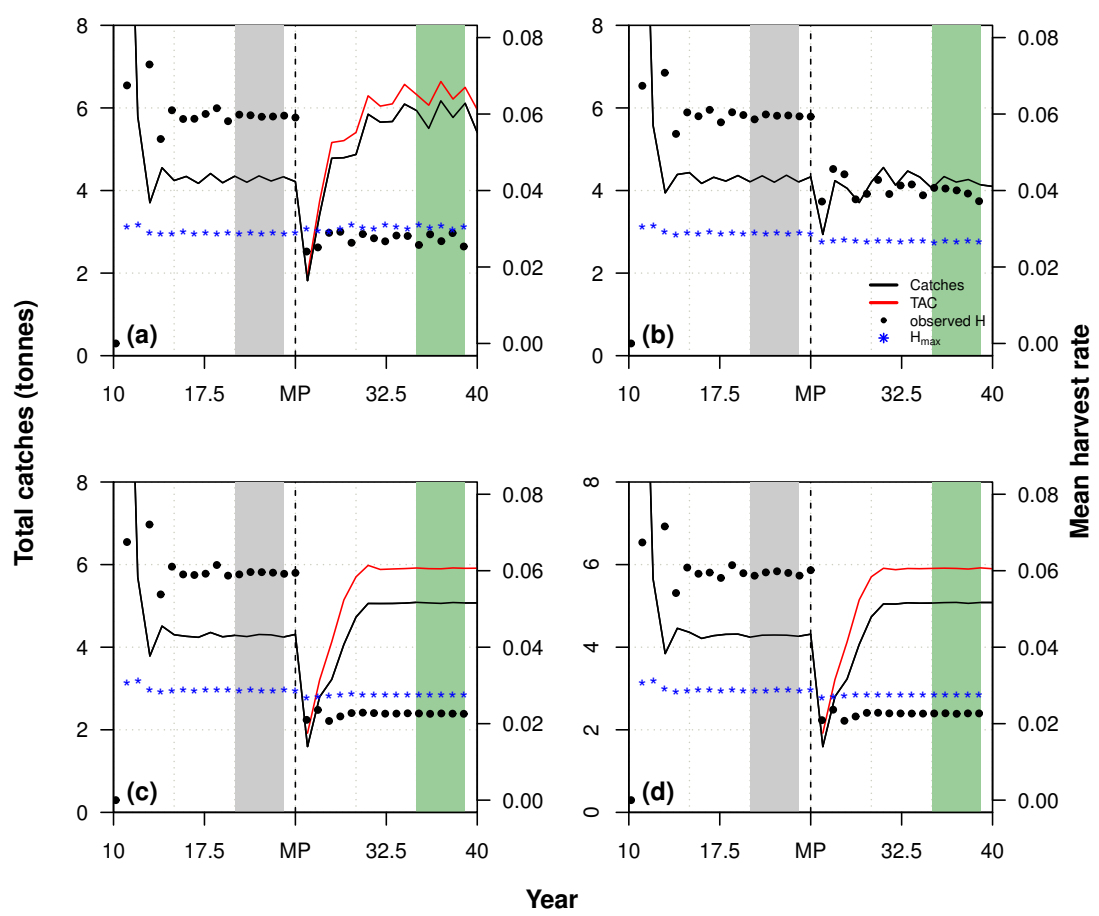

Figure 5.5: Modelled total annual catches (tonnes) for all vessels and both species: species $1(\mathrm{a}, \mathrm{c})$ and species $2(\mathrm{~b}, \mathrm{~d})$ in relation to the available individual quota (red line). In the top panels only species 1 quota constrained the fishery $(a, b)$, while in the bottom panels both species quota constrained the fishery $(\mathrm{c}, \mathrm{d})$. MP year reflects the year where the management plan was introduced. Grey and green areas reflect the pre- and post-manage 5 -year period, respectively.

period (Fig. 5.6). In the pre-manage period harvesting above the $H_{\max }$ (with values around 0.03, Fig. 5.5) caused instability in both populations. Overharvesting was caused by more significant harvesting juvenile specimens than adults, as reflected in the downward slope of the harvest rate curves with fish age (rather than selectively targeting older fish with higher price; Fig. 5.6). Average harvest rates was 0.06 (Fig. 5.6 and 5.7, black lines). Harvests and population biomass remained stable over time due to the constant annual recruitment. On the other hand, after the implementation of the MP there was an immediate decrease in harvest 
rates with values equal to or below $H_{\max }$. After a few years (mid-term), 2 to 6-year old fish were harvested at the same, while yearling fish (age class 1) was harvested at lower rates (Fig. 5.6 and 5.7, grey lines).

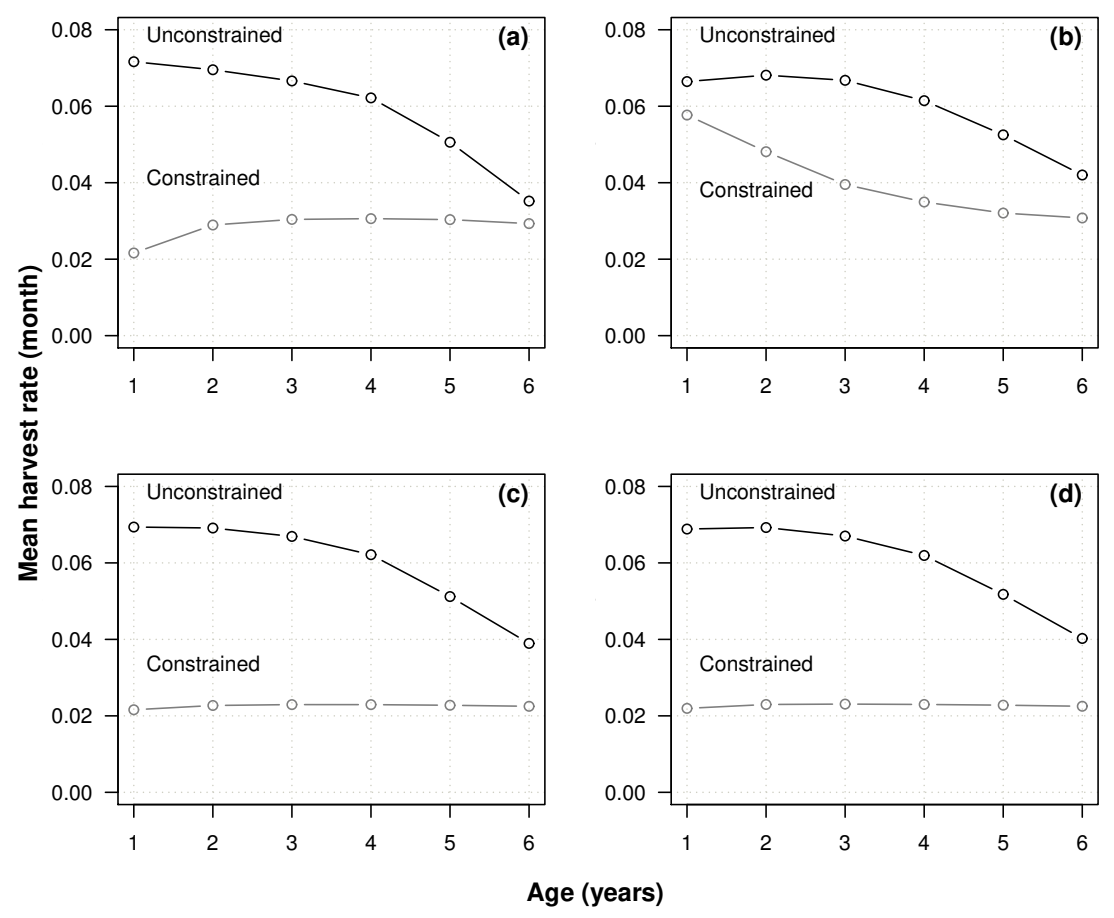

Figure 5.6: Modelled changes in harvest rates for both species in relation to the catch decision options made based in the available individual quota: species 1 $(\mathrm{a}, \mathrm{c})$ and species $2(\mathrm{~b}, \mathrm{~d})$. In top panels only species 1 quota constrained the fishery $(\mathrm{a}, \mathrm{b})$, while in bottom panels both species quota constrained the fishery $(\mathrm{c}, \mathrm{d})$. Black lines: mean harvest rates during the pre-manage period (unconstrained fishery); grey line: mean harvest rates during the post-manage period (constrained fishery). Periods are relative to the introduction of the management plan (grey and green areas in Fig. 5.5).

Expected yields as a function of harvest show that during the postmanage period both species were underharvested (Fig. 5.7; grey lines in a,c,d), except species 2 in the single-stock quota scenario which was overharvested due to the absence of any quota restriction (Fig. 5.7; panel b). Indeed, higher sustainable yields achieved with lower values of 
fishing mortality. When quotas were set for both species, yields were $25 \%$ higher than in the unmanaged situation. When a quota was set for just one species, yield for species 1 was $50 \%$ higher than the unconstrained fishery value. These differences in scenarios could be explained due to the choke effect. In general, the expected average yields shown similar values than the observed catches during the pre- and post-manage period selected (Fig. 5.7).

The fishing effort that would lead the fishery toward the biological management reference points can be seen in Figure 5.8. In an unmanaged situation, fishing in both the northern and southern fishing grounds would be equally profitable. Therefore, the fleet effort was equally distributed over both areas and generated a net profit of 130 thousand Euros/ year (Fig. $5.8 \mathrm{~b}$ and d). The vessels spend about $20 \%$ of their time in port. Fuel costs related to fishing choices were $40 \%$ of the incurred gross revenues (Fig. $5.8 \mathrm{~b}$ an d). Fishing in the northern (southern) area, during the pre-manage period, showed annual average catches of 3.1 tonnes/ year and 1.2 tonnes/year of species 1 and 2 , respectively (1.2 tonnes/year and 3.1 tonnes/ year), which in terms of activity would be fishing around 3100 days per area and season (Fig. 5.9 and 5.10 a and c). Some variability was apparent between patch choices in the two scenarios (Fig. 5.8 a and c, 5.9 and 5.10); however, gross and net revenues at the end of each year resulted in similar values (Fig5.8 b and d).

In the management scenario with a MSY quota set for one species the fleet generated $42 \%$ less revenue, in the short-term, and a $37 \%$ reduction in fishing effort than when compared to the unmanaged situation (Fig. 5.8). Vessels allocated $80 \%(20 \%)$ of the fishing effort in the southern (northern) fishing ground, while maintaining (reducing) both species catches (Fig. 5.9). On the other hand, such reductions in effort and changes in exploitation patterns led to an increase in stock biomass that generated a completely different picture in the mid-term. Maintaining the distribution of effort observed in the short-term, in the mid-term, the fleet would generate an average increase revenue of $77 \%$ with respect to the pre-managed period, while average fuel cost were reduced to $20 \%$ of the incurred gross revenues (Fig. 5.8 b). After the initial $57 \%$ to 32 $\%$ decline in catches of species 1 and 2 following the implementation of the MP, fishing in the southern (northern) area, during the post-manage period, showed on average $181 \%$ and $13 \%$ higher catch of species 1 and 

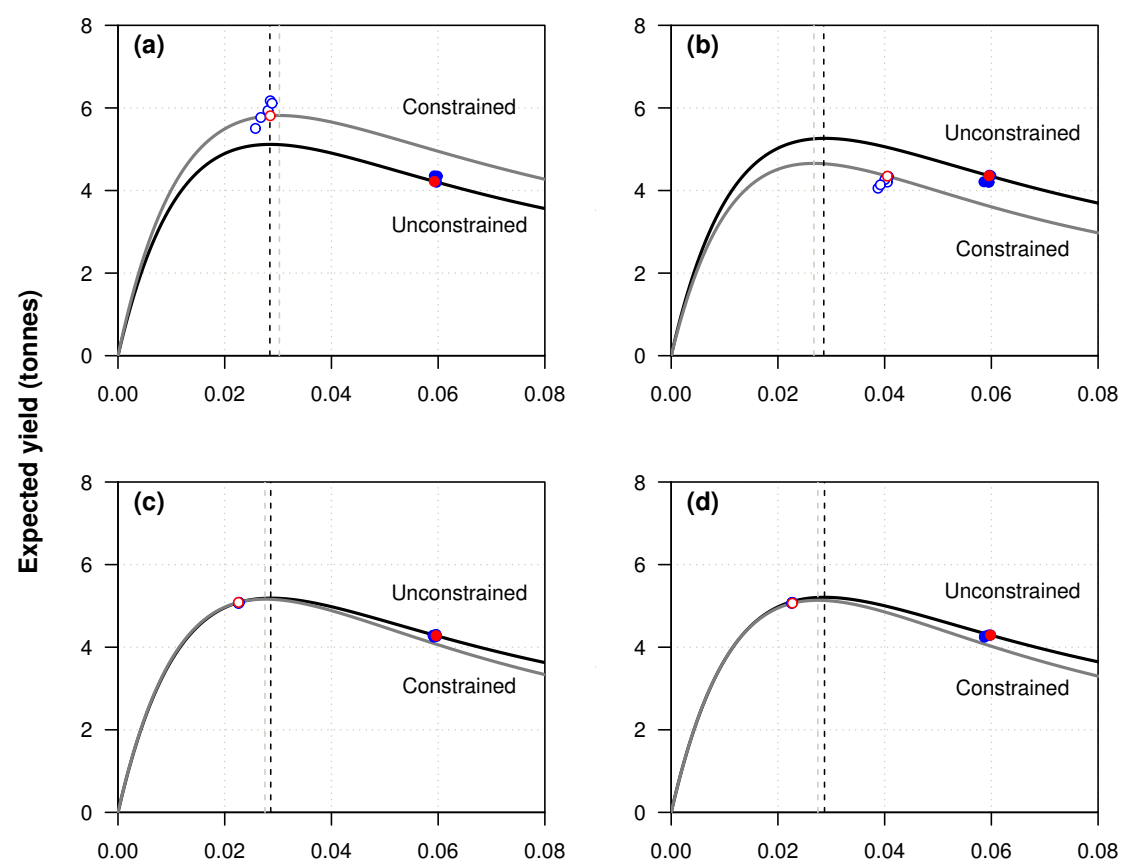

Mean harvest rate (ages)

Figure 5.7: Modelled yield per recruitment curves (tonnes) for both species in relation to the introduction of the management plan: species $1(\mathrm{a}, \mathrm{c})$ and species $2(\mathrm{~b}, \mathrm{~d})$. In top panels only species 1 quota constrained the fishery $(\mathrm{a}, \mathrm{b})$, while in bottom panels both species quota constrained the fishery $(\mathrm{c}, \mathrm{d})$. Black lines: expected yield during the pre-manage period (unconstrained fishery); grey line: expected yield during the post-manage period (constrained fishery). Periods are relative to the introduction of the management plan (grey and green areas in Fig. 5.5). Blue dots represent the observed catches at the mean harvest rate for each year during the 5 -year period (filled dots: pre-manage period and empty dots: post-manage period), while red dots are the expected yields at sustainable harvest rates.

2 than the pre-manage period, respectively ( $17 \%$ and $38 \%$ lower catches of species 1 and 2)(Fig. $5.9 \mathrm{a}$ and b). In terms of activity the average number of fishing days per season dropped to 3650 days (Fig. $5.10 \mathrm{~b}$ ). Vessels were incentivized to allocate the highest amount of effort early in the year (with around 1075 and 3700 fishing days in the northern and southern fishing grounds respectively), progressively decreasing to lower 


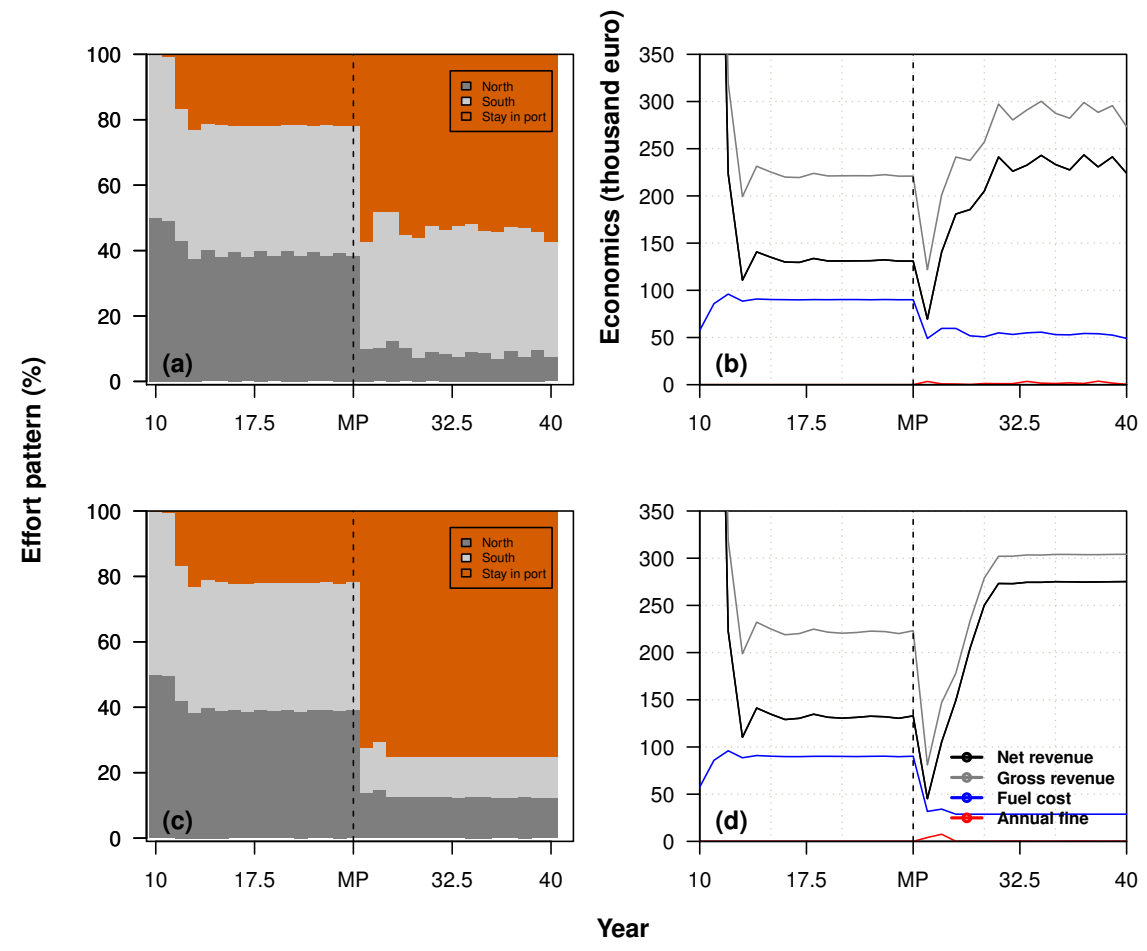

Figure 5.8: Modelled spatial allocation of effort per year (\%) and the respective economic performance when only species 1 has quota limitations (a, b) and both species are quota limited $(\mathrm{c}, \mathrm{d})$. Trade-offs between net revenue (black line), gross revenue (grey line), fuel cost (blue line) and annual fines (red line) for the fleet are shown in panels (b,d). MP years reflect the year where the management plan was introduced. In top panels only species 1 quota constrained the fishery $(\mathrm{a}, \mathrm{b})$, while in bottom panels both species quota constrained the fishery $(c, d)$.

levels over the course of the year (with around 121 and 1634 fishing days per area; Fig. 5.10 d).

The management scenario with a MSY quota set for both species showed a further reduction in fishing opportunities (Fig. 5.8). In the short-term, the fleet generated $61 \%$ less revenue and a $62 \%$ reduction in fishing effort than when compared to the unmanaged situation. Vessels indistinctly allocated the fishing effort in both fishing grounds (such in the pre-manage period) due to same model conditioning for both species. 

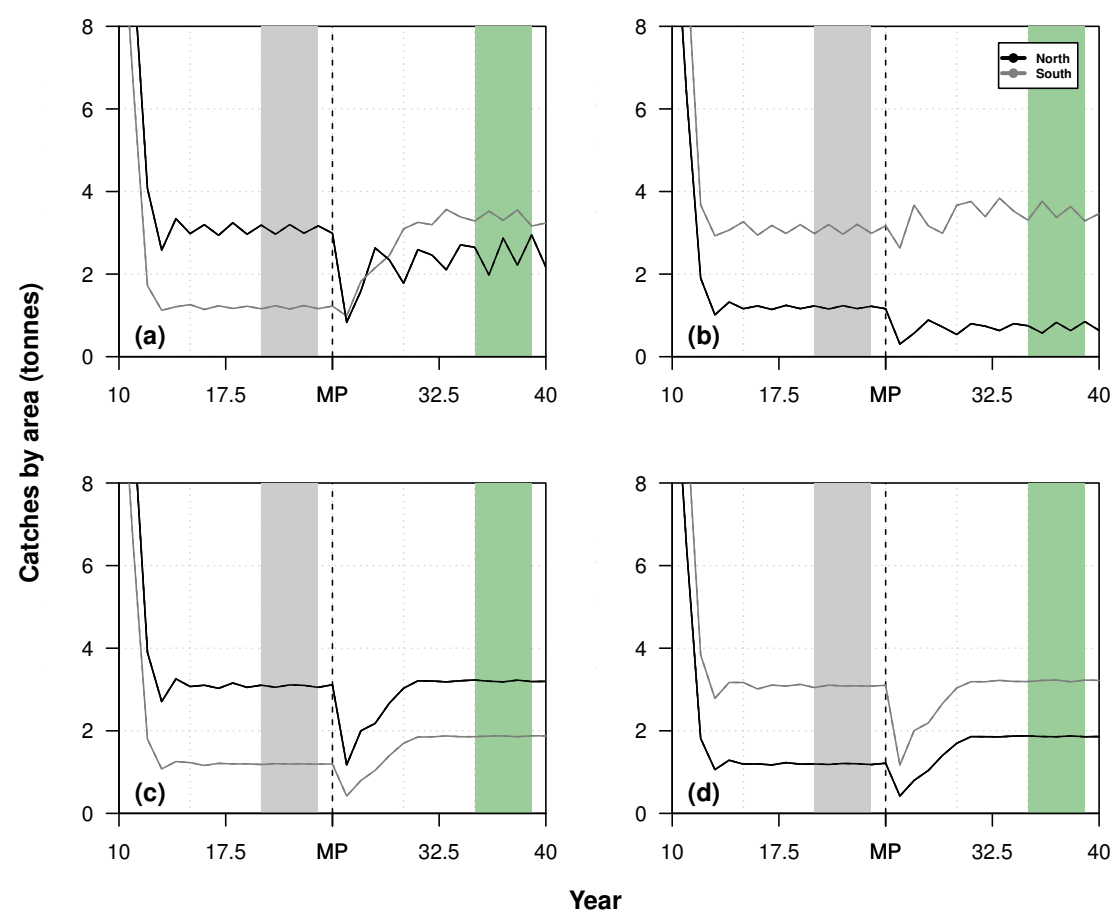

Figure 5.9: Modelled catches (thousand tonnes/year) by area (blue line: Northern area, red line: Southern area) for both (a,c) species 1 and $(b, d)$ species 2 in relation to the management plan period. In panels $(a, b)$ only species 1 quota constrained the fishery, while in $(\mathrm{c}, \mathrm{d})$ both species quota constrained the fishery. MP year reflects the year where the management plan was introduced. Grey and green areas reflect the pre- and postmanage 5-year period, respectively.

Therefore, after the initial $62 \%$ to $65 \%$ decline in cathes due to the MP implementation, fishing in the northern (southern) area, during the post-manage period, simulations showed in average $2 \%$ and $54 \%$ higher catches of species 1 and 2 than the pre-manage period, respectively (55\% and $4 \%$ )(Fig. $5.9 \mathrm{c}$ and d). The limiting species quota incentivized vessels to choose to allocate the highest amount of effort early in the year (with around 2500 fishing days per area), progressively decreasing to lower levels over the course of the year (with around 50 fishing days per area; Fig. 5.10 d). In the mid-term, the fleet would generate an average 
increase revenue of $107 \%$ with respect to the pre-managed period.
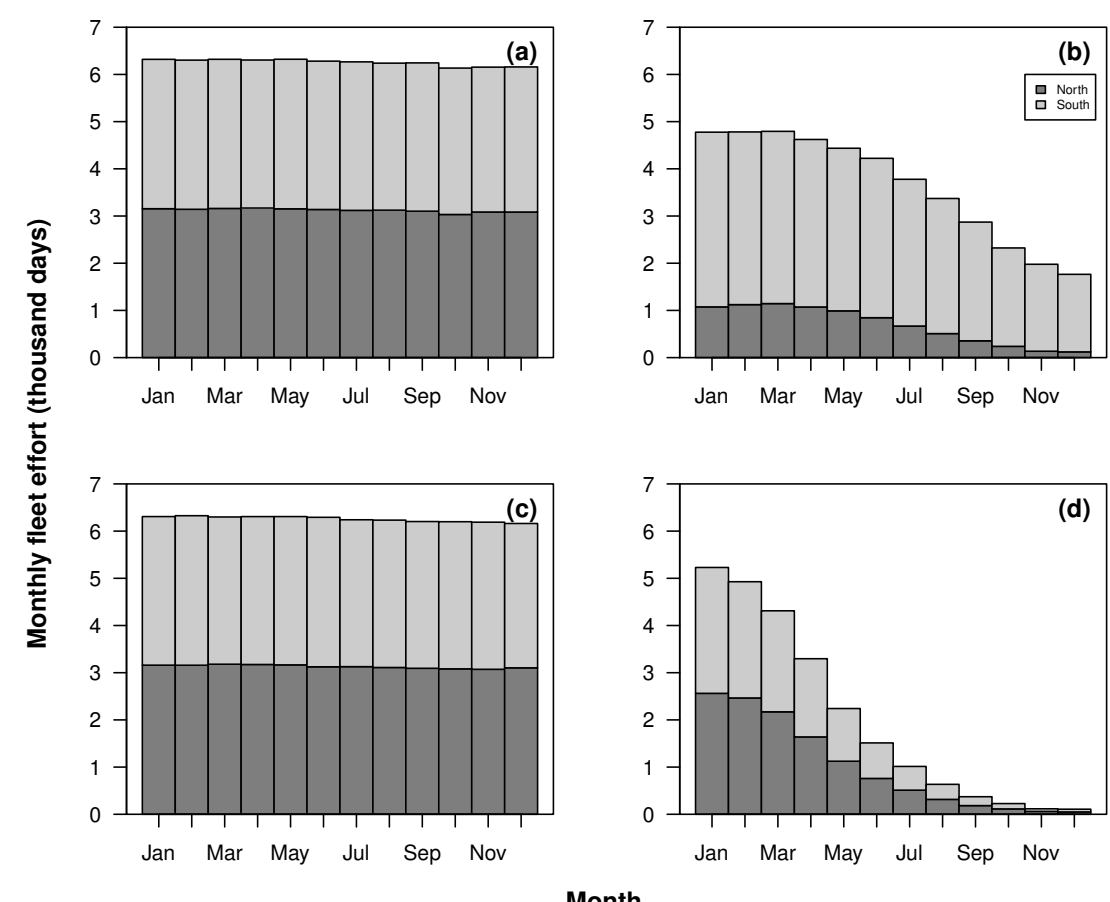

Month

Figure 5.10: Modelled average spatial allocation of effort (days/month) during the pre-manage $(\mathrm{a}, \mathrm{c})$ and post-manage periods $(\mathrm{b}, \mathrm{d})$. Periods are relative to the introduction of the management plan (grey and green areas in Fig. $5.9)$.

Modelling results suggested that moving from an unmanaged period to a sustainable stock situation, where one or both species were regulated by quotas and forced to keep fishing mortality below the MSY while it was not possible to discard, moderate and high reductions of fishing effort are expected (Fig. 5.8, b and d). Thus, moderate to high reductions in the number of vessels modelled are expected too (effort cost per vessel 1 day; Fig. 5.10, b and d). The relative annual contribution by vessel to the gross revenue was around 28 Euros, reduced to 17 Euros of net revenues due to the costs associated to fuel during the unmanaged situation (Fig. 5.11). This implies that, in the short-term, revenues under the two scenarios are predicted to result in a loss of profitability $(52 \%$ when 
accounting in one species MSY quota and 34\% when accounting in both MSY quota; Fig. 5.11). However, in the mid-term, when compared to the pre-manage period, accounting in one species MSY quota resulted in a 1.32 times larger gross revenues per vessel; while accounting in two species MSY quotas was 1.37 times larger benefits (Fig. 5.11).
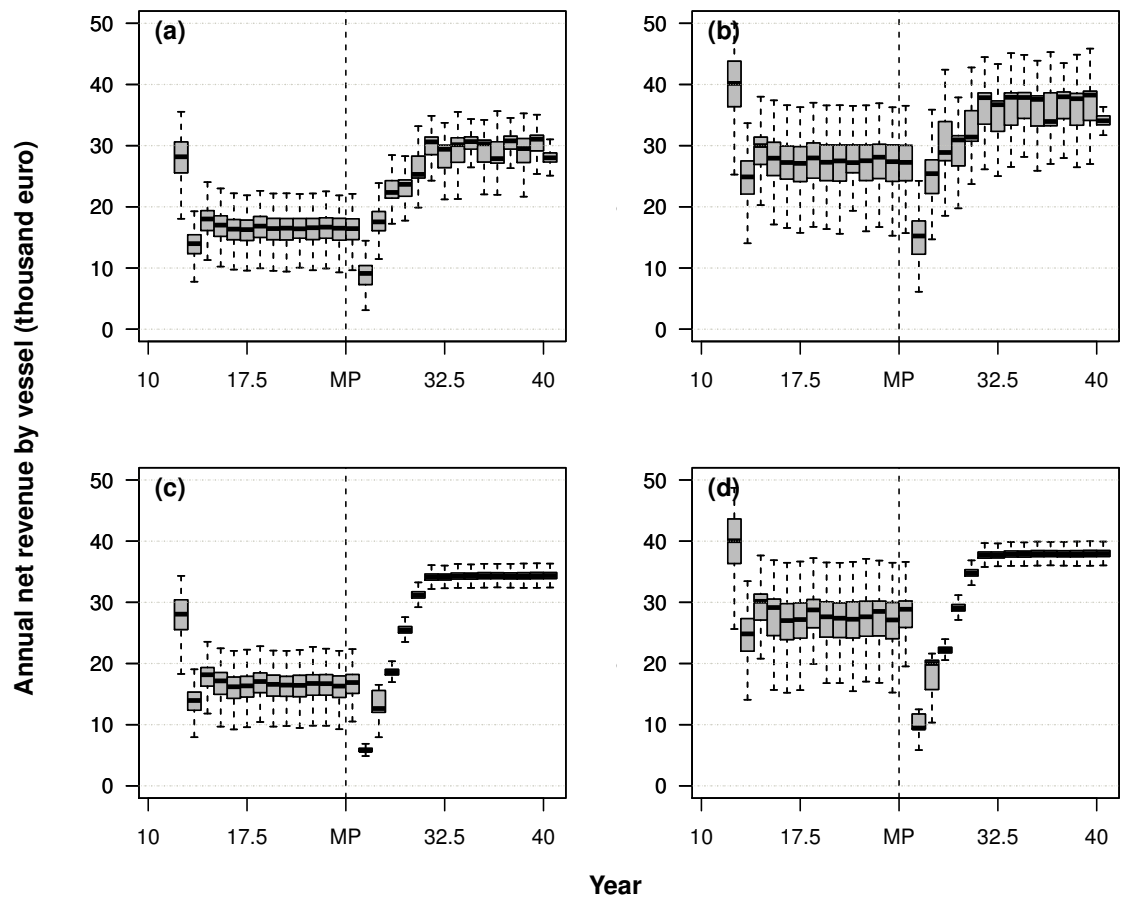

Figure 5.11: Modelled main economics by vessel (euro/ year): median annual net revenues $(\mathrm{a}, \mathrm{c})$ and median gross revenues $(\mathrm{b}, \mathrm{d})$ with the upper and lower limits of the box being the third and first quartile1 (75th and 25th percentile) respectively. MP year reflects the year where the management plan was introduced.

\subsection{Discussion}

Our results suggest that in mixed fisheries, constraining quota for a single-species can bring risk of eroding the production potential of other unconstrained species. The only prerequisite for this to happen is a difference in the spatial in distribution between the species of the juvenile 
and adult stages. In our study species differed only in the location of their nursery habitat, while growth, recruitment numbers, mortality, and price were the same for both species. Changes in quota constraints led to a spatial redistribution of the fishery and as a result of this redistribution the age-dependent exploitation for both species changed. The quota set for one species resulted in a shift of fishing pressure towards younger ages of the unconstrained species. This in turn decreased the production of the unmanaged stock, as can be seen from the yield curves (Fig. $5.6)$.

Meanwhile, when constraining both species, the production potential of both stocks was maintained, that is to say the yield curves were unchanged. The quota constraints were met by a reduction in fishing effort (Fig. 5.8). as predicted in general terms by (Ulrich et al., 2017). This led to a reduction in fishing cost and an increase in net revenue over the mid-term because biomasses and yields increased. However, individual quota combined with the stochastic fisheries catches resulted in lower than intended exploitation rates. The TACs were set so that the total TACs corresponded to the harvest rate that resulted in maximum sustainable yields. The TACs were divided in individual quotas for each fishing vessel. The lower than intended harvest rates were caused by the fact that despite their planning, fishers often exhausted one of the quotas before the other. If discarding is not allowed, individual fishers must stop fishing. This resulted in overall catches below the TACs. Although the lack of achieving MSY in mixed fisheries with multiple single-species quota has been described elsewhere (Hilborn et al., 2015; Kempf et al., 2016; Rindorf et al., 2017), it is generally attributed to differences in lifehistories among fished species. In this study, the discrepancy between the intended annual quotas at MSY and realized catches is caused only by stochasticity in the system. This stochasticity in catch rates is observed in most fisheries (Bernasconi et al., 2015; Sampson, 1988; Smith, 1980; Van Oostenbrugge et al., 2004). It is caused by the complex migration biology and the effects of environmental factors on fish behaviour. A well-functioning quota market would allow vessels to swap excess quota for constraining and thus bring realized catches closer to quotas.

In the case study explored here, setting quotas based on MSY for all species resulted in mixed fisheries that were economically more viable in the long run compared to the unconstrained case. It should be noted 
that this particular result may not hold true for mixed fisheries with unavoidable catches or bycatches of very low productive species. Fishing those species at their MSY levels would probably constrain effort to such an extent that the net revenue will be reduced in the long-term (Prellezo et al., 2016b; Rindorf et al., 2017).

The model aimed to evaluate the biological and economic effects of adopting a major policy change such as the CFP (EU, 2013). Starting from an overfished mixed fishery under open access conditions but with a landing obligation, the response of individual effort allocation and the interannual population dynamics are explicitly modelled, while adopting MSY objectives. The analysis extended earlier approaches that used short-term state-dependent decision-making models (e.g. (Alzorriz et al., 2018; Batsleer et al., 2016; Poos et al., 2010)) by including interannual population dynamics of fish stocks, and a management procedure that mimics the decisions of a management system. Such an MSE framework was thought of as a minimum realistic model (Kell et al., 2007; Punt and Butterworth, 1995). To keep the outcomes of the model simple, and to show the implications of the fishing effort allocation, the two fish populations modelled here are exactly the same apart from their spatial distribution difference (Fig. 5.3). As a result, if the landing obligation changes selectivity patterns in the short-term as predicted in (Alzorriz et al., 2018; Batsleer et al., 2016), the present MSE modelling approach allows the evaluation on the reference points for sustainable exploitation in longer terms by explicitly modelling how changes in exploitation rates impact fish populations and yields.

The forecasted effects of fisheries management in mixed fisheries result from spatial heterogeneity in resources and fishers adaptive behaviour. This emphasizes that human behaviour and decision-making are intrinsic parts of conservation and natural resource management and the need for incorporating detailed fishing dynamics in management strategy evaluation. Historically, the focus of management strategy evaluation has been primarily on population dynamics in single and multi-species fisheries (Butterworth, 2007; Dichmont et al., 2006; Punt and Hobday, 2009; Punt and Smith, 1999; Punt et al., 2016; Smith et al., 1999). Explicitly incorporating direct effects of human behaviour of those who harvest stocks is equally important (Fulton et al., 2011; Link et al., 2017; Milner-Gulland, 2012), but relatively few studies have attempted this (Andersen et al., 
2010; Ono et al., 2018; Simons et al., 2015). Our MSE that links a dynamic state variable model for fisher behaviour to a multi-species age structured model provides an alternative to those approaches.

The complexity of adding fishers behaviour in a minimum realistic model of mixed fisheries in an MSE framework requires making several simplifying assumptions. The details and possible consequences of these assumptions have been discussed in e.g. (Alzorriz et al., 2018), and include full compliance of fishers with the discarding policy, absence of a quota market, monthly choices on fishing, and a lack of interference competition among fishers. Also, the utility function only comprises of decisions based on annual net revenues, omitting any social dynamics or tradition. These social dynamics and traditions are potentially important (Girardin et al., 2017; Schlüter et al., 2012), and could be incorporated in future applications. Important assumptions about the dynamics of the population dynamics included negligible natural mortality, constant recruitment, constant growth, and constant migration.

In the study, the fishers were not allowed to discard, complying to a landings obligation. We did not include the use of discard flexibilities of the LO (CFP Article 15, (EU, 2013)) or annual quota swaps as they are currently implemented. We may thus have underestimated the flexibility of the fishery to respond to quota limitations imposed under both the landing obligation and exploiting at MSY (Prellezo et al., 2016a). Achieving a balance between quota flexibility, over-exploitation risk, and administrative simplicity is critical for the profitability and sustainability of multi-species fisheries (Alzorriz et al., 2018). The success of any new regulation also depends on achieving a balance between the costs and benefits of measures that promote voluntary compliance and those that punish non-compliance. With poor enforcement the economic benefits of non-compliance outweigh the risks of detection (Batsleer et al., 2013). In this MSE framework, detection rates were assumed to be $100 \%$ and fines were set sufficiently high so that no discarding occurred, reflecting full compliance with regulations. However, if detection rates are low and the short-term benefits of non-compliance are high (as our results suggest) then non-compliance is likely to be a substantial problem in the absence of measures promoting voluntary compliance. 


\subsection{Conclusions}

Achieving optimal yield from mixed fisheries is a pervasive problem in fisheries management (e.g., (Farcas and Rossberg, 2016; Prellezo et al., 2016c; Salomon et al., 2014; Ulrich et al., 2017; Voss et al., 2014)). A multi-species fishery MSE framework based on two populations was developed in this study to examine different management scenarios. The results highlight pitfalls in managing mixed fisheries where erosion of production potential can take place, or unintentional underharvesting. We argue for the inclusion of spatial dynamics and fleet dynamics when designing a multi-species fishery management strategy evaluation. Such MSE should be done when adopting a major policy change such as the CFP. Future studies aimed at building a realistic multi-species fishery MSE with significant discard constraints, should consider expanding the current model to include the whole suite of species exploited and managed in a real mixed fishery. The results highlighted the importance of accounting for technical interactions and their temporal dynamics in both quota allocation and fleet dynamics to design a realistic multispecies fishery management strategy analysis.

\subsection{Acknowledgements}

The content of this paper does not reflect the official opinion of the European Commission. Responsibility for the information and views expressed in this paper relies entirely with the authors. 


\subsection{References}

Alzorriz, N., Arregi, L., Herrmann, B., Sistiaga, M., Casey, J., and Poos, J. J. 2016. Questioning the effectiveness of technical measures implemented by the Basque bottom otter trawl fleet: Implications under the EU landing obligation. Fisheries Research, 175:116-126.

Alzorriz, N., Jardim, E., and Poos, J. J. 2018. Likely status and changes in the main economic and fishery indicators under various discard policies: a vase stufy of the Basque trawl fishery. Fisheries Research, 205:86-95.

Andersen, B. S., Vermard, Y., Ulrich, C., Hutton, T., and Poos, J. J. 2010. Challenges in integrating short-term behaviour in a mixed-fishery Management Strategies Evaluation frame: A case study of the North Sea flatfish fishery. Fisheries Research, 102(1-2):26-40.

Batsleer, J., Poos, J. J., Marchal, P., Vermard, Y., and Rijnsdorp, A. D. 2013. Mixed fisheries management: Protecting the weakest link. Marine Ecology Progress Series, 479:177-190.

Batsleer, J., Hamon, K. G., van Overzee, H. M. J., Rijnsdorp, A. D., and Poos, J. J. 2015. High-grading and overquota discarding in mixed fisheries. Reviews in Fish Biology and Fisheries, 25: 715-736.

Batsleer, J., Rijnsdorp, A. D., Hamon, K. G., van Overzee, H. M. J., and Poos, J. J. 2016. Mixed fisheries management: Is the ban on discarding likely to promote more selective and fuel efficient fishing in the Dutch flatfish fishery? Fisheries Research, 174:118-128.

Bernasconi, J., Perier, M., and Di Giácomo, E. 2015. Standardized catch rate of cock-fish, callorhinchus callorynchus, in a bottom trawl fishery of patagonia: Is it possible its use as a predictor of abundance trend? Brazilian Journal of Oceanography, 63(2):147-160.

Bunnefeld, N., Hoshino, E., and MilnerGulland, E. 2011. Management strategy evaluation: A powerful tool for conservation? Trends in Ecology and Evolution, 26(9):441-447.

Butterworth, D. S. 2007. Why a management procedure approach? Some positive and negatives. ICES Journal of Marine Science, 64(1995):613-617.

Clark, C. W. and Mangel, M. Dynamic state variable models in ecology: Methods and applications. Oxford University Press, New York, 2000. ISBN 0195122666.

Dichmont, C., Deng, A., Punt, A., Venables, W., and Haddon, M. 2006. Management strategies for short lived species: The case of australia's northern prawn fishery. 2. choosing appropriate management strategies using input controls. Fisheries Research, 82(1-3):221234.

Dowling, N. A., Wilcox, C., Mangel, M., and Pascoe, S. 2011. Assessing opportunity and relocation costs of marine protected areas using a behavioural model of longline fleet dynamics. Fish and Fisheries, 13(2):139-157.

EU. Regulation (EU) No 1380/2013 of the European Parliament and of the Council of 11 December 2013 on the Common Fisheries Policy, 2013.

Farcas, A. and Rossberg, A. 2016. Maximum sustainable yield from interacting fish stocks in an uncertain world : two policy choices and underlying trade-offs. Unpublished, 73:36. ISSN 1054-3139. doi: 10.1093/icesjms/ fsw113. URL http://arxiv.org/pdf/ 1412.0199v3.pdf. 
Fulton, E. A., Smith, A. D. M., and Smith, D. C. Quantitative MSE of Alternative Management Strategies for Southeast Australian Fisheries. Technical Report June, CSIRO, 2007. URL https: //research.csiro.au/atlantis/wpcontent/uploads/sites/52/2015/10/ AMS_Final_Report_v6.pdf.

Fulton, E. A., Link, J. S., Kaplan, I. C., Savina-Rolland, M., Johnson, P., Ainsworth, C., Horne, P., Gorton, R., Gamble, R. J., Smith, A. D. M., and Smith, D. C. 2011. Lessons in modelling and management of marine ecosystems: the Atlantis experience. Fish and Fisheries, 12(2):171-188.

Gillis, D. M., Pikitch, E. K., and Petermanc, R. M. 1995. Dynamic discarding decisions: foraging theory for highgrading in a trawl fishery. Behavioral Ecology, 6(2):146-154.

Girardin, R., Hamon, K., Pinnegar, J., Poos, J., Thébaud, O., Tidd, A., Vermard, Y., and Marchal, P. 2017. Thirty years of fleet dynamics modelling using discrete-choice models: What have we learned? Fish and Fisheries, 18:638655 .

Hilborn, R., Fulton, E., Green, B., Hartmann, K., Tracey, S., and Watson, R. 2015. When is a fishery sustainable? Canadian Journal of Fisheries and Aquatic Sciences, 72(9):1433-1441.

Houston, A. and McNamara, J. Models of Adaptive Behaviour. Cambridge University Press, Cambridge, 1999.

Kell, L. T., Mosqueira, I., Grosjean, P., Fromentin, J. M., Garcia, D., Hillary, R., Jardim, E., Mardle, S., Pastoors, M. A., Poos, J. J., Scott, F., and Scott, R. D. 2007. FLR: an open-source framework for the evaluation and development of management strategies. ICES Journal of Marine Science, 64:640-646.
Kempf, A., Mumford, J., Levontin, P., Leach, A., Ho, A., Hamon, K., Bartelings, H., Vinther, M., Stabler, M., Poos, J., Smout, S., Frost, H., van den Burg, S., Ulrich, C., and Rindorf, A. 2016. The msy concept in a multi-objective sheries environment - lessons from the north sea. Marine Policy, 69:146-158.

Link, J., Thébaud, O., Smith, D., Smith, A., Schmidt, J., Rice, J., Poos, J., Pita, C., Lipton, D., Kraan, M., Frusher, S., Doyen, L., Cudennec, A., Criddle, K., and Bailly, D. 2017. Keeping humans in the ecosystem. ICES Journal of Marine Science, 74(7):19471956.

Milner-Gulland, E. 2012. Interactions between human behaviour and ecological systems. Philosophical Transactions of the Royal Society B: Biological Sciences, 367(1586):270-278.

Ono, K., Haynie, A., Hollowed, A., Ianelli, J., McGilliard, C., and Punt, A. 2018. Management strategy analysis for multispecies fisheries, including technical interactions and human behavior in modelling management decisions and fishing. Canadian Journal of Fisheries and Aquatic Sciences, 75(8):1185-1202.

Poos, J. J., Bogaards, J. A., Quirijns, F. J., Gillis, D. M., and Rijnsdorp, A. D. 2010. Individual quotas, fishing effort allocation, and over-quota discarding in mixed fisheries. ICES Journal of Marine Science, 67(2):323-333.

Prellezo, R., Carmona, I., and García, D. 2016a. The bad, The good and the very good of the landing obligation implementation in the Bay of Biscay: A case study of Basque trawlers. Fisheries Research, 181:172-185.

Prellezo, R., I., G., and García, D. 2016b. The bad, the good and the very good of the landing obligation implementation in the Bay of Biscay: A case 
study of Basque trawlers. Fisheries Research, 181:172-185.

Prellezo, R., Santurtún, M., Andonegi, E., Louzao, M., García, D., and Iriondo, A. 2016c. The discard ban and its impact on the Maximum Sustainable Yield objective- The Atlantic Ocean: The Bay of Biscay case. Research for the PECH Committee, European Union, 17:9-81. URL http://www . europarl. europa.eu/ RegData/etudes/STUD/2016/573440/ IPOL_STU (2016) 573440_EN . pdf.

Punt, A. and Hobday, D. 2009. Management strategy evaluation for rock lobster, jasus edwardsii, off victoria, australia: Accounting for uncertainty in stock structure. New Zealand Journal of Marine Freshwater Research, 43(1): 485-509.

Punt, A. and Smith, A. 1999. Harvest strategy evaluation for the eastern stock of gemfish (Rexea solandri). ICES Journal of Marine Science, 56:860-875.

Punt, A. E. and Butterworth, D. S. 1995. The effects of future consumption by the cape fur seal on catches and catch rates of the cape hakes. 4 . modelling the biological interaction between cape fur seals arctocephalus pusillus pusillus and the cape hakes merluccius capensis and m. paradoxus. South African Journal of Marine Science, 16(1):255-285.

Punt, A. E., Butterworth, D. S., de Moor, C. L., De Oliveira, J. A. A., and Haddon, M. 2016. Management strategy evaluation: Best practices. Fish and Fisheries, 17:303-334.

Rademeyer, R. A., Plagányi, É. E., and Butterworth, D. S. 2007. Tips and tricks in designing management procedures. ICES Journal of Marine Science, 64:618-625.

Rindorf, A., Dichmont, C., Levin, P., Mace, P., Pascoe, S., Prellezo, R., Punt,
A., Reid, D., Stephenson, R., Ulrich, C., Vinther, M., and Clausen, L. 2017. Food for thought: Pretty good multispecies yield. ICES Journal of Marine Science, $74(2): 475-486$.

Sainsbury, K. 2000. Design of operational management strategies for achieving fishery ecosystem objectives. ICES Journal of Marine Science, 57(3):731741.

Salomon, M., Markus, T., and Dross, M. 2014. Masterstroke or paper tiger - The reform of the EU's Common Fisheries Policy. Marine Policy, 47:76-84. ISSN 0308597X. doi: 10.1016/j.marpol.2014. 02.001 .

Sampson, D. 1988. Fish capture as a stochastic process. ICES Journal of $M a$ rine Science, 45(1):36-45.

Schlüter, M., McAllister, R., Arlinghaus, N., R.and Bunnefeld, Eisenack, K., Hölker, F., Milner-Gulland, E., Müller, B., Nicholson, E., Quaas, M., and Stöven, M. 2012. New horizons for managing the environment: A review of coupled social-ecological systems modeling. Natural Resource Modeling, 25(1): 219-272.

Simons, S. L., Doring, R., and Temming, A. 2015. Combining area closures with catch regulations in fisheries with spatio-temporal variation: Bioeconomic implications for the North Sea saithe fishery. Marine Policy, 51:281292.

Smith, A. D. M., Sainsbury, K. J., and Stevens, R. A. 1999. Implementing effective fisheries-management systemsmanagement strategy evaluation and the Australian partnership approach. ICES Journal of Marine Science, 56: 967-979.

Smith, S. 1980. Comparison of two methods of estimating the variance 
of the estimate of catch per unit effort. Canadian Journal of Fisheries and Aquatic Sciences, 37(12):2346-2351.

Smith, S. J. 1994. Analysis of Data from Bottom Trawl Surveys. NAFO Sci. Coun. Studies, 28:25-53.

Ulrich, C., Vermard, Y., Dolder, P. J., Brunel, T., Jardim, E., Holmes, S. J., Kempf, A., Mortensen, L. O., Poos, J. J., Rindorf, A., and editor: Emory Anderson, H. 2017. Achieving maximum sustainable yield in mixed fisheries: a management approach for the north sea demersal fisheries. ICES Journal of Marine Science, 74(2):566575.

Van Oostenbrugge, J., Van Densen, W., and MacHiels, M. 2004. How the uncertain outcomes associated with aquatic and land resource use affect livelihood strategies in coastal communities in the central moluccas, indonesia. Agricultural Systems, 82(1):57-91.

Venables, W. N., Ellis, N., Punt, A. E., Dichmont, C. M., and Deng, R. A. 2009.
A simulation strategy for fleet dynamics in Australia's northern prawn fishery: Effort allocation at two scales. ICES Journal of Marine Science, 66(4):631645 .

Voss, R., Quaas, M. F., Schmidt, J. O., and Hoffmann, J. feb 2014. Regional trade-offs from multi-species maximum sustainable yield (MMSY) management options. Marine Ecology Progress Series, 498:1-12. ISSN 01718630. doi: $10.3354 /$ meps10639.

Zimmermann, F. and Heino, M. 2013. Is size-dependent pricing prevalent in fisheries? The case of Norwegian demersal and pelagic fisheries. ICES Journal of Marine Science, 70:1389-1395.

Zimmermann, F., Heino, M., and Steinsham, S. I. 2011. Does Size Matter? A Bioeconomic Perspective on Optimal Harvesting when Price is Sizedependent. Canadian Journal of Fisheries and Aquatic Sciences, 68:16511659 . 



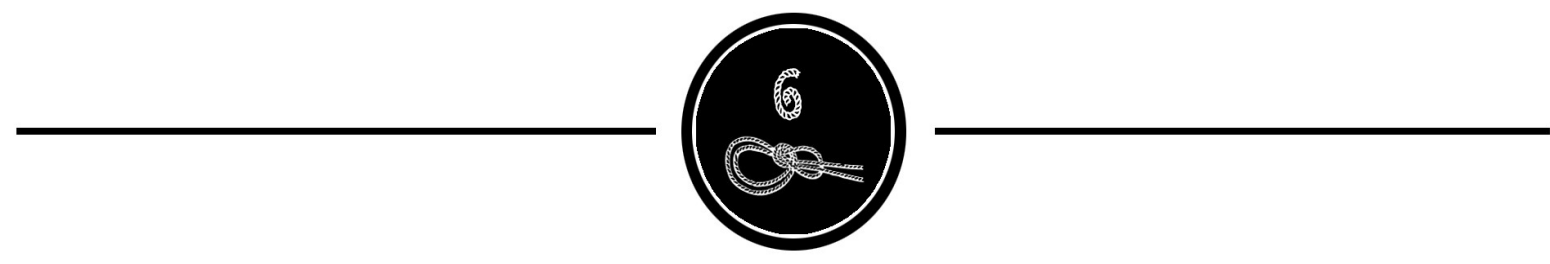

- SYNTHESIS · 


\subsection{General discussion}

This thesis studies the effects of the landing obligation that entered into force on 1 January 2014 aimed to reduce the discarding of unwanted catch. At the time that the landing obligation was decided, little was known about the effects of the landing obligation and the response of the fisheries to this drastic measure. Historically, discarding was a common practice in almost all developed fisheries worldwide: discards were estimated to be as much as $33 \%$ of global marine catch in commercial fisheries in the late 1990s and early 2000s (Alverson et al., 1994; Kelleher, 2005). However, fisheries discard practices can be expected to vary greatly across locations, gears, species and fishing grounds (Sigurǒardóttir et al., 2015; Uhlmann et al., 2013). Across EU fisheries, the amount of discards varies from more than $60 \%$ of the catch (in weight) on average in beam trawls to very low in others, such as pelagic trawling or seine fisheries (Hedley et al., 2015). There has also long been a great contrast between the situation in the EU waters, where discards rates have historically been estimated to be among the highest in the world, and the situation in the Norwegian waters where discarding has been banned since 1983 (Ulrich, 2018).

The landing obligation intends to fully stop discarding, that was seen as an undesirable practice: throwing fish overboard causes addition mortality on fish stocks and is considered an unethical waste of food without benefit for society. It also potentially contributes to the overexploitation of fish stocks, and hampers scientific advice, if discards are not correctly or fully monitored. Previously, market and regulatory forces motivated fishers to discard catches. For example, for some species or size classes, the market value was so low that catches would be returned to the sea. This included damaged fish, or fish for which there was not market at all. Regulatory forces included the exhaustion of landings quota for species that forced fishers to discard catches. Also, catches that did not meet a minimum landings size were legally required to be discarded (Bellido et al., 2011; Catchpole et al., 2018).

After discarding in commercial fisheries started receiving an increasing amount of (negative) attention, it was clear that fisheries management so far had failed to reduce discarding in European fisheries (Batsleer, 2016; Borges, 2015). In the 2013 reform of the CFP, discard reduction became a specific objective for European fisheries management (Regula- 
tion (EU) 1380/2013; EU (2013)) by including a step-wise introduction of a discard ban in European waters (see chapter 1). Article 15 of this regulation explains the circumstances under which the landing obligation becomes applicable. Details of the implementation of the landing obligation will be included in multi-annual plans, or in specific discard plans when no multi-annual plan is in place (chapter 1). In brief, this ban obliges fishing vessels to retain all catches of quota-regulated species and land them, including small size individuals, and requires all catches to be counted against the allocated quota, whilst undersized fish cannot be marketed for direct human consumption purposes by the year 2019 . The main stated objective of the landing obligation in the current CFP is to create economic incentives for the industry to reduce the capture of unwanted species and of smaller individuals. Details of the implementation by fishery of the landing obligation will have to be part of multi-annual management plans, or in specific discard plans when no multi-annual plan is in place (chapter 1).

The introduction of the landing obligation to land all catches represents probably the most important paradigm shift in the history of the CFP, and therefore, a fundamental change in the management approach to EU fisheries, as quotas now control what is caught at sea, rather than what is landed onshore (Catchpole and Ribeiro Santos, 2015; Cefas, 2014). There is a general perception that the introduction of the landing obligation is a positive forward step in the rationalization of fisheries in the European Union, part of a move towards "greener" fisheries (Borges and Penas Lado, 2019). Nevertheless, the precise implementation of the landing obligation is not without controversy, and the direct and indirect consequences of its application are open to discussion (see chapter 2).

In the reformed CFP, the landing obligation is combined with rules used for determining annual catch quotas that seek to achieve a "maximum sustainable yield" (Article 2.2; EU (2013)). Currently, these catch quotas are calculated on a stock-by-stock basis. Under the landing obligation, quotas are counted against total catches rather than landings, so vessels must ideally have adequate quotas for all species included in the ban that they are likely to catch during the course of their operations. Failing that, an early exhaustion of quota may cause the fishery to "choke" (i.e. a full stop of fishing activities) regardless of the availability 
of sufficient quota for other species (Borges, 2015; Ulrich, 2018). Hence, species for which a fleet has insufficient quota to cover the catches taken in their normal operations are referred to as choke species. There is not a general rule to alleviate choke problems, and actions need to be taken considering each stock and fleet combination. It is relevant and necessary to identify those stocks acting as choke, and explore, if possible, any management action that could prevent or at least reduce the impact of this issue on the activity of fleets exploiting mixed fisheries(Prellezo et al., 2018).

In short, the application of the new CFP, with the inclusion of the landing obligation, is expected to substantially change many fisheries in Europe in the short and medium term. The knowledge base for understanding and anticipating these changes is currently being built rapidly (see e.g. Arnason (2014); Catchpole and Ribeiro Santos (2015); Prellezo et al. (2018); STECF (2013, 2014a,b,c, 2015, 2017a, 2018); Uhlmann et al. (2019); Ulrich (2018)). Importantly, the landing obligation requires behavioural adaptations in many fisheries. In turn, these behavioural adaptations will have intended and unintended effects on both commercial fish stocks and bycatch species, with a further round of feedback to the fisheries. In addition, governing bodies setting policies for fisheries will have to deal with the exact implementation of the landing obligation, which has to be co-ordinated with in the whole range of objectives of the CFP, not only biological, but also economic and social.

The focus of my PhD-thesis is to study the implementation of the landing obligation in mixed fisheries by exploring the effects of fisheries management plans for discard reductions on the population dynamics of fish stocks and on the economics of mixed fisheries. This question entails four aspects, discussed below: (1) the ability of fishers to adapt when facing these new regulations (2) changing regulations in support of the implementation of the landing obligation; (3) the importance of fishers compliance inherent to the landing obligation implementation; and (4) using MSE to evaluate the uncertainties induced by the change in management such as the implementation of the CFP.

\subsection{Fishers adaptation}

When discarding is allowed, fishing is partly characterised by maximising the value of the fraction of the catch that can be landed. Under the 
landing obligation, the fishing industry is expected to reduce the capture of unwanted species and small individuals. Hence, a change in fishing practices is expected where catchability for those catches are reduced. Catchability changes due to the vulnerability and availability of fish and reflect the efficiency of a particular fishery. A number of factors might cause variations in the catchability coefficient including various aspects of the fishery, such as individual and population biology, characteristics of the fishing gear, amount of fishing, fishing strategies, and environmental fluctuation, among others (Beverton and Holt, 1957; Gulland, 1969; Marchal et al., 2003; Pascoe et al., 2001).

An important component of many discard reduction strategies is the use of more selective fishing gears which may also be associated with temporal and spatial closures (Bellido et al., 2019; O'Neill et al., 2019; Reid et al., 2019) or by changing the time and location of fishing to reduce unwanted catch (Kindt-Larsen et al., 2011).

\subsubsection{Improving gear selectivity}

The landing obligation is expected to stimulate fishers to improve the selectivity of their gear. Changes in selectivity might make it possible to reduce catches of small, low value size classes and the most quotarestricted species to increase profits from available quota. While historically, the risks of losing marketable catches when using more selective gears may have dissuaded fishers, this must now also be viewed in the context of lost fishing opportunities if quota becomes exhausted and the ability to convert previously discarded catches into quota for marketable fish. The introduction of the landing obligation shifts the emphasis from prescribing the fishing gears that are permissible, to a results-based system where the onus is on the fishers to develop and deploy gears that will avoid unwanted catches (Reid et al., 2019).

Technical conservation measures have a long history. Documented scientific trials with escape windows to reduce catches of young fish in trawls started over 100 years ago (G., 1915), and many documented selectivity experiments have been carried out (Broadhurst et al., 2002; Fonteyne and Polet, 2002; Graham et al., 2007; Herrmann, 2005; Madsen, 2007; Madsen et al., 2002, 2013; Tschernij et al., 2002). Improving the yield by increasing size selectivity (length of first capture) and reducing discards have been a management strategy for decades (Valentinsson et al., 2019). 
A series of scientific experiments have followed with the aim of developing and identifying new concepts to improve selectivity in the trawl fishery. As such, the L50 (50\% retention length) in a traditional diamond mesh codend can be increased by increasing the mesh size (Herrmann, 2005). The selectivity in traditional diamond mesh codends is normally reduced with increased catch weight due to closure of the mesh opening (Tschernij and Holst, 1999). A common solution to improve trawl selectivity is to fit the net with an escape window (i.e. square mesh panel). The efficiency of such selective devices depends not only on the gear characteristics such as the dimensions of the panel itself, the size of the meshes and the position of the panel in the trawl (Herrmann et al., 2015), but also on the reactions of the fish in the trawl during the fishing operation. The remaining part of the trawl is most often made of traditional diamond mesh netting. An advantage of the window is that it can be mounted directly in the existing trawl at low cost.

While it would be rational to move towards more selective gears, the development of technical modifications can be a challenge in mixed fisheries, since improving selectivity for a given species or size class would result in considerable losses or additional retention of other species (Graham et al., 2007). Chapter 3 showed that a window selective device used by the Basque mixed trawl fishery is quite ineffective in reducing unwanted catches of undersized species. Also, recent results from the MENDES project, for the same fishery, showed that increasing selectivity by increasing mesh size (from $70 \mathrm{~mm}$ to $100 \mathrm{~mm}$ ) will result in considerable reductions in unwanted catch, but also in high losses of the main commercial species (Azti, 2019). Another example of this can be found in the beam trawl fishery for sole (S. solea) in the North Sea, where there is considerable evidence to suggest that increasing mesh size will result in high losses in the catch of sole with only marginal gains in terms of reduction in undersized catches (Bayse and Polet, 2015; STECF, 2015). Therefore, the likely loss of marketable catches and thus the loss of economic profitability of the fishery, together with the existence of other tools under the CFP which offer quota flexibilities if changes in selectivity are shown to involve disproportionate costs (see below Regulations in support of the implementation of the EU landing obligation), is of particular concern, as it may deter fishers from using modified or alternative fishing gear to resolve the discard problems. The specific challenges posed by the landing obligation will depend on conditions 
such as the catching performance of the fishing gears, the total allowable catches and the size profile and spatial distribution of the stocks (Uhlmann et al., 2019; Ulrich, 2018). These conditions will vary from year to year, from fishery to fishery, and may even vary from trip to trip (O'Neill et al., 2019). Hence, although default requirements can be established at an European level, the most practicable way forward is one where there is a possibility to override gear requirements at regional and fishery level. In that case each fisher is in a position to adjust the specific selective performance of the fishery (chapter 3). In this regard, fishers need to have the flexibility to modify the selective performance of their fishing gear in response to what they observe on the fishing grounds and to what they bring on board.

In addition to technical adaptations, selectivity can be improved by adapting fishing behaviour. The adaptations concern mainly the spatial and temporal reallocation of fishing activities to protect juveniles, spawning fish, and protected species, thus helping to reduce bycatch discards (see also Space and time options below). Implementing gear restrictions, closures of specific areas or depth range may help to reduce discards by encouraging a reduction in the capture of unwanted catch and moving to areas where the catch composition is likely to be more appropriate (Bailey et al., 2010; MRAG, 2007). Norway, the Faroe Islands, Iceland, New Zealand, Canada, and the US have implemented temporary real-time closures to protect juveniles, spawning fish, and protected species, thus helping to reduce bycatch discards (Bailey et al., 2010; Condie et al., 2014a; Hopkins et al., 2013).To date, the EU does not have a centrally managed system to lead closures when a high retention of undersized fish is taken by a specific fishery (Bailey et al., 2010). In chapter $\mathbf{2}$, several of the case studies, where discard reduction policies have been implemented, mention spatial and temporal closures as possible mitigation strategies (see also Reid et al. (2019)). The space and time distribution of a fishing fleet is commensurate with the high-density areas of its target species, and therefore the orientation behaviour is reflected in the spatial distribution of the fleet relative to that of the fish (Quirijns et al., 2008). However, management measures may not always result in expected outcomes, as demonstrated when spatial measures implemented to protect spawning or nursery areas fail because of changes in the spatial and temporal fish distributions (Beare et al., 2013; Rijnsdorp et al., 2001). Also, management measures aimed 
at improving the sustainability of one component on the ecosystem can have negative ecosystem impacts elsewhere, such as when area closures lead to effort displacement to previously unfished areas (Dinmore et al., 2003).

Generally, developing mitigation measures, both improving gear selectivity and temporal and spatial closures, without taking account of the context in which the problem occurs could have unexpected and unwanted consequences (Batsleer, 2016). Thus, fishers are best placed to identify the challenges envisioned by the landing obligation, and in collaboration with gear makers, fishing gear technologists and fish behaviourists, are most likely to find solutions that are both acceptable and effective (O'Neill et al., 2019). This includes understanding the mechanistic aspects of their gear's performance, but also an awareness of the behavioural responses of the species caught (Diaz Pauli and Sih, 2017; O'Neill et al., 2019). In recent years, most industry-science collaborations in Europe have taken such a bottom-up approach (Armstrong et al., 2013; Mortensen et al., 2017), and a number of gears such as the netting grids in the Scottish Nephrops fishery (Drewery et al., 2012; Kynoch et al., 2012) have been successfully introduced. Likewise, fishers' local ecological knowledge together with scientifically based mapping programs of areas with high presence of juveniles (Reid et al., 2019) is equally necessary for the development of spatial and temporal closure management systems and to design sustainable strategies on where, when and how to fish (Dunn et al., 2011; Rijnsdorp et al., 2012).

There is scope to develop a Europe-wide regulation setting out basic requirements to change the fishing ground when the fishing operation begins to contravene the regulations, for example whenever bycatch limits or the permitted inter mixture of undersized fish have been exceeded. At the same time, regional planning and regional schemes could be developed which determine the practical modalities of the scheme and create information sharing platforms that would enable move-on decisions to be made and communicated quickly (Catchpole and Ribeiro Santos, 2015).

\subsubsection{Choices on space and time}

In mixed fisheries, the catchabilities for different species and size classes have to be adjusted to the productivity of the different species in the 
catch under the landing obligation. The catchability of a fishing fleet for different species and size classes depends not only on the characteristics of the fishing gear, but also on the spatial and temporal overlap between the fishery and the fish stocks. The changes in catchability that are potentially needed in mixed fisheries to stay within catch quota for a range of species can also be brought about by changes in the spatiotemporal fishing patterns (Quirijns et al., 2008).Such changes in the spatial distributions under changing quota regimes have historically been observed in an ITQ system (Poos et al., 2010), and are expected in fleets where the costs of choke species under unchanged behaviour are high. Thus, it is expected that fisheries could also reduce unwanted catches by actively reallocating fishing activities in relation to the spatial and temporal distribution of certain species, size or age classes under the landing obligation (Simons et al., 2015).

To maximise the benefits of their catches, fishers have to acquire knowledge of the distribution of marketable fish (Catchpole et al., 2005). Under the landing obligation, we expect that fishers will improve their knowledge on the distribution of by-catch species or species with a high concentration of juveniles. The broad scale patterns in these distributions are related to the annual migrations between spawning and feeding grounds of their target species and the recruitment of young fish to the fishing grounds (Poos and Rijnsdorp, 2007). Predicting the location of short-term patches, such as fish aggregation in response to food, is much more difficult and fishers have to gain the knowledge from the field. In order to avoid and relocate fishing activities, knowledge and information on areas with high catch rates of juvenile or non-target species will need to be acquired an exchange among fishers (i.e. providing information about high concentration of juveniles in an area) (Eliasen et al., 2014). Indeed, there is also the possibility of making tactical changes to potentially reduce the amount of bycatch such as the number of hauls, their duration and timetables.

The integration of all scientific data held by fisheries institutions (data from studies, landings and observers) can also be valuable in helping fishers to decide where and when to fish in order to avoid unwanted catches and maximize opportunities to catch their quotas (Reid et al., 2019). These include observer data with the detailed catch (landings and discards) by commercial vessels, landings and vessel monitoring system 
data showing where and when catches are made, research vessel studies showing the distribution of abundance, and fully documented fisheries pilot studies showing all details of complete fishing operations (Reid et al., 2019). In recent years, scientific emphasis has been placed on the development of decision support tools to be able to advise on where and when they could fish to reduce and avoid unwanted catches (i.e. the use of scientific data to illustrate the spatial and temporal distribution of fish, catches and discards; Cefas (2014); Quirijns and Pastoors (2014); Reid et al. (2019); Rochet et al. (2014)) largely supported by fine-scale and georeferenced data becoming increasingly available (e.g., Bastardie et al. (2010); Hintzen et al. (2012)). However, for such tools to work in real-time, close collaborations and exchange of data between industryscience communities would be necessary. Real-time, spatial management is based on the cooperation with fishers to transfer information, and increases the responsability of fishers (results-based management, e.g. Nielsen et al. (2015)).

As fishers adaptations remains uncertain and difficult to validate under a new management measure such as the landing obligation, while the technical descriptions of gears and fishing behaviour was limited, a framework is needed to describe the underlying behavioural processes in a fishery. The Dynamic State Variable model (Clark and Mangel, 2000; Houston and McNamara, 1999) used in this thesis was developed from the model used in Poos et al. (2010) to evaluate fleet responses to opportunity costs and explore the consequences of a number of new management scenarios (chapters 4 and 5). These types of models generally predict the effect in the short term (within a fishing trip or a quota year) by optimising a utility function and determining which choices yield the best chance of increasing utility, while monitoring the state of each individual. The effect of a choice on the utility depends on the economic environment (profit maximization), such as the home port of the vessel and the distance to fishing grounds, and the biological environment, such as the spatial distribution of the resources (Batsleer et al., 2016).

The model used in this thesis extends the model structure in Batsleer et al. (2015) to accommodate the range of quota flexibility and exemptions proposed (see next section; Regulations in support of the implementation of the EU landing obligation EU (2013)). The model incor- 
porates size-structured fish populations with seasonal changes in their distribution as well as seasonal variation in the ex-vessel price of the different species and size classes and annual fines for exceeding landings or catch quota provisions as in Batsleer et al. (2015, 2016), and extends earlier approaches by including errors in decision-making (following Dowling et al. (2011)) rather than assuming that individuals always make optimal choices. Extending the dynamic state variable model contributes to developing a generic model to explore more complex dynamics that govern decision-making (and errors in decision-making) such as gear choice and the spatial and temporal distribution of effort (and the socio-economic consequences thereof) and evaluate the consequences of implementing a wider range of the landing obligation management measures of demersal fisheries. Therefore, following Dowling et al. (2011), we introduced the sigma parameter to assume that fishers make errors in decision making (e.g. related to the assumption that they are utility maximizers). Although our modelling approach does not provide information on the actual cognitive processes underlying human dynamic decision-making (e.g. a thorough understanding of the mechanisms inherent in fishers' behaviour), it enables us to predict human behaviour and show roughly the same performance effects that can be found in empirical data reflecting decision-making, e.g., response rates (chapter 4).

Even more importantly, we aim at developing a general model of dynamic decision making. For the model to be general (e.g., not fit exclusively to one specific experimental setting or dataset), it needs to be simple (Punt and Butterworth, 1995). As a result, the modelling approach is capable to predict the short term fishers behaviour when harvesting choke species and the impossibility to discard unwanted quota fish, as the decision of when, where and how to harvest in the year taking into account the potential benefits of doing so elsewhere, in another way or at another time of the year. Including error in individual harvester decision-making particularly allowed for incorporating the short term dynamics forecasts into the consequent biomass of fish stocks and, therefore, explore the potential long-term interactions and feedbacks within the system in MSEs (see section Management Strategy Evaluation). Therefore, the thesis introduces a framework for a multi-species fishery MSE by accounting for fleet dynamics, multi-species fishery quota allocation, and the new dynamics of technical interactions (e.g. new 
quota provisions) in support of the EU (2013).

\subsection{Regulations in support of the implementation of the EU landing obligation}

As described in the previous section, fishers are expected to adapt their fishing practices to avoid discards (Simons et al., 2015), so that they exploit all stock in their catch according to the maximum sustainable yield objectives while not discarding any stocks for which there are quotas. The costs associated with this shift make fishing less profitable in the short-term (Condie et al., 2014a; Hoff et al., 2019; Prellezo et al., 2016a, 2018). Even in the scenario where fishers have sufficient quota to land their catches, a landing obligation makes fishing more costly as well as reduces the value of their catches (more work for the crew, more infrastructures needed, less valuable catches on board) because retaining, manipulating and landing size categories or species that were previously discarded and of low market value will reduce income perunit-effort (Condie et al., 2014a). Also in the long run, the flexibility of fishers in mixed fisheries to alter their selectivity may be limited. As a result, choke species may substantially compromise the profitability of some discard-intensive fisheries (at least in the short-term, Condie et al. (2014a); Hoff et al. (2019); Prellezo et al. (2016a, 2018)) since catch of some species will be constrained once catch of another species reaches its total quota leading to underutilisation of some of the quotas (Condie et al., 2014a). The scale of these short-term losses is case-specific.

For all these potential short-term negative economic repercussions for the industry of the implementation of the landing obligation, the CFP allows for some mechanisms for flexibility in support of the implementation (EU, 2013). Article 15 includes provisions which allow some flexibility in quota setting and quota use to alleviate an early cessation of fishing activities due to potential choke species (Table 6.1). Those provisions can be split in several categories. Some provisions are management regulations that existed prior to the landing obligation, such as quota swaps and quota year transfers such as borrowing and banking. Other provisions are regulations that were created within the landing obligation. These include the "high survivability" and "de-minimis" exemptions along with "inter-species quota" flexibility, and other tools that may arise from the identification of the problems and solutions (e.g. quota adjust- 
ments such as bycatch quotas, combined TACs and zero TACS among others) (Uhlmann et al., 2019).

When it comes the managerial procedures, the insertion of new management measures (e.g. new quota provisions, explained in chapter $\mathbf{1}$ and summarized in Table 6.1) must always guarantee the principle of relative stability (Sobrino and Sobrido, 2017). The challenge to guarantee the principle of relative stability is great, especially in certain mixed fisheries where the discard rate is very high. Fleets with high discards rates of certain species will be likely to have larger incentives to increase their quotas for those species than fleets with low discard rates. Exactly to what extent the relative stability is affected will depend on how the regulation's mechanisms are implemented and whether any further corrective action is taken (Sobrino and Sobrido, 2017).

Table 6.1: Overview over the possible provisions in quota introduced by the CFP.

\begin{tabular}{ll}
\hline provisions & description \\
\hline exemptions: & $\begin{array}{l}\text { species with scientific evidence of high survival rates after being discarded can have an exemption from } \\
\text { the obligation } \\
\text { a maximum of } 5 \% \text { after a transitional period starting at } 7 \% \text { of the total catch of species may be discarded } \\
\text { in cases "where scientific evidence indicates that increases in selectivity are very difficult to achieve" or "to } \\
\text { avoid disproportionate costs of handling unwanted catches, for those fishing gears where unwanted catches } \\
\text { per fishing gear do not represent more than a certain percentage, to be established in a plan, of total annual } \\
\text { catch of that gear" }\end{array}$ \\
de-minimis & $\begin{array}{l}\text { allowing member states to bank or borrow up to } 10 \% \text { of the quota of a species (inter-annual quota flexibility) } \\
\text { quota trades among member states that aim to align fishing opportunities of the fleets within the member } \\
\text { states to the member states quotas } \\
\text { proper documentation and landing unwanted catches was also the underlying assumption for increased } \\
\text { quotas, as landing quotas would be turned into catch quotas, based on historical discard estimates } \\
\text { allowing to deduct up to } 9 \% \text { of the TAC of a certain stock could be counted against another stock; (a) that } \\
\text { the stocks from which the catches are attributed to other stocks would be inside safe biological limits - to } \\
\text { prevent the mechanism to result in higher catches of weak stocks and (b) that the real catches by species } \\
\text { would be recorded, to avoid catch data being misleading. }\end{array}$ \\
quota adjustment &
\end{tabular}

Relative stability will continue to be the distribution key, where swaps (quota trades) among member states, that previously got rid of certain quotas, will now need to align fishing opportunities of the fleets within the member state to the member state's quotas to prevent that other species strangle the catches of its target species (Sobrino and Sobrido, 2017). Potentially, new ways of swapping quotas would be needed under the landing obligation to alleviate the choke effect of any of the quota limiting species (see chapter 4). The real challenges lie in certain mixed fisheries, especially those involving demersal species. Swaps are playing 
and will further play a key role while redistributing fishing companies' or producer organisations' quotas in a way that ensures a reasonable balance between fishing opportunities and usual catch composition is achieved. However, some limits to swaps can be predicted. Although we are still at the beginning of the full implementation of the landing obligation, the experience with pelagic species quota owners suggested that member states or fishers seem to retain their quota to prevent their fleets or own company to be restricted in their fishing activities rather than increase swapping (EC, 2016). Therefore, enhancing quota swaps through increasing transparency, and providing the European industry with a better knowledge of the swapping opportunities available in other member states, will both be needed.

In addition, the new regulation provides opportunities for flexibility in dealing with quotas through inter-annual quota transfers (by allowing member states to bank or borrow up to $10 \%$ of the quota of a species) and inter-species flexibilities (deduct up to $9 \%$ of quota of target species to cover catches of species exceeding their quota or for which no quota are owned) (Table 6.1). This inter-species flexibility mechanism was established in recognition that under relative stability, the shares of quota allocated to member states could, in some cases, make it extremely difficult to comply with the landing obligation (Sobrino and Sobrido, 2017). Use of inter-species quota flexibility could cause serious impacts to stock abundance when quota from a high volume/low value species is transferred to a low volume/high value stock (see chapter 4 ). This is not yet the case, in particular the use of inter-species quota flexibility with the inter-species cross-reporting mechanism, barely used so far (Hoff et al., 2019; STECF, 2018). However, when used, it should be related not only to the precautionary limits but also to the management target, i.e. the size of the stock and fishing mortality should be at a level preventing the stock from impaired recruitment (Blim and Flim) (Borges and Penas Lado, 2019).

The stepwise introduction of the landing obligation mean that for several fisheries all catches should be brought to shore and landed. To accommodate the predicted increase in landed catch from such fisheries, the relevant 2015, 2016 and 2017 TACs were increased in accordance with the estimated catch that formerly would have been discarded (Borges, 2018; Stockhausen, 2019). Meanwhile the increase in TAC or the de- 
minimis allowance should not jeopardise the MSY objectives or increase fishing mortality (Borges and Penas Lado, 2019; EC, 2018).

For some stocks, TAC management has been removed completely (i.e. the suppression of the combined TAC for dab and flounder in the North Sea as long as they remain largely bycatch species (EC, 2017; ICES, 2017). This was done to remove by-catch stocks from the TAC regime when TAC is not acting as a conservation mechanism. With the suppression of the TAC, dab and flounder stocks were removed from the LO and no longer constitute a risk for premature closure of the target fisheries for plaice and sole where they are bycaught. However, they continue to be discarded in high numbers, likely to have between $10 \%$ and $30 \%$ survival after discarding and low commercial value, but continue to be caught in fisheries that no longer have the incentive to improve selectivity (Borges and Penas Lado, 2019). Defining what constitutes a bycatch species is difficult as it may be a bycatch for one member state but a target species for another. A list of clearly identified prohibited species is provided for each sea basin and does not require any further reflection (species listed in the Convention on International Trade in Endangered Species of Wild Fauna and Flora (CITES) Appendix I are included on the prohibited list). For a number of species and stocks which pose a specific issue with the implementation of the landing obligation, TACs could be set to 0 and add them to the prohibited species list. They must therefore not be landed and means discarding can continue, and in absence of a high post-release survival, this measure adds little to the sustainability of the stock (Borges and Penas Lado, 2019). As the catches of non-target stocks are not necessarily accounted for in their respective TACs, there is a risk of overexploitation of those non-target stocks. Therefore, introducing bycatch quotas for stocks where some member states have zero quotas and where they cannot manage to obtain small quotas through swaps could alleviate this problem (Hoff et al., 2019). Although this option may be seen by many as a breach of relative stability, the annual fishing opportunities regulation already contain a number of such bycatch quotas (Borges and Penas Lado, 2019).

All new flexibilities are likely to alter the economics of fishing (STECF, 2013; Uhlmann et al., 2019). They can provide flexibility in the system to better adjust catch compositions to resemble fishing opportunities and increase both ecological and economic sustainability. Achieving a 
balance between quota flexibility, over- exploitation risk, and administrative simplicity is critical for the profitability and sustainability of multi-species fisheries. However, because these provisions could also be used to legally increase catches well above desired or intended levels, they will require careful consideration if negative and unintended consequences are to be avoided (STECF, 2013).

Additionally, there are two other possible exceptions to this obligation. First, the regulation allows for fishing operators to continue to discard species that, according to the best available scientific advice, have a high survival rate when released into the sea. Second, to cater for unwanted catches that are unavoidable even when all measures for their reduction are taken, certain de-minimis exemptions from the landing obligation may be established. In addition to these two possible exemptions, which are to be determined in the corresponding discard plan, fishing operators must discard catches of prohibited species (e.g. basking shark) and, since 2015, also predator-damaged fish. It should also be noted that the interpretation of the high survivability and deminimis exemptions is not always straightforward and therefore resulted in very loose provisions which have ample room for interpretation (Table 6.1). Those provisions provided in Article 15 are associated with great uncertainty, not only because the wording leaves room for subjective interpretation (Batsleer et al., 2016) (e.g. 'scientific evidence demonstrating high survival rates', 'increases in selectivity are very difficult to achieve', 'to avoid disproportionate costs') but also because definition of what threshold levels may be considered were not given. If de-minimis exemption is applied to a species in which the choke effect would not be mitigated, this approach would also to some extent negate the purpose of the landing obligation, which is to encourage more selective fishing by creating incentives to avoid catching species with lower quotas. Between October 2014 and beginning of 2018, the Commission adopted 15 discard plans in which the details of the high survival exemptions and the de-minimis are specified in preparation of the landing obligation (/https://ec.europa.eu/fisheries/cfp/fishing_rules/ discards_en\#Discard-plans).

Chapter 4 analyses the economic outcome under the landing obligation, relative to the expected outcome if the landing obligation had not been introduced, and the landing obligation mitigation scenarios bench- 
marked against the landing obligation with no exemptions or other mitigation strategies included. Some of the above mentioned mitigation measures have been modelled in order to assess the possible consequences on fishers adaptation in the short term. Similar comparison for seven different case studies can be found in Hoff et al. (2019), but only the long-term results are shown. Generally, both for the Basque trawl fishery in chapter 4 and for the ones analysed in Hoff et al. (2019), mitigation strategies such as selectivity changes, de minimis exemptions and quota adjustments equal to previous discarded quantities could enable fishing businesses to increase profits with the implementation of the landing obligation, but the profits are generally lower than or equal to profit with no landing obligation. Our results indicate that trading quotas (at rates undertaken in the past) does not alleviate the choking effect of the landing obligation for the Basque trawl fishery case study. In particular, under the landing obligation the transition from landing quota to catch quota was adjusted to include only the $80 \%$ of the formerly discards, to avoid any possible increase of fishing mortality and thus; jeopardising sustainable management. Our results suggest that reductions in fishing opportunities under a landing obligation that are caused by choke species (mackerel) could be alleviated by the use of inter-species quota flexibility (by transfers to horse mackerel quota), and lessen the negative short-term reduction in net profits produced by the landing obligation. These results suggest that there will be a large incentive for the Basque fleet to use this quota flexibility: a finding that is likely transferable to other fleets and fisheries. However, due to the lack of quota transferability in our model, the outcomes from chapter 4 may not fully correspond to actual observations.

At this point in time it is difficult to predict the future evolution of the application of all these provisions. The effects of the landing obligation as established cannot be assessed ex ante because these effects depend to a large extent on whether member states will make full use of the existing flexibility mechanisms (Borges and Penas Lado, 2019). Hence, it is difficult to predict how quota trading will develop under the landing obligation. Including quota transfer into the model will make it more operational for practical use, however, this would require a more detailed knowledge on the actual implementation of the management regulations. Generally, for the successfully implementation of all these exemptions and flexibilities, management bodies should ensure that the full use of 
tools will constrain catches to comply with the MSY objective in Article 2(2) of the CFP Basic Regulation (EU, 2013) and that fishing businesses have incentives to comply with the landing obligation.

Monitoring and enforcement are generally considered to be currently insufficient to motivate compliance. In this regard, if there is some evidence of weak implementation of the landing obligation, discarding in contravention of the landing obligation will still occur at some level. This would have potential consequences for catch data quality that feeds into the evaluation of stock status and the harvest strategy, as well as for confidence in the fishery compliance.

\subsection{Compliance issues}

Poor enforcement in European fisheries has often been identified as a factor that contributes to a situation where the potential economic benefits for fishers of noncompliance often outweigh the risks of detection (Catchpole et al., 2005) and the cost of sanctions (Batsleer et al., 2013). Indeed, one of the key questions inherent to the landing obligation enforcement is fishers compliance: given the potential for short-term and long-term negative impacts on economic performance, fishers may try to circumvent management rules (Rihan et al., 2019). When it is illegal to discard fish while incentives to discard remain, monitoring and control must be effectively invoked to offset incentives to discard (Hoff et al., 2019; Nuevo et al., 2019; Sutinen and Andersen, 1985). Therefore, moving to managing catches instead of landings also requires new forms of monitoring (Catchpole and Ribeiro Santos, 2015; James et al., 2019; Nuevo et al., 2019) and it is partly through this monitoring that the incentive for compliance with the landing obligation and the motivation to avoid unwanted catches can be generated (Borges and Penas Lado, 2019; Kraak and Hart, 2019). Also, social norms, trust and cooperation play a role (Kraak and Hart, 2019; Sutinen and Kuperan, 1999).

Discard management regimes experiences from fisheries around the world (see chapter 2) have shown that choosing the right technical measures when facing a discard restriction is not a simple process. In most cases, management authorities need to simultaneously implement complementary measures which will support implementation and encourage compliance with discarding rules. Measures to support discard reduction, already discussed in previous sections, can include both incentive mea- 
sures (e.g. access to a certain area and / or at certain times will only be granted to those using specific approved gears, or that those using approved gears benefit from additional quota or effort allocations), disincentive measures (e.g. a requirement to keep rejected fish aboard and stowed separately), or technical measures either at the gear level, through enhanced selectivity, or by spatial and temporal restrictions (Catchpole and Ribeiro Santos, 2015). The challenge in European fisheries is to monitor all implemented measures because vessel operators may decide not to comply with regulations if monitoring at sea is problematic (Condie et al., 2014a; Hoff et al., 2019). Therefore, monitoring and evaluation of the flexibility elements introduced into the Basic Regulation (EU, 2013) is challenging task.

It is recognized that the introduction of the landing obligation necessitates a review of certain aspects of the CFP regulatory framework, and that the challenges of a successful implementation require new fishing practices, methods, enforcement systems and technologies to control the new regulatory approach (Catchpole et al., 2018; Uhlmann et al., 2019). The most prominent regulatory challenge is frequently cited to be enforcement, in particular as the focus of monitoring and control shifts from landing to activities at sea. Typically fisheries control and enforcement is quite costly (Arnason, 2014), leading to potentially higher costs (Catchpole and Ribeiro Santos, 2015; Condie et al., 2014b).Indeed, the allowances on keeping or discarding legally some specimens (under high survivability, de-minimis, prohibited species exemptions) makes control and monitoring of this system even more difficult. Although new approaches from the European Fisheries Control Agency, based on catch comparison, are being developed to detect vessel operators with high risk of non-compliance (Nuevo et al., 2019), those only estimate such a risk after an inspection has already occurred. Therefore, this shift requires a high level of surveillance, fishing and discarding practices are 100 per cent monitored during fishing activities, in order to detect what is caught and whether there is illegal discarding.

In general, real time monitoring (and reporting) is likely to provide a management flexibility that could alleviate the undesired choke situations. However, it is difficult to evaluate how successful these measures have been in achieving conservation benefits, and difficult to implement and specially administer (Marchal et al., 2016). Currently applied Re- 
mote Electronic Monitoring (REM) and on-board monitoring methods, including satellite monitoring, enforcement patrols and on-board observer Programmes (see chapter 2), can meet the successful implementation of the landing obligation only to a limited extent (Catchpole et al., 2018; Hedley et al., 2015; James et al., 2019). A specific strategy is needed to permit the full use of control and monitoring tools for enforcement of the landing obligation. This strategy should take into account the development of new technologies that allow a full documentation of all catches (Catchpole et al., 2018, 2017).If such a strategy is successful and results in reliable monitoring of catches rather than landings, this should be counted as an unexpected side benefit of the reformed CFP. However, there is currently no agreed approach on how catch monitoring will be achieved (James et al., 2019). This could lead to a deterioration of the reliability of discard information if discard estimates come from a small sample of fishing trips: when discarding is allowed, the role of the scientific observer who estimate discards on board is not tainted by compliance issues. If all discards are to be landed, one should wonder about the representability of discard estimates when observers are on board. Any deterioration of the discards estimates will have critical repercussions on the quality of the advice on fishing opportunities because almost all stock assessments used for the advice depend on having accurate catch information (Bousquet et al., 2010; Breen and Cook, 2002; Catchpole and Ribeiro Santos, 2015; Cotter et al., 2004; Walters and Maguire, 1996).

Chapter $\mathbf{4}$ and $\mathbf{5}$ assume full compliance, and the model considers discarding a serious infringement under the regulation. Compliance to management was assumed by applying high sanctions for exceeding the quota and a $100 \%$ detection rate. Hence, fishers may respond to management regulations by substantially reducing discards, changing their distribution of fishing effort but trading-off their revenues. However, if detection rates are low and the short-term benefits of non-compliance are high (as our results suggest) then non-compliance is likely to be a substantial problem in the absence of measures promoting voluntary compliance. In theory, given the difficulty to have $100 \%$ detection rates, by introducing a premium in the decision function of the model would influence the outcome of our results (e.g. an increase in the price of fish that would otherwise be discarded because of a low price). In such a case, the vessel operator will include the benefit/penalty in their de- 
cision (invoked as a penalty placed on the estimated net benefit from discarding while considering also the probability of being detected). If the risk of being detected and the penalty are low, fish will probably be discarded and vice versa.

\subsection{Management Strategy Evaluation}

Clearly the substantial paradigm shift in the management of European fisheries related to the 2013 reform of the CFP will have large consequences for its fisheries. This underlines the importance of ensuring that the use of flexibility mechanisms of the landing obligation needs to be consistent with the achievement of the Maximum Sustainable Yield (MSY) objective of the CFP. The nature and magnitude of these consequences is unknown, but as they will include both the human dimension of the fisheries, and the biological dimension. One way of evaluating the potential effects of changes in management such as currently under the CFP is Management Strategy Evaluation (MSE).

Management Strategy Evaluation is a framework for the evaluation of management strategies using simulation to evaluate the trade-offs achieved by management strategies and to assess the potential long-term consequences of uncertainty for achieving management goals (Kell et al., 2007; Punt et al., 2016; Sainsbury, 2000). In most MSEs, the focus has been on the dynamics of fish stocks, and the uncertainties therein. In the landing obligation however, we see that the human aspect is equally important, if not more important (Fulton et al., 2011a; Garcia et al., 2013). MSE with explicit human (social) behaviour dimension is increasingly being used (Andersen et al., 2010; Ono et al., 2017) as additional sources of uncertainty are taken into account. In theory this should allow identifying management actions that ensure the sustainability of fisheries. In the case of the landing obligation the behavioural response of fishers to the landing obligation results in changes in their spatial and temporal distributions. Meanwhile the strength of this response will depend on the degree of compliance. In addition, the spatial and temporal distribution of fishers may also be influenced by additional provisions related to the exact implementation of the landing obligation, which are yet unknown.

Ideally these uncertainties should be addressed, or the mechanisms that are expected to play a role should be included in the MSE. In chapter 
5 I attempted to include a substantial part of the behavioural changes that can be expected as reaction to the landing obligation by including mechanistic dynamics in fishing effort allocation. These dynamics are captured by an extended Dynamic State Variable model that includes the consequent biomass of fish stocks and the management procedure to make its decision on how to respond to the state of the resource where individual skippers make intra-annual fishing choices based on their accumulated catches, their quotas, and their expectations of future catches. The MSE framework, was thought of as a minimum realistic model (Kell et al., 2007; Punt and Butterworth, 1995), and included temporal and spatial key processes in the dynamics of two fish populations, the fisheries and a re-evaluation of management targets. To keep the model simple, the two fish populations modelled in chapter $\mathbf{5}$ were exactly the same apart from their spatial distribution. Indeed, I did not include the use of any discard flexibilities or exemptions of the landing obligation, while estimated quotas were based on keeping fishing mortality below the MSY while it was not possible to discard. I may thus have underestimated the flexibility of the fishery to respond to quota limitations imposed under both the landing obligation and MSY fisheries management. However, this approach underlines the importance of ensuring that the use of flexibility mechanisms needs to be consistent with the achievement of the MSY objective of the CFP (Borges and Penas Lado, 2019). The results suggest that the landing obligation, which now applies for all quota species, may affect the productivity of non-quota species. In mixed fisheries, constraining quota only for a single-species brought risk of changing exploitation patterns also for the unconstrained stock, with younger fish being targeted for (Borges and Penas Lado, 2019; STECF, 2013, 2017b). Moving from an unmanaged period to a situation where one or both species were quota regulated by implementing MSY objectives in combination with a LO management regime (i.e. main CFP objectives: exploiting at MSY and no discarding allowance) led to a very restrictive fishing activity (chapter 5). Fishing effort was constrained by one or two quota stocks, as predicted in general terms by Ulrich et al. (2017), resulting in drastic reductions of effort over the short-term and mid-term. In addition to reconciling fishery and conservation objectives (such as the CFP), in agreement with Grafton et al. (20077), setting exploitation rates below $H_{\max }$ resulted in a reduction in fishing cost and an increase in net revenue over the mid-term (chapter 
5). However, as Prellezo et al. (2016b) concluded, since effort was drastically reduced to achieve the objectives of the CFP; the increase in net revenue gains were only experienced by some vessels. Consequently, a significant part of the fleet had to cease its activity.

While I used a mechanistic model in chapter 5, others have approached the problem from a slightly different angle: the choices of fishers can also be mimicked using regression techniques that estimate the likelihood of a given choice based on historical patterns and calculates coefficients for different covariates (Andersen et al., 2010; Holland and Sutinen, 2000; Marchal et al., 2009; Ono et al., 2017; Tidd et al., 2011).However, this retrospective approach, being driven by observations on historical patterns is less well suited to predict behavioural adaptations in relation to changing conditions (Dowling et al., 2011). In this context, Dynamic State Variable models have the advantage that they lack dependency on historical patterns to predict future choices. In addition, these models allow individuals to cope with opportunity cost such as the decision stay in port early in the year taking into account the potential future benefits of fishing later in the year fetching a higher price; as the introduction of errors in decision making (Dowling et al., 2011). These aspects make the Dynamic State Variable model an ideal tool to evaluate the influence of new or unknown measures such as the landing obligation or a credit system on behavioural adaptations of a fishing vessel (Batsleer, 2016).

While I modelled the intra-annual choices of individual skippers of a given fleet size, the longert-erm dynamics of the fleet size itself was not taken into account. This is an important aspect that is clearly missing. One would expect that vessel owners under adverse economic circumstances decide to disinvest. Meanwhile, models of the entry-exit dynamics do exist (see e.g. Tidd et al. (2011)) and could be incorporated. In the long term, choke situations and displacement of vessels to other areas are expected to reduce fishing pressure, leading to biomass increases and thus improved fishing possibilities. However, ensuing economic improvements will differ for individual fleet segments and vessel businesses, depending on catch composition and on whether TACs increase proportionally when biomasses increase (Hoff et al., 2019).

Despite theoretical advances in both fish stocks and fleet dynamics, an important aspect that determines management outcomes in general, and 
in the landing obligation in particular, is the behaviour of organizations. Some of these challenges have been present since governments began to actively manage fisheries; while other issues have emerged much more recently (Environment Canada, 2011). In particular, the large short term costs that are foreseen in the implementation of the landing obligation has spawned many provisions to alleviate its effects, such as the de-minimis and the high-survival exemption, quota flexibilities and the application of selectivity measures (EU, 2013). These provisions were instigated by the fisheries management, and one should wonder if the dynamics of these managers and their response to the actions of stakeholders can ever be captured in simplified dynamics. Fisheries are more likely to be sustainable if the organizations responsible for managing them take actions such as the ones showed in Environment Canada (2011): (i) adopt legislation and policies that consider clearly defined social, economic, and conservation objectives, and incorporate the ecosystem and precautionary approaches; (ii) engage stakeholders and communities through open and transparent processes; (iii) put in place appropriate accountability arrangements; (iv) use a decision-making process that is transparent, considers social and economic objectives, and respects the biological limits; (v) use the best available scientific research and analysis; (vi) develop fishing plans that reflect the objectives for the fishery and provide fishers with incentives to pursue fisheries in a sustainable manner; (vii) develop and put in place appropriate monitoring, control, and surveillance; (vii) and develop an enforcement capability that promotes and ensures compliance with legislation and supports fisheries planning.

\subsection{Outlook}

Fisheries policy is increasingly influenced by civil society organizations. The newest example of this is the formulation of the landing obligation, a regulation that should reduce the contested practice of discarding unwanted fish. The landing obligation, intended to reduce discarding of marketable fish, evolved from a generic management measure into a complicated micro-management system to alleviate the problem of choke species in mixed trawl fisheries. This system includes a range of potential exemptions from the discard ban when fish do not have to be landed (art. 15(4)), where the fish are prohibited to retain for conservation reasons, will be used for live bait, or if scientific evidence demonstrates 
high survival rates when discarded. However, providing the necessary evidence for each of these cases is challenging, subjective and fishery or stock-specific. The exemptions also appear to have different objectives, e.g. the avoidance of waste, improve stock sustainability, or improve financial viability. Similarly, a small amount (de minimis) of the total catch may be discarded if, either there are disproportionate costs of handling and storing the fish on board, or improving selectivity is proven to be difficult (EU, 2013). These are relevant where discards are relatively low.

With the implementation process of the landing obligation it becomes clear that fishers are working on diminishing discards. However, it also shows that for the legitimacy, and the effectiveness of policy it is not only vital to increase the influence of civil society actors, but also the participation of resource users. Their views, knowledge, and cooperation are vital for a successful implementation of the regulation. Otherwise, resistance become too high, and regulation becomes more symbolic than a tool for change.

Dynamic state variable models allow studying how fishers may respond to changing policies and what consequences this response may have for the economic and social performance of the fishery. To study the possible consequences on a longer time horizon, an MSE approach can be applied to evaluate the long term consequences of the changes in exploitation pattern on the productivity of the exploited stocks. Such an MSE should encompass all relevant dynamics of the fisheries system as a whole. However, fisheries systems are by their nature highly complex and include the biological, economic, and social processes along a wide range of actors. The models used to explore the possible response of the fishery and its consequences are necessarily strong simplifications of the fishery system, and so are the models used in this thesis.

Given the existing uncertainties in the precise implementation of the discard ban, the results presented in this thesis will not precisely correspond to future observed changes in the dynamics of the fleet. Our model, however, is particularly suitable to evaluate conservation and economic trade-offs and visualize consequences of management scenarios. The model can be used to evaluate the consequences and explore the scope of responses in fisheries behaviour under different survival, de minimis or inter-species flexibilities scenarios. Eventually, science often 
cannot provide a single true value, but can provide insight in the potential consequences of choices, leaving the decision whether something is high, difficult or disproportionate with the fisheries managers. As a result, not all provisions in the landing obligation could be included in the simulations. However, it is expected that the advance of computing power will allow for modelling the effects of policies in ever more detail. In order to make a realistic evaluation of management strategies in a mixed fisheries context, it is crucial to advance in the understanding of fleet dynamics. Thus, further investigation is needed in the inclusion of social dynamics of fisheries modelling. As shown here and previously pointed out by others, fleet behaviour can render stock management ineffective (Branch et al., 2006; J.E. et al., 2002; Salas and Gaertner, 2004): no matter how good a management strategy is, it will not work if the fishers do not comply with it (Garcia et al., 2013).

In any case, the practice of discarding is increasingly considered unacceptable from different points of view, including considerations about food security. Any possible future change in the policy is likely to be about adjustments to improve practical implementation and mitigate possible negative results, but a CFP with high levels of discarding is unlikely to return (Borges and Penas Lado, 2019). The actual outcomes of the landing obligation will depend on several factors, including the management system in place, the precise application of exemptions (e.g. de minimis allowance of discards up to 5\%), the use of interannual transfers, catch allowances of stocks without TACs, quota adjustments and quota swaps/movements, application of selectivity measures, costs of landing unwanted catch, prices obtained for unwanted fish and compliance of the sector (Hoff et al., 2019). Legitimacy on fisheries management, as demanded by the fishing industry, environmental organisations and the general public, depends on scientific advice for management decisions made by fisheries managers. Under the current CFP, managers need to ensure management measures contribute to the sustainable use of natural resources, while minimizing the ecosystem impact of fishing activities and maintaining economic resilient fisheries.

This thesis contributes to the ecosystem approach to fisheries management as an innovative spatial explicit simulation model is developed to deliver insights into complex socioeconomic and ecological trade-offs resulting from management measures. I show adaptive behaviour of a 
fishing fleet is certainly a factor which can influence the outcome of an important management decision, but which is easily overlooked. Hence, fleet dynamics is an essential element to understand the effectiveness of management measures. Fisheries advice should be extended to offer predictions of stock trajectories not only under a range of possible management measures, but also for a number of realistic outcomes in terms of compliance and enforcement of regulations (Fulton et al., 2011b). Following these predictions, and prior to implementation, a discards management regime should be evaluated (to the extent possible) by simulation, to ensure its robustness to prevailing uncertainties including those related to implementation (Butterworth, 2007; Punt and Donovan, 2007). 


\subsection{References}

Alverson, D. L., Freeberg, M. H., Pope, J. G., and Murawski, S. A. 1994. A global assessment of fisheries bycatch and discards. FAO Fisheries Technical Paper 339, Rome. Retrieved from: page 233. URL http://www.fao.org/ docrep/003/t4890e/t4890e00.htm.

Andersen, B. S., Vermard, Y., Ulrich, C., Hutton, T., and Poos, J. J. 2010. Challenges in integrating short-term behaviour in a mixed-fishery Management Strategies Evaluation frame: A case study of the North Sea flatfish fishery. Fisheries Research, 102(1-2):26-40.

Armstrong, M., Payne, A., Deas, B., and Catchpole, T. 2013. Involving stakeholders in the commissioning and implementation of fishery science projects: Experiences from the UK Fisheries Science Partnership. Journal of Fish Biology, 83:974-996.

Arnason, R. 2014. Best practice in the use of rights-based management to reduce discards in mixed fisheries. Directorate-general for international policies, policy department B: structural and cohesion policies. Fisheries. European Parliament.

Azti. Aproximación integral a la minimización y manejo de la captura no deseada (antes descartes) de la flota española que opera al arrastre en aguas del Golfo de Bizkaia y del Noroeste ibérico, 2019. URL https://www.azti.es/es/ ficha/mendes. Accessed: 2019-02-07.

Bailey, N., Campbell, N., Holmes, S., Needle, C., and Wright, P. 2010. Real time closures of fisheries. Directorategeneral for international policies, policy department B: structural and cohesion policies. Fisheries. European Parliament.

Bastardie, F., Nielsen, J., Ulrich, C., Egekvist, J., and Degel, H. 2010.
Detailed mapping of fishing effort and landings by coupling fishing logbooks with satellite-recorded vessel geolocation. Fisheries Research, 106:41-53.

Batsleer, J. Fleet dynamics in a changing policy environment. $\mathrm{PhD}$ thesis, Wageningen University, 2016.

Batsleer, J., Poos, J. J., Marchal, P., Vermard, Y., and Rijnsdorp, A. D. 2013. Mixed fisheries management: Protecting the weakest link. Marine Ecology Progress Series, 479:177-190.

Batsleer, J., Hamon, K. G., van Overzee, H. M. J., Rijnsdorp, A. D., and Poos, J. J. 2015. High-grading and overquota discarding in mixed fisheries. Reviews in Fish Biology and Fisheries, 25: 715-736.

Batsleer, J., Rijnsdorp, A. D., Hamon, K. G., van Overzee, H. M. J., and Poos, J. J. 2016. Mixed fisheries management: Is the ban on discarding likely to promote more selective and fuel efficient fishing in the Dutch flatfish fishery? Fisheries Research, 174:118-128.

Bayse, S. and Polet, H. 2015. Evaluation of a large mesh extension in a Belgian beam trawl to reduce the capture of sole (Solea solea). ILVO Instituut voor landbouwen visserijonderzoek report, February 2015:8. URL https: //www.vissersbond.nl/wp-content/ uploads/2015/11/Evaluation-ofa-Large-Mesh-Extension-in-aBelgian-Beam-Trawl.pdf.

Beare, D., McQuatters-Gollop, A., van der Hammen, T., Machiels, M., Teoh, S., and Hall-Spencer, J. 2013. Long-Term Trends in Calcifying Plankton and $\mathrm{pH}$ in the NorthSeal. PLoS ONE, 8:e6117. doi: 10.1371/journal. pone.0061175.

Bellido, J., Paradinas, I., Vilela, R., Bas, G., and Pennino, M. A ma- 
rine spatial planning approach to minimize discards: Challenges and opportunities of the landing obligation in european waters. In Uhlmann, S., Ulrich, C., and Kennelly, S., editors, The European Landing Obligation. Springer, 2019. URL http://doi.org/10.1007/ 978-3-030-03308-8_2.

Bellido, J. M., Santos, M. B., Pennino, M. G., Valeiras, X., and Pierce, G. J. 2011. Fishery discards and bycatch: Solutions for an ecosystem approach to fisheries management? Hydrobiologia, 670(1):317-333.

Beverton, R. J. H. and Holt, S. J. On the Dynamics of Exploited Fish Populations. MAFF Fishery InvestigationSeries II, XIX. HMSO, London, 1957.

Borges, L. 2015. The evolution of a discard policy in Europe. Fish and Fisheries, 16:534-540.

Borges, L. 2018. Setting of total allowable catches in the 2013 EU common fisheries policy reform: Possible impacts. Marine Policy, 91:97-103.

Borges, L. and Penas Lado, E. Discards in the common fisheries policy: The evolution of the policy. In Uhlmann, S., Ulrich, C., and Kennelly, S., editors, The European Landing Obligation. Springer, 2019. URL http://doi.org/10.1007/ 978-3-030-03308-8_2.

Bousquet, N., Cadigan, N., Duchesne, T., and Rivest, L. 2010. Detecting and correcting underreported catches in fish stock assessment: trial of a new method. Canadian Journal of Fisheries and Aquatic Sciences, 64:1247-1261.

Branch, T. A., Hilborn, R., Haynie, A. C., Fay, G., Flynn, L., Griffiths, J., Marshall, K. N., Randall, J. K., Scheuerell, J. M., Ward, E. J., and Young, M. 2006. Fleet dynamics and fishermen behavior: lessons for fisheries managers. Canadian Journal of Fisheries and Aquatic Sciences, 63(7):16471668 .

Breen, M. and Cook, R. 2002. Inclusion of discard and escape mortality estimates in stock assessment models and its likely impact on fisheries management. ICES CM 2002/V, 27:15 pp.

Broadhurst, M. K., Kangas, M. I., Damiano, C., Bickford, S. A., and Kennelly, S. J. 2002. Using composite square-mesh panels and the Nordmøregrid to reduce bycatch in the Shark Bay prawn-trawl fishery, Western Australia. Fisheries Research, 58(3):349-365.

Butterworth, D. S. 2007. Why a management procedure approach? Some positive and negatives. ICES Journal of Marine Science, 64(1995):613-617.

Catchpole, T. and Ribeiro Santos, A. 2015. The landing obligation and its implications on the control of fisheries. European Parliament Study IP/B/PECH/IC/2014-20.

Catchpole, T., Elliott, S., Peach, D., Mangi, S., and Gray, T. 2018. How to deal with the EU landing obligation: lessons from an English discard ban sea trial. ICES Journal of Marine Science, 75:270-278.

Catchpole, T. L., Frid, C. L. J., and Gray, T. S. 2005. Discards in North Sea fisheries: causes, consequences and solutions. Marine Policy, 29(5):421-430.

Catchpole, T. L., Ribeiro-Santos, A., Mangi, S. C., Hedley, C., and Gray, T. S. 2017. The challenges of the landing obligation in EU fisheries. Marine Policy, $82: 76-86$.

Cefas. Discard Atlas of the North Western Waters Demersal Fisheries. Technical Report December, CEFAS, 2014.

Clark, C. W. and Mangel, M. Dynamic state variable models in ecology: meth- 
ods and applications. Oxford University Press, New York, 2000.

Condie, H. M., Catchpole, T. L., and Grant, A. 2014a. The short-term impacts of implementing catch quotas and a discard ban on English North Sea otter trawlers. ICES Journal of Marine Science, 71(5):1266-1276.

Condie, H. M., Grant, A., and Catchpole, T. L. 2014b. Incentivising selective fishing under a policy to ban discards; lessons from European and global fisheries. Marine Policy, 45:287-292.

Cotter, J., Armstrong, M., Woods, T., Dann, J., White, P., and Keable, J. 2004. Final Report Programme 8: Gear selectivity in the Irish Sea. Part I: Eastern Irish Sea place fishery. Retrieved from, pages 1-19. URL http://citeseerx.ist.psu.edu/ viewdoc/download?doi=10.1.1.177. 4147\&rep=rep1\&type=pdf.

Diaz Pauli, B. and Sih, A. 2017. Behavioural responses to human-induced change: Why fishing should not be ignored. Evolutionary Applications, 10: 231-240.

Dinmore, T., Duplisea, D., Rackham, B., Maxwell, D., and Jennings, S. 2003. Impact of a large-scale area closure on patterns of fishingdisturbance and the consequences for benthic communities. ICES Journal of Marine Science, 60: 371-380.

Dowling, N. A., Wilcox, C., Mangel, M., and Pascoe, S. 2011. Assessing opportunity and relocation costs of marine protected areas using a behavioural model of longline fleet dynamics. Fish and Fisheries, 13(2):139-157.

Drewery, J., Watt, M., Kynoch, R., Edridge, A., Mair, J., and O'Neill, F. 2012. Catch comparison trials of the Flip Flap netting grid trawl. Marine Scotland Science Report 08/12, page 17 pp. URL https://www.researchgate . net/profile/Alex_Edridge/ publication/262932560_Catch_ Comparison_Trials_of_the_Flip_ Flap_Netting_Grid_Trawl/links/ 0a85e53957f67a5983000000/CatchComparison-Trials-of-the-FlipFlap-Netting-Grid-Trawl.pdf? origin=publication_detail.

Dunn, D., Boustany, A., and Halpin, P. 2011. Spatio-temporal management of fisheries to reduce by-catch and increase fishing selectivity. Fish and Fisheries, 12:110-119.

EC. 2016. Communication from the Commission to the European Parliament and the Council-Consultation on the fishing opportunities for 2017 under the Common Fisheries Policy. COM (2016) 396 final, 15.06.2016:p.10.

EC. 2017. Communication from the commission on the state of play of the common fisheries policy and consultation on the fishing opportunities for 2018. Retrieved from, 368: URL http://ec.europa.eu/transparency/ regdoc/rep/1/2017/EN/COM-2017368-1-EN-MAIN-PART-1.PDF.

EC. 2018. Communication from the commission to the european parliament and the council on the state of play of the common fisheries policy and consultation of the fishing opportunities for 2019. COM (2018) 452 final, 11.6.2018: p.14.

Eliasen, S., Papadopoulou, N., Vassilopoulou, V., and Catchpole, T. 2014. Socio-economic and institutional incentives influencing fishers' behaviour in relation to fishing practices and discard. ICES Journal of Marine Science, 71: 1298-1307.

Environment Canada. 2011. A study of managing fisheries for sustainability. Report of the Commissioner 
of the Environment and Sustainability Development, Chapter 4:Retrieved from: http://www.ec.gc.ca/doc/ed-es/p_123/s2_eng.htm.

EU. Regulation (EU) No 1380/2013 of the European Parliament and of the Council of 11 December 2013 on the Common Fisheries Policy, 2013.

Fonteyne, R. and Polet, H. 2002. Reducing the benthos by-catch in flatfish beam trawling by means of technical modifications. Fisheries Research, 55(1-3):219230 .

Fulton, E., Smith, A., Smith, D., and van Putten, I. 2011a. Human behaviour: the key source of uncertainty in fisheries management. Fish and Fisheries, 12:217.

Fulton, E. A., Link, J. S., Kaplan, I. C., Savina-Rolland, M., Johnson, P., Ainsworth, C., Horne, P., Gorton, R., Gamble, R. J., Smith, A. D. M., and Smith, D. C. 2011b. Lessons in modelling and management of marine ecosystems: the Atlantis experience. Fish and Fisheries, 12(2):171-188.

G., R. 1915. A new construction of trawl-net intended to separate under-sized fish. Svenska HydrografiskBiologiska Kommisionens skrifter, 6:121.

Garcia, D., Urtizberea, A., Díez, G., Gil, J., and Marchal, P. 2013. Bioeconomic management strategy evaluation of deepwater stocks using the flbeia model. Aquatic Living Resources, 26: 365-379.

Grafton, R. Q., Kompas, T., and Hilborn, R. W. 20077. Economics of Overexploitation Revisited. Science, 318:1601.

Graham, N., Ferro, R. S. T., Karp, W. A., and Macmullen, P. 2007. Fishing practice, gear design, and the ecosystem approach - three case studies demonstrating the effect of management strategy on gear selectivity and discards. ICES Journal of Marine Science, 64: 744-750.

Gulland, J. 1969. Manual of methods for fish stock assess-ment. Part I. Fish Population Analysis. FAO Manual of Fisheries Science, 4:44.

Hedley, C., Catchpole, T., and Santos, A. 2015. The Landing Obligation and its Implications on the Control of Fisheries. European Union, page 122. URL https://publications. europa.eu/en/publication-detail//publication/9ec98ef8-7644-454aad61-d1cd33125ca5/language-en.

Herrmann, B. 2005. Effect of catch size and shape on the selectivity of diamond mesh cod-ends. Fisheries Research, 71 (1):1-13.

Herrmann, B., Wienbeck, H., Karlsen, J. D., Stepputtis, D., Dahm, E., and Moderhak, W. 2015. Understanding the release efficiency of Atlantic cod (Gadus morhua) from trawls with a square mesh panel: effects of panel area, panel position, and stimulation of escape response. ICES Journal of Marine Science, 72(2): 686-696.

Hintzen, N., Bastardie, F., Beare, D., Piet, G., Ulrich, C., Deporte, N., Egekvist, J., and Degel, H. 2012. VMStools: Open-source software for the processing, analysis and visualisation of fisheries logbook and VMS data. Fisheries Research, 115-116:31-43.

Hoff, A., Frost, H., Andersen, P., Prellezo, R., Rueda, L., Triantaphyllidis, G., Argyrou, I., Tsikliras, A., Motova, A., Lehuta, S., Curtis, H., Rodríguez-Rodríguez, G., Ballesteros, H., Valeiras, J., and Bellido, J. Potential economic consequences of the landing obligation. In Uhlmann, S., Ulrich, C., and Kennelly, S., editors, The 
European Landing Obligation. Springer, 2019. URL http://doi.org/10.1007/ 978-3-030-03308-8_2.

Holland, D. and Sutinen, J. 2000. Location choice in new england trawl fisheries: Old habits die hard. Land Economics, 76:133-150.

Hopkins, C. C. E., Hegland, T. J., and Wilson, D. C. K. 2013. 'Maximising yield of fisheries while balancing ecosystem, economic and social concerns.' Review of the Faroe Islands fisheries governance system: Objective setting and implementation. EU FPr Project No: 289257.

Houston, A. and McNamara, J. Models of Adaptive Behaviour. Cambridge University Press, Cambridge, 1999.

ICES. 2017. Eu request on a combined dab and flounder tac and potential management measures besides catch limits. ICES Special Request Advice, 6:8 pp. URL http://citeseerx.ist. psu.edu/viewdoc/download?doi=10. 1.1.177.4147\&rep=rep1\&type=pdf.

James, K., Campbell, N., Við*arsson, J., Vilas, C., Plet-Hansen, K., Borges, L., González, O., van Helmond, A., Pérez-Martín, R., Taboada Antelo, L., Pérez-Bouzada, J., and Ulrich, C. Tools and technologies for the monitoring, control and surveillance of unwanted catches. In Uhlmann, S., Ulrich, C., and Kennelly, S., editors, The European Landing Obligation. Springer, 2019. URL http://doi.org/10.1007/ 978-3-030-03308-8_2.

J.E., W., M.D., S., D., L., and L.W., B. 2002. Avoiding surprises: incorporating fisherman behavior into management models. Bulletin of Marine Science, 70:553-575.

Kell, L. T., Mosqueira, I., Grosjean, P., Fromentin, J. M., Garcia, D., Hillary, R., Jardim, E., Mardle, S., Pastoors,
M. A., Poos, J. J., Scott, F., and Scott, R. D. 2007. FLR: an open-source framework for the evaluation and development of management strategies. ICES Journal of Marine Science, 64:640-646.

Kelleher, K. Discards in the world's marine fisheries An update. Technical report, FAO Fish Tech Pap T470, Rome, 2005.

Kindt-Larsen, L., Kirkegaard, E., and Dalskov, J. 2011. Fully documented fishery: a tool to support a catch quota management system. ICES Journal of Marine Science, 68:1606-1610.

Kraak, S. and Hart, P. Creating a breeding ground for compliance and honest reporting under the landing obligation: Insights from behavioural science. In Uhlmann, S., Ulrich, C., and Kennelly, S., editors, The European Landing Obligation. Springer, 2019. URL http://doi.org/10.1007/ 978-3-030-03308-8_2.

Kynoch, R., Edridge, A., and O'Neill, F. Catch Comparison Trials with the Faithlie Cod Avoidance Panel (FCAP). Scottish marine and freshwater science. Scottish Government, 2012. ISBN 9781782561071. URL https://books . google.es/books?id=u7JqAQAACAAJ.

Madsen, N. 2007. Selectivity of fishing gears used in the Baltic Sea cod fishery. Reviews in Fish Biology and Fisheries, 17:517-544.

Madsen, N., Holst, R., and Foldager, L. 2002. Escape windows to improve the size selectivity in the Baltic cod trawl fishery. Fisheries Research, 57(3):223235.

Madsen, N., Feekings, J., and Lewy, P. 2013. Discarding of plaice (Pleuronectes platessa) in the Danish North Sea trawl fishery. Journal of Sea Research, 75:129134. 
Marchal, P., Ulrich, C., Korsbrekke, K., Pastoors, M., and Rackham, B. 2003. Annual trends in catchability and fish stock assessments. Scientia Marina, 67: 63-73.

Marchal, P., Lallemand, P., and Stokes, K. 2009. The relative weight of traditions, economics, and catch plans in New Zealand fleet dynamics. Canadian Journal of Fisheries and Aquatic Sciences, 66:291-311.

Marchal, P., Andersen, J. L., Aranda, M., Fitzpatrick, M., Goti, L., Guyader, O., Haraldsson, G., Hatcher, A., Hegland, T. J., Le Floc'h, P., Macher, C., Malvarosa, L., Maravelias, C. D., Mardle, S., Murillas, A., Nielsen, J. R., Sabatella, R., Smith, A. D. M., Stokes, K., Thoegersen, T., and Ulrich, C. 2016. A comparative review of fisheries management experiences in the European Union and in other countries worldwide: Iceland, Australia, and New Zealand. Fish and Fisheries, 17:803-824.

Mortensen, L., Ulrich, C., Olesen, H., Bergsson, H., Berg, C., Tzamouranis, N., and Dalskov, J. 2017. Effectiveness of fully documented fisheries to estimate discards in a participatory research scheme. Fisheries Research, 187: 150-157.

MRAG. 2007. Impact assessment of discard policy for specific fisheries. European Commission Studies and Pilot Projects for Carrying out the Common Fisheries Policy. No. FISH/2006/17 - Lot 1, Brussels, page 289. URL http://ec.europa.eu/ fisheries/documentation/studies/ impact_assessment_discard_policy_ 2007_en.pdf.

Nielsen, K., Holm, P., and Aschan, M. 2015. Results based management in fisheries: Delegating responsibility to resource users. Marine Policy, 51:442451.
Nuevo, M., Morgado, C., and Sala, A. Monitoring the implementation of the landing obligation: Last haul programme. In Uhlmann, S., Ulrich, C., and Kennelly, S., editors, The European Landing Obligation. Springer, 2019. URL http://doi.org/10.1007/ 978-3-030-03308-8_2.

O'Neill, F., Feekings, J., Fryer, R., Fauconnet, L., and Afonso, P. Discard avoidance by improving fishing gear selectivity: Helping the fishing industry help itself. In Uhlmann, S., Ulrich, C., and Kennelly, S., editors, The European Landing Obligation. Springer, 2019. URL http://doi.org/10.1007/ 978-3-030-03308-8_2.

Ono, K., Haynie, A., Hollowed, A., Ianelli, J., McGilliard, C., and Punt, A. 2017. Management strategy analysis for multispecies fisheries, including technical interactions and human behavior in modelling management decisions and fishing. Canadian Journal of Fisheries and Aquatic Sciences, 75:1185-1202.

Pascoe, S., Andersen, J., and de Wilde, J. 2001. The impactof management regulation on the technical efficiency ofvessels in the Dutch beam trawl fleet. European Review ofAgricultural Economics, 28:187-206.

Poos, J. and Rijnsdorp, A. 2007. The dynamics of small-scale patchiness of plaice and sole as reflectedin the catch rates of the Dutch beam trawl fleet and itsimplications for the fleet dynamics. Journal of Sea Research, 58:100-112.

Poos, J. J., Bogaards, J. A., Quirijns, F. J., Gillis, D. M., and Rijnsdorp, A. D. 2010. Individual quotas, fishing effort allocation, and over-quota discarding in mixed fisheries. ICES Journal of Marine Science, 67(2):323-333.

Prellezo, R., Carmona, I., and García, D. 2016a. The bad, The good and the 
very good of the landing obligation implementation in the Bay of Biscay: A case study of Basque trawlers. Fisheries Research, 181:172-185.

Prellezo, R., I., G., and García, D. 2016b. The bad, the good and the very good of the landing obligation implementation in the Bay of Biscay: A case study of Basque trawlers. Fisheries Research, 181:172-185.

Prellezo, R., Iriondo, A., Santurtún, M., and Valeiras, J. 2018. Research for PECH Committee - Landing Obligation and Choke Species in Multispecies and Mixed Fisheries The South Western Waters, European Parliament, Policy Department for Structural and Cohesion Policies, Brussels. Retrieved from. URL http://www . europarl . europa.eu/ RegData/etudes/STUD/2018/617473/ IPOL_STU (2018)617473_EN . pdf.

Punt, A. E. and Butterworth, D. S. 1995. The effects of future consumption by the cape fur seal on catches and catch rates of the cape hakes. 4 . modelling the biological interaction between cape fur seals arctocephalus pusillus pusillus and the cape hakes merluccius capensis and m. paradoxus. South African Journal of Marine Science, 16(1):255-285.

Punt, A. E., Butterworth, D. S., de Moor, C. L., De Oliveira, J. A. A., and Haddon, M. 2016. Management strategy evaluation: Best practices. Fish and Fisheries, 17:303-334.

Punt, E. and Donovan, G. P. 2007. Developing management procedures that are robust to uncertainty: lessons from the International Whaling Commission. ICES Journal of Marine Science, 64: 603-612.

Quirijns, F. and Pastoors, M. Discard Atlas of North Sea fisheries. Technical report, Wageningen: IMARES Wageningen UR, 2014.
Quirijns, F., Poos, J., and Rijnsdorp, A. 2008. Standardizing commercial CPUE data in monitoring stock dynamics: Accounting for targeting behaviour in mixed fisheries. Fisheries REsearch, $89: 1-8$.

Reid, D., Calderwood, J., Afonso, P., Fauconnet, L., Pawlowski, L., PletHansen, K., Radford, Z., Robert, M., Rochet, M., Rueda, L., Ulrich, C., and Vermard, Y. The best way to reduce discards is by not catching them! In Uhlmann, S., Ulrich, C., and Kennelly, S., editors, The European Landing Obligation. Springer, 2019. URL http://doi.org/10.1007/ 978-3-030-03308-8_2.

Rihan, D., Uhlmann, S., Ulrich, C., Breen, M., and Catchpole, T. Requirements for documentation, data collection and scientific evaluations. In Uhlmann, S., Ulrich, C., and Kennelly, S., editors, The European Landing Obligation. Springer, 2019. URL http://doi.org/10.1007/978-3030-03308-8_2.

Rijnsdorp, A., Piet, G., and Poos, J. 2001. Effort allocation of the Dutch beam trawl fleet in response to atemporarily closed area in the North Sea. ICES CM, 1:17.

Rijnsdorp, A., van Overzee, H., and Poos, J. 2012. Ecological and economic trade-offs in the management of mixed fisheries: a case study of spawning closures in flatfish fisheries. Marine Ecology Progress Series, 447:179-194.

Rochet, M. J., Arregi, L., Tereza, F., Pereira, J., Perez, N., Ruiz Gondra, J., and Valeiras, J. 2014. Demersal discard atlas for the South Western Waters. Report, page 121. URL http://www.repositorio.ieo.es/eieo/handle/10508/9074.

Sainsbury, K. 2000. Design of operational management strategies for achiev- 
ing fishery ecosystem objectives. ICES Journal of Marine Science, 57(3):731741.

Salas, S. and Gaertner, D. 2004. The behavioural dynamics of fishers: management implications. Fish and Fisheries, 5:153-167.

Sigurǒardóttir, S., Stefánsdóttir, E. K., Condie, H., Margeirsson, S., Catchpole, T. L., Bellido, J. M., Eliasen, S. Q., Goñi, R., Madsen, N., Palialexis, A., Uhlmann, S. S., Vassilopoulou, V., Feekings, J., and Rochet, M. J. 2015. How can discards in European fisheries be mitigated? Strengths, weaknesses, opportunities and threats of potential mitigation methods. Marine Policy, 51: 366-374.

Simons, S. L., Doring, R., and Temming, A. 2015. Modellin fisher's respond to discard prevention strategies: the case of the North Sea saithe fishery. ICES Journal of Marine Science, 72(5): 1530-1544.

Sobrino, J. and Sobrido, M. The common fisheries policy: A difficult compromise between relative stability and the discard ban. In Andreone, G., editor, The Future of the Law of the Sea. Springer, 2017. URL http://doi.org/ 10.1007/978-3-319-51274-7.

STECF. 2013. Scientific, Technical and Economic Committee for Fisheries (STECF). Landing obligation in EU fisheries (STECF-13-23). Publications Office of the European Union, Luxembourg, EUR 263301 EN, JRC 86112:115 pp.

STECF. 2014a. Scientific, Technical and Economic Committee for Fisheries (STECF). Landing Obligation in EU Fisheries - part II (STECF-1401). Publications Office of the European Union, Luxembourg, EUR 26551 EN, JRC 88869:67 pp.
STECF. 2014b. Scientific, Technical and Economic Committee for Fisheries (STECF). Landing Obligations in EU Fisheries - part 3 (STECF-1406). Publications Office of the European Union, Luxembourg, EUR 26610 EN, JRC 89785:56 pp.

STECF. 2014c. Scientific, Technical and Economic Committee for Fisheries (STECF). Landing Obligations in EU Fisheries - part 4 (STECF-1411). Publications Office of the European Union, Luxembourg, EUR 26943 EN, JRC 93045:96 pp.

STECF. 2015. Scientific, Technical and Economic Committee for Fisheries (STECF). Landing Obligation - part 5 (demersal species for NWW, SWW and North Sea) (STECF-15-10). Publications Office of the European Union, Luxembourg, EUR 27407 EN, JRC 96949:62 pp.

STECF. 2017a. Scientific, Technical and Economic Committee for Fisheries (STECF). Data and information requested by the Commission to support the preparation of proposals for fishing opportunities in 2018 (STECF-17-13). Publications Office of the European Union, Luxembourg, doi:10.2760/628725, JRC 108053:43 pp. STECF. 2017b. 55th Plenary meeting report (PLEN-17-02). Publications Office of the European Union, Luxembourg, EUR 28359 EN. doi:10.2760/53335:.

STECF. 2018. Scientific, Technical and Economic Committee for Fisheries (STECF) - Evaluation of the landing obligation joint recommendations (STECF-18-06). Publications Office of the European Union, Luxembourg, doi:10.2760/999971, JRC 112740: 223 pp.

Stockhausen, B. How the implementation of the landing obligation was 
weakened. In Uhlmann, S., Ulrich, C., and Kennelly, S., editors, The European Landing Obligation. Springer, 2019. URL http://doi.org/10.1007/ 978-3-030-03308-8_2.

Sutinen, J. and Andersen, P. 1985. The economics of fisheries law and enforcement. Land Economics, 61:387-397.

Sutinen, J. and Kuperan, K. 1999. A socio-economic theory of regulatory compliance. International Joirnal of Social Economics, 26:174-193.

Tidd, A. N., Hutton, T., Kell, L. T., and Padda, G. 2011. Exit and entry of fishing vessels: An evaluation of factors affecting investment decisions in the North Sea English beam trawl fleet. ICES Journal of Marine Science, 68: 961-971.

Tschernij, V. and Holst, R. 1999. Evidence of factors at vessel-level affecting codend selectivity in Baltic cod demersal trawl fishery. International Council for the Exploration of the Sea, 02:24.

Tschernij, V., Suuronen, P., Ministerrad, N., and Nordisk, R. 2002. Improving trawl selectivity in the Baltic. Utokning av tralselektion $i$ Ostersjon. TemaNord, 512:56.

Uhlmann, S., Ulrich, C., and Kennelly, S. E. The European Landing Obligation. Reducing Discards in Complex, MultiSpecies and Multi-Jurisdictional Fisheries. Springer Open, 2019.

Uhlmann, S. S., van Helmond, A. T. M., Kemp Stefánsdóttir, E., Sigurǒardóttir, S., Haralabous, J., Bellido, J. M., Carbonell, A., Catchpole, T., Damalas, D., Fauconnet, L., Feekings, J., Garcia, T.,
Madsen, N., Mallold, S., Margeirsson, S., Palialexis, A., Readdy, L., Valeiras, J., Vassilopoulou, V., and Rochet, M. J. 2013. Discarded fish in European waters: general patterns and contrasts. ICES Journal of Marine Science, 71(5): 1235-1245.

Ulrich, C. 2018. Research for PECH Committee - Landing Obligation and Choke Species in Multispecies and Mixed Fisheries - The North Sea, European Parliament, Policy Department for Structural and Cohesion Policies, Brussels. Retrieved from. URL http://www . europarl . europa . eu/ RegData/etudes/STUD/2018/617471/ IPOL_STU (2018) 617471_EN.pdf.

Ulrich, C., Vermard, Y., Dolder, P. J., Brunel, T., Jardim, E., Holmes, S. J., Kempf, A., Mortensen, L. O., Poos, J. J., Rindorf, A., and editor: Emory Anderson, H. 2017. Achieving maximum sustainable yield in mixed fisheries: a management approach for the north sea demersal fisheries. ICES Journal of Marine Science, 74(2):566575 .

Valentinsson, D., Ringdahl, K., StorrPailsen, M., and Madsen, N. The baltic cod trawl fishery: The perfect fishery for a successful implementation of the lanfiding obligation? In Uhlmann, S., Ulrich, C., and Kennelly, S., editors, The European Landing Obligation. Springer, 2019. URL http://doi.org/ 10.1007/978-3-030-03308-8_2.

Walters, C. and Maguire, J.-J. 1996. Lessons for stock assessment from the northern cod collapse. Reviews in Fish Biology and Fisheries, 6:125-137. 




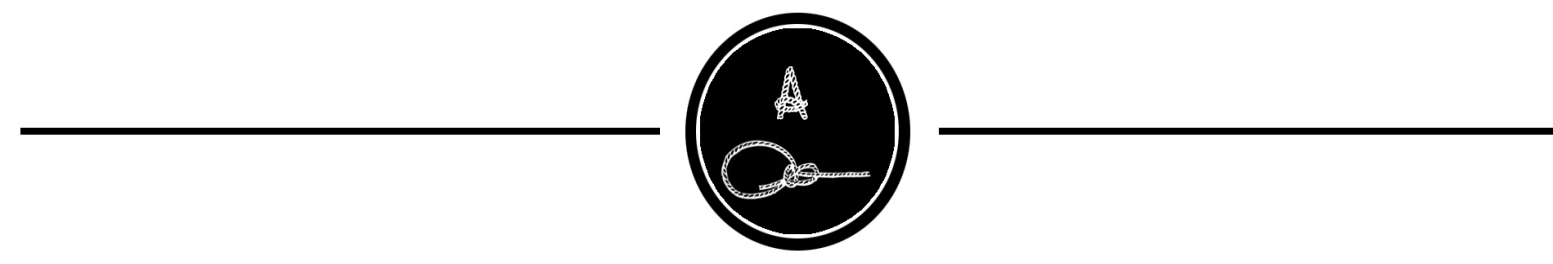

- ADDENDUM · 


\section{Summary}

This thesis brings a contribution to the debate, formally recognising fishers as an integral part of the ecosystem, by investigating the implications of applying a policy of limiting discards at sea in complex mixed fisheries that are managed under catch limits for the well-being of both the ecosystem and humans.

Discard restrictions and discard management regimes have been implemented to different extents in a number of fisheries around the world (e.g., Chile, Norway, Faroe Islands, Iceland, New Zealand, Namibia, Canada, and the US). The implementation, monitoring and control of the landing obligation generates some new challenges. In particular, the focus of monitoring and control shifts from landing to activities at sea leading to potentially higher costs of enforcement as it might require, for successful implementation, full observer coverage or electronic video monitoring to validate a self-reporting system. In chapter 2 , experiences from fisheries around the world show that choosing the right measures is not a simple process and therefore, management authorities need to simultaneously implement complementary measures which will support implementation and encourage compliance with discarding rules.

The need to adapt the regulatory framework does not just concern enforcement systems. Other measures, including adaptations to the technical measures framework, also need to be considered. Improved selectivity of fishing gears remains a primary and important tool to avoid discards. In chapter 3 I studied the selective properties of a bottom trawl fitted with a $70 \mathrm{~mm}$ diamond mesh codend and a $100 \mathrm{~mm}$ top square mesh panel (SMP) in the commercial Basque bottom otter trawlers in the Bay of Biscay. Results suggested that a $100 \mathrm{~mm}$ SMP potentially enable undersized and immature individuals to escape through the meshes. However, the selectivity cruises demonstrated that in practice, the SMP was largely ineffective at releasing undersized and the release potential for the diamond mesh codend was found to be significantly lower than the length-at-maturity and the legal minimum conservation reference size for hake, pouting and red mullet. The introduction of the obligation to land all catches will create new challenges for this trawl fleet and thereby an incentive to improve selectivity to avoid unwanted catches of undersized individuals. 
Moving to using more selective gears (bigger mesh size codend) may provide a partial solution to mitigate the potential impact of the landing obligation. However such a measure may also lead to losses in marketable catch and reductions in revenue that make the fishery unviable in the short-term and perhaps in the long-term. Hence, dynamic state variable models allow studying how fishers may respond to changing policies and what consequences this adaptive response may have for the economic and social performance of the fishery. The model results suggested that these negative short-term impacts could be alleviated by incorporation of inter-species quota flexibility in the implementation of the landing obligation. The results indicate that there will be a strong incentive to use this policy arrangement to alleviate the choke effect problem where species with limiting quotas constrain the fishery. To study the possible consequences on a longer time horizon, an MSE approach can be applied to evaluate the long term consequences of the changes in exploitation pattern on the productivity of the exploited stocks. Combining the main CFP objectives: exploiting at MSY and no discarding allowance, the MSE showed that quota species brought risk of changing exploitation patterns also for non quota stocks. Fishing effort was constrained by one or two quota stocks, resulting in drastic reductions of effort over the short-term and mid-term. 


\section{List of abbreviations}

The following table describes the significance of various abbreviations and acronyms used throughout the thesis.

\section{Abbreviation Meaning}

\begin{tabular}{|c|c|}
\hline $\mathrm{ACE}$ & Annual catch entitlements \\
\hline BoB & Bay of Biscay \\
\hline $\mathrm{CAN}_{\mathrm{BCG}}$ & Canada Brithish Columbia groundfish fishery \\
\hline CAN NSG & Canada Nova Scotia groundfish fishery \\
\hline CCTV & Closed circuit televisions \\
\hline CFP & Common Fisheries Policy \\
\hline CHL & Chile \\
\hline EU & European Union \\
\hline FLR & Fisheries Library in $\mathrm{R}$ \\
\hline FRO & Faroe Islands \\
\hline GDP & Gross Domestic Products \\
\hline HCR & Harvest Control Rules \\
\hline ISL & Iceland \\
\hline ITQs & Individual Ltransferable quotas \\
\hline JRC & Joint Research Centre \\
\hline LO & Landings Obligation \\
\hline MCRS & Minimum Conservation Reference Size \\
\hline MLS & Minimum Landing Size \\
\hline MP & Management Procedure \\
\hline MS & Member States \\
\hline MSE & Management Stategy Evaluation \\
\hline MSY & Maximum Sustainable Yield \\
\hline NA & Not available \\
\hline NAM & Namibia \\
\hline NOR & Norway \\
\hline NZL & New Zealand \\
\hline OM & Operating Model \\
\hline OTB & Bottom Otter trawls \\
\hline РТВ & Bottom Pair trawls \\
\hline RTCs & Real time area closures \\
\hline RPs & Reference Points \\
\hline SA & Stock Assessment \\
\hline STECF & Scientific Technical and Economic Committee for Fisheries \\
\hline TAC & Total allowable catch \\
\hline TAL & Total allowable landings \\
\hline USA $_{\text {ALG }}$ & USA Alaskan groundfish fishery \\
\hline VHVO & Very High Vertical Opening \\
\hline
\end{tabular}




\section{Dankwoord}

So many good and bad times have had to pass before writing these words of thanks but the much awaited moment has finally arrived. During these years of work many people have accompanied me, either in person or not, in this roller coaster of emotions, experiences and learning that preparing the thesis has involved.

I could not start with anyone other than my thesis supervisors. Jan Jaap Poos, Iago Mosquiera, Adriaan Rijnsdorp, Ernesto Jardim, thank you for all your teaching, dedication, help, for the direction and accuracy you have provided to this work. I have learnt different things from each one of you, thank you very much, because it was a pleasure to grow both professionally as well as personally in your company.

I would also like to thank the European Commission for hiring me to prepare this thesis. Working for Europe has provided me with many new experiences, with the opportunity to learn first hand about fisheries management and marine research from a much wider perspective and with the wonderful opportunity to live in Italy for 3 years. These 3 years would not have been the same without extraordinary colleagues such as Finlay Scott, John Casey, Arina Motova, Dimitrios Damalas and many others from the Water and Marine Resources Unit of the JRC, thank you, thank you and thank you for sharing with me not only your professionalism but also your human quality. Thank you, "Hermanos Infernales", for providing the soundtrack to this thesis and, of course, thank you, Lily, Fuen, Bea, Sara, Cris, my great findings from Ispra, thank you for your friendship, moments of endless laughter, of mutual growth, of thesis therapies... with your company everything seemed to be much better.

Nothing would have been the same in my periodical stays in IJmuiden without the never-ending hospitality of Agnita and Katell. Thank you for opening the doors of your homes to me, for the countless dinners and for making me feel that in every visit I made, I had a place in your families; you have been incredible. And you too, Alfonso, I was lucky to see you again in the Netherlands after meeting you in Italy.

This adventure has taken place between Italy and the Netherlands. So, thank you, Italy, thank you, Holland, thank you for showing me the beautiful Alps, the wonderful Haarlem dunes, IJmuiden, thank you for 
captivating me with your truly special corners.

And although this experience took place away from home, the bond with my beloved Cantabrian Sea, the Gulf of Biscay, has remained present in this thesis. Thank you, AZTI, for providing me with data about the Basque fleet and giving me the opportunity to delve into the lives of our fishers, even from afar. Special thanks to Marina Santurtún, Jon Ruiz, Lucía Zarauz, Estanis Mugerza and my dearest former boss Luis Arregi, thank you, Peli, for the sea outings, for teaching me about nets, for accompanying me in my first steps in the world of fisheries, in short, for soaking me in sea salt and fish scales. I would also like to thank those who were my mates at Azti and are now treasured friends, Aizkorri, Nerea, Nagore, I am really lucky for having you.

Thank you, my friends from Bakio, thank you, Kuadri (if I mention the entire bunch I will never end these acknowledgements), thank you for your support, for your continuous interest, for supporting me and encouraging me when I was running out of steam. Thank you, Bakio, for teaching me to love the sea.

I would also like to thank my family, those who are with us and those who have gone, for so many shared moments and so much love. Thank you, Mum, Iratxe and Aunty; my muses, my warriors, my greatest loves, thank you for being my inspiring energy, for supporting me and accompanying me in all my adventures, any road with you by my side is worthwhile. My sister, life companion and eternal love, thank you for always being by my side, thank you, Mum, for your continuous advice, thank you for being my pillar of strength. My other pillar, Dad, you left very soon, too soon, but thank you because your teachings and your whole being and savoir-faire are still my beacon and my compass. 
Cuantos buenos y malos ratos han tenido que pasar hasta llegar a escribir estas palabras de agradecimiento, pero por fin ha llegado el deseado momento. Durante estos años de trabajo muchas personas me han acompañado, presentes o no, en esta montaña rusa de emociones, vivencias y aprendizaje que ha supuesto hacer la tesis.

No podría empezar por otras personas, que por mis supervisores de tesis. Jan Jaap Poos, Iago Mosquiera, Adriaan Rijnsdorp, Ernesto Jardim, gracias por todas las enseñanzas, dedicación, ayuda, por la dirección y el rigor que habéis aportado a este trabajo. De cada uno de vosotros he aprendido distintas cosas, muchísimas gracias, porque ha sido un placer crecer profesional y personalmente en vuestra compañía.

Mi más sincero agradecimiento a la Comisión Europea por contratarme para realizar esta tesis. Trabajar para Europa me ha colmado de nuevas experiencias, de la oportunidad de conocer de primera mano el funcionamiento de la gestión pesquera y la investigación marina desde un prisma mucho más amplio y de la preciosa oportunidad de vivir en Italia durante 3 años. Esos 3 años no hubieran sido lo mismo sin extraordinarios compañeros cómo Finlay Scott, John Casey, Arina Motova, Dimitrios Damalas y tantos otros de la Unidad de Recursos Hídricos y Marinos del JRC, gracias, gracias y gracias por compartir conmigo no sólo vuestra profesionalidad, sino también vuestra calidad humana. Gracias "hermanos Infernales" por ponerle banda sonora a esta tesis y como no, gracias Lily, Fuen, Bea, Sara, Cris, mis grandes descubrimientos Isprenses, gracias por vuestra amistad, momentos de risas infinitas, de crecimiento juntas, de terapias de tesis, con vuestra compañía todo se veía mucho mejor.

Nada hubiera sido lo mismo en mis periódicas estancias en IJmuiden sin la infinita hospitalidad de Agnita y Katell. Gracias por abrirme las puertas de vuestras casas, por las innumerables cenas y por hacerme sentir que en cada visita que hacía, tenía un hueco en vuestras familias, habéis sido increíbles. A ti también Alfonso, reencontrarte en Holanda después de conocerte en Italia fue una suerte.

Y entre Italia y Holanda ha sido esta aventura. Así que gracias Italia, gracias Holanda, gracias por enseñarme los preciosos Alpes, las maravillosas dunas de Haarlem a IJmuiden, gracias por cautivarme con vuestros rincones tan especiales. 
Y aunque esta experiencia transcurría fuera de casa, el vínculo a mi amado Cantábrico, al Golfo de Bizkaia, ha permanecido muy presente en esta tesis. Gracias AZTI por brindarme datos de la flota vasca permitiéndome que, aun estando lejos, haya tenido la oportunidad de profundizar en la vida de nuestros arrantzales. Especialmente gracias a Marina Santurtún, Jon Ruiz, Lucía Zarauz, Estanis Mugerza y mi apreciado exjefe Luis Arregi, eskerrik asko Peli por las salidas a la mar, por enseñarme de redes, por acompañarme en mis primeros pasos en el mundo de las pesquerías, en definitiva por empaparme en sal y escamas. Gracias a las que fueron mis compañeras en Azti y hoy son preciosas amigas, Aizkorri, Nerea, Nagore, que suerte teneros.

Gracias amigos de Bakio, gracias Kuadri (si menciono a toda la kuadri no acabo nunca estos agradecimientos), gracias por vuestro apoyo, por vuestro incesante interés, por seguir apoyándome y animándome cuándo yo ya estaba desfondada. Gracias Bakio por enseñarme a amar el mar.

Eskerrik asko familia, los que están y los que se fueron, por tantos momentos compartidos y tanto amor. Gracias ama, Iratxe e izeko; mis musas, mis guerreras, mis amores más grandes, gracias por ser la energía inspiradora, por apoyarme y acompañarme en todas mis aventuras, cualquier camino con vosotras al lado merece la pena. Hermana mía, compañera de vida y amor eterno, gracias por estar siempre a mi lado, gracias amatxu por tus continuos consejos, gracias por ser mi pilar. Mi otro pilar, aitatxu, te fuiste pronto, muy pronto, pero gracias porque tus enseñanzas y tu ser y saber estar siguen siendo mi faro y mi brújula. 
Zenbat une on eta txar igaro behar izan diren harik eta eskerroneko hitz hauek idatzi arte, baina, azkenean, irrikatutako une hori iritsi da. Lanean emandako urteotan, jende asko egon da nirekin, lekuan bertan edo ez, tesia egitean sortutako emozioen, bizipenen eta ikasbideen errusiar mendi honetan.

Hasteko, ezinbestekoa da nire tesiko ikuskatzaileak aipatzea. Jan Jaap Poos, Iago Mosquiera, Adriaan Rijnsdorp eta Ernesto Jardim, eskerrik asko irakaskuntza guztiengatik, zuon arduraldi zein laguntzagatik eta lan honi eskainitako zehaztasun eta zuzendaritzagatik. Zuok gauza desberdinak irakatsi dizkidazue, eskerrik asko, plazera izan delako zuokin batera arlo profesionalean eta pertsonalean haztea.

Nire eskerrik beroena Europako Batzordeari, tesi hau egiteko kontratatzeagatik. Europarentzat lan egitean, esperientzia berriak bizi izan ditut, zuzenean nahiz ikuspegi zabalago batetik ezagutu ahal izan dut arrantzaren kudeaketako eta itsas ikerketako jarduera eta 3 urtez Italian bizitzeko aukera paregabea ere izan dut. 3 urte horiek ez ziren berbera izango honako lankide bikain hauek izan ez banitu: Finlay Scott, John Casey, Arina Motova, Dimitrios Damalas eta JRCko Ur eta Itsas Baliabideen Unitateko beste hainbeste. Mila, mila, mila esker zuon profesionaltasuna eta zuon giza kalitatea nirekin partekatzeagatik. Eskerrik asko, "Hermanos Infernales", tesi honi soinu-banda jartzearren. Zer esanik ez, eskerrik asko, Lily, Fuen, Bea, Sara eta Cris. Ispran egin nituen aurkikuntza handiak zarete. Eskerrik asko zuon adiskidetasunagatik, irribarre amaigabeko uneengatik, elkarrekin izandako hazkuntzagatik, tesietako terapiengatik. Zuon laguntzaz, den-dena askoz hobeto ikusten zen.

Ezer ez zen berbera izango IJmuidenen egindako aldian aldiko egonaldietan, Agnitaren zein Katellen abegi eskerga izan ez banu. Eskerrik asko zuon etxeko ateak irekitzeagatik, ezin konta ahala afari eskaintzeagatik eta egiten nuen bisitaldi bakoitzean zuon familietan lekua nuela sentiarazteagatik. Ikaragarriak izan zarete. Zeuri ere bai, Alfonso, zorionekoa izan zelako Italian ezagutu ondoren berriro ere Holandan elkartu izana.

Abentura hau Italia eta Holanda artean garatu da. Hori dela eta, eskerrik asko, Italia, eskerrik asko, Holanda. Eskerrik asko, Alpe ederrak eta Haarlemetik Ijmuidenera doazen duna zoragarriak erakusteagatik. Es- 
kerrik asko, bertako bazter ezin bereziagoekin liluratuta utzi ninduzuelako.

Nahiz eta esperientzia hau etxetik kanpo bizi, nire Kantauri maitearekin, Bizkaiko Golkoarekin dudan lotuneak bere horretan jarraitu du betebetean tesi honetan. Eskerrik asko, AZTI, euskal flotaren datuak emateagatik. Horri esker, nahiz eta urrun egon, gure arrantzaleen bizimoduan sakondu ahal izan dut. Batez ere, eskerrik asko, Marina Santurtún, Jon Ruiz, Lucía Zarauz, Estanis Mugerza eta Luis Arregi, nire nagusi ohi preziatua. Eskerrik asko, Peli, itsasora egindako txangoengatik, sareen inguruko irakaskuntzengatik, arrantza-tokien munduan lehenengo urratsak ematen laguntzeagatik eta, azken batean, kresalean zein ezkatetan bustitzeagatik. Eskerrik asko AZTIn izan nituen lankideei eta gaur egun lagun maitagarriak diren Aizkorriri, Nereari eta Nagoreri. Zorte handia da zuok edukitzea.

Eskerrik asko, Bakioko lagunok. Eskerrik asko, "kuadri" (adiskide guztiak aipatzen baditut, ez ditut inoiz eskerron hauek amaituko). Eskerrik asko zuon laguntzagatik, zuon interes etengabeagatik, laguntzen eta adorea ematen jarraitzeagatik, neure onenak emanda nengoenean. Eskerrik asko, Bakio, itsasoa maitatzen irakasteagatik.

Eskerrik asko, familia, berton daudenei eta joan zirenei, partekatutako hainbat unegatik eta hainbesteko maitasunagatik. Eskerrik asko, ama, Iratxe eta izeko. Nire musak, nire gerlariak, nire maitasun handienak. Eskerrik asko energia inspiratzailea izatearren, abentura guztietan babestu eta laguntzeagatik. Zuok alboan izanda egindako edozein bidek merezi du. Ahizpa maitea, bidelaguna eta betiereko maitasuna. Eskerrik asko, beti nire ondoan egoteagatik. Eskerrik asko, amatxo, zure etengabeko aholkuengatik. Eskerrik asko, nire zutabea izateagatik. Nire beste zutabea, aitatxo, laster joan zinen, oso laster, baina eskerrik asko, zure ikasbideak, zure izaera eta zure antzea nire itsasargia eta iparrorratza direlako oraindik. 


\section{Publications}

\section{Peer-reviewed journal publications}

Alzorriz, N., Jardim, E., Poos, J. J. 2018. Likely status and changes in the main economic and fishery indicators under the landing obligation: a case study of the Basque trawl fishery. Fisheries Research, 205: 8695.

Alzorriz, N., Arregi, L., Herrmann, B, Sistiaga, M., Casey, J., Poos, J. J. 2016. Questioning the effectiveness of technical measures implemented by the basque bottom otter trawl fleet: Implications under the EU landing obligation. Fisheries Research, 175: 116-126.

Jardim, E., Eero, M., Silva, A., Ulrich, C., Pawlowski, L., Holmes, S. J., Ibaibarriaga, L., De Oliveira, J. A. A., Riveiro, I., Alzorriz, N., Citores, L., Scott, F., Uriarte, A., Carrera, P., Duhamel, E., Mosqueira, I. 2018. Testing spatial heterogeneity with stock assessment models. PLOS ONE 13(1): e0190791.

https://doi.org/10.1371/journal.pone.0190791

Jardim, E., Millar, C., Mosqueira, I., Scott, F., Osio, G.C., Ferretti, M., Alzorriz, N., Orio, A. 2014. What if stock assessment is as simple as a linear model? The a4a Initiative. ICES Journal of Marine Science, 72(1): 232-236.

Millar, C. P., Jardim, E., Scott, F., Osio, G. C., Mosqueira, I., and Alzorriz, N. 2014. Model averaging to streamline the stock assessment process. ICES Journal of Marine Science, 72 (1): 93-98.

\section{Peer-reviewed book chapter}

Prespo- Desarrollo Sostenible de las Pesquerías Artesanales del Pais Vasco. Editorial: País Vasco. Servicio Central de Publicaciones, Eukal Herria. Eusko Jaurlaritzaren Argitalpen Zerbitzu Nagusia (2013). Coleccion ITSASO. ISBN 10: 8445732668. 


\section{Other scientific publications}

\section{Workshops and Technical reports}

Alzorriz, N., Mosqueira, I., Jardim, E., Osio, G.C. 2014. Exploratory data analysis of the Bay of Biscay operating model. JRC Technical report, JRC 89152, 64 pp.

Alzorriz, N., Mosqueira, I., Jardim, E., Osio, G.C. 2014. Review of discards management regimes. Publications Office of the European Union, Luxembourg, $20 \mathrm{pp}$.

Jardim, E., Alzorriz, N., Oliveira, J., Eero, M., Holmes, S., Scott, F., Ulrich, C. 2015. a4a short research project- Studying spatial effects on stock dynamics of North Sea cod and plaice in the Skagerrak.

Murillas, A., Mugerza, E., Arregi, L., Alzorriz, N., Artetxe, I. 2012. PRESPO. Desarrollo Sostenible de las Pesquerías Artesanales del Arco Atlántico. Elaborado por AZTI-Tecnalia para Eusko Jaurlaritza - Gobierno Vasco, Dpto. de Medio Ambiente, Planificación Territorial, Agricultura y Pesca, Viceconsejería de Pesca e Industrias Alimentarias.

Mugerza, E., Murillas, A., Arregi, L., Alzorriz, N., Artetxe, I. 2011. La Base del Conocimiento para la Gestión Eficiente de la Flota Artesanal Vasca. Elaborado por AZTI-Tecnalia para la Federación de Cofradías de Guipuzkoa.

STECF. 2013. Scientific, Technical and Economic Committee for Fisheries (STECF)- Landing Obligation in EU Fisheries- part I (STECF13-23). Publications Office of the European Union, Luxembourg, EUR 26330 EN, JRC 86112, 115 pp.

WG6's partners, 2011. Synthesis of the methodologies used to assess the selectivity and the discards rate in the artisanal fisheries. Report of Project PRESPO.

\section{Conferences}

Alzorriz, N., Arregi, L., Herrmann, B., Sistiaga, M., Poos, J. J. 2015. Questioning the effectiveness of implemented technical measures under the EU landing obligation: the Basque bottom otter trawl fishery case study. ICES Working group on Fishing Technology and Fish Be- 
haviour (WGFTFB), Lisbon, Portugal, 4-7 May 2015. Communication: Oral.

Alzorriz, N., Jardim, E., Mosqueira, I., Osio, G.C., Poos, J.J., Rijnsdorp, A., 2014. Likely status and changes in the main economic and fishery indicators under the various discards policies. ICES Annual Science Conference, A Coruna, Spain, 15-19 September 2014. Communication: Oral.

Alzorriz, N., Orio, A., Millar, C., Jardim, E. 2013. The a4a stock assessment model a non linear mixed effects model in FLR/R with an interface based on linear an additive model formulae. World Conference on Stock Assessment Methods, Boston, 15-19 July 2013. Communication: Poster.

Alzorriz, N. 2013. Discarding - waste of valuable natural resources/ Gli scarti di pesca - Ridurre lo spreco di una risorsa naturale. JRC Open day, Ispra, 15-19 July 2013. Communication: Poster.

Alzorriz, N., Rubio, A., Fontán, A., Ferrer, L. and González, M. 2010. Oceanic surface water circulation over the SE Bay of Biscay continental shelf and slope. EOF, Encuentro de Oceanografía Física, Barcelona, Spain, 13-15 October 2010. Communication: Poster.

Jardim, E., Alzorriz, N., Oliveira, J., Eero, M., Holmes, S., Scott, F., Ulrich, C. 2015. Testing fish stock's spatial structure with assessment models. ICES Annual Science Conference, Copenahagen, Denmark, 2125 September 2015. Communication: Oral.

Mugerza, E., Murillas, A., Arregi, L., Alzorriz, N., Artetxe, I. 2014. Monitoring artisanal fisheries in the Basque Country: Skippers involvement and participation in the data collection process. Fishery Dependent Information, Rome, 3-6 March 2014. Communication: Oral.

Rubio, A., Mader, J., Fontán, A., Ferrer, L., González, M. and Alzorriz, N. 2010. Coastal stations, offshore buoys and HF radar for monitoring high frequency ocean processes in the SE Bay of Biscay: some examples of model validation. Oceanphys, International Liège colloquium on ocean dynamics, Belgium, 26-30 April 2010. Communication: Oral. 


\section{TSP}

\begin{tabular}{|c|c|c|}
\hline \multicolumn{2}{|c|}{ Training and Supervision Plan } & Graduate School WIAS \\
\hline Name PhD student & Nekane Alzorriz & \\
\hline Project title & $\begin{array}{l}\text { Evaluation and implementation of } \\
\text { discards policies under catch-based fisheries } \\
\text { management regimes. }\end{array}$ & \\
\hline Group & $\begin{array}{l}\text { Wageningen Marine Research/ WUR AFI } \\
\text { Dr Jan Jaap Poos }\end{array}$ & \\
\hline Daily supervisor(s) & $\begin{array}{l}\text { Dr Iago Mosqueira } \\
\text { Dr Ernesto Jardim }\end{array}$ & \\
\hline Supervisor(s) & Prof. Dr Adriaan Rijnsdorp & \\
\hline Project term & 15-mar-2013 / 15-mar- 2017 & \\
\hline
\end{tabular}

$\begin{array}{lll}\text { Education and Training } & \text { Year } & \text { Credits }\end{array}$

The Basic Package

JRC Introduction Course 2013

Course on philosophy of science ans/or ethics 2018

\section{Scientific Exposure}

Synthesis of the methodologies used to assess the selectivity and the 2011

discards rate in the artisanal fisheries (PRESPO), Paris (oral)

Oceanphys, International Liege colloquium on ocean dynamics, Belgium, 2013

26-30 April

The a4a stock assessment model- a nonlinear mixed effects model in 2013

FLR/R with an interface base on linear and additive model formulae.

World conference on Stock Assessment Methods, Boston (poster)

EWG 13-16: Landing Obligations in EU Fisheries - Varese, Italy

EWG 14-01: Landing Obligations in EU Fisheries - Varese, Italy

EWG 14-11: Landing Obligations in EU Fisheries - Varese, Italy

ICES Annual Science Conference, A Coruña, Spain, 15-19 Sept

Likely changes in economic and fishery indicators under various discards 2014

policies. ICES ASC, A Coruña, Spain (oral)

Workshop: a4a short research project- Studying spatial effects on stock 2014

dynamics of North Sea cod and plaice in the Skagerrak, Ispra, Italy

EWG 15-05: Landing Obligations in EU Fisheries - Arona, Italy

Questioning the effectiveness of implemented technical measures under $2015 \quad 1.0$

the EU landing obligations. ICES WGFTFB, Lisbon (oral)

EWG 16-04: Landing Obligations in EU Fisheries - Brussels

$2016 \quad 1.5$

In-Depth Studies

Fish capture technology, DTU Aqua National Institute of Aquatic Re- $2012 \quad 2.5$ sources, DK

Impact Assessment, JRC, Italy

Sensitivity Analysis of Model Output, Angera, Italy

$2013 \quad 0.6$

The Economic Evaluation of Projects of Policy Decisions, JRC, Italy

1.5

Professional Skills Support Courses

Introduction to R and FLR, JRC, Italy

Course Techniques for Scientific Writing, Ispra, Italy

Course Techniques for Public Speaking, Ispra, Italy

$2013 \quad 1.5$

$2012 \quad 0.6$

$2013 \quad 0.6$

\section{Research Skills Training}

Preparing own $\mathrm{PhD}$ research proposal

$2012 \quad 6.0$

Simulation testing- a4a framework

$2013 \quad 2.0$

\section{Didactic Skills Training}

Lecturing FLR and a4a for Quantitative Fisheries Science Course, JRC, 2014

Ispra

Lecturing FLR and a4a for Quantitative Fisheries Science Course, JRC, 2015

Ispra

Preparing course material FLR and a4a, JRC, Ispra

Preparing course material FLR and a4a, JRC, Ispra

$2014 \quad 2.0$




\section{Propositions}

1. Fisheries need to adapt their fishing behaviour to reduce discards and mitigate the choke risks posed by the landing obligation. (this thesis)

2. The robustness of a management strategy evaluation with respect to prevailing uncertainties should be assessed before implementation of management rules.

(this thesis)

3. Social dynamics are an indispensable element in science based management.

4. Scientific journals should demand authors to publish their code to promote transparency.

5. Reconnecting people with nature is necessary to solve today's sustainability changes.

6. Equal numbers of men and woman in leadership positions are not possible without quotas.

Propositions belonging to the thesis, entitled

Evaluation of the design and implementation of discards policies under catch-based fisheries management regimes

Nekane Alzorriz Gamiz

Wageningen, 4 December 2019 
The research described in this thesis was financially supported by the European Commission, Joint Research Centre (JRC), Ispra, Italy.

\section{COLOFON}

Graphic design cover and photography:

Jon Aspuru (www.jonaspuru.com)

Printed by:

Proefschriftmaken.nl, Uitgeverij Boxpress 

